\title{
Effects of macroalgal habitats on the community and population structure of temperate reef fishes
}

by

\section{Alejandro Pérez Matus}

\author{
A thesis \\ submitted to Victoria University of Wellington \\ in fulfilment of the \\ requirements for the degree of \\ Doctor of Philosophy \\ in Marine Biology

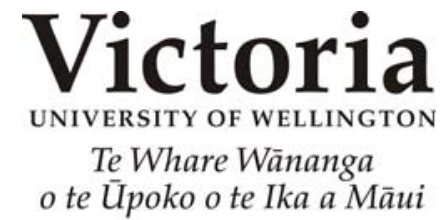

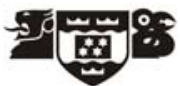 \\ Victoria University of Wellington \\ Te Whare Wānanga o te Ūpoko o te Ika a Mãui
}


This thesis was conducted under the supervision of:

\author{
Dr. Jeffrey S. Shima (Primary Supervisor) \\ Victoria University of Wellington, \\ Wellington, New Zealand
}

\author{
Dr. Russell Cole
}

National Institute of Water and Atmospheric Research (NIWA),

Nelson, New Zealand

and

Dr. Malcolm Francis

National Institute of Water and Atmospheric Research (NIWA),

Wellington, New Zealand 


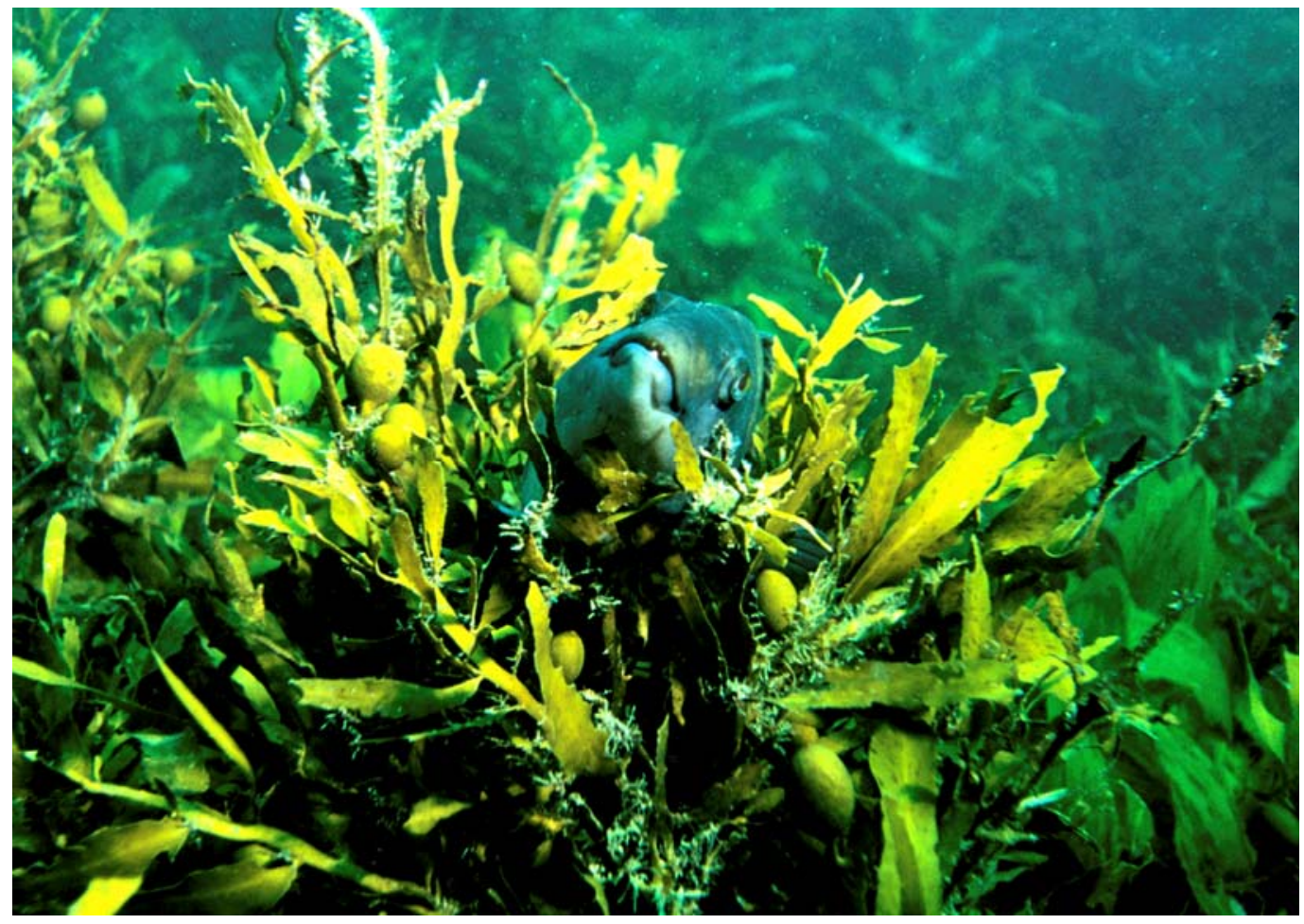

Notolabrus fucicola over Carpophyllum flexuosum, Kapiti Island, Wellington

"Among the fishes, a remarkably wide range of biological adaptations to diverse habitat has evolved" Dr. T. Pitcher. 


\section{Abstract}

Two families of brown macroalgae that occur in sympatry dominate temperate subtidal rocky coasts: the Laminareales, and the Fucales. Both of these families are habitat-forming species for a wide variety of invertebrates and fishes. Variation in the presence, density, and composition of brown macroalgae can have large influences on the evolution and ecology of associated organisms. Here, using a series of observational and experimental studies, I evaluated the effects of heterogeneity in the composition of brown macroalgal stands at the population and community levels for reef fishes.

A central ecological challenge is the description of patterns that occur at local scales, and how these are manifested at larger ones. I conducted further sampling across a set of sites nested within locations over three regions, Juan Fernández Islands (Chile), Northern New Zealand, and Tasmania (Australia), to evaluate patterns of variation in the diversity and composition of fish assemblages. Specifically, I explored spatial variation in fish assemblages as a function of rocky reef habitats (dominated by brown-macroalgae) and other sources of variation (abiotic and biotic factors) that potentially mediate the relationship between fishes and reef habitats. Analyses suggest that spatial variation in diversity (e.g., species and trophic) may be explained by spatial variation in depth, temperature, and composition of macroalgal habitats. At each location, only 2-3 families dominated the composition of fish assemblages, but species identities varied among locations. In a subsequent study, I assessed the fish-habitat associations from sites within the Juan Fernández Islands, an isolated eastern Pacific Island that lack large brown macroalgae. I found that, despite the

close proximity of these Islands to the South American continent, fish 
assemblages were mostly composed of endemic representatives from families that dominate the fish assemblages in New Zealand and Australia. Spatial variation in depth and temperature did not contribute to the observed variation in fish abundance. Instead, I found that benthic habitat-forming species (particularly foliose brown macroalgae) appeared to limit the abundance of some reef fishes. These results suggest that a mixture of large-scale (e.g., stochastic recruitment) and small-scale processes (i.e., relating to habitat heterogeneity) influence the diversity, composition and abundance of fish assemblages.

Subsequently, I evaluated relationships between reef fishes and macroalgae composition across multiple sites, surveyed repeatedly over four seasons. I found that fishes were associated with different components of heterogeneity in macroalgal habitats, potentially indicating interspecific partitioning of resources that may arise from differential feeding habits and sizesusceptibility to predation. Seasonal variation in the fish-habitat associations was detected, and site differences in macroalgal composition explained significant variation in the local diversity of fishes.

Using a series of small-scale lab and field-based manipulative experiments, I determined the demographic and behavioural responses of reefassociated fishes to heterogeneity in the composition of brown macroalgal habitats. I found that (i) different fish species distinguished between monospecific macroalgae stands (macroalgal identity affected the abundance of 7 of 15 reef fish species); (ii) there is within-species variation in the response of fishes to macroalgal composition (suggesting ontogenetic habitat shifts); and (iii) the abundance of 5 of 7 reef fish species, and the overall structure of the local fish assemblage, varied with the composition of mixed-species macroalgal stands. 
Lastly, I evaluated the potential for fishes to provision demographic feedbacks to macroalgae. Specifically, I conducted a mesocosm experiment to evaluate the effects of fishes on grazing amphipods, and therefore, the potential indirect-effects of fishes on large-brown macroalgae. I found that only one of the two fish species studied reduced grazer abundance. Although the second fish species did not consume grazing amphipods, its presence altered amphipod behaviour to significantly reduce grazing efficiency on the macroalgal-host. This study illustrates how density and trait-mediated indirect interactions can have similar effects on primary producers.

Overall, my observational and experimental components of this thesis emphasize the influence of heterogeneity in macroalgal structures on the breadth of habitat use for reef fishes at multiple locations. I found strong behaviourally mediated linkages between the abundance of reef fishes and composition of macroalgal stand. I also provide some evidence that mutualistic relationships may exist between kelp and associated fishes. 
Dedicated to my grandfather 


\section{Acknowledgments}

Although most of the Chapters here are written in first person, I have to mention that without the support that I have received from many people and institutions, this thesis would have never to come to an end. I have to thank them all.

All my family and particularly Isabel, Barbara, Maria Isabel and my father, and Katja have done everything for me to make this journey possible. In all the moments I have received their support, thanks.

The completion of this thesis is indebted to my supervisors. I have to say that I have world-class researchers in my committee. I had contributions from all of them. First, I have received valuable guidance, encouragement, support, and friendship from my primary supervisor, Dr. Jeff Shima. I am impressed by the amount of knowledge that Jeff has as a marine ecologist and his writing skills. I consider myself fortunate to be his student. Second, I was pleased to have Russell Cole. Despite his claims to a lack of memory, he is a library of information regarding the ecology of fishes and statistics. I learned a lot from him particularly through the editing of this thesis. But this all started when Malcolm Francis went to Chile with Eduardo Villouta. With Malcolm's Book of reef fishes from New Zealand, I started to get on track. Every fish scientist knows Malcolm's work. His support of my thesis and me has been priceless.

I have received incredible support and several researchers have influenced me. Special mentions are deserved to Dr. Shirley Pledger (how lucky I was to meet her, thanks for sharing your knowledge in stats and in $\mathrm{R}$ ), $\mathrm{KC}$ Burns, Nicole Phillips, Joe Zuccarello, Nokuthaba Sibanda, Shane Geange and Phil Neubauer who have helped me a lot in analyzing data and commenting on 
my work. From other universities and institutions I must thank Dr. Alistair Poore (University of South Wales), Dr. Michael Graham (Moss Landing Marine Lab, California), Dr. Giacomo Bernardi (University of California), Dr. Patricio Ojeda (Pontificia Universidad Católica de Chile), Dr. Alvaro Palma (Pontificia Universidad Católica de Chile), Dr. Martin Thiel (Universidad Católica del Norte, Chile), Dr. Carlos Gaymer (Universidad Católica del Norte, Chile), Dr. Clive Roberts (Museum of NZ Te Papa Tongarewa), Dr. Franz Smith (CSIRO), Dr. Andrew Stewart (Museum of NZ Te Papa Tongarewa), Clinton Duffy and Helen Kettles (Department of Conservation, New Zealand). Lastly special recognition of this work goes to Dr. Steve Swearer (University of Melbourne), Dr. Richard Taylor (Auckland University), and Dr. Stephen Hartley (Victoria University of Wellington) who have provided reviews and useful comments that improved the quality of this work.

The data from this thesis involved a lot of fieldwork; I travelled and dived into many different places. In most, I was pleased to meet friends and spend long days in the field. I started here in Wellington with my friend, Anna Smith, who helped me in the first data chapter. Her support was incredible and I don't think I would have finished without her support. Without the help of el tila (no one in Chile could mentioned Tyler Eddys's name properly) and Fabian Ramírez (very motivated student specially when diving), the surveys at Juan Fernández Islands in Chile would have been hard to do. My trip to north New Zealand was extraordinary with my friend Phillip (filipa) Neubauer and Anto do Santos. In Tasmania Carolina Zagal, Nikita and her pelirojo (Simon) hosted me and gave me all the support and friendship I could ask for. I have to thank a very keen diver and boat master, Paul Di Benedetto, and his family who provided 
support and help in the field with his boat and scuba tanks while in Tasmania. Benjamin Magaña, Alejandra Perea-Blazquez, Ursula Rojas, Katja Klopfer, Pelirojo Salinas, Gareth Williams, Claudio Sáez, Fletcher Warren, Sergio Carrasco, la ratilla (Sebastian Hernández) and Matilda Hegarty friends who helped me a lot in the field when I was doing experiments and/or surveys in Wellington.

Technicians from NIWA and VUW gave me all their help in constructing mesoscosm, pumps, pipes, etc. Special recognition goes to John Van der Sman and Daniel McnNaughtan (Snout), and Don Nelson at VUCEL; Phil Fisher, Nicky Alcock, Steve Mercer and Rob Stewart at NIWA.

I have to thank all my fellow students and office-friends that eased the writing portion of the thesis by keeping a good/cool atmosphere. Thanks to Bionda Morellisen, Sergio, Jade, Phil, Shane, Cesar Cardenas, Tim, Andrea Varela, Ale Perea, Shane, Snout, and Erasmo.

A lot of friends helped me during this time either here or in Chile (I have good friends in Peru, Brazil, USA as well). With special recognition I have to thank Erasmo Macaya (HDGMCC) who constantly gave me scientific advice and friendship, thanks compare. Enrique Mundaca, Franzinho, las ratas Seviche, Mashin, Phil, Mati and Keko were all good friends here.

To my family in Chile, I must thank all of them. Also my South American friends here in Welly, Daniela Diaz, Marisol Castro, Mariana Lazzaro, Pelayo Salinas (what's a "pelayo" is from Spain), Ursula, Profe Carrizo, Anita Ojeda, Carlos Gonzalez, Gaston Bossus, Gina and Mario Garcia. My Soccer team the "international Marist", such nice games. 
Many thanks to the staff at the SBS, Patricia Stain, Sandra Taylor, Paul Mardsen, and Mary Murray, have been very nice to work with you guys here. Special thanks to Shona De Sain at the faculty of science for all her help during my PhD.

Finally, but also very important I am gratefully of the sources of funding for this research. CONICYT, Chile; Victoria University of Wellington, New Zealand Study Abroad, Museum of New Zealand, CONAF (Chile) and NIWAFRST research Grant.

Thanks so much for all your help. 


\section{Table of Contents}

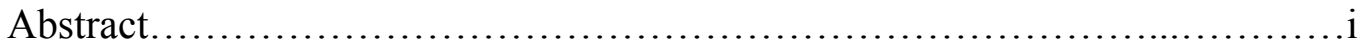

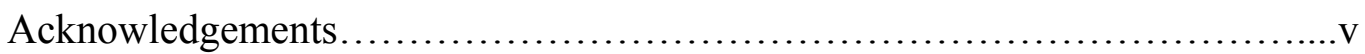

CHAPTER 1 Effects of macroalgal habitats on the community and population structure of temperate reef fishes: Introduction, overview, and thesis structure

1.1 The focal habitat: temperate reefs and the large-brown macroalga .................5

1.2 Consistent patterns of abundance of reef fishes among multiple sites ............ 7

1.3 Role of large brown-macroalgae in controlling the distribution and abundance of temperate reef fishes

1.4 Direct and indirect effects of the relationship between fish and large-brown

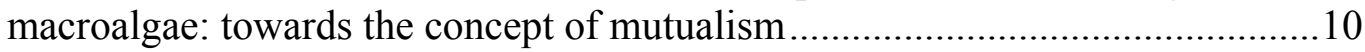

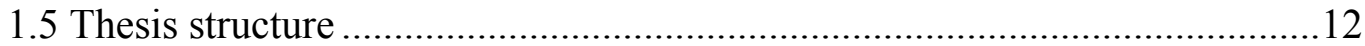

CHAPTER 2 Reef fish diversity associated to macroalgae: an exploratory comparison of temperate reef fish faunas.........................................................16

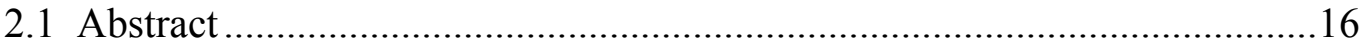

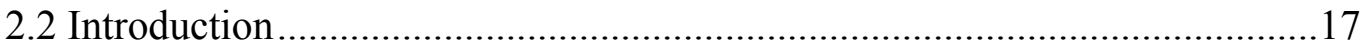

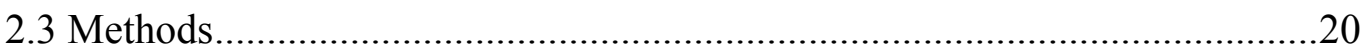

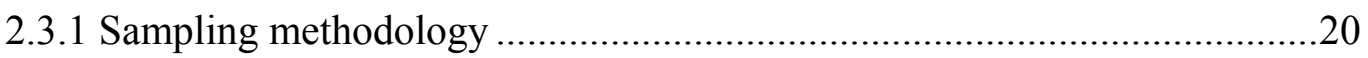

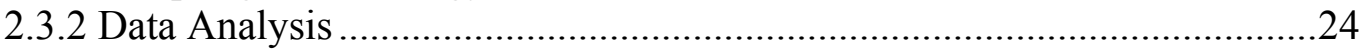

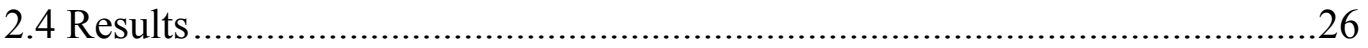

2.4.1 Changes in species diversity and substratum species ..............................26

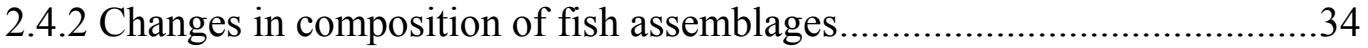

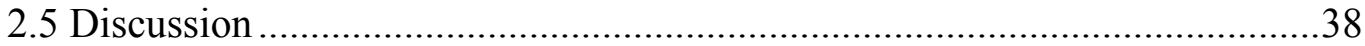

CHAPTER 3 Community structure at Juan Fernández Islands: How are temperate fish assemblages organized in non-kelp dominated habitats?.....41

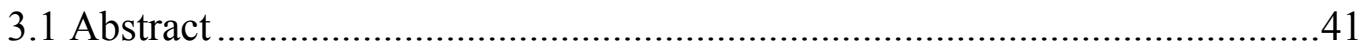

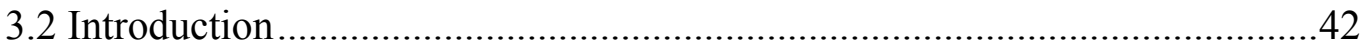

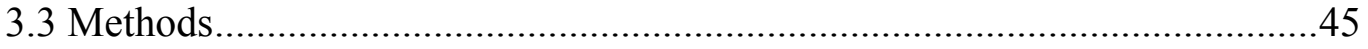

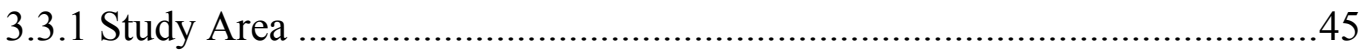

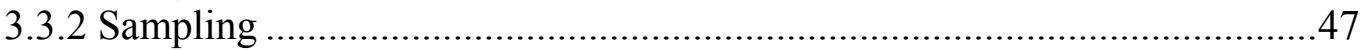

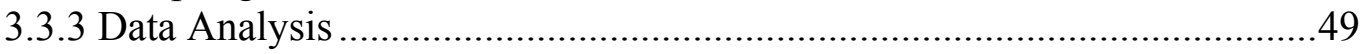

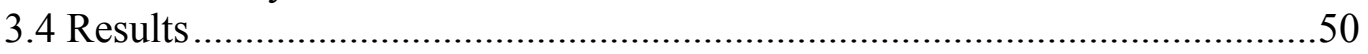

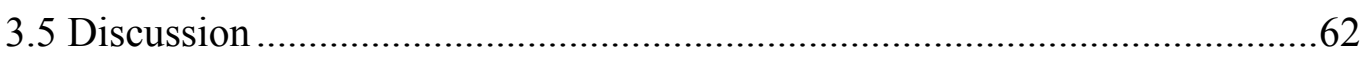

CHAPTER 4 Fish abundance and biomass associations with heterogeneous habitat: a year of surveys in the temperate Kapiti Island...............................69

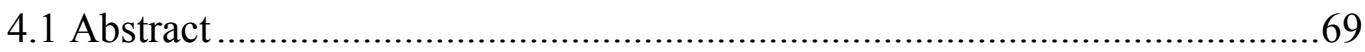

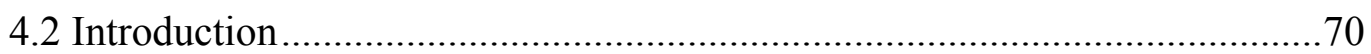

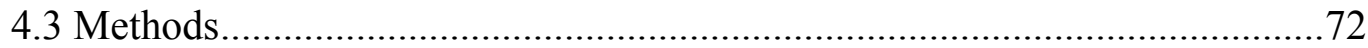

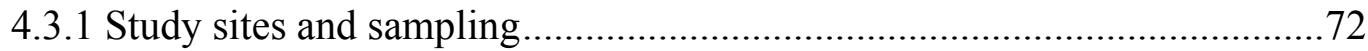

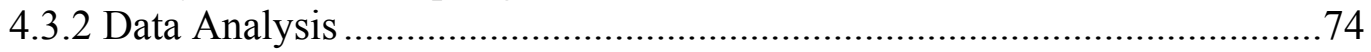




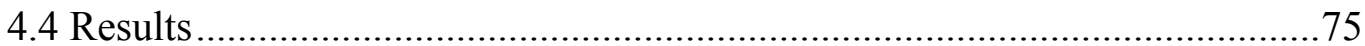

4.4.1 The fish fauna: seasonal changes in abundance and biomass ....................75

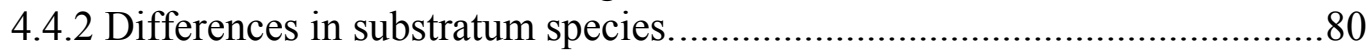

4.4.3 Diversity of fish assemblages: seasonal and sites differences ...................81

4.4.4 Substratum associations with reef fish abundance....................................8.

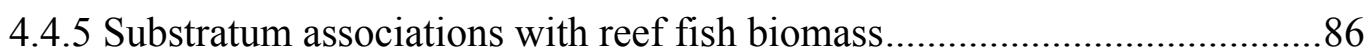

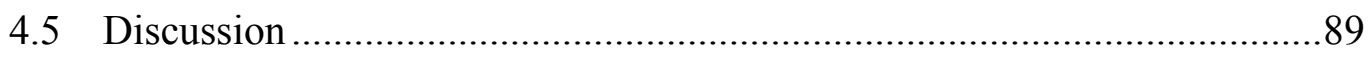

CHAPTER 5 Disentangling the effects of macroalgae on the abundance of temperate reef fishes .......................................................................................................93

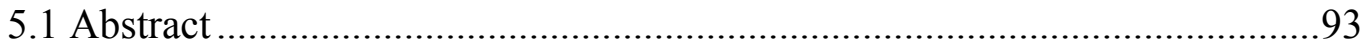

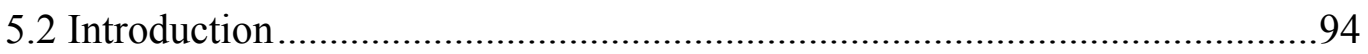

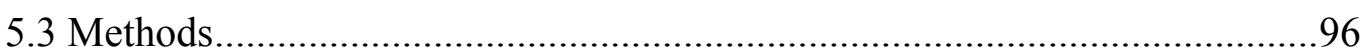

5.3.1 Laboratory experiment - Capacity for behaviourally mediated habitat

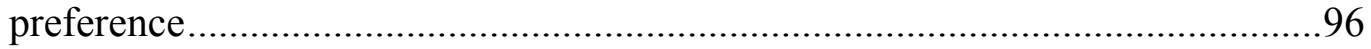

5.3.2 Field experiment - Effects of habitat heterogeneity on the abundance of reef fishes and the local fish assemblage ..........................................................100

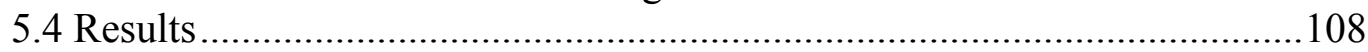

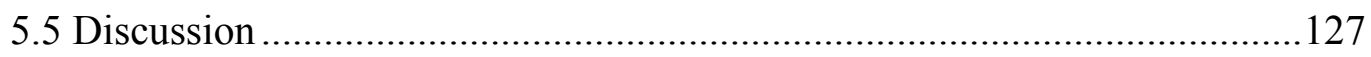

CHAPTER 6 Density and trait-mediated effects of fish predators on amphipod grazers: potential indirect benefits for the giant kelp, Macrocystis

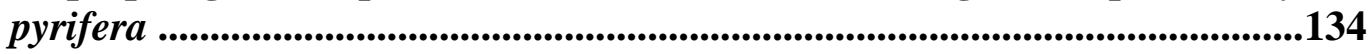

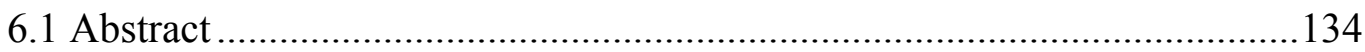

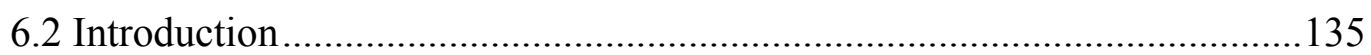

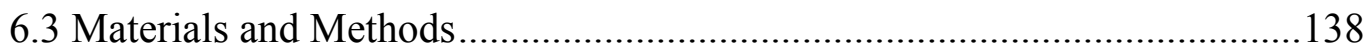

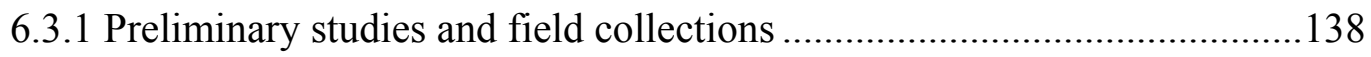

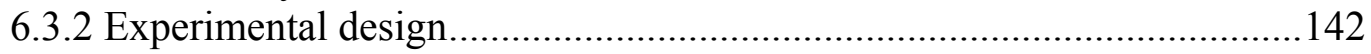

6.3.3 Density-mediated effects of fishes on amphipods ................................145

6.3.4 Trait-mediated effects of fishes on the grazing efficiency of amphipods. 146

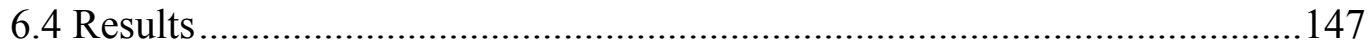

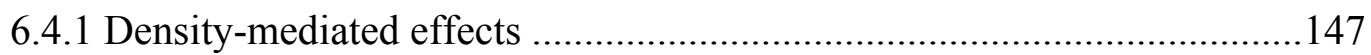

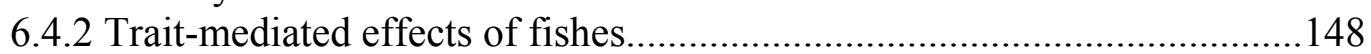

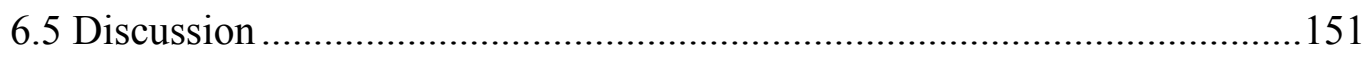

CHAPTER 7 Summary, final considerations and future research .............156

7.1 Diversity of fishes temperate reefs: the importance of spatial hierarchies ..156

7.2 The effects of macroalgae on fish populations ..........................................159

7.3 Potential positive effects of fishes on macroalgal habitats: towards the

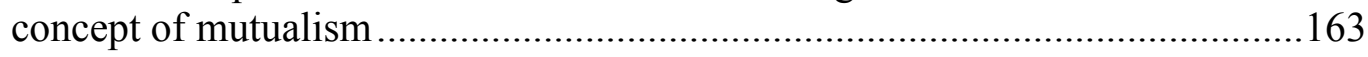

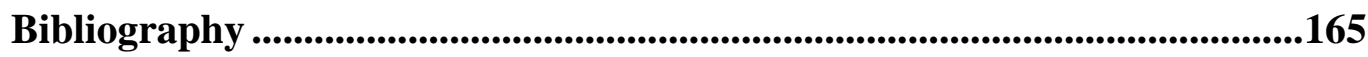

APPENDIX 1 Disentangling the effects of macroalgae on the abundance of temperate reef fishes .........................................................................................................180 
APPENDIX 2 Density- and trait-mediated effects of fish predators on amphipod grazers: potential indirect benefits for the giant kelp Macrocystis pyrifera

APPENDIX 3 Additional research 198 


\section{CHAPTER 1}

\section{Effects of macroalgal habitats on the community and population structure of temperate reef fishes: Introduction, overview, and thesis structure}

Fish are the most abundant vertebrates in both marine and fresh water environments, with more than 28,000 representatives (Nelson 1984). Almost $60 \%$ are marine species for all or part of their lives (Moyle and Cech 1982). Fishes represent a paraphyletic group and the most recently evolved are the Actinopterygii (ray-finned fishes). The diversity of the fishes reflects the great variety of habitats that are available for their distribution and speciation (Kramer et al. 1997). Within habitats fishes also occupy almost every possible feeding role, from detritivore to herbivore to carnivore. Fishes also exhibit considerable diversity in their reproductive modes, life cycles, and dispersal abilities. These differences have important implications for patterns of distribution and abundance at both local and regional scales (Macpherson et al. 2009).

Suitable habitat is essential to the ecological and evolutionary success of most organisms including fishes (Kramer et al. 1997; Beck 2000). Particular habitat attributes may shape local population densities (Choat and Ayling 1987), survival rates (Anderson 1994; Tolimieri 1995), dispersal patterns of adults, and recruitment dynamics (Carr 1991; Carr 1994). Biotic habitats such as macroalgae are often important for fishes, providing refuge from predators, and food (either directly or indirectly, by facilitating higher concentrations of prey; 
(e.g., Taylor 1998b; Edgar et al. 2004b)). Similarly, positive demographic feedbacks from fishes to habitat-forming organisms (e.g., seaweeds) have been described, as some fishes may facilitate vegetative structures via consumption of important grazers (Davenport and Anderson 2007; Newcombe and Taylor 2010). Given that the distributions and local abundances of ecologically and/or economically important species may depend upon suitable habitat, a mechanistic understanding of the effects of different habitat components on population demography and collective fish communities is essential for the successful management and/or conservation of many species.

\subsection{The focal habitat: temperate reefs and the large-brown macroalga}

Habitat heterogeneity is an important indicator of species interactions with the surrounding environment. Temperate reefs may be comprised of a mixture of habitat types, including brown macroalgae, sand, and boulder interstices. These habitat types contribute to a heterogeneous landscape (Connell and Irving 2008), and in this landscape, motile organisms may encounter patches that vary in quality. Organisms may perceive the quality of a particular habitat depending on their requirements for food, protection, and potential for interactions with other resident organisms. Organisms may then distribute themselves in habitats that minimize costs and maximise rewards (Bélisle 2005).

Large brown seaweeds are among the best-known forms of macroalgae. They inhabit nearshore environments of most temperate coasts (Dayton 1985a). Two orders comprise the assemblage of large brown algae: the Laminariales and Fucales (Schiel and Foster 1986). There are around 30 genera, which vary in size, morphology, and life-span. They are particularly abundant where the water 
temperature is generally lower than $20^{\circ} \mathrm{C}$, often forming dense stands, with individuals of some species reaching more than 30m in length (Schiel and Foster 2006). Attached to the substratum by holdfasts, stands of large brown macroalgae often provide important three-dimensional structure in subtidal environments. They remain erect by stiff stipes, thick cell walls, and/or pneumatocysts (gas bladders), depending on the species (Fig. 1.1). Communities of large brown macroalgae are typically highly productive, and sustain some of the most diverse and dynamic ecosystems on earth (Graham et al. 2007b). Their holdfasts represent areas for feeding, refuges from predators and settlement habitats for a variety of organisms (Vásquez and Buschmann 1997; Vásquez et al. 2001).
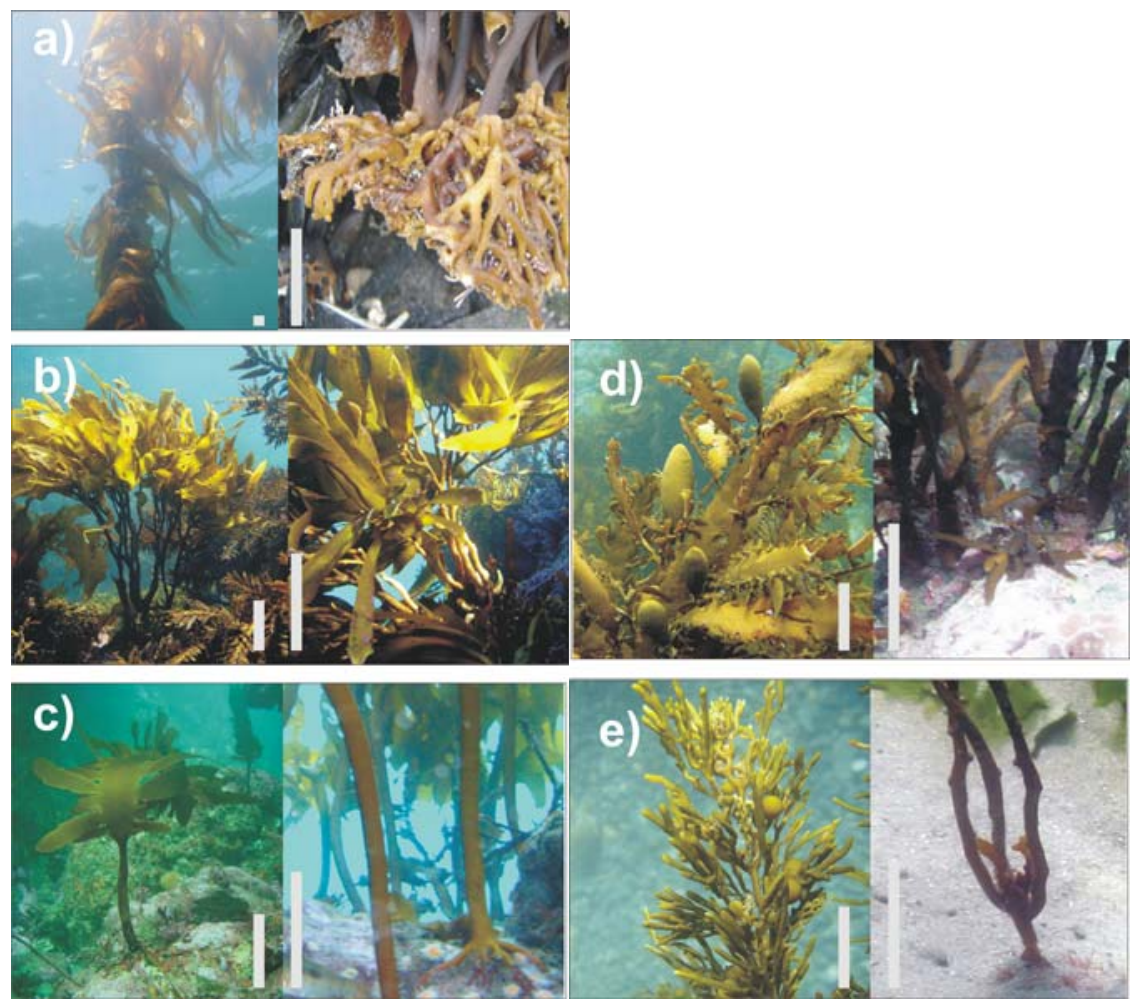

Figure 1.1 Fronds and holdfast of abundant large brown macroalgal species in subtidal environments around New Zealand. Laminareales: a) Macrocystis pyrifera, b) Lessonia variegata, c) Ecklonia radiata; Fucales: d) Carpophyllum maschalocarpum and e) Cystophora retroflexa. Scale bars $=500 \mathrm{~mm}$ (Photo credits: E. Macaya and A. Pérez-Matus) 
Communities of large brown macroalgae are characterized by numerous species, which vary in space and time. The factors that explain changes in organization of macroalgal communities include: (a) variable life-histories (e.g., annual vs perennial species); (2) competitive interactions (within and between species); (c) herbivory, particularly dislodgement by grazing sea urchins and consumption by mesograzers; and (d) physical factors (i.e., variation in temperature, nutrient levels, light, degree of exposure to wave action and bottom relief) (for reviews see: North 1971; Schiel and Foster 1986; Schiel 1988; Schiel and Foster 2006; Graham et al. 2007b).

\subsection{Consistent patterns of abundance of reef fishes among multiple sites}

A major goal in ecology is to identify processes controlling species abundance over large scales. Early studies in coral reef systems considered that assemblage structure of reef fish was stable through time and space, placing competitive interactions as the primary mechanism that determined the fates of individuals, and the structure of populations and communities (Smith 1978). More recently, observations of dramatic spatio-temporal variation in reef fish assemblages has spawned the idea that variable recruitment is a primary mediator of reef fish population and community structure (Sale 1980; Sale 1988). Debate continued and expanded among reef-fish ecologists, many of whom attributed the unpredictability of fish - habitat associations to stochastic processes such as recruitment (Sale et al. 1994). However, more recent studies have suggested that the contribution of recruitment may be a scale-dependent phenomenon (e.g., White and Caselle 2008). 
Considerable variation has been documented for the effects of habitat on fish populations (Syms and Jones 1999; Valesini et al. 2004). Some of the apparent discrepancy among studies may arise from different categorizations of habitat. For example, Holbrook et al. (2000) describe broad habitat groupings (i.e., coral, sand, kelp), which are often used by scientists to characterize a particular habitat. These broad groupings, coupled with the scale of observations, can obscure specific habitat requirements of some fish species (Holbrook et al. 2000). Other authors have noted that fishes may be responding to spatial variation in habitat variation (e.g., O hman et al. 1997; Valesini et al. 2004; Pérez-Matus et al. 2007; Wellenreuther et al. 2007; Williams et al. 2008). Whether these associations are able to predict large-scale (regional) patterns of abundance and diversity of reef fishes is still unknown. Generally speaking, however, a consensus exists regarding the positive effect of habitat on fishes, particularly early in their life-history, e.g., at recruitment and for subsequent juvenile-adult stages, although much of this evidence comes from studies that were conducted at small spatial scales (McDermott and Shima 2006). These observations made at small spatial scales may not be sufficient to predict abundance at larger-scales, where, in general, oceanographic processes appear to play a greater role in demographic patterns (Caselle and Warner 1996; White and Caselle 2008). Contrary examples suggesting reasonable relationships between observations from small- to large scales are limited, and appear to be species dependent (but see, Munday 2002). 


\subsection{Role of large brown-macroalgae in controlling the distribution and abundance of temperate reef fishes}

The physical structure of large brown macroalgae may provide food (or feeding areas), refuge from predators, and mating sites for a wide variety of fishes. Asssociated fauna may use the same structures of a seaweed for different purposes, or they may partition their activities among different components of an individual seaweed (e.g., fronds may be used for refuge/shelter, holdfasts for feeding sites) (Steneck et al. 2002; Christie et al. 2007). The surfaces of macroalgae harbour dense and diverse populations of motile organisms, including amphipods, isopods, gastropodos, polychaetes and copepods, collectively known as epifauna. Congruently, different macroalgae (with different architecture) sustain different associated fauna. For example, fronds of Carpophyllum species are small, numerous and dense, and greater complexity provides additional space for a wider range of epifauna. In contrast, Ecklonia species have relatively fronds and a single stipe, which leaves the fronds more exposed to wave action and provides comparatively little space for epifauna (Taylor and Cole 1994). Specific macroalgal features vary spatially and temporally.and consequently the associated fauna vary over short distances (Graham 2004). This variation may depend upon local environmental conditions (e.g., degree of wave exposure), herbivory, competition, or be a function of the phenotypic traits of the macroalgae themselves (e.g., the number of stipes or fronds, and whether individual seaweeds occur in monospecific or mixed canopy stands) (Taylor and Cole 1994; Thiel and Vásquez 2000; Christie et al. 2007). Specific macroalgal traits may act in synergy to shape patterns of distribution 
and abundance of fishes. Consequently, macroalgal habitats likely offer multiple sources of environmental variation that combine to determine overall "habitat quality".

The non-random demographic effects of a particular habitat structure can facilitate habitat selection by dependent organisms. Distributional models arise from organism' habitat selection. Distributional models have attempted to predict patterns of movement and dispersal of species among different habitats (Hugie and Grand 1998; Levin et al. 2000). Both the ideal free distribution (IFD) and the ideal despotic distribution (IDD) describe trade-offs that arise from behavioural decisions of individuals (for a review see Kramer et al. 1997). In their application, both distributional models are sometimes based on untested assumptions of an individual's ability to perceive and discriminate among locally available habitats and/or other resources (Roshier et al. 2008). From the perspective of an individual of a given species, the decision to move from one patch to another may depend upon a range of (potentially conflicting) motives that, for example, may include the use of food resources and/or mating opportunities, minimization of risk from predators and/or competitors (Kramer et al. 1997; Connell and Kingsford 1998; Crowe and Underwood 1998)

\subsection{Direct and indirect effects of the relationship between fish and large-brown macroalgae: towards the concept of mutualism}

Demographic feedbacks from fishes to macroalgal structures may arise because of a predatory influence of fish on other macroalgal-associated organisms (e.g., invertebrate grazers). Macroalgal-dominated environments are often characterized by high concentrations of grazers of various sizes and forms 
(e.g., sea urchins, snails, small crustaceans) (Coyer 1984; Taylor 1998b). Seaurchins, one of the best-studied of these grazers, are capable of changing the macroalgal habitats to "barren" environments, and their activities subsequently limit future recruitment of large brown macroalgae (reviewed in Lawerence 1975; Vásquez and Buschmann 1997). Similarly, but less well-understood, small crustacean epifauna (e.g., amphipods) are able to decrease macroalgal biomass (Duffy 1990; Haggitt and Babcock 2003). After El Niño events, outbreaks of these small crustacean assemblages can disrupt recruitment and growth of kelp (Dayton 1985b; Duffy and Hay 2000). Trophic cascades mediated by populations of fish and small herbivores appear to be indicative of the potentially important indirect effects that fishes can have on macroalgal demographic rates (Davenport and Anderson 2007; Korpinen et al. 2007; Newcombe and Taylor 2010).

There are two main ways in which positive indirect effects occur over primary producers: (a) the classical effect of predator-prey interactions in which the predator reduces numerical abundance (i.e., density-mediated interaction) of herbivore populations, thus reducing their effect on plants, and (b) the mere presence of a predator produces a behavioural response over a prey population (trait-mediated interactions) causing them to disperse or hide, and thus reducing their effect on plants (Schmitz 2003; Schmitz et al. 2004). Linear chains of reactions, whereby one predator inflicts damage on one grazer, poorly represent most ecological communities. More commonly, multiple species may cause similar effects on a target species (Schmitz 2007). The role of multiple predators and predator diversity is an increasing area of ecological study (reviewed by Schmitz 2007). Emergent effects of multiple predators arise when two or more 
predators enhance the per-capita effect on prey-populations (reviewed by Sih et al. 1998). Alternatively, predators may interfere with one another, thus reducing the effects on prey populations. Another mechanism that dampens the per-capita effect of a predator on prey populations occurs when a potential competitor can also serve as prey for the other member of the competitive interaction (i.e., intraguild predation) (Schmitt et al. 2009). Intra-guild predation is a common feature in both subtidal and intertidal marine environments (Van Son and Thiel 2006).

These interactions highlight the potentially complex relationships between consumers and primary producers. Such relationships can have implications for the organisms (e.g., macroalgae) that often provide demographically important habitat for fish populations (see Taylor and Schiel 2010). Alternatively, resulting feedbacks can facilitate positive responses from both interacting entities. Such feedbacks may be described as a mutualism.

\subsection{Thesis structure}

In my $\mathrm{PhD}$, I have included both manipulative and observational studies of different aspects of community ecology related to the associations between fish and macroalgae. Specifically in Chapter 2, I explored the changes in abundance and diversity of fishes over multiple sites within different locations and regions. Specifically, I explored variation in diversity and composition of fish assemblages as a function of multiple sites in algal-dominated subtidal habitats. This chapter provides an evaluation of fish and macroalgal community similarities across a range of hierarchical spatial scales. This chapter is largely descriptive, and patterns are explored in greater quantitative detail in subsequent chapters. Subsequently (Chapter 3), I explore the potential effects of stochastic 
recruitment and availability of habitat as primary determinants of reef fish population and community structure. Specifically, I assessed the influence of abiotic factors and habitat on reef fish abundance and diversity in an isolated island (i.e., a largely closed ecological system). This allowed me to understand what proportion of the fish assemblage came from elsewhere and what proportion remains within the islands, and subsequently, what habitats influence the abundance of a particular fish species.

In Chapter 4, I assessed the temporal variation in habitat heterogeneity and the associated fish assemblage, to determine whether the associations between fish and different levels of habitat heterogeneity were consistent among seasons within a year, and across three widely distributed study sites.

Because I found that the effects of macroalgae were important in explaining variation in the abundance of reef fishes in space and time, I conducted a lab-based experiment to evaluate the ability of two common fish species to discern between different macroalgal structures (Chapter 5). Furthermore, I conducted a larger field experiment that built upon this lab study, to evaluate the responses of a fish assemblage to habitat heterogeneity. I repeated this study at two sites (a wave-protected site and an exposed site) and I manipulated the identity, density, and composition of large brown-macroalgae (e.g., as either single species or mixed species canopies).

Finally, in Chapter 6, I evaluated the potential indirect effects (including multi-predator effects) of fish predators on giant kelp, Macrocystis pyrifera. I evaluated the direct consumptive and behavioural effects of fishes on invertebrate mesograzers (amphipods). This study enabled me to understand the potential positive feedbacks that exist between fishes and macroalgae. The 
results given in this chapter are based solely upon a mesocosm study because a larger scale field experiment was destroyed due to the strong weather conditions along the south coast of New Zealand.

Because these chapters were written as a series of independent studies, some redundancy regarding motivations and conclusions may be evident. I summarize the results of these chapters, indicating possible areas of future research, in Chapter 7. 
I indicate the actual and/or intended publication status of my thesis chapters below:

\section{- Chapter 2.}

Pérez-Matus, A. Neubauer, P. Francis, M. \& Shima, J. Changes in reef fish diversity associated with macroalgae. To be submitted

\section{- Chapter 3.}

Pérez-Matus, A. Ramírez, F. Eddy, T \& Cole, R. Community structure at Juan Fernández Islands: How are temperate fish assemblages organized in non-kelp dominated habitats? Pacific Conservation Biology. In review.

\section{- Chapter 4.}

Pérez-Matus, A. Neubauer, P. Francis, M. \& Shima, J. Changes in reef fish diversity associated with macroalgae. To be submitted

\section{- Chapter 5.}

Pérez-Matus, A. \& Shima, J. (2010) Disentangling the effects of macroalgae on the abundance of temperate reef fishes. Journal of Experimental Marine Biology and Ecology. 388:1-10 (see appendix 1)

\section{- Chapter 6.}

Pérez-Matus, A. \& Shima, J. (2010) Density and trait-mediated effects of fish predators on amphipod grazers: potential indirect benefits for the giant kelp, Macrocystis pyrifera. Marine Ecology Progress Series. 417:151-158 (see appendix 2). 


\section{CHAPTER 2}

Reef fish diversity associated with macroalgae: an exploratory comparison of temperate reef fish faunas

\subsection{Abstract}

Biogeography acknowledges that distributional patterns have their origins at community levels where several intrinsic mechanisms underpin species cooccurrence. Diversity is a fascinating but controversial topic: observed causes and consequences depend on the resolution and scale of observation. Several hypotheses have been proposed in order to explain diversity and co-occurrence in natural communities. Given that most of these have been tested at local scales, our capacity to identify the boundaries at which small-scale patterns can be generalised over large areas may be compromised. By sampling several spatial scales (metres to thousands of kilometres) from Juan Fernández Islands (Chile), Northern New Zealand, and Tasmania (Australia), I explored the differences in reef fish diversity and composition of fish assemblages. Using model selection criteria the abiotic (spatial scale, depth, or temperature) and biotic (brown macroalgae structures) factors influencing fish diversity were determined. Results from this exploratory work indicate variation in species and trophic diversity rather than familial or ordinal diversity. Best predictors of species and trophic diversity were different to those correlated with higher taxonomic diversity levels, specifically, few parameters explained diversity at higher taxonomic resolution relative to species level. The composition of the fish 
assemblage varies among sampled locations. The ecological mechanisms that may underlie these patterns are inherent to each location such as the substratum availability, trophic structure, and abiotic factors. These imply that patterns between habitat types and fish diversity may be predictable.

\subsection{Introduction}

The number of species varies widely over the surface of the earth. The mechanisms underlying patterns in the two main components of diversity, species richness and the relative abundance of species have been widely investigated by early ecologist. As a consequence a plethora of hypotheses were put forward in order to explain patterns of species diversity among ecosystems (e.g., Patten 1962; MacArthur 1965; Pianka 1966) with no clear consensus in definition and the use of estimates of species' diversity (see Peet 1974).

Diversity is considered to be a controversial topic. Hurlbert's (1971) article pointed out the misuse of diversity in many ecological studies. Since then, a number of temporal, environmental and biotic factors as have been correlated with species diversity (review Gaston 2000). The most influential patterns are shown in the diagram below. These models provide plausible explanations for species' coexistence, but the outcomes are context-dependent (diagram 2.1). In general, ecologists have agreed that temperature, environmental fluctuations and geological processes influence species richness over large regional scales; while competition, predation, recruitment, migration and disturbance may more 
commonly affect patterns of species diversity at local scales (Mora et al. 2003;

Ricklefs 2004; Connolly et al. 2005).

a)

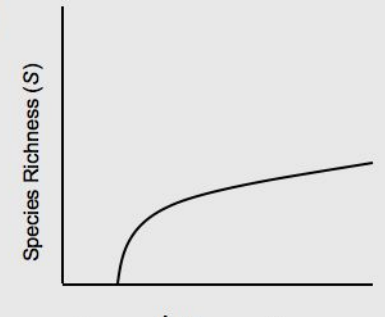

b)

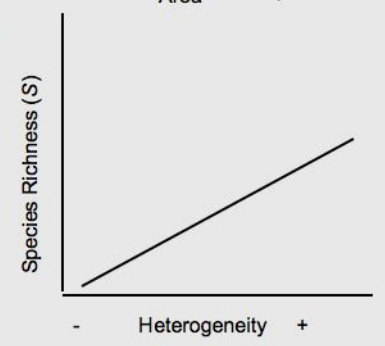

Equilibrium c)

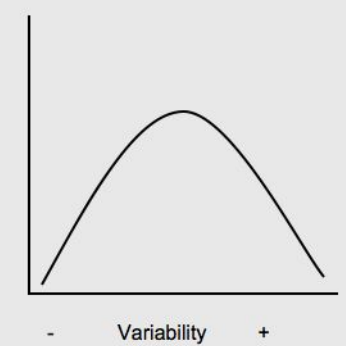

d)

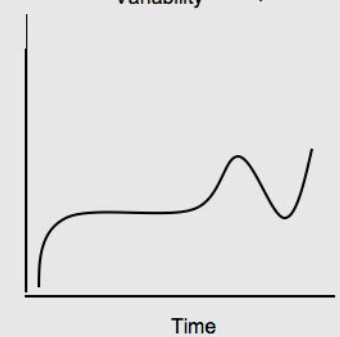

Non - Equilibrium

Diagram 2.1 Proposed hypothesis of species diversity: equilibrium state hypotheses a) diversity increases with area and b) highly heterogeneous areas allows the species co-existence. Non-equilibrium stare hypothesis such c) environmenal variability refers that intermediate state disturbances sustain higher number of species and d) some species remains in variable, predictable environments, while other are being replaced due to environmental change. (adapted from Jacksic \& Marone 2007a)

The complexity of many ecological systems, with their physical and biological spatial scales influences the way scientists view populations and ecosystems (Levin 1992). At local scales for instance, rules apply when species are combined to form local assemblages. Therefore, understanding the consequences of the intrinsic and extrinsic factors (both biotic and abiotic) that play a significant role in determining the structure at local and regional scales is a major challenge in community ecology (Sale et al. 1994). Substantial evidence of patterns, such as species abundance and distribution, has accumulated in a 
wide variety of habitats at small spatial scales (Fraschetti et al. 2005). The understanding of the influence of regional processes on populations and communities requires large-scale research assessments (Lawton 1996). Identifying the boundaries at which a small-scale can be generalised over largescales has attracted the interest of ecologists due to the fact that most ecological studies work under small $(10-100 \mathrm{~m})$ and at medium scales $(100$ to $1000 \mathrm{~m})$ (but see Fowler-Walker and Connell 2002; Irving et al. 2004; Connell and Irving 2008; Wellenreuther et al. 2008). Ecologists are therefore increasingly considering larger geographic scales in order to understand patterns at a more regional (100 to $1000 \mathrm{~km})$ and biogeographic (over $1000 \mathrm{~km})$ scales (MacNeil et al. 2009).

The shallow marine environments of the South Pacific including Australia, New Zealand and Chilean coasts are similar in terms of habitat and seawater temperature fluctuations. Locations that are dominated by large brown macroalgae offer a good framework for comparisons of factors that drive abundance and diversity of fishes. The present study aims to explore patterns of variation in reef fish diversity at different geographical scales. Specifically, I compared different levels of fish diversity among different spatial scales such as 21 sites within 7 locations within 3 regions. Subsequently, using model selection, I identified a set of factors that may influence patterns of diversity. An additional aim of this chapter is to compare the different composition of fish assemblages associated with brown macroalgae. This contributes to our understanding of similarities in fish communities across distant geographic areas that are dominated by macroalgae. 


\subsection{Methods}

All regions, locations and study sites were defined a priori according to similar level of exposure to wave action, and dominance of large brown macroalgae as the primary substratum type. Sites were characterized by being semi-exposed to wave-action and a substrate dominated by Laminareales, Fucales, or other brown macroalgae species. Three main regions compose the largest scale of this study: Oceanic Chile, New Zealand and Australia. Oceanic Chile the Juan Fernández Islands $\left(33^{\circ} \mathrm{S}\right)$ were surveyed but for a broader comparison I've included Northern Chilean coast from my previous published studies (Pérez-Matus et al. 2007); in New Zealand locations include the Poor Knights Islands (34 $\mathrm{S})$, Auckland $\left(35^{\circ} 174^{\circ} \mathrm{W}\right)$, Kapiti Island $\left(40^{\circ} \mathrm{S}\right)$ and Wellington $\left(41^{\circ} \mathrm{S}\right)$. Southern Australia included two locations in Tasmania (43$44^{\circ} \mathrm{S} 178^{\circ} \mathrm{W}$ ) (Fig. 4.1). Each location includes three different sites. Sites were separated from each other by more than $400 \mathrm{~m}$ but less than $1000 \mathrm{~m}$ of distance.

\subsubsection{Sampling methodology}

The sampling methodology consisted of underwater visual census (UVC) and underwater photography for species identification. All surveys were conducted by means of SCUBA. UVC is a quick, non-destructive, and inexpensive method for estimating reef fish abundance. Transect and point counts are the most commonly employed UVC methods, and both may produce fast and precise fish counts (Watson and Quinn 1997). However, accuracy of UVC is difficult to evaluate. Observer error, diver's speed, fish detectability and observer's presence are some of recognised sources of bias of UVC methods (Thresher and Gunn 1986; McCormick and Choat 1987). Here, a transect refers 
to a straight line along which observations are made by a diver swimming at a constant speed. Point counts, in contrast, are conducted at randomly selected stations, where observer remains for a short period of time (2-5 min interval) measuring marine life in radius $180-360^{\circ}$ (Kingsford and Battershill 1998). Arguably, the use of UVC have been criticised as may underestimate the abundance of more cryptic members of the local fish assemblage, such as triplefins, gobies, clinids, bythitids (Willis 2001). Wellenreuther et al. (2007), however, challenged the critiques of UVC for quantifying reef fish abundance (particularly with reference to cryptic fauna), suggesting that Willis (2001) a) failed to restrict the census target to triplefin species; b) census conducted were all above $0.5 \mathrm{~m}$ the substratum, and thus did not search the substratum accurately; and d) the area using UVC and destructive techniques to census cryptic species was dissimilar. Wellenreuther (2007) conclude that cryptic species can be surveyed under UVC and with robust estimates by "a close, rigorous and systematic searching pattern, spending at least 1 min on each quadrate, with all interstices and overhangs examined to ensure a complete census".

In view of the above, and in order to reduce both logistical and operational costs, I used UVC to quantify fish abundance. In the present study (and also for surveys described in chapters 3 and 4), I use both transect (to detect larger benthic, demersal, and pelagic species) and point count (to detect smaller cryptic species) UVC methods. Specifically, I divided each site into five different depth strata $(3 \mathrm{~m}, 6 \mathrm{~m}, 9 \mathrm{~m}, 12 \mathrm{~m}$ and $18 \mathrm{~m})$. I sampled within each depth strata using ten different stations, each separated by four meters (i.e., 10 stations per depth strata). At each station, I first quantified the large fish assemblage for a period of a one-minute, recording the species identities and estimating the abundance and 
sizes of all observed individuals (Fig. 2a) over two meters to the left and to the right of a four meter long transect over substratum. Subsequently, I quantified the cryptic assemblage (focusing principally on small cryptic fauna) by searching every crevice, rock, and holdfast for another minute in the same area (Fig. 2b). Following these transect and point counts at a given station, I moved four to five meters alongshore to select a new station. For guidance I used a tape measure.

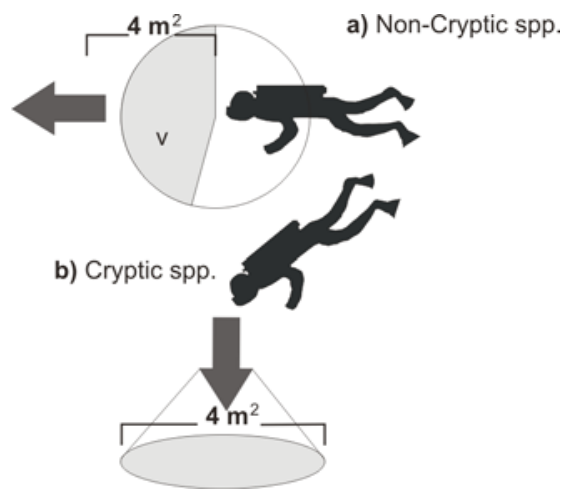

Figure 2.1 diagram of a) transect of non-cryptic species survey and b) point count of cryptic species. V means area of sampling. Fishes were counted under the shaded areas. (Figure adapted from Watson \& Quinn 1997)

Additionally at each sampling station (10 per depth strata), the species of macroalgae and/or type of substratum was also characterised. The presence of canopy forming habitat at each station was also classified as different levels of heterogeneity using the following criteria: (1) no algae (lithic) where no canopy or less than $10 \%$ of the surveyed area was composed of canopy forming algae; (2) monospecific canopies (i.e., single laminarean, fucalean), when more than $90 \%$ of quadrat is covered by single alga; and (3) mixed stands when two or more canopies comprised $40-60 \%$ of the stand.

Surveys were performed during spring (October through December) 2007 (Juan Fernández Islands), 2008 (New Zealand and Australia). 


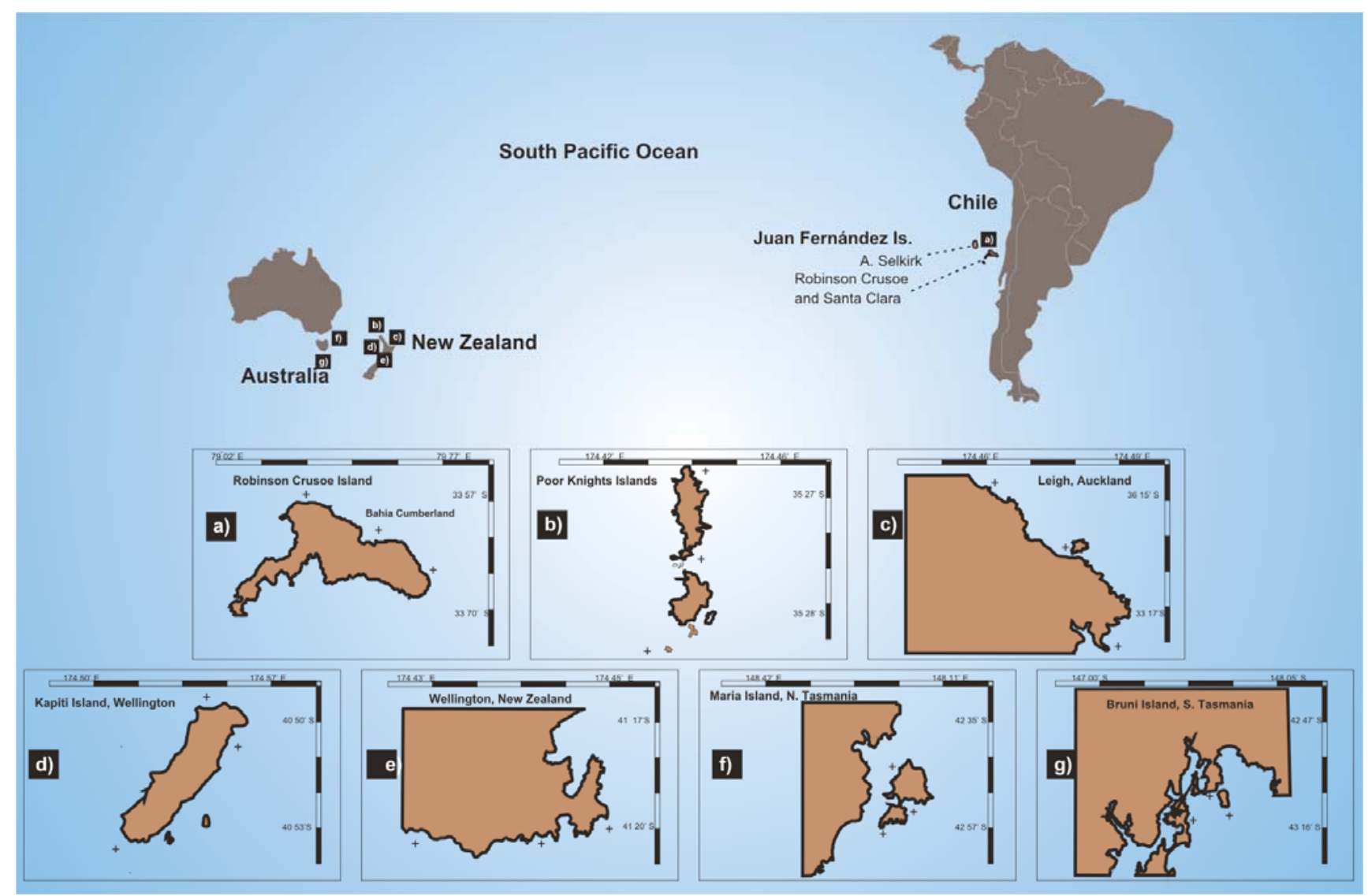

Figure 2.2 Map of the surveyed locations (n=7) and sampling site, denoted by +, (n=21) of a) Juan Fernández Islands, b) Poor Knights Islands, c) Leigh, Auckland Northern New Zealand, d) Kapiti Island, Wellington, e) Wellington, south North Island New Zealand, f) Maria Island, norther Tasmania, and g) Bruni Island, south Tasmania. (map is not to scale 


\subsubsection{Data Analysis}

All surveys were compiled in a matrix of pooled stations by transects. Fishes were grouped into different trophic levels, labelled as: 1) herbivores, 2) planktivores, 3) invertivores of soft shelled prey (i.e., amphipods), 4) invertivores of hard shelled prey (i.e., molluscs), 5) both invertivores, and 6) piscivores. Trophic groups were based on published dietary information, field guides, thesis, and unpublished data. Simpson's diversity index (Simpson 1949) was calculated per transect for different taxonomic levels (Order, Family, Genus, and species) and for trophic groups.

To determine how diversity levels (richness, abundance, and Simpson's Index) is partitioned between different spatial scales (region, location, site) I performed univariate analysis. The structure of this analysis of variance (ANOVA) treated the factor "region" as a fixed effect, "geographic location" and "Site" nested within "region" and "geographic location" respectively. To visualize differences in the total composition of reef fishes among different regions I used non-metric Multidimensional Scaling (n-MDS) (Clarke 1993). Before multivariate analyses, count data were subjected to a dispersionweighting pre-treatment; in which the abundances of the different species were differentially weighted on the basis of their observed variability in each transect samples. This is an appropriate transformation as some species of reef fish exhibit strong spatial clustering (i.e., pelagic species) (Clarke et al. 2006).

I evaluated the effects of scale (location, site), abiotic factors (temperature, depth) and biotic factors (habitats) and their interactions. I used model selection with Simpson's diversity as the dependent variable. I tested a 
total of 22 different candidate models and evaluate their relative support in explaining changes in diversity (see table 2.1). The full model contains both main effects and their interaction (Burnham and Anderson 1998).

To assess which model best explained fish species diversity, Akaike Information Criterion (AIC) approach was used:

$A I C=-2 \log (L(X \mid \Theta))+2 k$

where, $\mathrm{N}$ is the total sample size, $\mathrm{L}(\mathrm{X} \mid \Theta)$ is the likelihood of the model given the estimated parameters $\Theta$, and $\mathrm{K}$ the number of parameters in the model. Lower AIC values indicate a better model for the data at hand.

Table 2.1 Candidate model using measurable abiotic and biotic factors. In parenthesis () denotes nested factors; X, interactions; +, fixed main effects; Macroalgae, brown macroalgae (Laminareales, Fucales and Dictyotales); Understorey (foliose algae, vermetid molluscs, bryozoans and hydroids).

ID. Candidate models

1. Geographic Location

2. Macroalgae

3. Understorey

4. Temperature X Depth

5. Geographic Location + Temperature X Depth

6. Geographic Location (Site) + Temperature X Depth

7. Geographic Location + Macroalgae

8. Geographic Location X Macroalgae

9. Geographic Location + Understorey

10. Geographic Location X Understorey

11. Macroalgae + Understorey

12. Macroalgae X Understorey

13. Macroalgae + Temperature + Depth

14. Macroalgae X Temperature X Depth

15. Understorey + Temperature + Depth

16. Understorey X Temperature X Depth

17. Macroalgae + Understorey + Temperature $X$ Depth

18. Geographic Location + Macroalgae + Temperature X Depth

19. Geographic Location + Macroalgae + Understorey + Temperature + Depth

20. Geographic Location (Site) + Macroalgae + Understorey + Temperature + Depth

21. Geographic Location (Site) + Macroalgae + Temperature X Depth

22. Geographic Location (Site) + Understorey + Temperature X Depth 


\subsection{Results}

2.4.1 Changes in species diversity and substratum species

A total of 121 species from 70 genera 39 families and 8 orders were sighted in this study. Families that were most important in terms of numerical abundance were Labridae, Tripterygiidae, Kyposidae and Pomacentridae.

Geographic patterns of reef fish diversity indicate that more numbers of species were present at the 35.5 and 42.7 latitudinal degrees (Fig. 4.2). Changes in diversity were evidenced with longitude variation. Species richness peaks in the 175 of longitude (Fig. 2.3). 

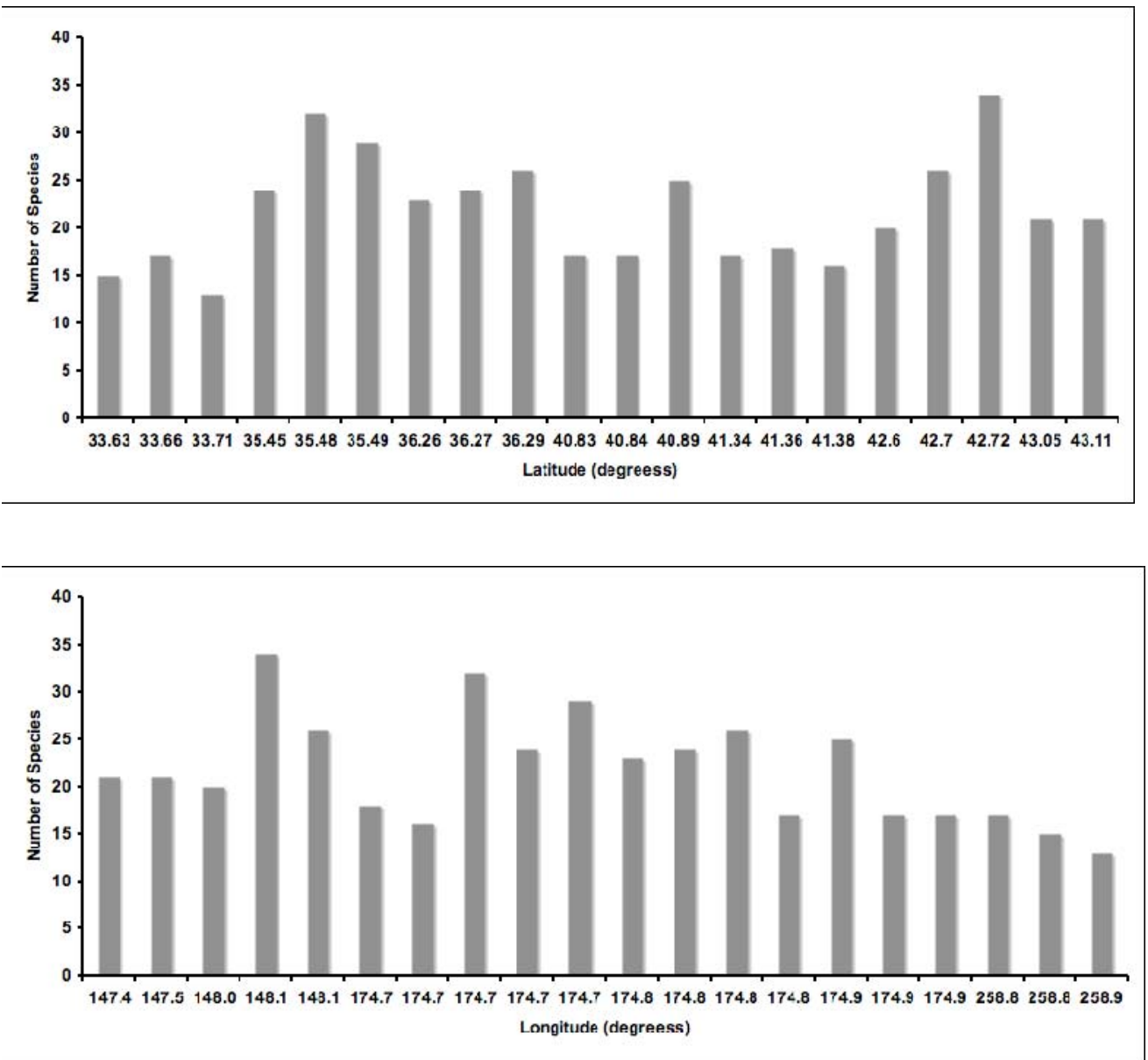

Figure 2.3 Geographical patterns in reef fish diversity over the sampled locations for latitudinal and longitudinal changes of total number of species

The species that cover the substratum differed among locations. In most kelp-dominated areas, single laminarean species (i.e., Macrocystis pyrifera, Ecklonia radiata, and/or Lessonia variegata) occurred in high frequency in all but northern Tasmania, Australia (Fig. 2.4). Mixed large brown macroalgae (laminarean with fucalean) were important in southern North Island, New Zealand and Northern Tasmania. Here, fucalean species occurred but in less amounts. Foliose algae (i.e., Dictyota spp, Padina spp) were important in the Juan Fernández Islands only (Fig. 2.4). 


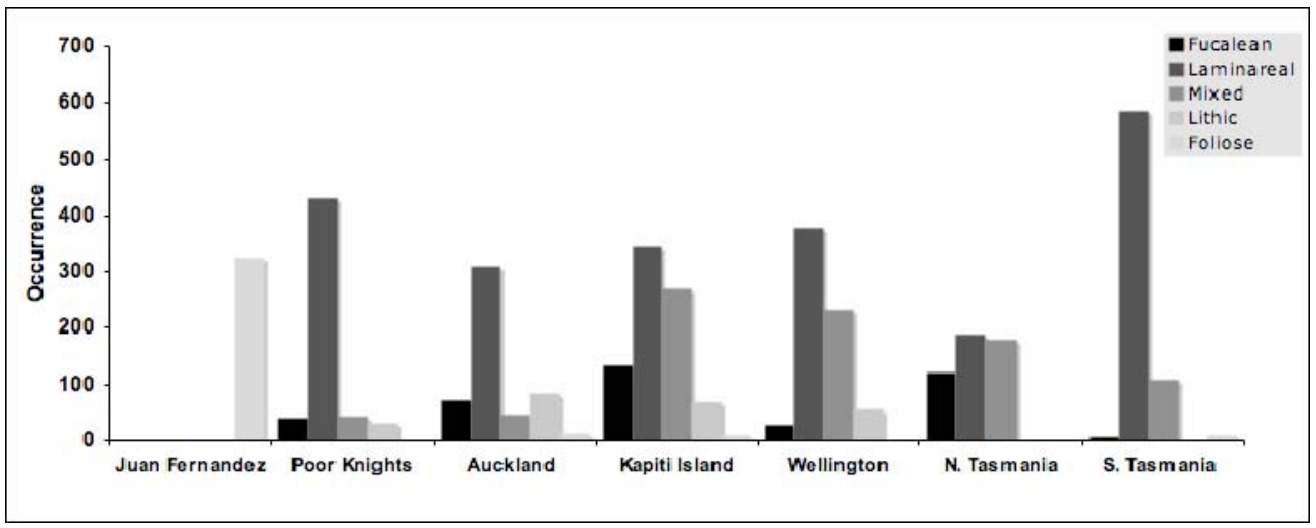

Figure 2.4 Total occurrence, pooled by sites, of substratum species among sampled locations for latitudinal and longitudinal changes of total number of species

There were differences in fish species richness detected at large scales (regions) and at small scales (i.e., sites within regions). Intermediate scales (i.e., locations) showed no significant variation in fish species richness (Table 2.2). Species richness (S) was higher in northern New Zealand (Poor Knights and Auckland), followed by Tasmania, Wellington and Juan Fernández Islands (Fig. 2.5).

Table 2.2. Results of ANOVA testing for differences in species richness between different levels of spatial scale among Regions, Locations, and Site. Significance in bold

\begin{tabular}{l|llll}
\hline & d.f. & $M S$ & F value & $p$-value \\
& & & & \\
\hline Region & 3 & 63.4 & 9.58 & $\mathbf{0 . 0 0 0 1}$ \\
Location(Region) & 6 & 11.5 & 1.73 & 0.16 \\
Site(Location(Region)) & 14 & 16.8 & 2.54 & $\mathbf{0 . 0 0 4}$ \\
Residual & 84 & 6.6 & & \\
& & & & \\
\hline
\end{tabular}

Cochran's C test of homogeneity of variance $\mathrm{P}>0.05$. 


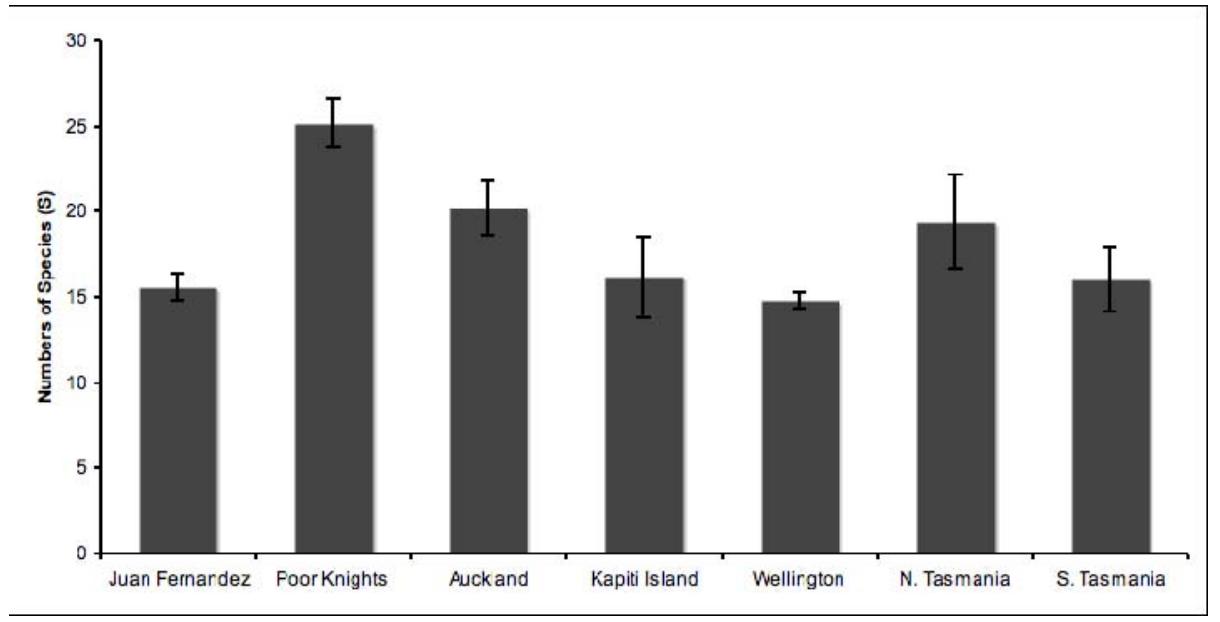

Figure 2.5 Mean $( \pm \mathrm{SE})$ number of species per sampled locations

Abundance showed significant changes at intermediate spatial scales (i.e., among locations) and larger spatial scales (among regions, Table 2.3). The Juan Fernández Islands sustained the highest fish abundance, followed by Kapiti Island, the Poor Knights Islands and Southern Tasmania. Northern Tasmania was the location with the lowest abundance of fish per site (Fig. 2.6).

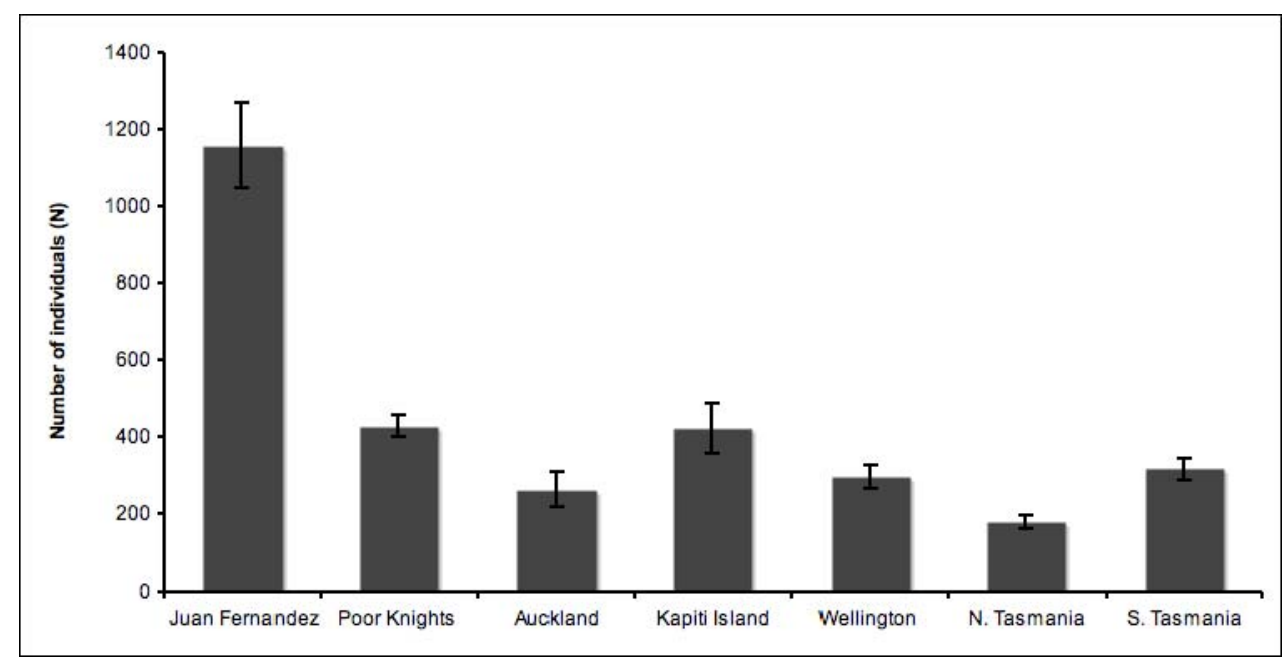

Figure 2.6 Mean $( \pm \mathrm{SE})$ number of individuals per sampled locations 
Table 2.3 Results of ANOVA testing for differences in abundance of fish species across different levels of spatial scale, i.e., among Regions, Locations, and Sites. Significance in bold

\begin{tabular}{l|llll}
\hline & d.f. & $M S$ & F value & $p$-value \\
& & & & \\
\hline Region & 3 & 9.5 & 45.97 & $\mathbf{0 . 0 0 0 1}$ \\
Location(Region) & 6 & 2.4 & 11.65 & $\mathbf{0 . 0 0 0 1}$ \\
Site(Location(Region)) & 14 & 0.3 & 1.53 & 0.11 \\
Residual & 84 & 0.2 & & \\
\hline
\end{tabular}

$\overline{\text { Data were log transformed. Cochran's C test of homogeneity of variance } \mathrm{P}}>0.05$.

Simpson's diversity index revealed differences at the lowest level of spatial scales (sites within region) (Fig. 2.7, Table 2.4). Highest diversity index was found in northern New Zealand including Auckland and the Poor Knight Islands, followed by the Juan Fernández Island (Fig. 2.7-8).

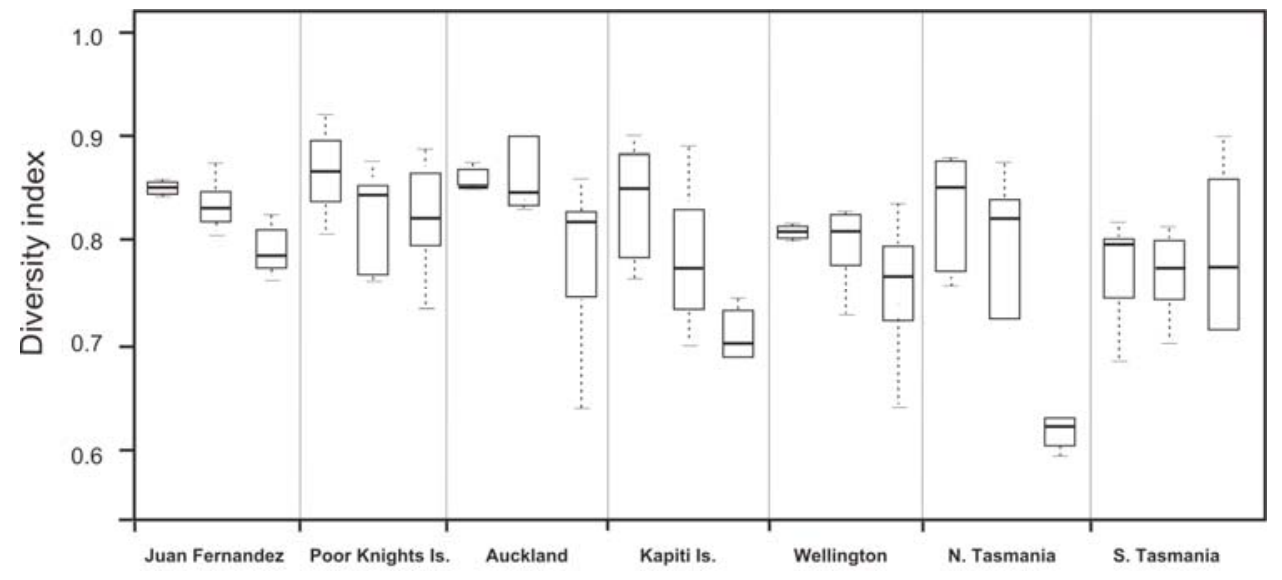

Figure 2.7 Boxplot of Simpson's diversity index among different sites within locations 


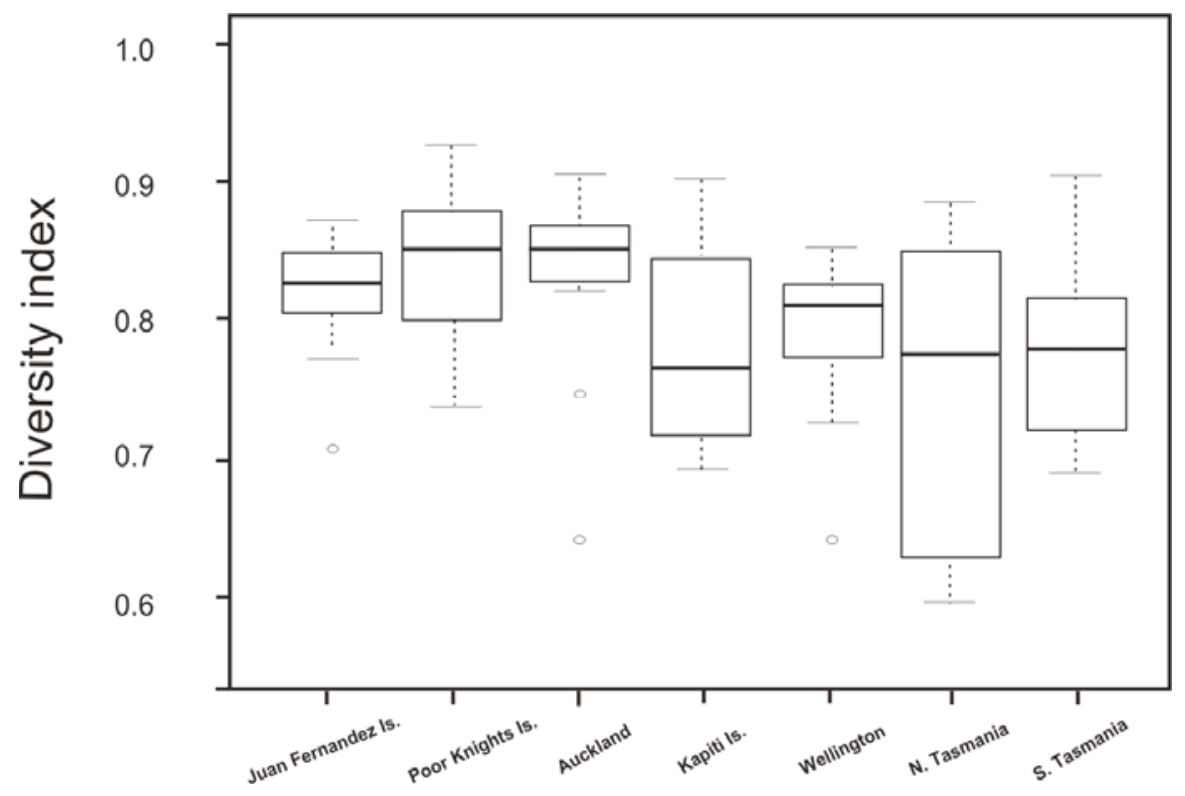

Figure 2.8 Boxplot of Simpson's species diversity index for all locations

Table 2.4 Results of ANOVA testing for differences in Simpson's diversity index of fish species across spatial scales, i.e., among Regions, Locations, and Site. Significance in bold

\begin{tabular}{l|llll}
\hline & d.f. & $M S$ & F value & $p$-value \\
& & & & \\
\hline Region & 3 & 0.1 & 0.88 & 0.45 \\
Location(Region) & 6 & 0.1 & 0.49 & 0.68 \\
Site(Location(Region)) & 14 & 0.42 & 2.6 & $\mathbf{0 . 0 0 3}$ \\
Residual & 84 & 0.2 & & \\
& & & & \\
\hline
\end{tabular}

$\overline{\text { Data were log transformed. Cochran's C test of homogeneity of variance } \mathrm{P}}>0.05$.

One of the 22 different models considerably outweighed all other models in predicting species diversity (Table 2.5). This model contained interactions between depth and temperature, as well as the biotic factor habitat (i.e., macroalgae) and geographic location. The next best candidate models included site nested within location, and understorey species (Table 2.2). 
Table 2.5 Species diversity. AIC results of the best three models

\begin{tabular}{lll}
\hline ID & Best models & AIC weights \\
\hline 18 & Geographic Location + Macroalgae + Depth X Temperature & 0.72 \\
21 & $\begin{array}{c}\text { Geographic location (Site) + Macroalgae + Depth X } \\
\text { Temperature }\end{array}$ & 0.14 \\
19 & $\begin{array}{c}\text { Geographic location + Macroalgae + Understorey + Depth + } \\
\text { Temperature }\end{array}$ & 0.10 \\
\hline
\end{tabular}

A similar trend with species diversity was followed by diversity of families. Higher numbers of families were observed at Northern New Zealand and the Juan Fernández Islands. Southern New Zealand holds the lowest numbers of families (Fig. 2.9).

Two main models best explained diversity of family, one including sites nested within geographic location with the interaction between temperature and depth. Other models with some support include depth and the interaction with temperature and macroalgal substratum species (Table 2.6).

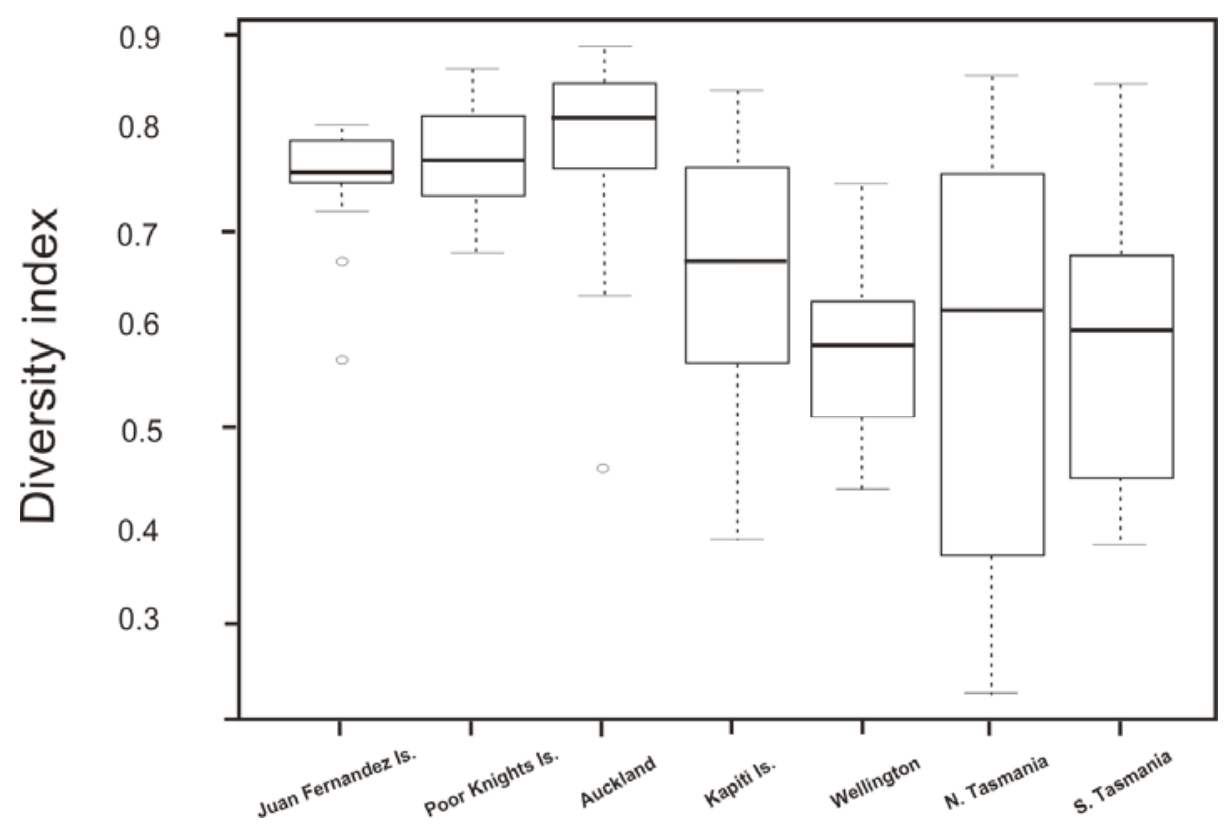

Figure 2.9 Boxplot of Simpson's diversity of fish families among sampled locations 
Table 2.6 Familial diversity. AIC results of the best three models

\begin{tabular}{|c|c|c|}
\hline ID & Best model & AIC \\
\hline 5 & Geographic Location (Site) + Depth X Temperature & 0.50 \\
\hline 21 & $\begin{array}{l}\text { Geographic location (Site) }+ \text { Macroalgae }+ \text { Depth X } \\
\text { Temperature }\end{array}$ & 0.43 \\
\hline 20 & $\begin{array}{l}\text { Geographic location }(\text { Site })+\text { Macroalgae }+ \text { Understorey }+ \\
\text { Depth }+ \text { Temperature }\end{array}$ & 0.06 \\
\hline
\end{tabular}

As opposed to species and familial diversity, ordinal diversity of fish was high in lower latitude areas (except in southern North Island New Zealand locations) such in Tasmania, Australia. Juan Fernández and northern New Zealand showed similar diversity of orders (Fig. 2.10). Geographic location was the model that best explained diversity of orders, with overwhelming support.

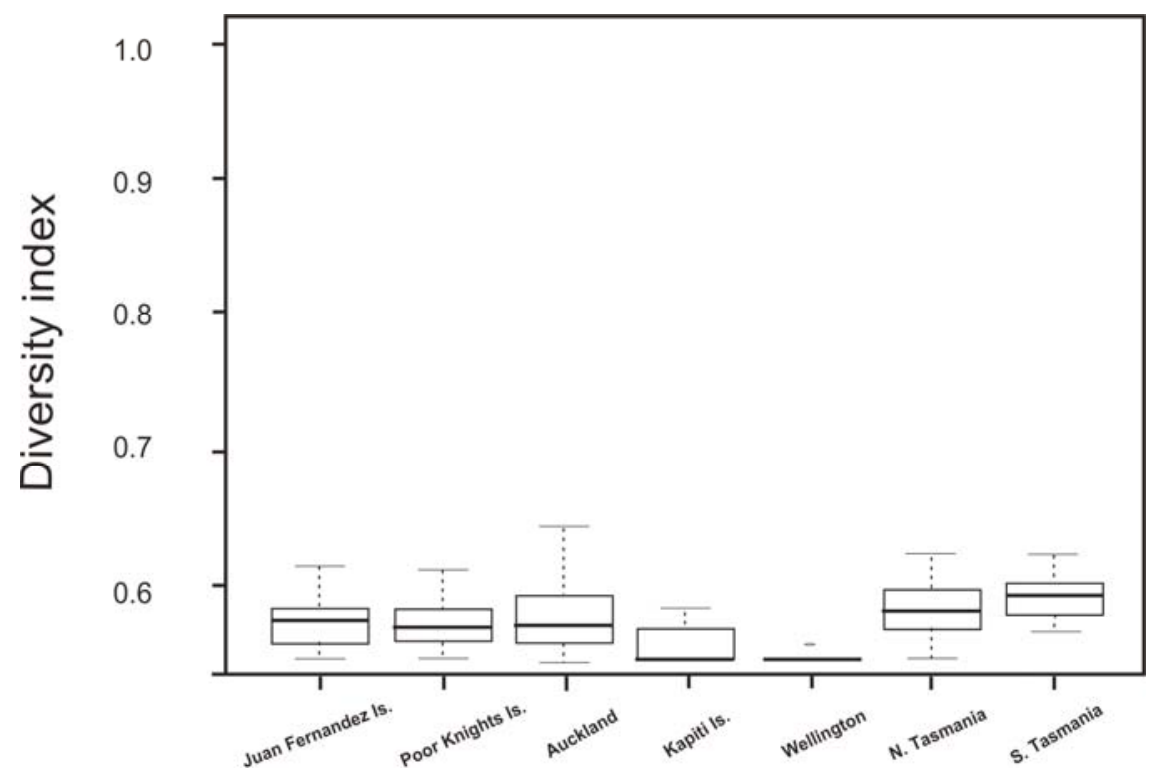

Figure 2.10 Boxplot of Simpson's Ordinal diversity among different locations

A total of 11 different trophic groups were evidenced among the 121 fish species surveyed. Species consuming soft-shelled invertebrates (i.e., amphipods, crustaceans) as prey were the most important in terms of richness and numerical abundance. The Juan Fernández Islands were the most diverse in terms of trophic 
groups (Fig. 2.11). The model which best-explained diversity of trophic levels includes the geographic location, macroalgae and the interaction between depth and temperature.

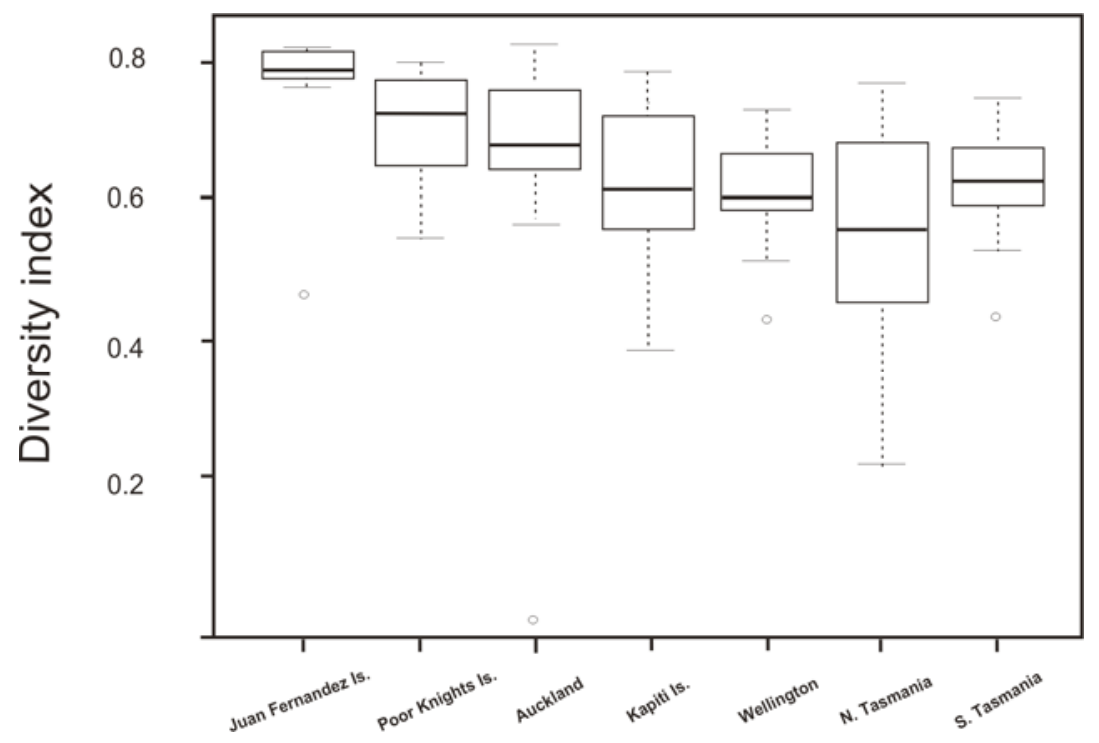

Figure 2.11 Boxplot of Simpson's trophic species diversity among different locations

\subsubsection{Changes in composition of fish assemblages}

The proportion of families that dominates the fish assemblages within a location varies among geographic areas. Families were dominated by pomacentrids ( 2 species), cheilodactylids (1 species) and by members (two species) of the Haemulidae. These families composed more than the $50 \%$ of the proportion of fish assemblages in northern Chile. Wrasses (2 species) and kyphosids ( 2 species) composed more than $70 \%$ of the total proportion of fish species at the Juan Fernández Islands, whereas five families dominate the assemblages at the Poor Knights Islands. The most important families in terms of numerical abundance were Pomacentridae (3 species) and Tripterygidae ( 8 species) followed by Kyphosidae and Carangidae (2 species each) at Poor Knights islands. Four families had similar proportions within the fish 
assemblages at Auckland. Here, the Carangidae and Labridae (3 species) composed the $40 \%$ of the fish assemblages followed by Kyphosidae and Triplefins (6 species), which together made up $20 \%$ of the reef fishes. Both locations in the southern portion of New Zealand's North Island were dominated by wrasses ( 3 species). Members of this family (Labridae) dominate the assemblage, making up more than $45 \%$ of the total abundance, followed by Serranidae (2 species). Similarly, wrasses (7 species) composed more than the $50 \%$ of the fish assemblages at the two locations in southern Australia. The second most abundant family here was the Dinolestidae followed by the six species members of the Monacanthidae (Fig. 2.12). 


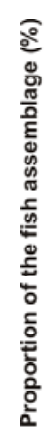

Northern Chile
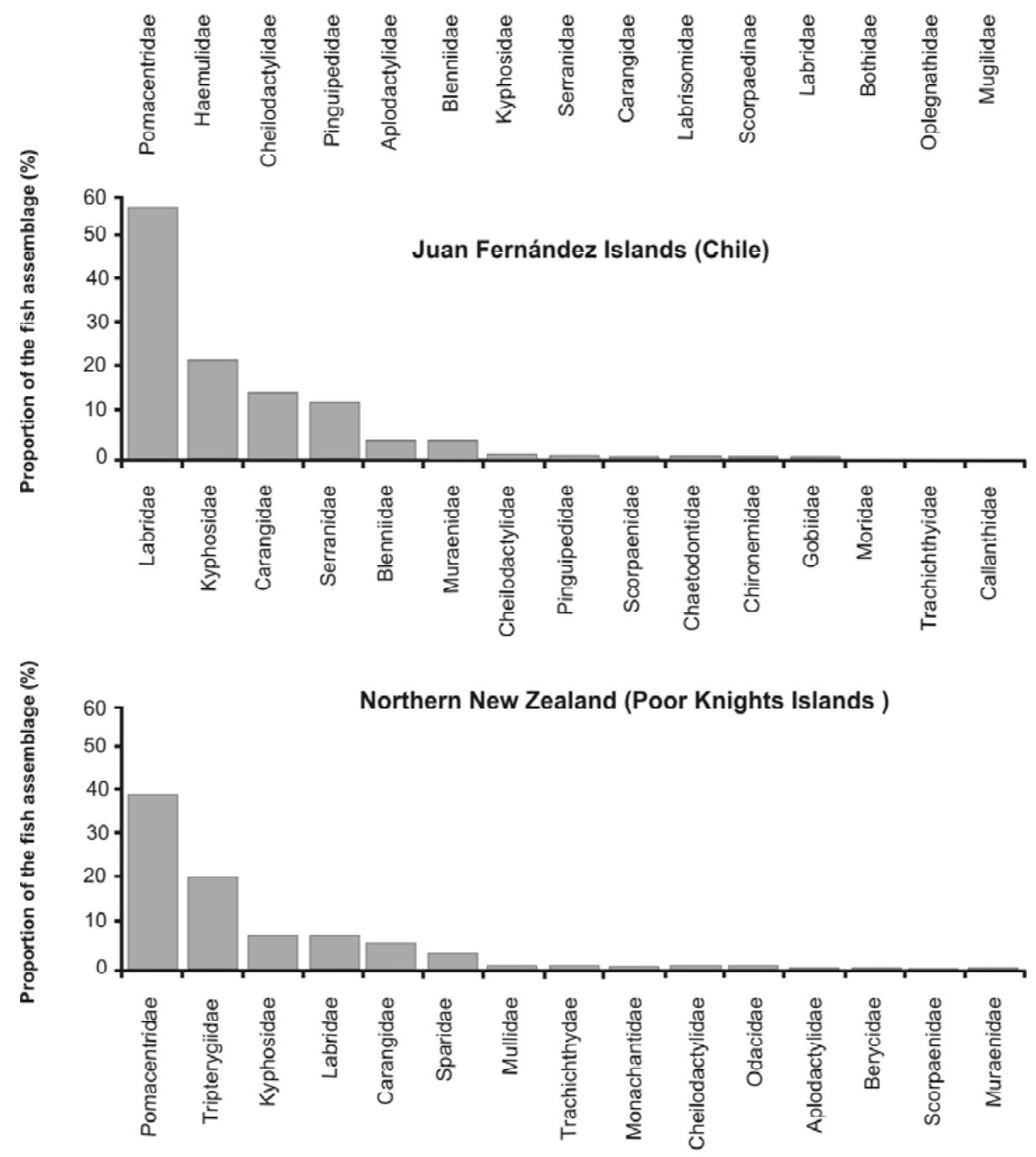

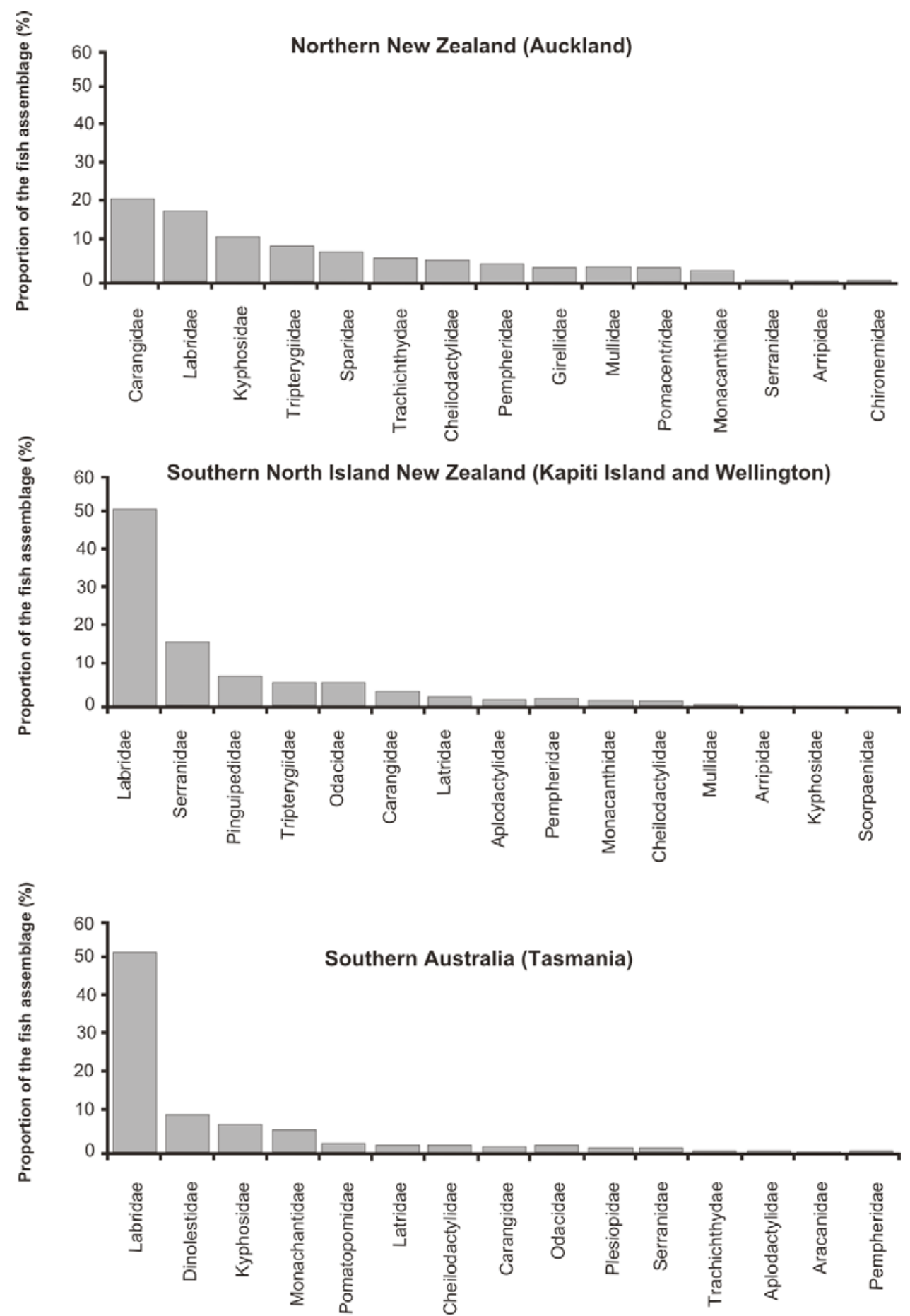

Figure 2.12 Proportion (\%) of fish asemblages from the total numerical abundance per location surveyed. Families representing less than $0.1(\%)$ are not represented. Northern Chile correponds Pérez-Matus et al. (2007).

Fish communities at each region were distinct (Fig. 2.13). nMDS graphically detected patterns of fish community distribution. According to nMDS, fish communities in Juan Fernández Island were separated from those of 
New Zealand and Tasmania in the first axis of the MDS. Juan Fernández Islands were close to North Island New Zealand. In the second axis of the n-MDS plot, fish community at Tasmania clustered but were closely associated to fish communities of New Zealand (Fig. 2.13).

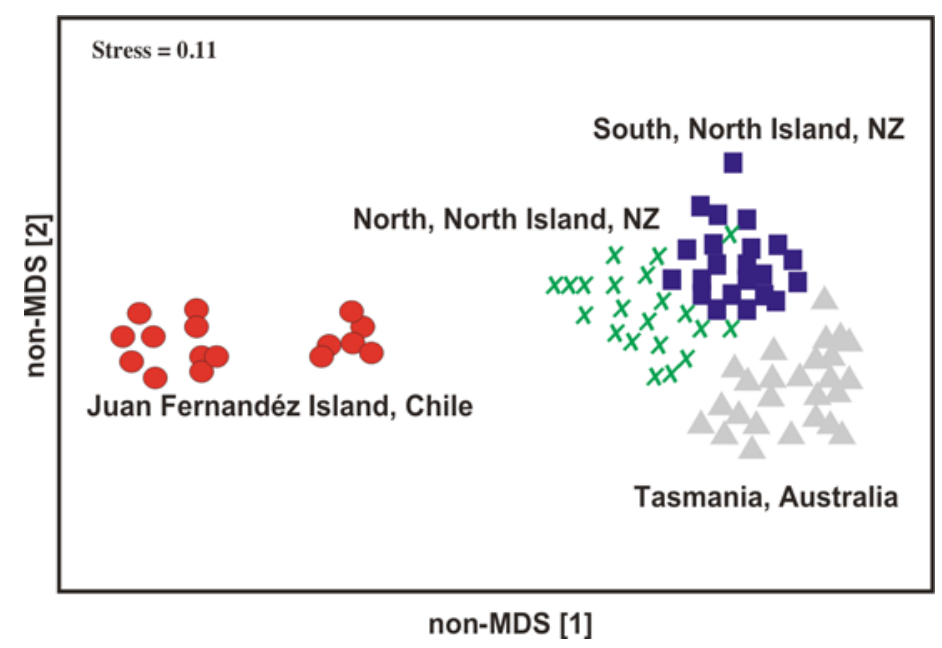

Figure 2.13 non-metric Multidimensional Scaling of fish communities among four different sampled regions. Transect represent the unit of replication per regions (Juan Fernández $n=15$, South North Island $n=30$, North NorthIsland New Zealand $n=30$, Tasmania $\mathrm{n}=30$ ).

\subsection{Discussion}

The present exploratory comparison revealed: (a) latitudinal and longitudinal trends in reef fish diversity, (b) geographic location coupled with physical (temperature and depth) and biotic factors such as macroalgaedominated substratum contributed to the observed differences in diversity at different levels of reef fish organization (trophic, species); (c) factors depending on the scale of observation influence familial and ordinal diversity; (d) with few exceptions only 2 families contribute to the $50 \%$ of individuals within sampled 
locations, therefore only 8 of the 39 families were important in terms of their contribution to reef fishes in macroalgae-dominated habitats.

Distributional ranges of species can explain the observed differences with latitude and longitude. Differences of diversity represent the most widely macroecological pattern studied with more than 30 hypotheses (Rohde 1992). No causal mechanism has proven to be consistent with changes in number of species among taxas but for marine fishes (as well as many other taxa), diversity increases at lower latitudes (i.e., tropical areas) and the longitudinal variation in the number of species is higher in western areas in both Atlantic and Pacific Oceans (Mora et al. 2003; Connolly et al. 2005). The Indo-Australian Area (IAA) (i.e., joint area of Pacific and Indian Ocean) is by far the most diverse in terms of reef fish and is believed to be the centre of origins of reef fish fauna. In the IAA fish diversity reaches a maximum with gradual decreases with distance (Macpherson et al. 2009).

On large (regional) scales habitat may have little influence on total diversity. At this scale diversity of fish can be correlated with dispersal abilities of fish species (Bellwood and Hughes 2001). This can be indirectly evidenced here. For example, laminarean was a dominant substratum at most of the sampled location but diversity and abundance of species differed (at most taxonomic resolution). At local scales, diversity is influenced by habitats. Habitat differed among the sampled location and this maybe translated into differences in fish diversity. Further, hierarchical modelling (i.e., patch occupancy ratios) is needed here to understand if habitat is the primary correlate with fish community structure at multiple spatial scales (see MacNeil et al. 2009). 
Interestingly, two or three main families shape most of fish communities at all sampled locations. Although the identities vary from one location to another a consistent pattern was evidenced in terms of dominance of fish assemblages. The pattern observed here might be related to a particular history of each of the sampled locations (the structure of communities in one of the locations are fully explored in a subsequent Chapter, 3). Traditionally, differences in diversity were attributable to variation of the physical environment (Fernández et al. 2007). The diversification of lineages from a particular ecological zone (see Wellenreuther et al. 2007) might bring further insight of patterns of reef fish diversity. Further analysis is required here in order to understand how differences in regional diversity influence diversity at local scales (Ricklefs 2006). 


\section{CHAPTER 3}

Community structure at Juan Fernández Islands: How are temperate fish assemblages organized in non-kelp dominated habitats?

\subsection{Abstract}

The macroalgal forests of subtidal temperate rocky reefs provide food, shelter and refuge from predators, and their presence or absence may determine the demography of fish populations. The Juan Fernández Archipelago, (33 $37^{\prime} \mathrm{S}, 78^{\circ} 51^{\prime} \mathrm{W}$ ) an isolated groups of islands $650 \mathrm{~km}$ west of continental Chile, has a high degree of endemism in its marine biota. Although influenced by the cool Humboldt Current, Juan Fernández lacks kelp forests. Using visual census we surveyed fish and habitat associations at 5 different sites around two islands of the archipelago. Given the strong effects of isolation and the lack of kelp habitats, I asked: what is the composition of reef fish faunas at these isolated islands? What habitat dominate subtidal environments and what influences the abundances of reef fishes? The analysis conducted here suggests that the ichthyofauna at Juan Fernández comprises a mixture of subtropical and temperate taxa, with more similarities with western than eastern South Pacific fauna. I identified different fish assemblages at wave-exposed and wavesheltered sites. Macroalgal-dominated reefs such as those composed of brown and red macroalgae significantly constrained the abundances of some reef fishes. To my knowledge this is the first attempt to identify patterns of community 
structure in subtidal environments off Juan Fernández Islands. These data are of particular importance for future assessment of the impact of the tsunami in February 2010, which had conspicuous effects on the ecology, economy, and social structure of the islands.

\subsection{Introduction}

Biotic habitats influence faunas in terrestrial and marine environments (Bell et al. 1991). The effects of habitat on the distribution and abundance of species have been documented for many areas and taxa (e.g., Buckley and Roughgarden 2005; Schaffers et al. 2008). In response to habitat degradation and loss, the understanding of habitat-fauna linkages has become valuable for conservation purposes, as it provides information for proper management and restoration (Fuhlendorf et al. 2006; Herrick and Sarukhán 2007). The identification of such linkages in marine environments is elusive as the early life history of many marine species includes a pelagic larval stage which acts to disperse propagules (Scheltema 1986). Spawning and oceanographic conditions during the pelagic phases are important for species with planktonic life histories as they may control survival and the probability of finding habitat at the end of planktonic development (Swearer et al. 1999). Isolated and endemic faunas offer good opportunities for testing divergent hypotheses such as whether recruitment is independent of reproduction (Sale 1980) or if there is local replenishment of populations driven by physical (i.e., suitable habitat) (Wolanski and Hamner 1988) and behavioural (Lecchini et al. 2005) mechanisms. Isolated faunas have

been essential in the progress and development of biogeographic and 
evolutionary theory due to the relationship between biodiversity and degrees of isolation and endemism (Darwin 1859; MacArthur and Wilson 1967; Robertson 2001).

One of the most important characteristics of the environment is biotic habitat. Biotic habitat elements such as coral reefs and kelp forests in tropical and temperate marine environments, respectively, may influence the demography of other organisms (Bell et al. 1991). When the availability of habitat influences mortality and recruitment, habitat can directly regulate population size (Jones 1988b; Shima et al. 2008). The effects of habitat on fishes in shallow temperate environments have been studied in both northern (DeMartini and Roberts 1990) and southern (Choat and Ayling 1987; PérezMatus et al. 2007; Williams et al. 2008) hemispheres. These studies suggest that distinct assemblages of fishes characterize substrata dominated either by large brown macroalgae or encrusting or sessile species (particularly coralline algae). The abundance, diversity, and trophic structure of reef fishes in algal habitats are often more complex than those in areas without kelp beds (Angel and Ojeda 2001; Graham 2004). Kelp provides several "services" to fishes such as food, shelter and refuge from predators (Holbrook et al. 1990b). Accordingly, the presence and composition of macroalgal stands may determine the fate of fish populations (Anderson 1994; White and Caselle 2008) and distribution of reefassociated fishes (Choat and Ayling 1987; Levin and Hay 1996). Depending on the composition of macroalgal-dominated habitats, fish abundances are affected positively by the availability of macroalgal stands (Pérez-Matus and Shima 2010). Alternatively, the three-dimensional structure provided by kelps may 
directly affect negatively some species that attempt to form schools or aggregations (Siddon et al. 2008).

The Juan Fernández Archipelago (33 $37^{\prime} \mathrm{S}, 78^{\circ} 51^{\prime} \mathrm{W}$ ) is a young group of islands (estimated age of $6 \mathrm{My}$ ) located $650 \mathrm{~km}$ west of continental Chile (Stuessy et al. 1984; Haase et al. 2000). The main port is Bahía Cumberland, a small fishing community ( $\sim 700$ inhabitants) with approximately 180 fishers who mainly exploit the Juan Fernández lobster, Jasus frontalis. This artisanal fishery operates from approximately 40, $7 \mathrm{~m}$ length, boats that exploit the resources around the three islands, including a northern island of Alejandro Selkirk (Arana and Ziller 1985; Sernapesca 2009). Management of this fishery includes the use of traps, seasonal fishing closures (May through September) and no diving is allowed in the islands for commercial resource extractions (Arana and Ziller 1985). Species such as Seriola lalandi, Scorpis chilensis, Nemadactylus gayi and Gymnothorax porphyreus are targeted for bait and local consumption using hook and line only (A. Pérez-Matus pers. obs). As for many isolated islands, the archipelago is volcanic in origin, and possesses a high degree of endemism in marine flora and fauna, with $30,67,26,23$, and $26 \%$ endemism reported for macroalgae, anthozoans, molluscs, decapod crustaceans and reef fishes respectively (Rozbaczylo and Castilla 1987; Santelices 1992; Pequeño and Lamilla 2000; Pequeño and Sáez 2000).

Marine taxa of Juan Fernández such as macroalgae and reef fishes are more related to western geographic areas, despite the geographic distance (Santelices 1992; Pequeño and Lamilla 2000). Oceanographic currents and possible repetitive unidirectional dispersal account for these similarities (Burridge et al. 2006). According to island biogeographic models, immigration 
to remote islands is slow and components of the biota result from evolutionary changes; speciation thus increases with isolation and area of the island (MacArthur and Wilson 1963). Marine populations are often organized by processes at both large (e.g., stochastic events such as recruitment) and small spatial scales (e.g, availability of suitable habitats) (Levin 1992). Juan Fernández Islands offer a good opportunity to test the influence of local scale phenomena on assemblage structure. Furthermore there are no ecological studies in subtidal environments of the Islands that have addressed: (a) how assemblages of reef fishes are composed; (b) how benthic assemblages are organized; and (c) if the abundances of fish species are constrained by particular substratum species as they are in other temperate regions.

\subsection{Methods}

\subsubsection{Study Area}

This study was conducted on the reef systems surrounding the Juan Fernández Archipelago, oceanic islands off continental Chile. Juan Fernández Archipelago comprises three islands located $650 \mathrm{~km}$ west of the Pacific port of San Antonio, Chile and $750 \mathrm{~km}$ south of Desventuradas Islands, another group of two islands, San Felix and San Ambrosio (Fig. 3.1). Within Juan Fernández Archipelago, Robinson Crusoe and Santa Clara Islands, with areas of 47.9 and $2.2 \mathrm{~km}^{2}$ respectively, are the closest to the continent. The third island, Alejandro Selkirk, $49 \mathrm{~km}^{2}$ in area, is located $178 \mathrm{~km}$ east of Robinson Crusoe at $33^{\circ} 45^{\prime} \mathrm{S}$, $80^{\circ} 45^{\prime} \mathrm{W}$. I sampled on Islas Robinson Crusoe and Santa Clara, due to limited 
access to Isla Akejandro Selkirk. I selected 5 study sites around Isla Robinson Crusoe and one at Isla Santa Clara, mainly limited by weather conditions at the time of the survey (Fig. 3.1). I hypothesized a priori that community structures would differ based on spatial separation, different subtidal habitats, and exposure to wave action. The sampling was conducted at three wave-protected and three wave-exposed sites (Fig. 3.1). In general, wave-protected sites occurred on the north-eastern side of Robinson Crusoe Island where the substratum is characterized by low bottom relief with small boulders, cobbles, and sand. Wave-exposed sites occur on the south-western and north-western sides of Robinson Crusoe and Santa Clara, respectively and are characterized by high bottom relief, with vertical walls, large boulders, and caves. 


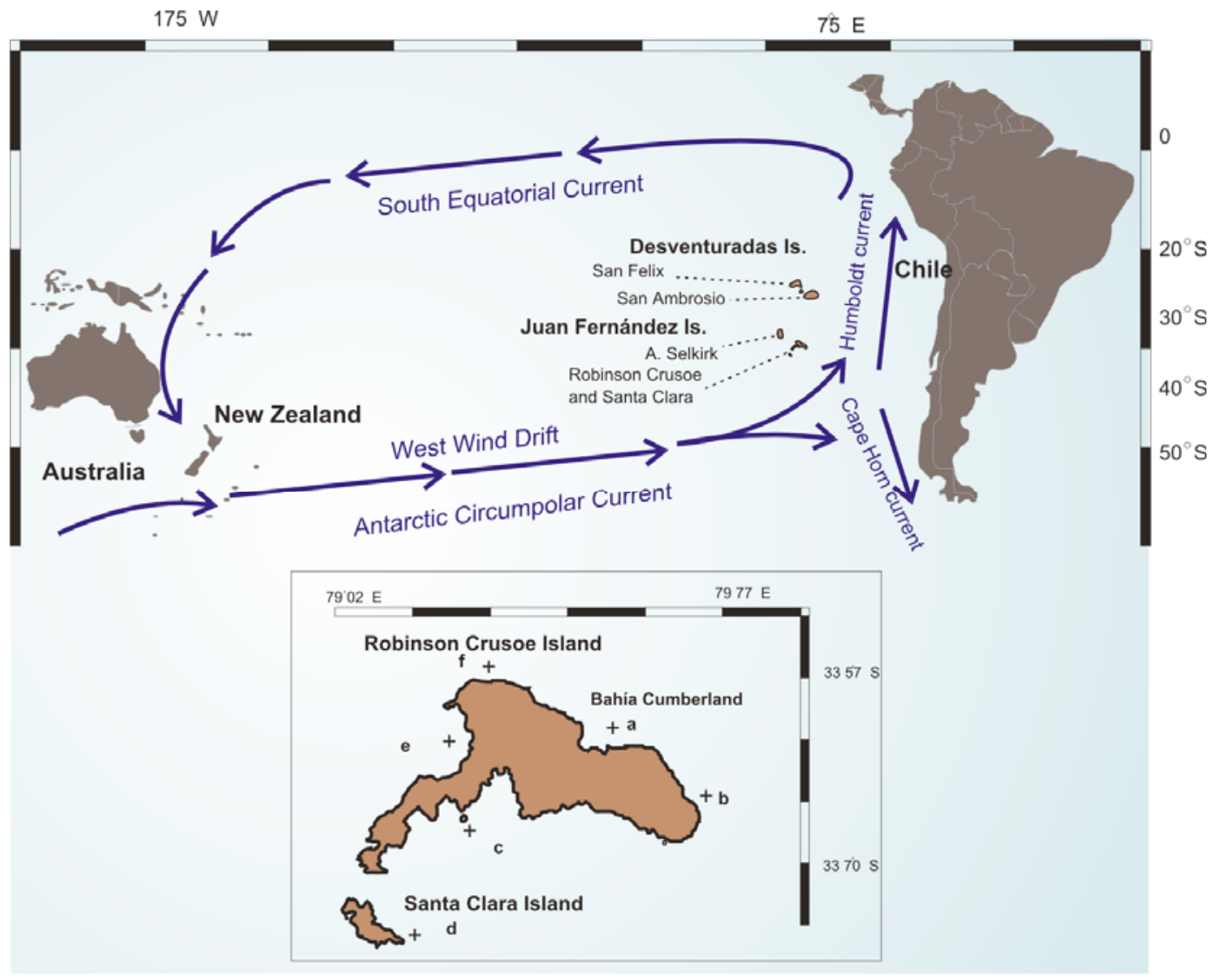

Figure 3.1 Map giving the location of the study sites at Robinson Crusoe and Santa Clara islands of Juan Fernández Archipelago (not to scale) and currents in the region. Sites are represented as: (a) Bahía Cumberland, (b) El Francés, (c) Los Chamelos, (d) Punta Freedy, (e) Bahía Tres Puntas, and (f) Sal si Puedes.

\subsubsection{Sampling}

All sampling was performed in austral spring (September 15 through October 21) 2007. Underwater visual census were performed under the same methodology as per chapters 2. At each study site fish surveys were conducted at different depth strata (e.g., 3-6 m, 6-9 m, thereafter in $3 \mathrm{~m}$ intervals to a maximum of $30 \mathrm{~m}$ ) covering, whenever possible, entire habitat zonation (i.e., barrens, macroalgal-dominated bottoms, encrusting and sessile fauna). At each depth stratum, I laid a $\sim 36 \mathrm{~m}$ transect. On each transect, ten stations, separated 
by four meters, were sampled. At each station, one of two observers using scuba (APM and TDE) remained stationary and quantified fish species richness, abundance, and size by visual census over a two-minute period (20 min per transect in a $40 \mathrm{~m}^{2}$ area). Each diver performed census on a different depth stratum. I compared the results for fish density measured by the two observers using a Kruskal-Wallis rank sum test (Kruskal and Wallis 1952). Because differences were small (Kruskal-Wallis, $\mathrm{df}=1, \mathrm{H}=1.79, p$-value $=0.182$ ), we combined the data of the two observers.

Percentage cover of sessile organisms were obtained using a random point contact (RPC) method. A $50 \times 50 \mathrm{~cm}$ quadrat $\left(0.25 \mathrm{~m}^{2}\right)$ divided into a matrix of 16 dots was randomly placed at 2 positions within each of the stations along each transect (see above). Counts of sessile species were recorded in situ. Sessile species were identified to the lowest taxonomic level possible. Unidentified items were retrieved, stored in buffered formalin (5\%), and identified in the laboratory.

I sampled a total of 47 (mean $=7.8 \pm 2.5(S D)$ per site) fish transects and 22 $($ mean $=3.7 \pm 1.4(S D)$ per site) RPC transects. The unbalanced sampling design was due to logistic constraints. At each transect I recorded water temperature and underwater visibility. 


\subsubsection{Data Analysis}

To identify differences in diversity (measured as species richness) and abundance of reef fishes per site we calculated the total number of species (S) and the total number of individuals $(\mathrm{N})$ observed. Differences among sites were tested formally by one-way analysis of variance (ANOVA). If ANOVA indicated significant differences, Tukey post-hoc tests were used for further evaluation. Normality and homogeneity of variance were assessed using the Shapiro-Wilk normality and the Fligner-Killeen tests, respectively (Crawley 2007). Results were considered statistically significant when $p$-values $<0.05$.

Data from fish transects and RPC transects by site were compiled into an abundance by site matrix and used to calculate the similarity among all sites. I conducted non-metric, one-way pairwise analysis of similarity among groups (ANOSIM; Clarke and Warwick 1994) and a SIMPER analysis to determine the species that contributed most to the similarities and differences in fish assemblages per site. Since SIMPER does not indicate statistical significance, we tested significance of the discriminating species using canonical analysis of principal coordinates (Anderson and Willis 2003). The $p$-values for site effects were obtained using 999 permutations of the observed data. To visualize differences and clustering of data among study sites we used non-metric multidimensional scaling (MDS; Clarke 1993). Owing to the large number of fish censuses (47 transects), I calculated and presented only the centroids obtained from the principal coordinate analysis (following Terlizzi et al. 2005). To assess how much of the variation in fish abundance and benthic cover was explained by depth, the relationship between multivariate species data and the 
factor "depth" was analysed using non-parametric multivariate regression with distance-based linear models "DISTLM" (McArdle and Anderson 2001).

I performed a redundancy analysis (RDA) of the abundant species from the fish assemblage against major substratum species. I selected this constrained method due to the a priori hypothesis of the possible effects of substratum on abundances of reef fishes. To test for associations between fish abundance and substratum species I performed permutational analysis of variance (PERMANOVA) test among sites (Legendre and Legendre 1998). I used the Hellinger transformation of the fish and point-count data; this transformation makes the data amenable for the types of analyses performed here (see Legendre and Gallaher 2001 for details). I used RDA to graphically display the differences of the most abundant species among the study sites and report the contribution of each contraints. All analysis was conducted using the package vegan for the computing environment R 2.10 (http://www.r-project.org/).

\subsection{Results}

Subsurface water temperature measurements had a mean of $13.5{ }^{\circ} \mathrm{C} \pm$ $0.3(S D))$ and underwater visibility a mean of $14.6 \mathrm{~m} \pm 1.8(S D)$ among sites.

Our fish surveys documented a total of 26 species (Table 3.1). These 26 species represent 23 genera, 19 families, 6 orders and 1 class. From the total of sighted species, 16 fishes were rare and had low abundances (Table 3.1). A total of $35 \%$ of the species were endemic to the archipelago (Table 3.2). Sixty percent of the total sighted species occur also in Desventuradas Islands (Table 
3.2). Less than thirty percent of surveyed fish species are common within the Pacific region (Table 3.2). Species that are shared with other geographic areas include one at the Galápagos Islands (e.g., Scorpaena fernandeziana), and other transpacific species (e.g., Seriola lalandi, Caprodon longimanus, Trachurus murphyi, Mola mola). Only $19 \%$ of species surveyed are also common in continental Chile, Easter Island or New Zealand. A slightly higher percent of species is shared with Australia (Table 3.2).

Table 3.1 Mean $( \pm S D)$ abundance per transect $\left(160 \mathrm{~m}^{2}\right)$ of all the species recorded at the 6 sites at Juan Fernández. $\mathrm{N}=$ number of transects sampled per site.

\begin{tabular}{|c|c|c|c|c|}
\hline Family & Species & $\begin{array}{c}\text { a) Bahía } \\
\text { Cumberland } \\
\mathrm{N}=8\end{array}$ & $\begin{array}{l}\text { b) El Francés } \\
\qquad \mathrm{N}=8\end{array}$ & $\begin{array}{c}\text { c) Los } \\
\text { Chamelos } \\
\mathrm{N}=3\end{array}$ \\
\hline Molidae & Mola mola & - & - & - \\
\hline Bothidae & Paralichthys fernandezianus & - & - & - \\
\hline Chaetodontidae & Amphichaetodon melbae & $0.4 \pm 1.1$ & $0.1 \pm 0.35$ & - \\
\hline Callanthiidae & Callanthias platei & - & $0.1 \pm 0.35$ & $2.7 \pm 4.6$ \\
\hline \multirow[t]{2}{*}{ Serranidae } & $\begin{array}{l}\text { Caprodon longimanus } \\
\text { Hypoplectrodes }\end{array}$ & $29.9 \pm 64.9$ & $73.9 \pm 119.1$ & $153.0 \pm 66.8$ \\
\hline & semicinctum & $17.1 \pm 8.0$ & $14.4 \pm 6.30$ & $3.3 \pm 1.5$ \\
\hline Chironemidae & $\begin{array}{l}\text { Chironemus bicornis } \\
\text { Chironemus delfini }\end{array}$ & $0.1 \pm 0.4$ & $\begin{array}{l}0.9 \pm 1.24 \\
0.4 \pm 0.74\end{array}$ & - \\
\hline \multirow[t]{2}{*}{ Kyphosidae } & Girella albostriata & - & $3.1 \pm 3.48$ & $7.0 \pm 9.5$ \\
\hline & Scorpis chilensis & $45.7 \pm 30.3$ & $80.3 \pm 45.27$ & $20.0 \pm 23.3$ \\
\hline Labridae & $\begin{array}{l}\text { Malapterus reticulatus } \\
\text { Pseudolabrus gavi }\end{array}$ & $\begin{array}{c}54.4 \pm 3.2 \\
141.9 \pm 81.1\end{array}$ & $\begin{array}{l}95.0 \pm 20.63 \\
84.5 \pm 46.48\end{array}$ & $\begin{array}{c}55.3 \pm 21.1 \\
90.0 \pm 41.9\end{array}$ \\
\hline Cheilodactylidae & Nemadactylus gayi & $6.7 \pm 13.6$ & $5.4 \pm 5.70$ & $9.0 \pm 14.7$ \\
\hline Pinguipedidae & Parapercis dockinsi & $6.4 \pm 9.7$ & $0.8 \pm 1.48$ & - \\
\hline Gobiidae & Paratrimma nigrimenta & - & - & - \\
\hline \multirow[t]{3}{*}{ Carangidae } & Pseudocaranx chilensis & $5.7 \pm 8.1$ & $107.2 \pm 81.92$ & $16.7 \pm 8.9$ \\
\hline & Seriola lalandi & - & $0.1 \pm 0.35$ & $1.0 \pm 1.7$ \\
\hline & Trachurus murphyi & - & $33.9 \pm 52.94$ & $9.0 \pm 15.6$ \\
\hline \multirow[t]{2}{*}{ Blenniidae } & Scartichthys variolatus & $6.9 \pm 5.1$ & $11.6 \pm 5.39$ & $1.7 \pm 2.1$ \\
\hline & Scartichthys viridis & - & - & - \\
\hline Sciaenidae & Umbrina reedi & - & - & - \\
\hline \multirow[t]{2}{*}{ Scorpaenidae } & Scorpaena fernandeziana & $0.3 \pm 0.5$ & $0.3 \pm 0.46$ & $0.3 \pm 0.6$ \\
\hline & Scorpaena thomsoni & $0.1 \pm 0.4$ & - & - \\
\hline Moridae & $\begin{array}{l}\text { Lotella fernandeziana } \\
\text { Paratrachichthys }\end{array}$ & $0.1 \pm 0.4$ & $4.1 \pm 7.35$ & $0.3 \pm 0.6$ \\
\hline Trachichthyidae & fernandezianus & $0.5 \pm 0.8$ & $1.5 \pm 2.13$ & - \\
\hline Muraenidae & Gymnothorax porphyreus & $0.3 \pm 0.5$ & $0.5 \pm 0.53$ & $2.0 \pm 1.0$ \\
\hline \multirow{2}{*}{\multicolumn{2}{|c|}{$\begin{array}{l}\text { Total Abundance }(\mathrm{N}) \\
\text { Total Richness }(S)\end{array}$}} & $316.5 \pm 103.5$ & $518.5 \pm 140.0$ & $371.6 \pm 122.2$ \\
\hline & & $8.4 \pm 2.5$ & $12.0 \pm 1.1$ & $10.7 \pm 2.1$ \\
\hline
\end{tabular}


Cont, Table 3.1

\begin{tabular}{|c|c|c|c|c|}
\hline Family & Species & $\begin{array}{l}\text { d) Punta } \\
\text { Freedy } \\
\mathrm{N}=10\end{array}$ & $\begin{array}{l}\text { e) Bahía tres } \\
\text { Puntas } \\
\mathrm{N}=9\end{array}$ & $\begin{array}{l}\text { f) Sal si } \\
\text { Puedes } \\
N=8\end{array}$ \\
\hline Molidae & Mola mola & $0.1 \pm 0.3$ & - & - \\
\hline Bothidae & Paralichthys fernandezianus & $0.1 \pm 0.3$ & - & $0.1 \pm 0.4$ \\
\hline Chaetodontidae & Amphichaetodon melbae & $1.2 \pm 1.9$ & $0.3 \pm 0.5$ & $1.3 \pm 1.5$ \\
\hline Callanthiidae & Callanthias platei & - & - & - \\
\hline \multirow[t]{2}{*}{ Serranidae } & Caprodon longimanus & $14.0 \pm 35.0$ & $32.0 \pm 38.4$ & $27.9 \pm 58.0$ \\
\hline & Hypoplectrodes semicinctum & $9.6 \pm 9.8$ & $13.4 \pm 10.4$ & $12.9 \pm 5.0$ \\
\hline \multirow[t]{2}{*}{ Chironemidae } & Chironemus bicornis & - & $0.25 \pm 0.7$ & - \\
\hline & Chironemus delfini & - & $0.1 \pm 0.4$ & - \\
\hline \multirow[t]{2}{*}{ Kyphosidae } & Girella albostriata & $2.4 \pm 1.9$ & $4.4 \pm 6.0$ & $4.1 \pm 9.0$ \\
\hline & Scorpis chilensis & $57.7 \pm 56.2$ & $123.6 \pm 49.1$ & $65.9 \pm 54.2$ \\
\hline \multirow[t]{2}{*}{ Labridae } & Malapterus reticulatus & $88.2 \pm 34.2$ & $77.4 \pm 33.8$ & $77.4 \pm 23.7$ \\
\hline & Pseudolabrus gayi & $115.6 \pm 46.8$ & $136.8 \pm 46.0$ & $77.9 \pm 34.5$ \\
\hline Cheilodactylidae & Nemadactylus gayi & $0.2 \pm 0.6$ & $0.5 \pm 0.9$ & $3.7 \pm 7.4$ \\
\hline Pinguipedidae & Parapercis dockinsi & - & - & $0.9 \pm 1.5$ \\
\hline Gobiidae & Paratrimma nigrimenta & $1.1 \pm 3.5$ & - & - \\
\hline \multirow{3}{*}{ Carangidae } & Pseudocaranx chilensis & $6.2 \pm 11.6$ & $44.5 \pm 69.0$ & $62.8 \pm 56.5$ \\
\hline & Seriola lalandi & $0.1 \pm 0.3$ & $0.1 \pm 0.4$ & $3.5 \pm 9.5$ \\
\hline & Trachurus murphyi & - & $0.1 \pm 0.4$ & $0.3 \pm 0.7$ \\
\hline \multirow[t]{2}{*}{ Blenniidae } & Scartichthys variolatus & $29.0 \pm 22.1$ & $13.3 \pm 5.5$ & $12.5 \pm 7.2$ \\
\hline & Scartichthys viridis & - & $0.9 \pm 1.8$ & - \\
\hline Sciaenidae & Umbrina reedi & - & - & $0.1 \pm 0.4$ \\
\hline \multirow[t]{2}{*}{ Scorpaenidae } & Scorpaena fernandeziana & $2.0 \pm 5.6$ & - & $0.3 \pm 0.5$ \\
\hline & Scorpaena thomsoni & $1.4 \pm 1.6$ & $0.3 \pm 0.5$ & - \\
\hline Moridae & $\begin{array}{l}\text { Lotella fernandeziana } \\
\text { Paratrachichthys }\end{array}$ & - & $1.8 \pm 4.2$ & $1.0 \pm 1.8$ \\
\hline Trachichthyidae & fernandezianus & - & $0.4 \pm 1.1$ & $6.0 \pm 10.5$ \\
\hline Muraenidae & Gymnothorax porphyreus & $5.7 \pm 5.1$ & $0.1 \pm 0.4$ & $0.3 \pm 0.7$ \\
\hline \multicolumn{2}{|c|}{ Total Abundance (N) } & $335.2 \pm 78.7$ & $450.4 \pm 123.4$ & $358.6 \pm 109.3$ \\
\hline \multicolumn{2}{|c|}{ Total Richness $(S)$} & $9.5 \pm 1.4$ & $9.6 \pm 1.7$ & $9.9 \pm 1.9$ \\
\hline
\end{tabular}


Table 3.2 Occurrences of subtidal fish species at Juan Fernández and in relation to other regions of the South Pacific. Easter Island encompasses Sala y Gómez Islands; New Zealand includes the Kermadec Islands, and South Pacific region includes Galápagos Islands. Adapted from (Pequeño and Sáez 2000)

\begin{tabular}{|c|c|c|c|c|c|c|c|}
\hline & Endemic & Desventuradas & $\begin{array}{l}\text { Easter } \\
\text { Island }\end{array}$ & Chile & $\begin{array}{c}\text { New } \\
\text { Zealand }\end{array}$ & Australia & $\begin{array}{l}\text { South- } \\
\text { Pacific }\end{array}$ \\
\hline Mola mola & & + & + & + & + & + & + \\
\hline $\begin{array}{l}\text { Paralichthys } \\
\text { fernandezianus }\end{array}$ & + & & & & & & \\
\hline $\begin{array}{l}\text { Amphichaetodon } \\
\text { melbae }\end{array}$ & & + & + & & & & \\
\hline Callanthias platei & & + & & & & + & + \\
\hline $\begin{array}{l}\text { Caprodon } \\
\text { longimanus }\end{array}$ & & & & & + & & + \\
\hline $\begin{array}{l}\text { Hypoplectrodes } \\
\text { semicinctum }\end{array}$ & & + & & & & & \\
\hline $\begin{array}{l}\text { Chironemus } \\
\text { bicornis }\end{array}$ & & + & & & & & \\
\hline $\begin{array}{l}\text { Chironemus } \\
\text { delfini }\end{array}$ & + & & & & & & \\
\hline $\begin{array}{l}\text { Girella } \\
\text { albostriata }\end{array}$ & + & & & & & & \\
\hline Scorpis chilensis & & + & & & & & \\
\hline $\begin{array}{l}\text { Malapterus } \\
\text { reticulatus }\end{array}$ & & + & & & & & \\
\hline $\begin{array}{l}\text { Pseudolabrus } \\
\text { gayi }\end{array}$ & & + & & & & & \\
\hline $\begin{array}{l}\text { Nemadactylus } \\
\text { gayi }\end{array}$ & + & & & & & & \\
\hline $\begin{array}{l}\text { Parapercis } \\
\text { dockinsi }\end{array}$ & & + & & + & & & \\
\hline $\begin{array}{l}\text { Paratrimma } \\
\text { nigrimenta }\end{array}$ & + & & & & & & \\
\hline $\begin{array}{l}\text { Pseudocaranx } \\
\text { chilensis }\end{array}$ & + & & & & & & \\
\hline Seriola lalandi & & + & + & + & + & + & + \\
\hline $\begin{array}{l}\text { Trachurus } \\
\text { murphyi }\end{array}$ & & + & + & + & + & + & + \\
\hline $\begin{array}{l}\text { Scartichthys } \\
\text { variolatus }\end{array}$ & & + & & & & & \\
\hline $\begin{array}{l}\text { Scartichthys } \\
\text { viridis }\end{array}$ & & & & + & & & \\
\hline $\begin{array}{l}\text { Umbrina reedi } \\
\text { Scorpaena } \\
\text { fernandeziana }\end{array}$ & + & + & & & & & + \\
\hline $\begin{array}{l}\text { Scorpaena } \\
\text { thomsoni }\end{array}$ & + & & & & & & \\
\hline $\begin{array}{l}\text { Lotella } \\
\text { fernandeziana }\end{array}$ & & + & & & & + & \\
\hline $\begin{array}{l}\text { Paratrachichthys } \\
\text { fernandezianus }\end{array}$ & + & & & & & & \\
\hline $\begin{array}{l}\text { Gymnothorax } \\
\text { porphyreus }\end{array}$ & & + & + & + & + & + & + \\
\hline TOTAL (\%) & 34.6 & 57.7 & 19.2 & 23.1 & 19.2 & 23.1 & 26.9 \\
\hline
\end{tabular}


Labrids contributed nearly $50 \%$ of the total abundance of the reef fish assemblage (Fig. 3.2). The next most abundant family of fishes was Kyphosidae (15\%), and then two families - Carangidae and Serranidae - each contributed $10 \%$ of the total number of individuals. Blennioid fishes contributed less than $4 \%$ and the other 14 families each contributed less than $1 \%$ of the total proportion of individuals in the fish assemblage (Fig. 3.2). The most abundant and frequent species in the study sites were Pseudolabrus gayi and Malapterus reticulatus (Labridae), followed by Scorpis chilensis, Pseudocaranx chilensis and the serranids Caprodon longimanus and Hypoplectrodes semicinctum (Table 3.1).

Statistically significant differences among sites were found for fish species richness and total abundance only (ANOVA, richness $\mathrm{df}=5, \mathrm{~F}=3.63 ; p$-value $=$ 0.008 ; abundance $\mathrm{df}=5, \mathrm{~F}=3.88 ; p$-value $=0.005)$. Post-hoc analyses revealed that El Francés had significantly greater species richness and total fish abundance (Table 3.1).

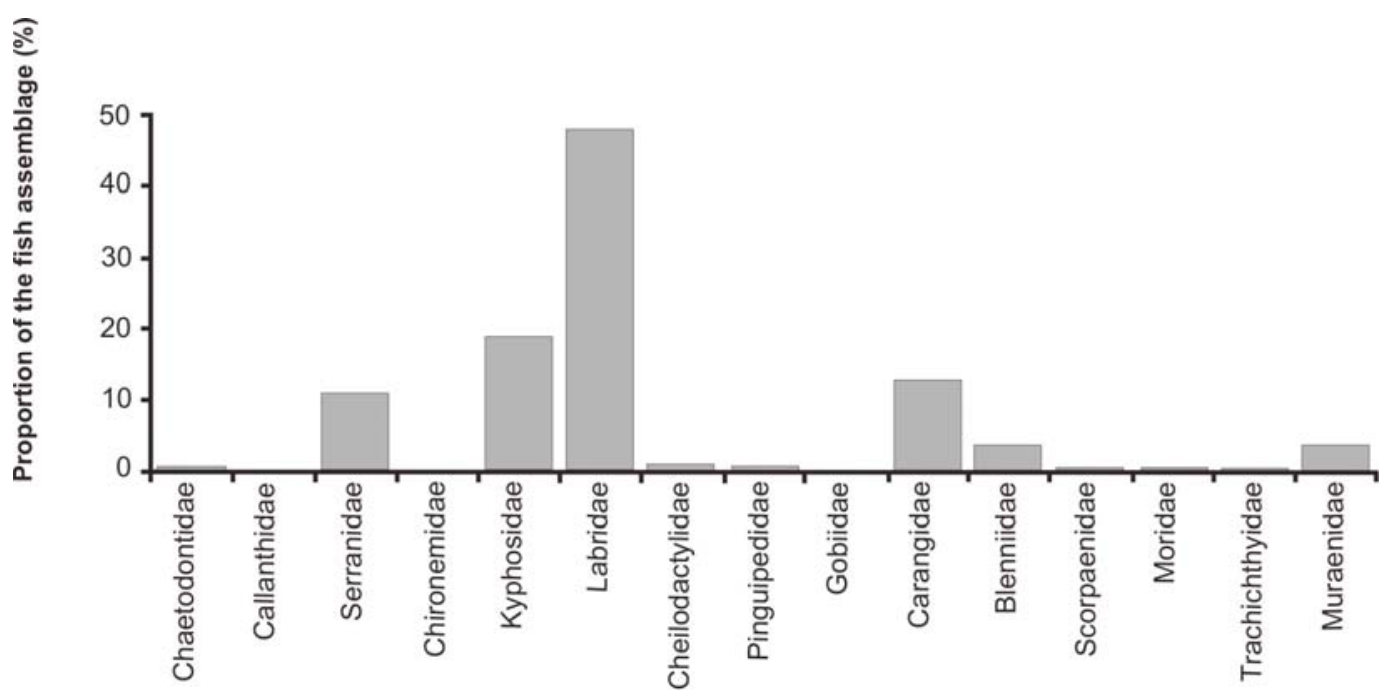

Figure 3.2 Percent (\%) of total fish population surveyed from the total relative abundances of species summed to family level. 
Sites differed in total fish species abundance and richness of reef fishes. Variation in reef fish assemblages was globally significant among sites (ANOSIM, $\mathrm{R}=0.25, p$-value $=0.001)$. This pattern was further confirmed by the CAP analysis $(\mathrm{df}=5, \mathrm{~F}=2.39, p$-value $=0.005)$. The nMDS plot identified three main clusters: one characterized by the similarities between Bahía Cumberland and Sal si Puedes (which are nearly identical), and the second by the wave-exposed sites Los Chamelos and Bahía tres Puntas. The last two sites (El Francés and Punta Freedy) are close to each other but do not form a cluster as do the aforementioned sites (Fig. 3.3a). Several fish species were identified by SIMPER analysis as contributing to these differences (Table 3.3). The wrasses Malapterus reticulatus and Pseudolabrus gayi contributed more than $60 \%$ of similarity (Table 3.3). The serranid Hypoplectrodes semicinctum, combined with the wrasses, contributed more than $70 \%$ of the numeric abundance in the species assemblage at Bahía Cumberland, El Francés and Sal si Puedes. Other species such as Caprodon longimanus, Scartichthys variolatus and Scorpis chilensis were also abundant at Los Chamelos, Punta Freedy and Bahía Tres Puntas respectively (Table 3.3).

The random point contact (RPC) counts revealed differences among species and their abundance among the different sampling sites (ANOSIM, $\mathrm{R}=$ $0.50, p$-value $=0.001)$ and this was confirmed by CAP analysis $(\mathrm{CAP}, \mathrm{df}=5, \mathrm{~F}$ $=4.26, p$-value $=0.005)$. With the exception of Bahía tres Puntas, which shares similarities in abundances of substratum species with all other sites, two clusters were formed. One cluster comprised the wave-exposed sites (on the right side of the biplots) and the other comprised the wave-protected sites (left side of the biplots) (Fig. 3.3). Bahía Cumberland and El Francés clustered together (Fig. 
3.3b). Patterns in species that comprised the benthic flora and fauna aid in distinguishing sites. For example, in general macroalgae dominated the substratum at all sampled depths at the wave-protected sites. Species such as Padina spp. dominated the cover at Bahía Cumberland, El Francés, Bahía tres Puntas and Sal Si Puedes (Fig. 3.4). Rhodophyta (turfing algae), were also abundant at shallow depths at these sites (Fig. 3.4). Covers of sessile fauna were high at wave-exposed sites and also at deep zones at wave-protected sites. Cnidarians (e.g., Parazoanthus juanfernandezi and Corynactis spp.) and barnacles dominated the subtratum at los Chamelos and Punta Freedy (Fig. 3.4). Vermetid molluscs (Serpulorbis sp.) were abundant on benthic substrata at El Francés, Punta Freedy, Bahía tres Puntas, and Sal si Puedes (Fig. 3.4). Differences among sites are displayed in the multivariate biplots (Fig. 3.3). According to our SIMPER analysis, species responsible for the cluster in the wave-protected sites were Padina spp., Colpomenia spp. and Dictyota spp., collectively contributing more than $80 \%$ of variation explained. Serpulorbis sp. and cnidarians contributed to similarities among our wave-exposed sites (Table 3.4). 

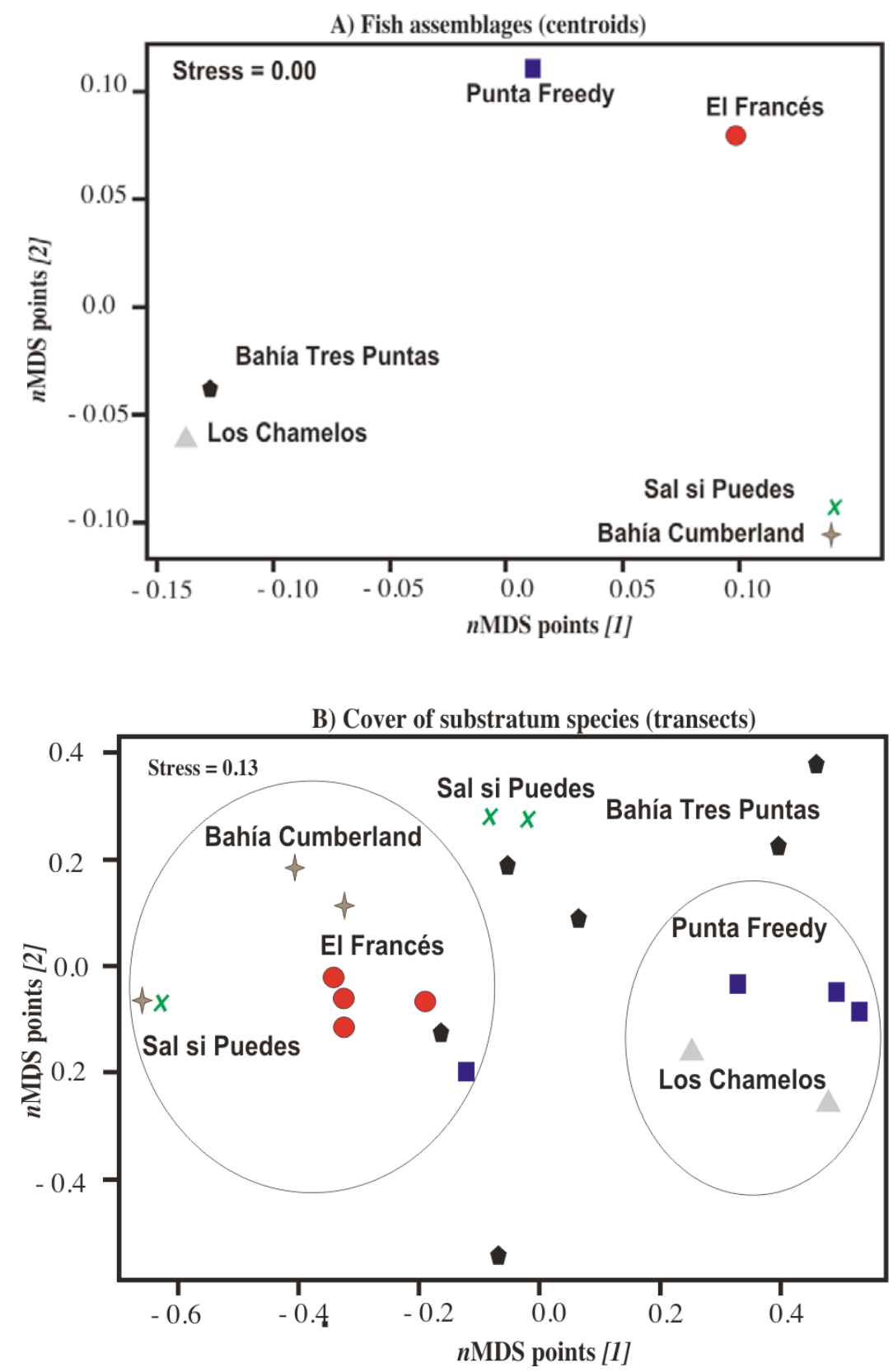

Figure 5.3 Unconstrained nMDS ordination plot of (a) centroids fish assemblages per site (refer to methods for details) and (b) RPC cover of substratum species by transect per site. 


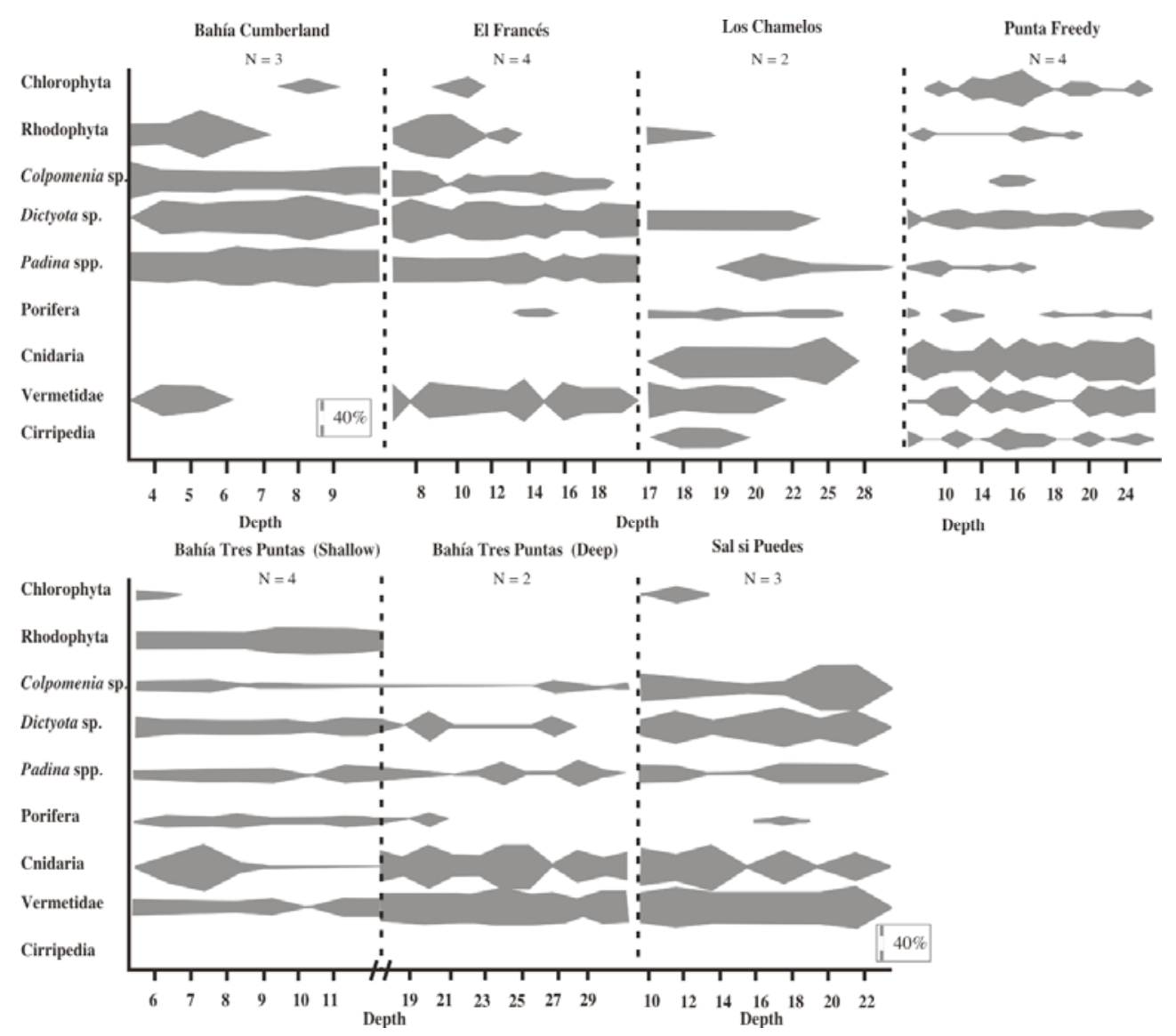

Figure 3.4 Kite diagrams of benthic species zonation by depth at the 6 study sites.

Scale bar represents $40 \%$ of cover in $0.025 \mathrm{~m}^{2}$ quadrats. Number of transects $(\mathrm{N})$ are given per site.

Table 3.3 Percent (\%) similarity contribution of each study sites and between-site similarity among fish species as calculated by SIMPER analysis on the abundance of reef fish species. Species that contributed most are represented in bold.

\begin{tabular}{lccc}
\hline Species & $\begin{array}{c}\text { Bahía Cumberland } \\
(66.21 \%)\end{array}$ & $\begin{array}{c}\text { El Francés } \\
(66.99 \%)\end{array}$ & $\begin{array}{c}\text { Los Chamelos } \\
(57.78 \%)\end{array}$ \\
\hline Malapterus reticulatus & $\mathbf{4 0 . 4}$ & $\mathbf{4 8 . 9}$ & $\mathbf{4 6 . 9}$ \\
Pseudolabrus gayi & $\mathbf{2 9 . 0}$ & $\mathbf{1 2 . 5}$ & $\mathbf{2 7 . 5}$ \\
Hypoplectrodes semicinctum & $\mathbf{1 7 . 3}$ & $\mathbf{1 0 . 5}$ & - \\
Scorpis chilensis & 6.0 & 8.2 & - \\
Scartichthys variolatus & - & 7.4 & - \\
Pseudocaranx chilensis & - & 6.2 & - \\
Caprodon longimanus & - & & $\mathbf{9 . 8}$ \\
Gymnothorax porphyreus & - & & 7.5 \\
\hline
\end{tabular}

- Non contributing species 
Cont, Table 3.3

\begin{tabular}{|c|c|c|c|}
\hline \multirow[b]{2}{*}{ Species } & \multicolumn{3}{|c|}{ Bahía Tres } \\
\hline & $\begin{array}{c}\text { Punta Freedy } \\
(59.97 \%)\end{array}$ & $\begin{array}{c}\text { Puntas } \\
(67.29 \%)\end{array}$ & $\begin{array}{c}\text { Sal sí Puedes } \\
(63.65 \%)\end{array}$ \\
\hline Malapterus reticulatus & 45.1 & 37.0 & 48.5 \\
\hline Pseudolabrus gayi & 22.2 & 26.3 & 15.8 \\
\hline Hypoplectrodes semicinctum & - & 7.8 & 12.9 \\
\hline Scorpis chilensis & 4,0 & 16.5 & 6.6 \\
\hline Scartichthys variolatus & 13.7 & 9.4 & 9.1 \\
\hline Pseudocaranx chilensis & - & - & - \\
\hline Caprodon longimanus & - & - & - \\
\hline Gymnothorax porphyreus & 7.3 & - & - \\
\hline
\end{tabular}

Table 3.4 Percent (\%) similarity contribution of each study sites and between-site similarity among benthic species as calculated by SIMPER analysis on the abundance of substratum species. Species that contributed most are represented in bold.

\begin{tabular}{lccc}
\hline & $\begin{array}{c}\text { Bahía Cumberland } \\
(60.7 \%)\end{array}$ & $\begin{array}{c}\text { El Francés } \\
(69.6 \%)\end{array}$ & $\begin{array}{c}\text { Los Chamelos } \\
(51.8 \%)\end{array}$ \\
Species & - & - & - \\
\hline Rhodophyta & $\mathbf{2 7 . 6}$ & $\mathbf{1 4 . 5}$ & - \\
Colpomenia spp & $\mathbf{2 1 . 8}$ & $\mathbf{3 1 . 8}$ & $\mathbf{2 4 . 8}$ \\
Dictyota spp & $\mathbf{4 3 . 2}$ & $\mathbf{3 6 . 9}$ & 8.4 \\
Padina spp & - & - & $\mathbf{2 1 . 0}$ \\
Porifera & - & - & $\mathbf{2 6 . 7}$ \\
Cnidaria & - & 12.9 & 16.1 \\
Vermetidae & - & - & - \\
Cirripedia & \multicolumn{1}{c}{ Non contributing species } & &
\end{tabular}

Cont, Table 3.4

\begin{tabular}{lccc}
\hline Species & $\begin{array}{c}\text { Punta Freedy } \\
(56.4 \%)\end{array}$ & $\begin{array}{c}\text { Bahía Tres Puntas } \\
(47.7 \%)\end{array}$ & $\begin{array}{c}\text { Sal sí Puedes } \\
(66.3 \%)\end{array}$ \\
\hline Rhodophyta & 8.1 & 5.1 & - \\
Colpomenia spp & - & - & $\mathbf{2 2 . 1}$ \\
Dictyota spp & $\mathbf{2 4 . 1}$ & 8.6 & $\mathbf{2 3 . 3}$ \\
Padina spp & - & $\mathbf{9 . 9}$ & 12.8 \\
Porifera & - & - & - \\
Cnidaria & $\mathbf{4 0 . 0}$ & $\mathbf{2 4 . 7}$ & - \\
Vermetidae & $\mathbf{1 2 . 9}$ & $\mathbf{4 2 . 7}$ & 32.2 \\
Cirripedia & 7.4 & $\mathbf{9 . 9}$ & - \\
\hline
\end{tabular}

Non contributing species

Depth, in turn, made a relatively small contribution in explaining patterns in fish, benthic substratum species and reef community structure. Only $9 \%$ of the total variation in the reef fish assemblage was explained by depth (DISTLM, $\mathrm{F}=6.63, p$-value $=0.001)$. In terms of variation in substratum species, depth explained $15 \%($ DISTLM, F $=11.76, p$-value $=0.001)$. Eleven percent of the 
total variation in reef communities (i.e., fishes and benthic species combined) at our sampling sites at Juan Fernández Islands was explained by depth only $(\mathrm{DISTLM}, \mathrm{F}=8.24, p$-value $=0.001)$

Among sites, different subsets of substratum species were associated with different subsets of fish species. Redundancy analysis (RDA) and, further, permutation tests revealed associations between substratum species and fish species in our study sites at Juan Fernández (pseudo $\mathrm{F}=1.93 ; p$-value $=0.035$ ). For example, when present, brown macroalgae such as Dictyota spp. and a cluster of red algae species such as crustose coralline algae and turfing algae, contributed to the observed associations with reef fishes (Dictyota spp.; pseudo F $=1.71, p$-value $=0.04$ and Rhodophyta; pseudoF $=2.09, p$-value $=0.02)$. Substratum explained $82,41,100,43,48$, and $99 \%$ of the variation in total fish abundance at Bahía Cumberland, El Francés, Los Chamelos, Punta Freedy, Bahía tres Puntas, and Sal si Puedes, respectively. Graphically, macroalgae were grouped in the first two quadrants of the biplot whereas encrusting and sessile fauna lay in the lower upper quadrants; this suggests different associations between fish and substratum species (Fig. 3.5). For example, Nemadactylus gayi and Trachurus murphyi did not show a particular association with any substatum variable. A weak association was evident between Pseudolabrus gayi and cirripedians (Fig. 3.5). Scartichthys variolatus was more associated with red and green algae, as was Scorpis chilensis, whereas Malapterus reticulatus was associated with red algae (Fig. 3.5). Brown macroalgae occurred in the right upper corner of the biplot and fishes such as Hypoplectrodes semicinctum and Pseudocaranx chilensis were associated with Padina spp. and Dictyota spp. (Fig. 3.5). In the lower quadrants of the biplots Gymnothorax porphyreus was 
associated with sponges and Girella albostriata was more associated with cnidarians. Caprodon longimanus showed a tendency for association with vermetid molluscs (Fig. 3.5).

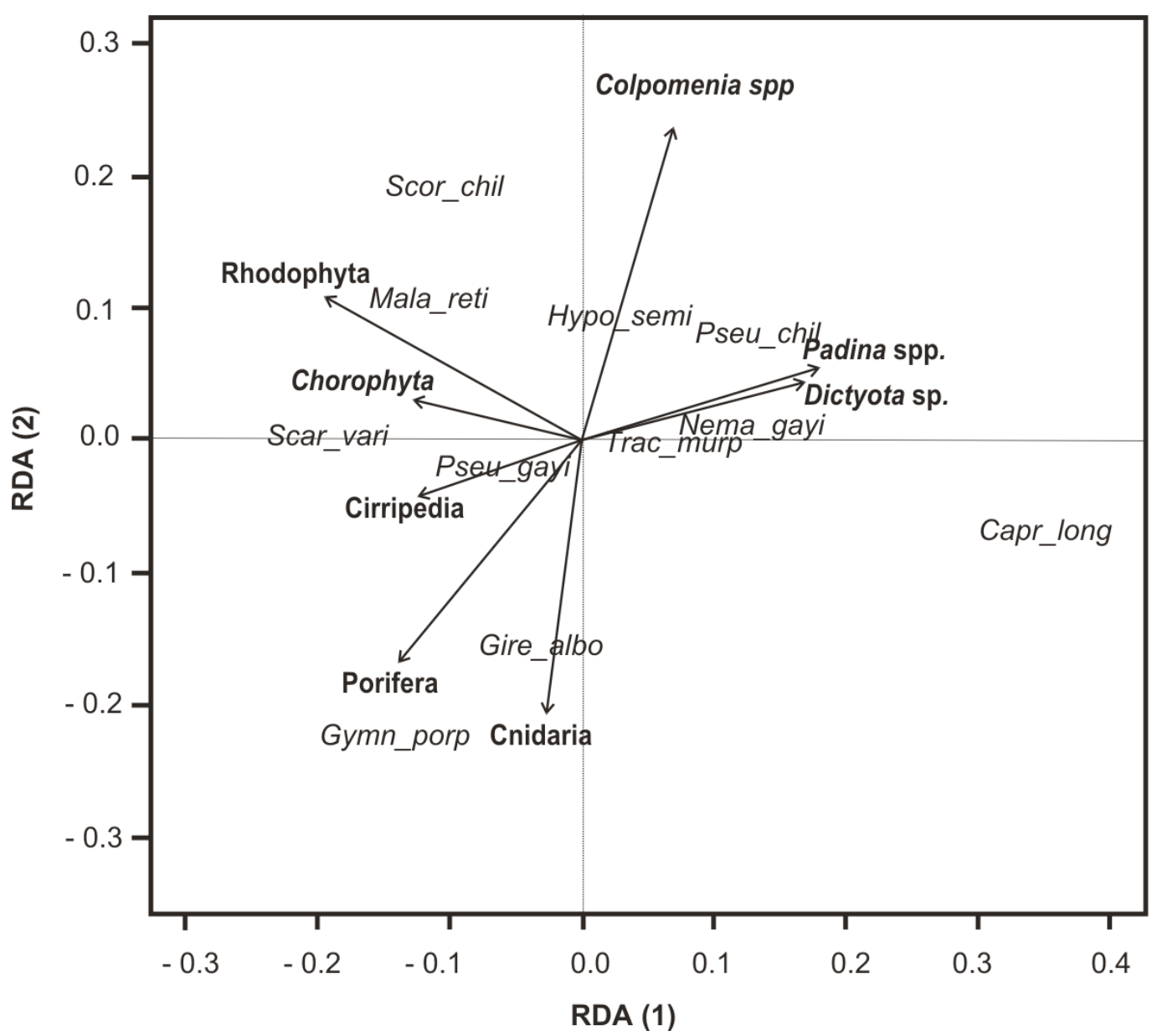

Figure 3.5 Redundancy Analysis (RDA) ordination plots of the most abundant fish species over the sampled sites. Vectors represent benthic substratum species cover and centroids of fish species abundance. The lengths of vectors represent the variability and association with each fish species. Fish species names were formed using the first four letters of their genus and species. 


\subsection{Discussion}

Reef fish assemblages at Juan Fernández are dominated by few species, most of which are endemic to the archipelago. Four families of fishes dominate the entire assemblage at Juan Fernández and this composition resembles those in more western areas of the Pacific. Differences in the composition of fishes among our study sites were principally driven by differences in the composition of substratum species which both maybe driven by levels of wave exposure.

One of the goals of this study was to identify subtidal ichthyofauna of Juan Fernández in relation to other zoogeographic areas. The ichthyofauna of the Juan Fernández Islands has been studied over many years. Intrigued by the isolation of these islands, Molina (1782) first recorded the fish fauna at Robinson Crusoe, but Mann (1954) first discovered possible relationships of fauna with other geographic areas. Juan Fernández and Easter, Sala y Gómez and Desventuradas Islands shared more similarities with one another than with continental Chile, despite the geographic distance (Mann 1954). According to Briggs (1995), the Indo-Pacific region also includes Easter Island and the Desventuradas Islands, 750 km north of Juan Fernández (Briggs 1995). Pequeño and Lamilla (2000) identified clear zoogeographic affinities between the Desventuradas Islands and western geographic areas; according to Pequeño and Saéz (2000) and the present study, similarities in fish faunas between Juan Fernández and Desventuradas Islands are in the order of more than $65 \%$. Pequeño and Saéz (2000) argued that for fishes, the region of the west IndoPacific could be extended to Juan Fernández Archipelago. 
The arrival of eggs and larvae or juveniles at Juan Fernández Archipelago via rafting, surface currents, or other possible mechanisms of transport from distant areas deserve further research. For example, Burridge et al. (2006) identified a possible route of colonization via submerged islands. These islands, seamounts, might connect western faunas and this can be illustrated by the network of seamounts in the South Pacific (Yáñez et al. 2009). Rojas and Pequeño (1998) put forward another explanation for the distribution and colonization of serranids (e.g., $H$. semicinctum, $C$. longimanus) in the archipelago, arguing that dispersal capabilities depend on the abilities of larvae to use water masses. Some species use equatorial counter current (ECC) and the equatorial submerged current (ESC) that drift from west to east to colonize tropical areas (Clarke 1995). The importance of currents and water masses is that the chemical, physical and thermal conditions are stable, favouring the transport of larvae and thus facilitating colonization from western Indo-Pacific regions to south-eastern Pacific areas, such as Juan Fernández Islands (Briggs 1961; Clarke 1995; Rojas and Pequeño 1998).

The most abundant fish species were either endemic to Juan Fernández or shared with Desventuradas Islands. When surveys of species abundance or biomass are taken into account in reef studies, the number of endemic species is usually lower than those reported solely by presence-absence data (Pequeño and Sáez 2000). Presence-absence data may be problematic for ecological studies, as they assign equal weights to all species (Francis et al. 1987; DeMartini and Friedlander 2004). The higher abundance of endemic species in the study sites and the level of endemism in Desventuradas with Juan Fernández suggests selfreplenishment (see Swearer et al. 2002, for a review) within these archipelagos. 
Both geographical and oceanographic isolation influence the dispersal of larvae to settle on reefs; the barriers generated by currents limit the colonization of Desventuradas and Juan Fernández from continents, and this suggests that the high levels of endemism must have resulted from local reproduction. Endemism is frequent across the Eastern Pacific Islands and Central Atlantic (Robertson 2001; DeMartini and Friedlander 2004). Life history characteristics may differ between endemic and non-endemic species. De Martini and Friedlander (2004) found that for endemic pomacentrids larval duration was considerably shorter than for non-endemic species, though this is countered by studies of wrasses (Cowen and Sponaugle 1997) and according to Victor \& Wellington (2000) larval duration is not often correlated with species' geographic range. Swearer et al. (2002) listed possible life history characteristics and adaptations that may facilitate self-recruitment. Developmental modes that reduce passive dispersal and improve active control over dispersal during larval stages, increased reproductive capacity (larger size, early maturation) and increased spawning synchrony and aggregation were among the characteristics they identified. A comparison between the early life history characteristics of endemic and nonendemic species warrants further research.

The composition of the fish assemblages in shallow subtidal environments at Juan Fernández more closely resembles that in western than that in eastern Pacific regions. Labrids comprise $\sim 50 \%$ of the fish assemblage in this study location, and kyphosids were the next most abundant taxon. In northern Chile, within kelp-dominated environments $\left(\sim 19^{\circ}-30^{\circ} \mathrm{S}\right)$, pomacentrids and cheilodactylids dominate assemblages (Angel and Ojeda 2001; Pérez-Matus et al. 2007), and similar patterns have been observed along the Peruvian coast 
( $12^{\circ}$ S) (Gárate and Pacheco 2004). In contrast, notothenids dominate the fish faunas of more southern $\left(\sim 50^{\circ} \mathrm{S}\right)$ kelp-dominated environments (Moreno and Jara 1984). In the western temperate Pacific, such as in northern New Zealand, fish assemblages are also characterized by abundant wrasses species (3-4 species) as well as pomacentrids and kyphosids (Choat and Ayling 1987) but the fish fauna in the south of New Zealand is more dominated by wrasses, particularly Notolabrus celidotus (Choat and Ayling 1987; Hickford and Schiel 1995, Cole et al. unpublished data). At Kermadec Islands where the substratum lacks kelp forests $\left(31^{\circ} 21^{\prime} \mathrm{S}, 178^{\circ} 48^{\prime} \mathrm{W}-2^{\circ} 15^{\prime} \mathrm{S}, 177^{\circ} 55^{\prime} \mathrm{W}\right)$, kyphosids, pomacentrids, and labrids dominate the fish assemblage, and these islands are known for their components of both subtropical and temperate faunas (Schiel et al. 1986; Francis et al. 1987; Francis 1996). The fish assemblage present in Galápagos Archipelago (Jennings et al. 1994) is also dominated by the same 3 western Pacific temperate families, although biogeographical differences occur within the archipelago (Edgar et al. 2004a). No such divisions were evident at the Juan Fernández Islands, though this sampling was limited to two islands. In spite of this, Rojas \& Pequeño (1998) identified endemic fish species occurring only at A. Selkirk (the western island of the Juan Fernández Archipelago).

Differences in the abundance and richness of fish species among our study sites were identified. Southern sites generally had slightly more abundant and rich fish faunas than northern sites. Two possible reasons can be supplied for these differences; (a) self-recruitment is important at these islands, and (b) the substratum offers different types of invertebrate prey species and habitat for most fishes. Whether fish communities are structured by recruitment or suitable habitat availability has been pondered by many authors (e.g., Shima et al. 2008; 
White and Caselle 2008). Most fishes generate benthic or pelagic eggs and nearly all have dispersive larval stages (Sale 1988). At recruitment, juveniles have the ability to encounter and select habitats (Kingsford 1995) which may or may not enhance population fitness (Shima and Osenberg 2003; Shima et al. 2008). Landaeta and Castro (2004), who studied eggs and larval abundances of littoral and oceanic fish species at the Juan Fernández Islands, found large differences in the abundance and richness of egg and fish larvae among different sites. They confirmed that the high contributions of the families Blenniidae and Labridae as opposed to other families may be due to their relatively short pelagic life history and suggested that most reef fishes of the Juan Fernández Archipelago depend on the substratum for their ontogenetic development. The high abundance of wrasses in the fish assemblages at all the study sites herein surveyed might be explained by the findings of Landaeta and Castro (2004).

Benthic substratum species differed greatly among study sites depending on the probable exposure to wave-action. Sites where characterized by green and brown macroalgae on wave-sheltered areas and by encrusting fauna such as cnidarians and vermetids in wave-exposed sites. These differences were reflected in different compositions of the associated fish fauna, where more pelagic schooling species dominated in wave-exposed sites and more resident, demersal, species dominated in wave-protected sites. Two mechanisms are known to explain differences in fish composition at either waveexposed/protected sites: (a) different swimming abilities to overcome the surrounding environment (Bellwood and Wainwright 2001) and (b) different feeding habits and performance that allow fishes to handle prey that are either associated to hard encruting substratum or more soft (algal-dominated) habitats 
(McGehee 1994; Ferry-Graham et al. 2002). Floeter et al (2007) explore the changes in fish and benthic fauna on a gradient of exposure to wave action. They found differences in benthic habitats and fish fauna depending the level of exposure: more planktivorous and schooling fishes were observed in waveexposed sites, whereas more site-attached and reef-associated species in waveprotected sites.

I detected important habitat associations in the abundance of reef fishes from Juan Fernández Islands. At three sites habitat explained a high percentage of variation in reef fish abundance, a pattern that is consistent at both tropical and temperate regions for some reef fish species. The influence of tropical faunas in the temperate islands is principally due to a coral reef component of the benthic substratum (e.g., in Kermadec Islands Gardner et al. 2006). Although we did not find coral reefs in our surveys, components of tropical fish fauna were present (e.g., Serranidae, Chaetodontidae). This may be because the survival thresholds of cold waters are higher for these fish families than for coral species. The higher temperature fluctuations and the barrier provided by the Humboldt Current may also limit the possible colonization by kelp in Juan Fernández archipelago (Graham et al. 2007b) or, alternatively kelp forests may occur at depths beyond those we surveyed (Graham et al. 2007a). In the absence of both corals and large brown macroalgae, other substratum species influenced reefassociated fishes. In some cases this was important, as for the brown algae, Dictyota spp. This macroalga has a widespread distribution in the Pacific Ocean and may be a dominant species in both tropical and temperate regions (De Clerck et al. 2006). The ability of Dictyota to deter herbivores allows them to be a good 
competitor for substratum and light (De Clerck et al. 2006) and this may explain the high abundance of this species at the study sites.

The other taxon that covered much of the substratum at Juan Fernández was vermetid molluscs. These form reefs and add structural complexity in subtidal environments. On temperate Mediterranean reefs, the fish fauna associated with vermetid molluscs is distinct from that associated with other substratum species (Consoli et al. 2008), a pattern similar to our findings. Further manipulative studies are required to understand to what extent these habitats influence the distribution of fishes and other organisms, and what kinds of "services" (niche requirements) they provide to reef fishes.

To my knowledge the present study is the first attempt to identify patterns of reef fish community structure in Juan Fernández Archipelago. This is of particular interest for conservation, management, and the assessment of the effects of the recent tsunami strike on the shores of Robinson Crusoe (Kaiser and Regalado 2010). Additionally, because of the limited information regarding the ecological role of seamounts in the connectivity and dispersal of reef fishes (Yáñez 2009) and the lack of management of benthic resources (except the Juan Fernández lobster fishery (Arana and Ziller 1985)). I urge conservation practices to be applied to the entire ichthyofauna of the region. 


\section{CHAPTER 4}

Fish abundance and biomass associations with heterogeneous habitat: a year of surveys in the temperate Kapiti Island

\subsection{Abstract}

Brown macroalgae dominate most temperate rocky coasts. In sympatry, two main families, the Laminareales and Fucales, dominate most of the brown algal assemblages with species-specific variation. This difference may serve as a proxy for habitat heterogeneity in temperate reefs environments. Previous experimental work indicated that there is strong specificity in the use of different habitat types by fishes and fish assemblages at relatively small scales. Differences in the use of macroalgal stands may be driven by different behavioural trade-offs and niche requirements among fish species. In this study, I investigated the consistency of habitat use patterns of fish in natural marcoalgal habitats over four seasons and at three sites at Kapiti Island, southern North Island, New Zealand. By means of visual census, the fish assemblage composition and association with substratum species was surveyed in the subtidal environments. Results indicate that abundance and biomass of fish species varied among sites but only biomass changed seasonally. Biomass changes were attributable to the contribution of planktivorous and piscivorous species to fish assemblages over spring and summer months. The composition of the fish assemblages did not exhibit temporal variation and fish assemblages did not vary among sites. According to model selection criteria, the site 
differences in macroalgal composition best explained the diversity of fishes in Kapiti Island. Clear associations between fishes and substratum species indicate that fishes partition their use of macroalgal stands. Different feeding habits and size-susceptibility to predation may be the possible mechanisms of association with different habitat structures. The pattern observed here is congruent with those exhibited by the same fish species during a small-scale experimental study.

\subsection{Introduction}

Diversity, abundance and composition of the habitat types may serve as proxies for the structural complexity and heterogeneity of the environment. The degree to which this structural complexity and heterogeneity is able to predict reef fish composition and diversity has been studied by several authors (Roberts and Ormond 1987; Holbrook et al. 2002; Valesini et al. 2004). Contributions of the habitat types to the abundance (Roberts and Ormond 1987; Anderson and Millar 2004), survival (Carr 1994; Tolimieri 1998), and overall organization of reef fish communities are evident (Angel and Ojeda 2001). Alternatively, other studies have found minimal influence of habitat on the composition of the fish assemblages (e.g., Ault and Johnson 1998).

Habitat influences the survival of individuals and promotes diversity. A possible mechanism of this contribution is through persistence of natural assemblages composed of competing species (Schoener 1974): animals may choose habitats that are less preferred by their natural enemies. However the structure (i.e., habitat), seen as the spatial relationship between distinctive habitat within a prescribed area, undergoes changes in composition (i.e., re-arrangement of objects in space) (Arias-González et al. 2006). This variation may be an 
important determinant of the organization and abundance of local reef fish assemblage (Choat and Ayling 1987). Thus, the variations in heterogeneity are manifested as local differences in food, refuge from predators, and mating sites (Choat and Ayling 1987; Holbrook et al. 1990a; Holbrook et al. 1990b). These differences are important determinants of patterns of fish diversity and abundance at both small (Pérez-Matus and Shima 2010) and large scales (Ault and Johnson 1998). Consequently not all habitat types are equally important in shaping fish communities (Jones and Syms 1998).

In shallow subtidal waters of Northern New Zealand, two main families of brown-macroalgae coexist: the Fucales and Laminareales (Schiel 1990). These large brown algae dominate most marine rocky coasts, providing food, and biogenic habitat (Dayton 1985a; Schiel and Foster 1986). They thereby feature a distinct flow of energy, materials, organisms and individuals within algaldominated habitats (Steneck et al. 2002). The interactions between the associated organisms differ between algal-dominated habitats and open areas with a low level of habitat heterogeneity (Angel and Ojeda 2001; Graham 2004). However, changes on associations between different algal structures and associated fish species over temporal scales have not being explored yet.

Previous results based on experimental manipulations at small spatial scales revealed that macroalgal identities affect the abundance of 7 reef fish species and the composition (structure) of the macroalgae affected the abundance of 5 of them. These linkages between fish species and algal-dominated habitats are potentially mediated by behavioural trade-offs and different niche requirements (Pérez-Matus and Shima 2010). A central ecological challenge is the description of patterns that occur at local scales that are repeated at larger 
scales (Connell and Irving 2008). Here, the linkages between fish species with the structure (i.e., habitat) and heterogeneity of the subtidal habitats were studied incorporating three study sites and four seasons. A secondary objective was to investigate the function of algal-dominated habitat expressed as the total fish biomass that is sustained by that structure.

\subsection{Methods}

\subsubsection{Study sites and sampling}

This study was conducted on the reef systems surrounding Kapiti Island, New Zealand. Kapiti Island is approximately $10 \mathrm{~km}$ long and $2 \mathrm{~km}$ wide, and isolated from the mainland by approximately $7 \mathrm{~km}$. On the reefs surrounding Kapiti Island, I selected three different study sites, each separated by more than 5 $\mathrm{km}: 1)$ an eastern site $\left(40^{\circ} 50^{\prime} \mathrm{S} 174^{\circ} 56^{\prime} \mathrm{W}\right)$, which is partly sheltered from southerly swells and characterized by narrow boulder-rock reefs separated by patches of sand; 2) a western site ( $\left.40^{\circ} 49^{\prime} \mathrm{S} 174^{\circ} 54^{\prime} \mathrm{W}\right)$; and 3 ) a southern site $\left(40^{\circ} 53^{\prime} \mathrm{S} 174^{\circ} 52^{\prime} \mathrm{W}\right)$. Shallow bottom, large boulders, and exposure to wave action characterize both the western and southern sites (Fig. 4.1). The eastern and the western sites are both within a marine reserve, which was established in 1991. 


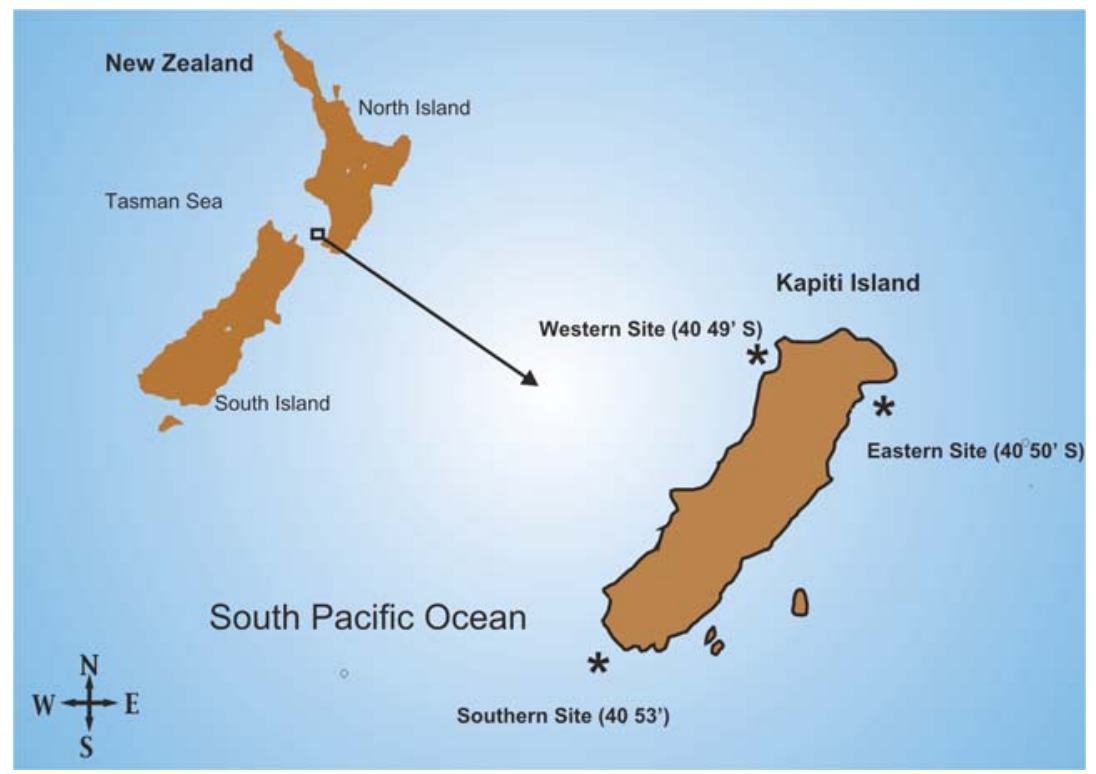

Figure 4.1 Map of the selected study sites.

At each site I conducted seasonal surveys, every three months from February 2008 through January 2009. Surveys were conducted using the same UVC methodology as in Chapter 2 and 3. The substratum off the island is characterized by brown macroalgae; the order Laminareales is represented only by Ecklonia radiata whereas Fucales are represented by Carpophyllum flexusosum, Cystophora retroflexa and C. torulosa (hereafter, Cystophora spp). Levels of habitat heterogeneity were quantified using the following criteria: (1) no algae (lithic) where no canopy or less than $10 \%$ of the quadrate (4 by $4 \mathrm{~m}$ ) area was composed of canopy forming algae; (2) monospecific canopies (i.e., single laminarean, fucalean), when more than $90 \%$ of quadrate is covered by single alga; and (3) mixed stands when two or more canopies comprised $40-60$ $\%$ of the stand. Depth, water temperature, and visibility were also recorded. Census began at the deepest transect, and progressively worked shallower. 
Estimates of size and abundance of each fish species were converted to biomass ( $\mathrm{g}$ wet weight $\mathrm{m}^{-2}$ ) using the allometric equation

$W=a L^{b}$

where the weight $(W)$ was obtained from the length of the fish $(L)$ and the constants $(a, b)$ for each species. Constants $(a, b)$ were obtained from FishBase (http://www.fishbase.org/search.php (Froese and Pauly 2009). Total biomass per census was estimated as the average weight multiplied by the abundance.

\subsubsection{Data Analysis}

I tested differences in mean on total abundance and biomass of the all fish species per site and seasons. Since the response variable was count data with unequal variance and non-normally distributed errors, I used generalized linear models (GLM) (Crawley 2007). For both, abundance and biomass I used untransformed data and specified a quasipoisson error distribution with log link function when needed (O’Hara and Kotze 2010).

The changes in diversity of fish were tested using Simpson's diversity index (Simpson 1949) over pooled transects by sites and seasons. Occurrence of macroalgae species diversity per transects was calculated based on Simpson's diversity index. I evaluated the influence of site, season, diversity of macroalgae species and the interaction among these using a model selection approach (Burnham and Anderson 1998). Different candidates' models were tested and their relative support in explaining changes in fish species diversity were assessed (see table 4.2). To assess which model best explained fish species diversity, Akaike Information Criterion (AIC) approach was used.

$A I C=-2 \log (L(X \mid \Theta))+2 k$ 
where, $\mathrm{N}$ is the total sample size, $\mathrm{L}(\mathrm{X} \mid \Theta)$ is the likelihood of the model given the estimated parameters $\Theta$, and $\mathrm{K}$ the number of parameters in the model. Lower AIC values indicate a better model for the data at hand.

In order to determine associations between the substratum species and different levels of heterogeneity I used multivariate analyses. I incorporated the ten most common reef fish species among the study sites and used both biomass and abundance of the reef fish against both different types of substratum species and levels of heterogeneity (no macroalgae - lithic-, fucalean, laminarean or mixed canopies) using redundancy analysis (RDA) on Hellinger transformation of the fish data. This transformation makes the data more amenable for the types of analyses performed above (see Legendre and Gallaher 2001 for details). To test for significant associations between fish abundance and substratum species and different levels of heterogeneity, a permutation of the constraints for constrained analysis among sites was performed. All analysis was conducted using the package vegan (Oksanen) for the computing environment R 2.10.

\subsection{Results}

4.4.1 The fish fauna: seasonal changes in abundance and biomass

Over all 12 censuses, 7,310 sightings of fish were recorded: 2,434; 1,582; and 3,294 in Eastern, Southern, and Western sites respectively. The Western site sustain more fishes per $\mathrm{m}^{2}$ than the other sampled sites (Fig. 4.2). Seasonal changes were evidenced and total amount was 2,495 over fall, 908 in winter, 2,122 in spring and 1,785 over summer. Significant differences were detected in 
terms of the total abundance over seasons only, where winter was significantly lower relative to the other seasons $(\mathrm{GLM} ; \mathrm{df}=48, \mathrm{t}=-2.7$, $\mathrm{p}$-value $<0.001)$.

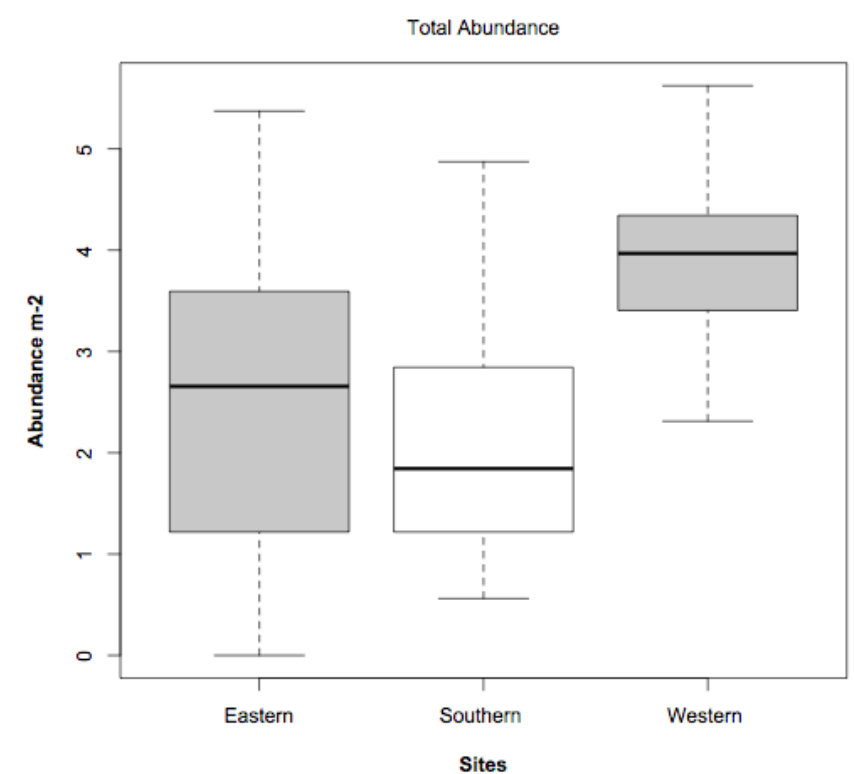

Figure 4.2 Box plot of the fish abundance per $\mathrm{m}^{-2}$ among seasons

A total of 38 species belonging to 18 families were recorded (Table 4.1). The triplefins (Tripterygiidae) and the wrasses (Labridae) were the most important families in terms of numbers of species represented and total abundance respectively (Table 4.1). Ten species belonging to 7 families accounted for $90 \%$ of the total abundance of the fish assemblage in the surveyed area. Notolabrus celidotus (31\% of the sightings) was the most numerically abundant species followed by $N$. fucicola (17\%) and Parapercis colias (12\%). Other abundant species were, Aplodactylus arctidens, Pseudolabrus miles, Latridopsis ciliaris, Odax pullus, Forsterygion lapillum, F. maryannae, and F. varium (Table 4.1). 
Table 4.1 Mean $( \pm S D)$ of all the species recorded at the different sites and seasons (data were pooled per depth strata).

\begin{tabular}{|c|c|c|c|c|c|}
\hline \multirow[b]{2}{*}{ Family } & \multirow[b]{2}{*}{ Species } & \multicolumn{4}{|c|}{ a) Eastern } \\
\hline & & Fall & Winter & Spring & Summer \\
\hline \multirow[t]{2}{*}{ Moridae } & Lotella rhacinus & - & - & - & - \\
\hline & Pseudophycis barbata & - & - & - & $0.2 \pm 0.4$ \\
\hline \multirow[t]{2}{*}{ Trachichthyidae } & Optivus elongatus & - & - & - & - \\
\hline & Paratrachichtys sp. & - & $0.4 \pm 0.8$ & - & - \\
\hline Scorpaenidae & Scorpaena papillosa & $0.2 \pm 0.4$ & $0.2 \pm 0.4$ & - & - \\
\hline \multirow{3}{*}{ Serranidae } & Caesioperca lepidoptera & - & - & - & - \\
\hline & Caprodon longimanus & $0.4 \pm 0.8$ & - & - & - \\
\hline & Hypoplectrodes sp. & - & $0.2 \pm 0.4$ & - & - \\
\hline \multirow[t]{2}{*}{ Carangidae } & Seriola lalandi & - & - & - & - \\
\hline & Trachurus murphyi & $0.8 \pm 1.6$ & - & - & - \\
\hline Arripidae & Arripis trutta & $0.2 \pm 0.4$ & $0.2 \pm 0.4$ & - & $0.2 \pm 0.4$ \\
\hline \multirow[t]{2}{*}{ Mullidae } & Upeneichthys lineatus & $0.6 \pm 1.2$ & - & $0.4 \pm 0.8$ & - \\
\hline & Upeneus francisi & - & - & $1.4 \pm 2.8$ & $0.4 \pm 0.5$ \\
\hline \multirow[t]{2}{*}{ Pempheridae } & Pempheris adspersa & - & - & - & - \\
\hline & Pempheris analis & - & - & - & - \\
\hline \multirow[t]{2}{*}{ Kyphosidae } & Kyphosus sydneyanus & - & - & - & - \\
\hline & Scorpis lineolatus & - & - & - & $0.2 \pm 0.40$ \\
\hline Aplodactylidae & Aplodactylus arctidens & $1 \pm 1.5$ & - & $0.2 \pm 0.4$ & $1 \pm 2.0$ \\
\hline \multirow[t]{2}{*}{ Cheilodactylidae } & Cheilodactylus spectabilis & - & $0.6 \pm 1.2$ & - & $0.8 \pm 0.7$ \\
\hline & Nemadactylus macropterus & $1.4 \pm 2.80$ & - & - & - \\
\hline \multirow[t]{3}{*}{ Latridae } & Latridopsis ciliaris & $1 \pm 0.9$ & - & $0.6 \pm 0.8$ & $1.8 \pm 1.6$ \\
\hline & Latridopsis forsteri & - & - & - & - \\
\hline & Mendosoma lineatum & - & - & - & - \\
\hline Pomacentridae & Chromis dispilus & - & - & - & $0.6 \pm 0.5$ \\
\hline \multirow[t]{4}{*}{ Labridae } & Notolabrus celidotus & $13.8 \pm 7.3$ & $4.4 \pm 3.9$ & $13.8 \pm 7.08$ & $18.8 \pm 10.5$ \\
\hline & Notolabrus cinctus & - & - & - & - \\
\hline & Notolabrus fucicola & $8.1 \pm 8.4$ & $3 \pm 2.7$ & $4.6 \pm 5.50$ & $8 \pm 8.4$ \\
\hline & Pseudolabrus miles & - & $0.4 \pm 0.8$ & $1.4 \pm 1.96$ & $1 \pm 1.3$ \\
\hline Odacidae & Odax pullus & $3.2 \pm 3.87$ & - & $2.6 \pm 3.2$ & $1.8 \pm 2.7$ \\
\hline Pinguipedidae & Parapercis colias & $4.8 \pm 4.3$ & - & $8.2 \pm 10.2$ & $9.8 \pm 12.5$ \\
\hline \multirow[t]{7}{*}{ Tripterygiidae } & Forsterygion capito & $0.2 \pm 0.4$ & - & - & - \\
\hline & Forsterygion flavonigrum & $0.4 \pm 0.5$ & $0.2 \pm 0.40$ & $0.2 \pm 0.4$ & $1.2 \pm 1.2$ \\
\hline & Forsterygion lapillum & $3.4 \pm 2.2$ & $1.6 \pm 2.1$ & $4.4 \pm 3.7$ & $4 \pm 3.4$ \\
\hline & Forsterygion malcolmi & - & $1.2 \pm 1.6$ & $0.6 \pm 1.2$ & $0.8 \pm 1.2$ \\
\hline & Forsterygion maryannae & $0.2 \pm 0.4$ & $1.8 \pm 1.6$ & $0.6 \pm 0.8$ & $0.6 \pm 0.8$ \\
\hline & Forsterygion varium & $2 \pm 1.8$ & $0.6 \pm 0.8$ & $3.4 \pm 3.1$ & $1.8 \pm 1.5$ \\
\hline & Ruanoho whero & - & $0.4 \pm 0.8$ & $0.4 \pm 0.5$ & - \\
\hline Monacanthidae & Meuschenia scaber & $0.4 \pm 0.8$ & - & $0.2 \pm 0.4$ & $0.4 \pm 0.8$ \\
\hline Total Abundance & & $42.6 \pm 15.8$ & $15.2 \pm 14.2$ & $43.0 \pm 15.8$ & $53.4 \pm 28.2$ \\
\hline Total Richness & & $7.6 \pm 1.85$ & $4.6 \pm 4.45$ & $6.6 \pm 2.65$ & $8.4 \pm 5.3$ \\
\hline
\end{tabular}


Cont, Table 4.1

\begin{tabular}{|c|c|c|c|c|c|}
\hline \multirow[b]{2}{*}{ Family } & \multirow[b]{2}{*}{ Species } & \multicolumn{4}{|c|}{ b) Southern } \\
\hline & & Fall & Winter & Spring & Summer \\
\hline \multirow[t]{2}{*}{ Moridae } & Lotella rhacinus & - & - & $0.2 \pm 0.4$ & - \\
\hline & Pseudophycis barbata & - & - & - & - \\
\hline \multirow[t]{2}{*}{ Trachichthyidae } & Optivus elongatus & - & - & - & $0.2 \pm 0.4$ \\
\hline & Paratrachichtys sp. & - & $0.2 \pm 0.4$ & - & - \\
\hline Scorpaenidae & Scorpaena papillosa & - & - & $0.2 \pm 0.4$ & $0.2 \pm 0.4$ \\
\hline \multirow[t]{3}{*}{ Serranidae } & Caesioperca lepidoptera & $0.2 \pm 0.4$ & - & $2.6 \pm 2.6$ & - \\
\hline & Caprodon longimanus & - & - & - & - \\
\hline & Hypoplectrodes sp. & - & - & $0.2 \pm 0.4$ & $0.2 \pm 0.4$ \\
\hline \multirow[t]{2}{*}{ Carangidae } & Seriola lalandi & - & - & - & $0.2 \pm 0.4$ \\
\hline & Trachurus murphyi & - & - & $0.2 \pm 0.4$ & $0.4 \pm 0.5$ \\
\hline Arripidae & Arripis trutta & - & - & - & - \\
\hline \multirow[t]{2}{*}{ Mullidae } & Upeneichthys lineatus & - & $0.2 \pm 0.4$ & - & - \\
\hline & Upeneus francisi & - & - & - & - \\
\hline \multirow[t]{2}{*}{ Pempheridae } & Pempheris adspersa & - & - & $0.4 \pm 0.5$ & - \\
\hline & Pempheris analis & - & - & $0.2 \pm 0.4$ & - \\
\hline \multirow[t]{2}{*}{ Kyphosidae } & Kyphosus sydneyanus & - & - & $0.2 \pm 0.4$ & - \\
\hline & Scorpis lineolatus & - & - & - & - \\
\hline Aplodactylidae & Aplodactylus arctidens & $0.2 \pm 0.4$ & $1.2 \pm 1.5$ & $4.8 \pm 3.5$ & $2.8 \pm 2.8$ \\
\hline \multirow[t]{2}{*}{ Cheilodactylidae } & Cheilodactylus spectabilis & - & $0.4 \pm 0.8$ & $0.2 \pm 0.4$ & $1.4 \pm 1.5$ \\
\hline & Nemadactylus macropterus & - & - & $0.2 \pm 0.4$ & $0.6 \pm 1.2$ \\
\hline \multirow[t]{3}{*}{ Latridae } & Latridopsis ciliaris & $0.4 \pm 0.5$ & - & $3 \pm 2.3$ & $0.2 \pm 0.4$ \\
\hline & Latridopsis forsteri & - & - & $0.2 \pm 0.4$ & - \\
\hline & Mendosoma lineatum & - & - & $0.2 \pm 0.4$ & - \\
\hline Pomacentridae & Chromis dispilus & - & - & - & $0.2 \pm 0.4$ \\
\hline \multirow[t]{4}{*}{ Labridae } & Notolabrus celidotus & $6.6 \pm 2.8$ & $5.2 \pm 6.5$ & $4.2 \pm 2.7$ & $4.2 \pm 2.5$ \\
\hline & Notolabrus cinctus & - & - & - & $0.2 \pm 0.4$ \\
\hline & Notolabrus fucicola & $11.2 \pm 13.2$ & $12.8 \pm 12.4$ & $15.6 \pm 11.3$ & $4.4 \pm 3.9$ \\
\hline & Pseudolabrus miles & $0.8 \pm 0.7$ & $5.6 \pm 7.3$ & $5.4 \pm 3.7$ & $5.8 \pm 7.7$ \\
\hline Odacidae & Odax pullus & $3.6 \pm 2.4$ & $2.4 \pm 4.8$ & $7.4 \pm 6.1$ & $2.2 \pm 0.7$ \\
\hline Pinguipedidae & Parapercis colias & - & $2 \pm 1.7$ & $2 \pm 2.1$ & $3 \pm 5.1$ \\
\hline \multirow[t]{7}{*}{ Tripterygiidae } & Forsterygion capito & - & - & - & - \\
\hline & Forsterygion flavonigrum & - & - & $0.4 \pm 0.5$ & $1.2 \pm 1.5$ \\
\hline & Forsterygion lapillum & - & - & - & - \\
\hline & Forsterygion malcolmi & - & $0.4 \pm 0.5$ & $0.6 \pm 0.8$ & $0.6 \pm 0.8$ \\
\hline & Forsterygion maryannae & $0.8 \pm 1.2$ & $0.8 \pm 0.7$ & $1.2 \pm 1.0$ & $1.4 \pm 1.8$ \\
\hline & Forsterygion varium & $0.6 \pm 0.5$ & $1.4 \pm 1.0$ & $0.8 \pm 1.6$ & $2.0 \pm 2.8$ \\
\hline & Ruanoho whero & - & - & $0.2 \pm 0.4$ & $0.2 \pm 0.4$ \\
\hline Monacanthidae & Meuschenia scaber & $0.6 \pm 0.8$ & - & $1.2 \pm 1.8$ & $0.2 \pm 0.4$ \\
\hline Total Abundance & & $25.0 \pm 12.0$ & $32.6 \pm 15.3$ & $51.8 \pm 16.8$ & $31.8 \pm 18.6$ \\
\hline Total Richness & & $5.6 \pm 1.5$ & $6.8 \pm 1.2$ & $12.0 \pm 3.8$ & $10.0 \pm 2.3$ \\
\hline
\end{tabular}


Cont, Table 4.1

\begin{tabular}{|c|c|c|c|c|c|}
\hline \multirow[b]{2}{*}{ Family } & \multirow[b]{2}{*}{ Species } & \multicolumn{4}{|c|}{ c) Western } \\
\hline & & Fall & Winter & Spring & Summer \\
\hline \multirow[t]{2}{*}{ Moridae } & Lotella rhacinus & - & - & - & - \\
\hline & Pseudophycis barbata & - & - & - & - \\
\hline \multirow[t]{2}{*}{ Trachichthyidae } & Optivus elongatus & - & - & - & - \\
\hline & Paratrachichtys sp. & - & - & - & - \\
\hline Scorpaenidae & Scorpaena papillosa & - & $0.2 \pm 0.4$ & - & $0.2 \pm 0.4$ \\
\hline \multirow[t]{3}{*}{ Serranidae } & Caesioperca lepidoptera & $1 \pm 1.3$ & - & $2.4 \pm 4.8$ & $2.2 \pm 3.9$ \\
\hline & Caprodon longimanus & - & - & - & - \\
\hline & Hypoplectrodes sp. & - & - & - & - \\
\hline \multirow[t]{2}{*}{ Carangidae } & Seriola lalandi & - & - & - & - \\
\hline & Trachurus murphyi & $0.2 \pm 0.4$ & - & - & - \\
\hline Arripidae & Arripis trutta & - & - & - & - \\
\hline \multirow[t]{2}{*}{ Mullidae } & Upeneichthys lineatus & $0.2 \pm 0.4$ & - & $0.2 \pm 0.4$ & - \\
\hline & Upeneus francisi & - & - & - & - \\
\hline \multirow[t]{2}{*}{ Pempheridae } & Pempheris adspersa & - & - & - & - \\
\hline & Pempheris analis & - & - & - & - \\
\hline \multirow[t]{2}{*}{ Kyphosidae } & Kyphosus sydneyanus & - & - & - & - \\
\hline & Scorpis lineolatus & - & - & - & - \\
\hline Aplodactylidae & Aplodactylus arctidens & $1.4 \pm 2.0$ & $0.8 \pm 1.6$ & $2.4 \pm 2.1$ & $3.6 \pm 4.2$ \\
\hline \multirow[t]{2}{*}{ Cheilodactylidae } & Cheilodactylus spectabilis & $0.4 \pm 0.5$ & $0.8 \pm 1.0$ & $0.4 \pm 0.8$ & $0.4 \pm 0.5$ \\
\hline & Nemadactylus macropterus & - & - & $0.8 \pm 1.6$ & $0.6 \pm 1.2$ \\
\hline \multirow[t]{3}{*}{ Latridae } & Latridopsis ciliaris & $1.8 \pm 1.3$ & - & $2 \pm 4.0$ & $0.4 \pm 0.8$ \\
\hline & Latridopsis forsteri & - & - & - & - \\
\hline & Mendosoma lineatum & $0.2 \pm 0.4$ & - & - & $0.2 \pm 0.4$ \\
\hline Pomacentridae & Chromis dispilus & - & - & - & - \\
\hline \multirow[t]{4}{*}{ Labridae } & Notolabrus celidotus & $10.2 \pm 3.1$ & $10.6 \pm 4.5$ & $12.8 \pm 7.1$ & $8.4 \pm 2.1$ \\
\hline & Notolabrus cinctus & - & - & - & - \\
\hline & Notolabrus fucicola & $12.0 \pm 10.9$ & $19.0 \pm 7.5$ & $14.8 \pm 4.1$ & $11.2 \pm 9.3$ \\
\hline & Pseudolabrus miles & $6.2 \pm 5.3$ & $6.4 \pm 5.0$ & $7.4 \pm 5.4$ & $9.0 \pm 4.4$ \\
\hline Odacidae & Odax pullus & $14.4 \pm 4.0$ & $2.6 \pm 2.8$ & $8.0 \pm 8.6$ & $11.6 \pm 3.7$ \\
\hline Pinguipedidae & Parapercis colias & $9 \pm 6.1$ & $9 \pm 9.3$ & $10.2 \pm 9.7$ & $8.0 \pm 5.3$ \\
\hline \multirow[t]{7}{*}{ Tripterygiidae } & Forsterygion capito & - & - & - & - \\
\hline & Forsterygion flavonigrum & - & - & $1.0 \pm 2.0$ & $1.2 \pm 2.4$ \\
\hline & Forsterygion lapillum & - & - & - & - \\
\hline & Forsterygion malcolmi & - & - & - & $0.4 \pm 0.8$ \\
\hline & Forsterygion maryannae & $2.2 \pm 1.6$ & $0.6 \pm 0.8$ & $1.6 \pm 1.6$ & $4 \pm 3.0$ \\
\hline & Forsterygion varium & $1.0 \pm 1.1$ & $1.4 \pm 0.8$ & $3.6 \pm 2.6$ & $2 \pm 1.2$ \\
\hline & Ruanoho whero & $0.2 \pm 0.4$ & $0.2 \pm 0.4$ & $0.4 \pm 0.8$ & - \\
\hline Monacanthidae & Meuschenia scaber & $2.6 \pm 2.2$ & - & $1.0 \pm 1.5$ & $1.4 \pm 1.5$ \\
\hline Total Abundance & & $63.0 \pm 15.8$ & $51.2 \pm 10$ & $69 \pm 15.8$ & $64.8 \pm 5.6$ \\
\hline Total Richness & & $9.2 \pm 1.6$ & $7.0 \pm 1.1$ & $8.6 \pm 2.4$ & $10 \pm 1.7$ \\
\hline
\end{tabular}

- $\quad$ represents species absent

Total fish biomass among sites and seasons was 350,858 $\mathrm{g}$ of wet weight per $160 \mathrm{~m}^{2}$. The western site sustain the highest biomass, $217,7 \mathrm{~g}$ wet weight per $40 \mathrm{~m}^{2}$, followed by the Southern site $(117,2 \mathrm{~g})$ and eastern site with $103.6 \mathrm{~g}$ of wet weight per $\mathrm{m}^{2}(\mathrm{GLM} ; \mathrm{df}=48, \mathrm{t}=2.6, \mathrm{p}$-value $<0.01)$. Site and seasonal interactions during winter $(\mathrm{GLM}$; $\mathrm{df}=48, \mathrm{t}=-2.034, \mathrm{P}<0.04)$ were evidenced: winter had the lowest amount of fish biomass, 85,2 $\mathrm{g}$ wet weight per $\mathrm{m}^{2}$, relative to autumn, spring and summer seasons, 85,$6 ; 149,5$; and $118,4 \mathrm{~g}$ wet weight per $\mathrm{m}^{2}$ respectively (Fig. 4.3). 


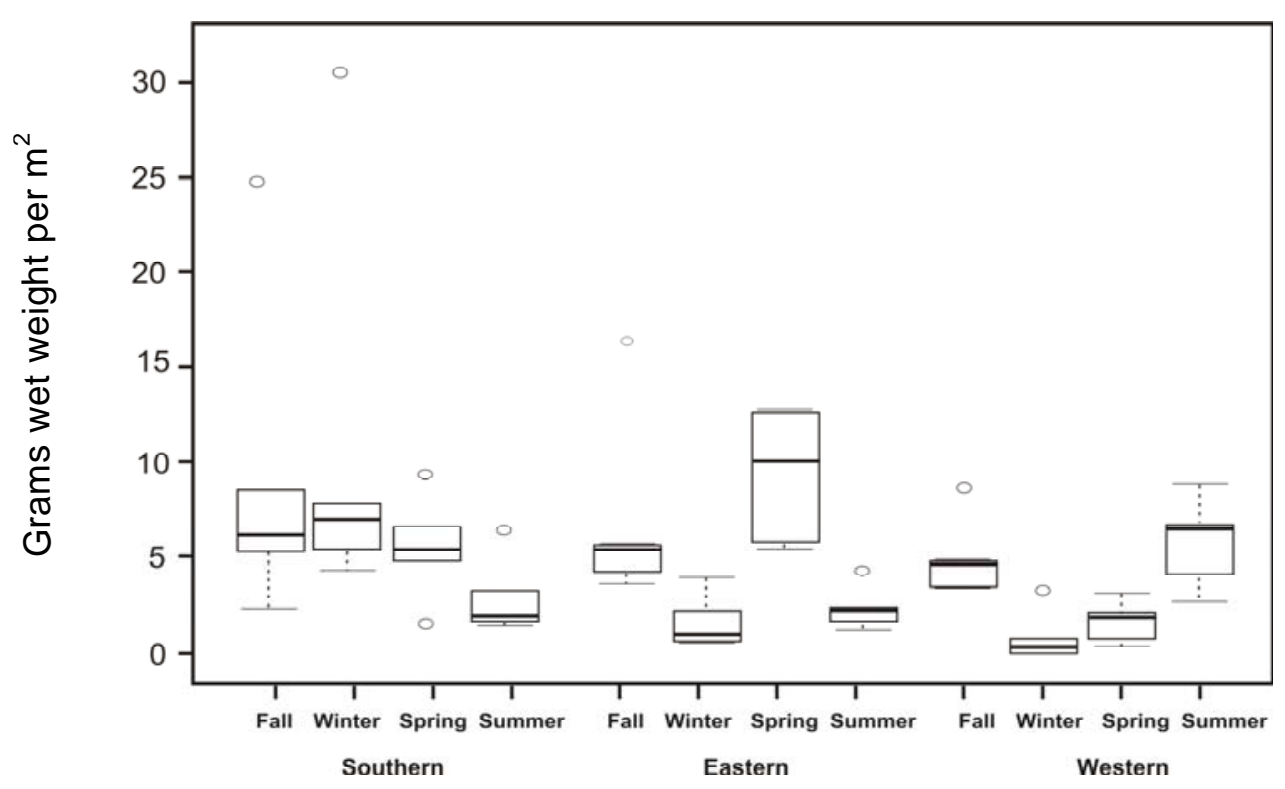

Figure 4.3 Box plot of the biomass per $\mathrm{m}^{-2}$ among sites and seasons

The wrasses (Labridae) accounted for nearly $50 \%$ of the total fish biomass and Notolabrus fucicola contributed $30 \%$ of this biomass. Other important families were the Odacidae (Odax pullus), Pinguipedidae (Parapercis colias) and Latridae (Latridopsis ciliaris and Nemadactylus macropterus). Species such Cheilodactylus spectabilis, Nemadactylus macropterus, Aplodactylus arctidens, Arripis trutta, Latridopsis ciliaris, Caesioperca lepidoptera, Mendosoma lineatum and Trachurus murphyi contributed to the remaining $\sim 50 \%$ of the total biomass of reef fishes among sites and seasons.

\subsubsection{Differences in substratum species.}

Sites differed in the composition of the substrate. Southern site substratum was covered with monospecific stands of $E$. radiata and with mixed macroalgae (principally by E. radiata with $C$. flexuosum). Non-macroalgal (lithic) habitat occurred but in less proportion than monospecific stands of fucalean species (Fig. 4.4). 
Mixed macroalgae (principally by Ecklonia radiata with Carpophyllum flexuosum and Cystophora spp) covered high proportions of the substatum at the Eastern site. Non-macroalgal (lithic) habitat was less frequent than algal dominated patches (Fig. 4.4)

The Western site substrata was covered with monospecific stands of $E$. radiata and in higher proportion by mixed macroalgae (principally by Ecklonia radiata with Carpophyllum flexuosum). Fucales also occurred but in less proportion than monospecific stands of laminarean and mixed species. Most of the substratum in this site was covered with macroalgae (Fig. 4.4)
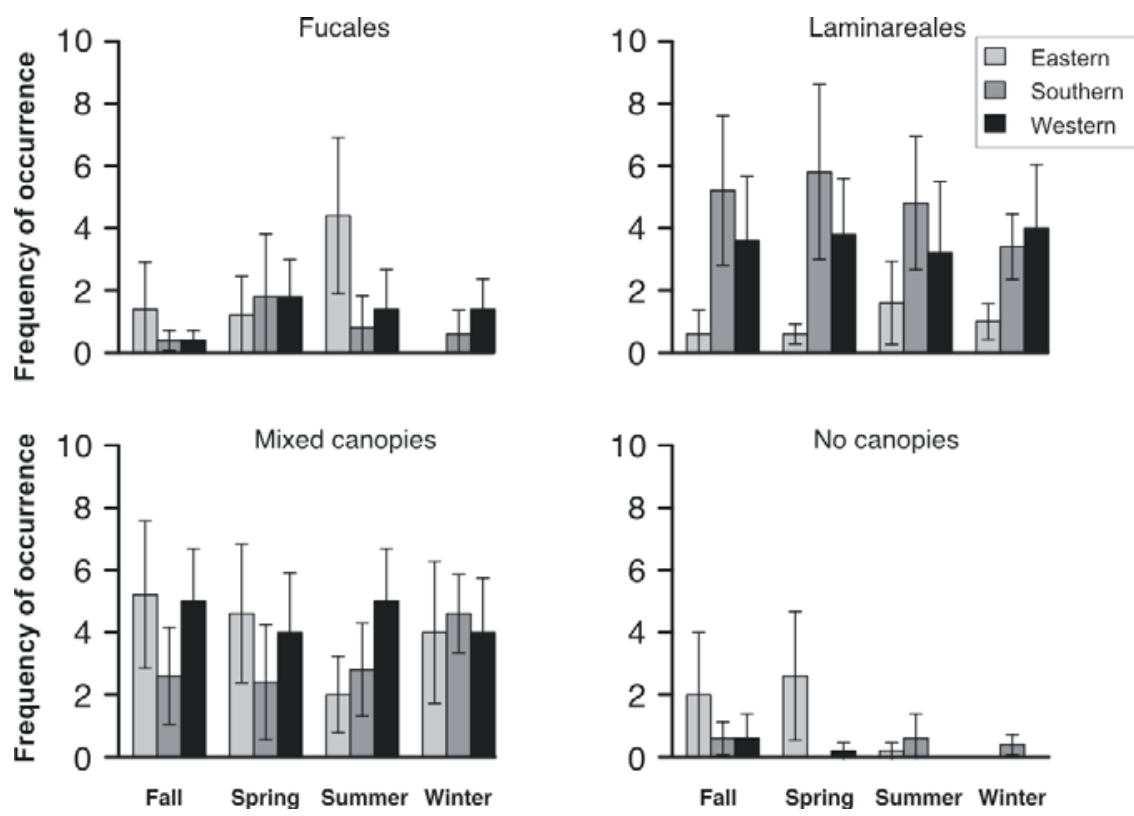

Figure 4.4 Mean frequency ( \pm SD) of occurrence of Fucales (Carpophyllum and Cystophora spp), Laminareales (Ecklonia radiata), Mixed canopies (Fucales + Laminareales), and no canopies substratum among the different study sites at Kapiti Island, New Zealand.

\subsubsection{Diversity of fish assemblages: seasonal and sites differences}

Mean Simpson's diversity index was highest in Southern and Western sites and highly variable in the Eastern site (Fig. 4.5). 


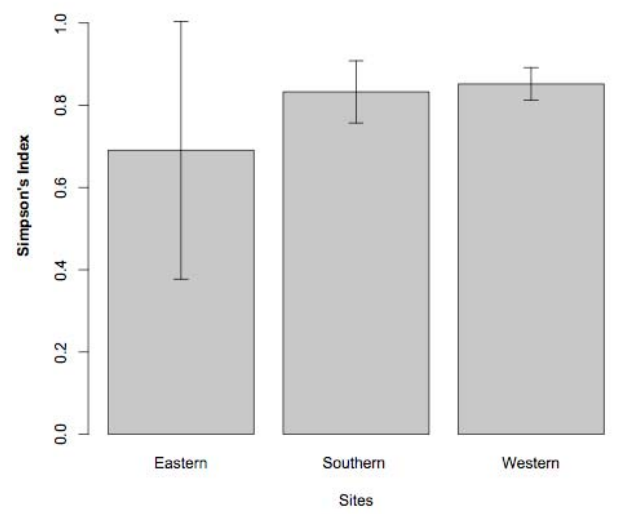

Figure 4.5 Mean $( \pm S D)$ per transect Simpson's diversity index among seasons

The model that best explained species diversity included site and diversity of macroalgae with the interaction between them (Table 4.2). Note that the next best models included effects of site and macroalgae by itself. Those that include season had the highest AIC values (Table 4.2)

Table 4.2 Summary of model selection analysis and AIC terms that fits of three studied parameters to explain Simpson's diversity index (per transect). In bold the lowest AIC score

\begin{tabular}{lcccc}
\hline \multicolumn{1}{c}{ Terms } & \multicolumn{4}{c}{ Fish Species Diversity } \\
& Rank & AIC & $\Delta$ AIC & AIC w \\
\hline 1. Site & 3 & -64.99 & 3.16 & 0.11 \\
2. Season & 7 & -61.31 & 6.84 & 0.05 \\
3. Macroalgae & 2 & -65.79 & 2.37 & 0.16 \\
4. Site + Season & 8 & -60.20 & 8.60 & 0.01 \\
5. Site + Macroalgae & 5 & -63.66 & 4.49 & 0.01 \\
6. Macroalgae + Season & 6 & -61.31 & 7.96 & 0.01 \\
7. Site + Season + Site X Season & 9 & -59.46 & 8.70 & 0.01 \\
8. Site + Macroalgae + Site X & $\mathbf{1}$ & $\mathbf{- 6 8 . 1 6}$ & $\mathbf{0 . 0 0}$ & $\mathbf{0 . 5 5}$ \\
Macroalgae & & & & \\
9. Season + Macroalgae + Macroalgae & 4 & -63.68 & 4.47 & 0.11 \\
X Season & 10 & -58.12 & 10.04 & 0.00 \\
10. Site + Season + Macroalgae & & & & \\
\end{tabular}


4.4.4 Substratum associations with reef fish abundance

Significant associations between different fish species and habitat species were evidenced. The redundancy analysis (RDA) and further the permutation test revealed significant associations between substratum species and the eleven fish species analyzed (pseudo $\mathrm{F}=2.0 ; p$-value $=0.01$ ). These associations did not change among sites and seasons (pseudo $\mathrm{F}=1.3 ; p$-value $=0.20$ ).

Abundance of reef fish assemblage was influenced by the presence of different substratum species. Associations were present between fish and different substrata (Fig. 4.6). Ecklonia radiata alone contributed significantly to different associations (pseudo $\mathrm{F}=3.7$; $p$-value $=0.01$ ) with Pseudolabrus miles and slightly with Forsterygion maryannae. Abundance of Odax pullus is driven by single cannopies of $E$. radiata and with mixed canopies of E. radiata and $C$. flexuosum. This habitat had important contribution (pseudo $\mathrm{F}=5.0$; $p$-value= 0.005) and was associated with $N$. fucicola (Fig. 4.6). F. varium is associated to some extent (pseudo $\mathrm{F}=2.2 ; p$-value $=0.04$ ) with no-macroalgal habitats (Fig. 4.6). Fosterygion lapillum is associated with a cluster of mixed macroalgae (Fig. 4.6). 


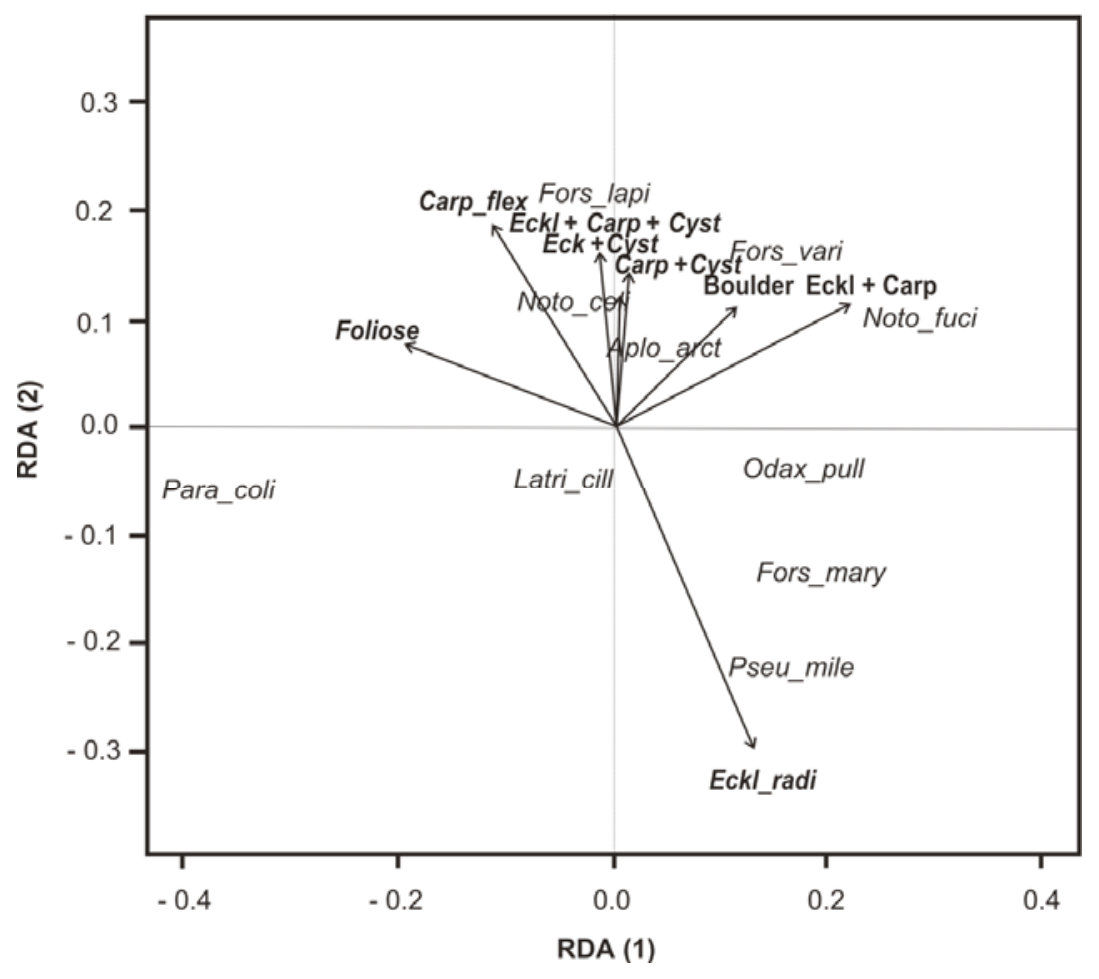

Figure 4.6 Redundancy Analysis (RDA) ordination plots of the most abundant fish species over the sampled sites and seasons. Vectors represent 7 categories of benthic substratum occurrence and centroids of fish species abundance. The lengths of vectors represent the strenght of the association with each fish species. Species names are formed with first our letters of the genus and species, these apply to all biplots.

When habitats were grouped as a proxy for habitat heterogeneity, single and mixed canopies showed more strong associations with fish species (Fig. 4.7). The four wrasses, most of the triplefins, and O. pullus were associated with single laminareal and mixed canopies (Fig. 4.7). The blue cod, P. colias, showed clear association with no-macroalgae dominated habitats and did not differ in terms of numerical abudance among different substratum (Fig. 4.7). Species $F$. varium and L. cilliaris, in turn, showed no clear associations as there are in the centrer of the biplots (Fig. 4.7). 


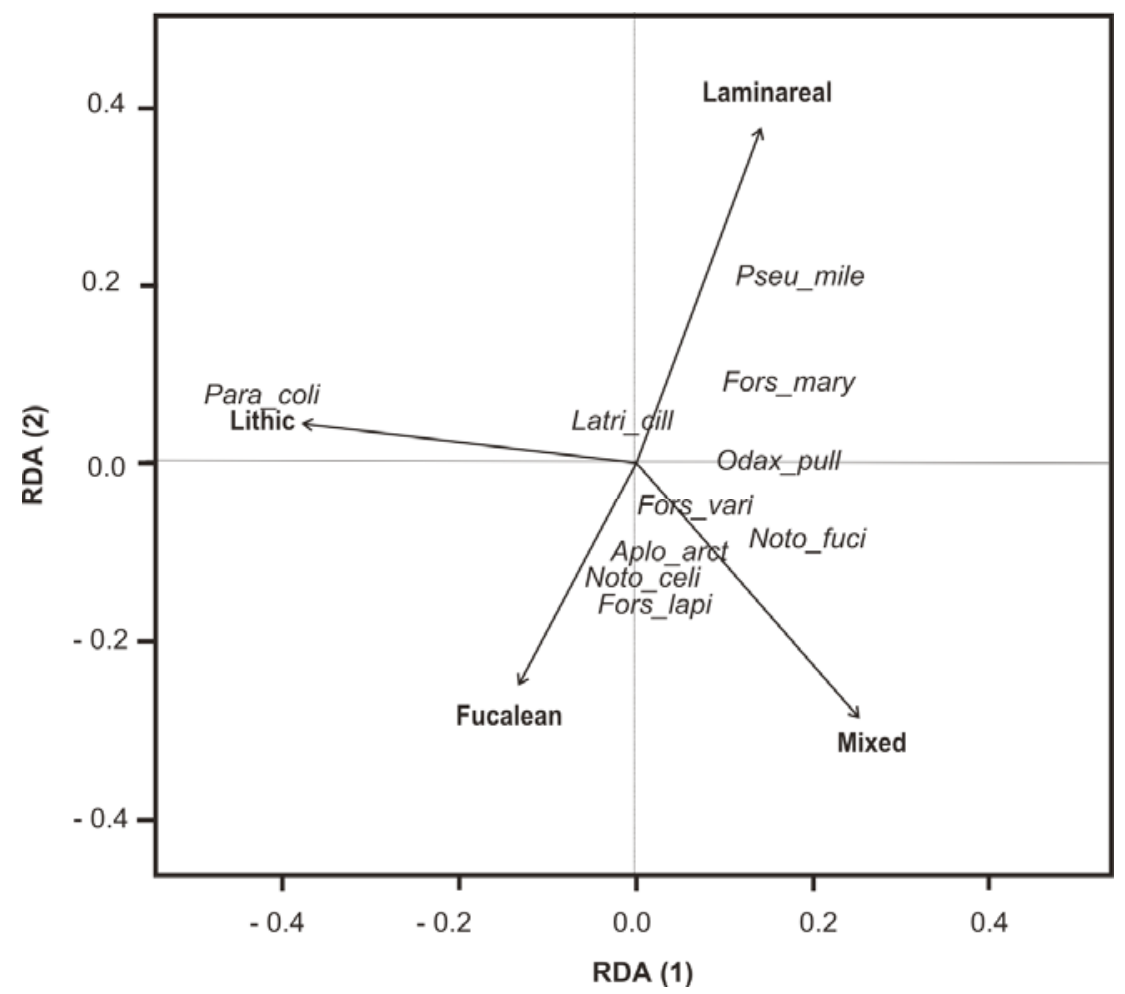

Figure 4.7 Redundancy Analysis (RDA) ordination lots with grouped in four habitat categories and the ten most abundant fish species.

Single laminarean and mixed canopies showed more abundance of wrasses and Odax pullus than single fucalean or no-macrolagae patches (Fig. 4.8). A similar tendency can be evidenced by the triplefins. On the contrary, grouped habitats hold similar amounts of sand perches (Pinguipedidae), but their abundance was less variable in lithic habitats (Fig. 4.8) 


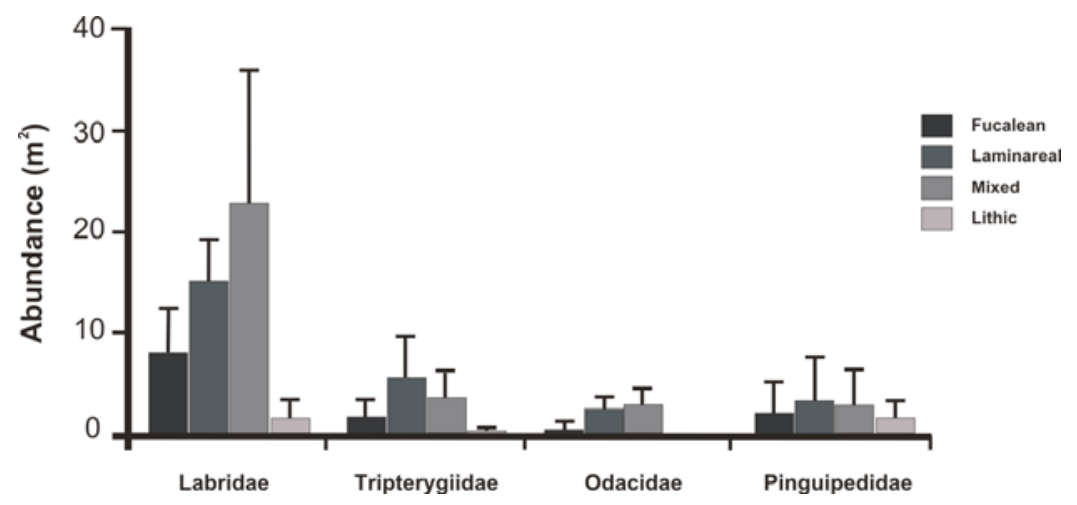

Figure 4.8 Mean abundance per $\mathrm{m}^{-2} \pm(2 S E)$ of the four most abundant families over four habitat groups.

\subsubsection{Substratum associations with reef fish biomass}

Substratum species sustained different amounts of biomass of reef fishes. Kelp beds of E. radiata contributed to reef fish biomass (pseudo $\mathrm{F}=2.2 ; p$ value $=0.05$ ). On the contrary, mixed canopies were driving the biomass of the wrasses, P. miles and N. fucicola and also the odacid, O. pullus (Fig. 4.9) and these associations were important (pseudo $\mathrm{F}=6.9, p$-value $=0.01$ ).

The species such as $C$. spectabilis, $C$. lepidoptera, $M$. lineatum which contributed in biomass to the fish assemblages at Kapiti are not shown as they were in the center of the biplots indicating no clear habitat associations (Fig. 4.9). 


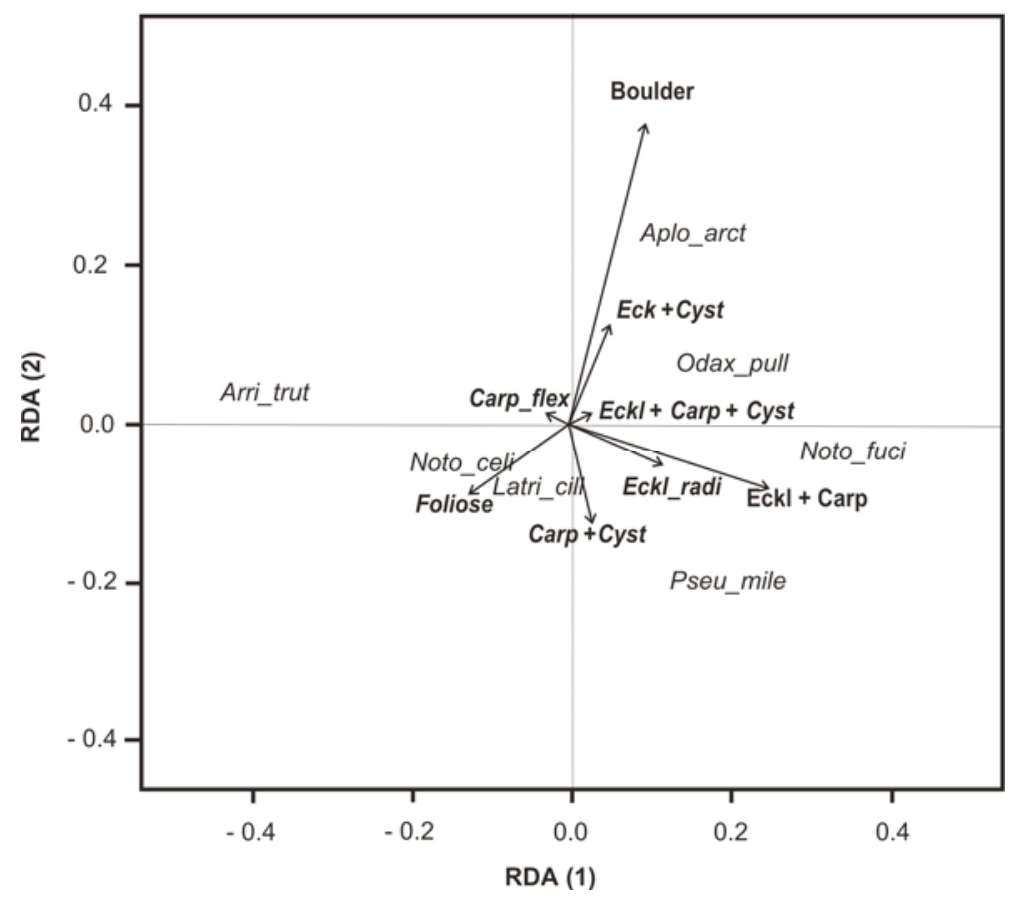

Figure 4.9 Redundancy Analysis (RDA) ordination lots with 7 substratum categories and the ten most important fish species in terms of wet weight.

Mixed canopies were associated with N. fucicola. A tendency of this association was evidenced by $O$. pullus, C. spectabilis, and P. miles (Fig. 4.10). Single Fucaleans were clearly associated with $F$. lapillum. The pelagic species, Arripis trutta was more associated with non-heterogeneous habitats a tendency present with $N$. celidotus (Fig. 4.10). 


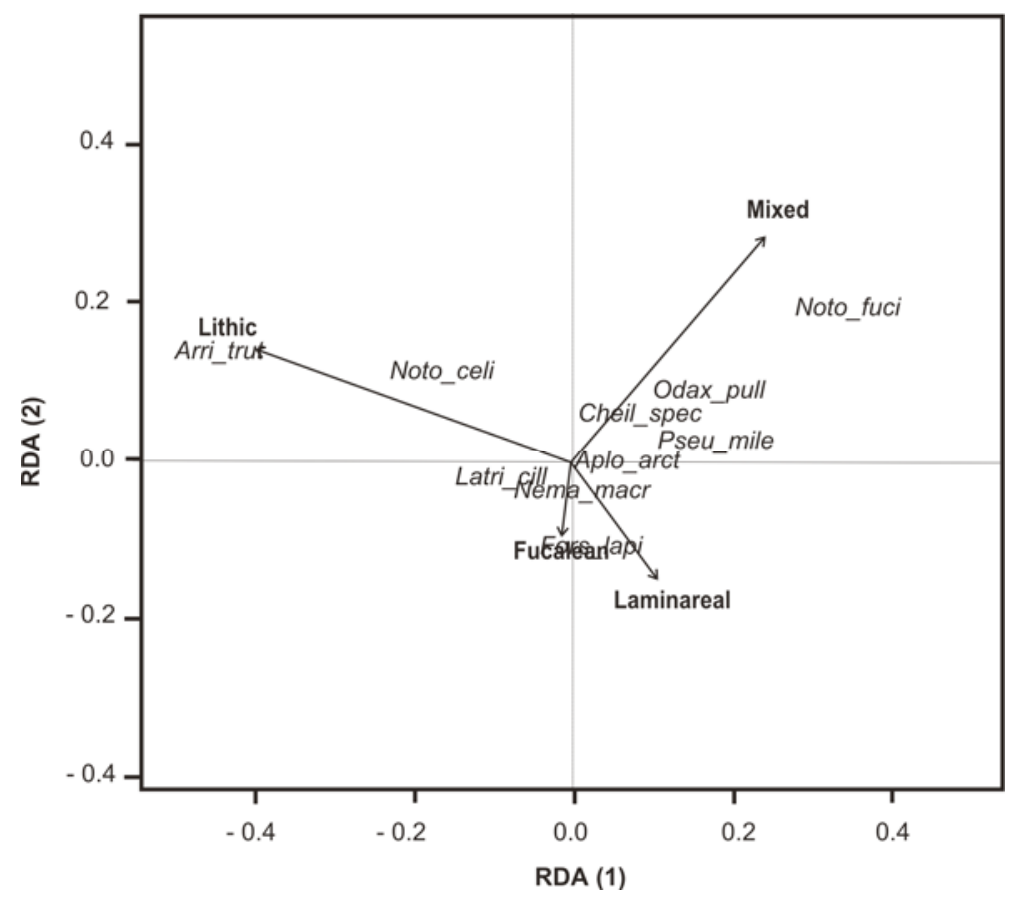

Figure 4.10 Redundancy Analysis (RDA) ordination lots with grouped habitats and the ten most weighty fish species

Laminareal and mixed canopies were the habitats that sustained the most fish biomass per $\mathrm{m}^{2}$ (Fig. 4.11). Slight differences were evidenced between these habitats: both contributed similarly to the biomass of wrasses while laminareals sustained more members of the family Latridae and mixed canopies more odacids (Fig. 4.11). No clear differences were evidenced among different habitats and P. colias (Fig. 4.11). No-macroalgae, lithic, sustained less amount of biomass (Fig. 4.11). 


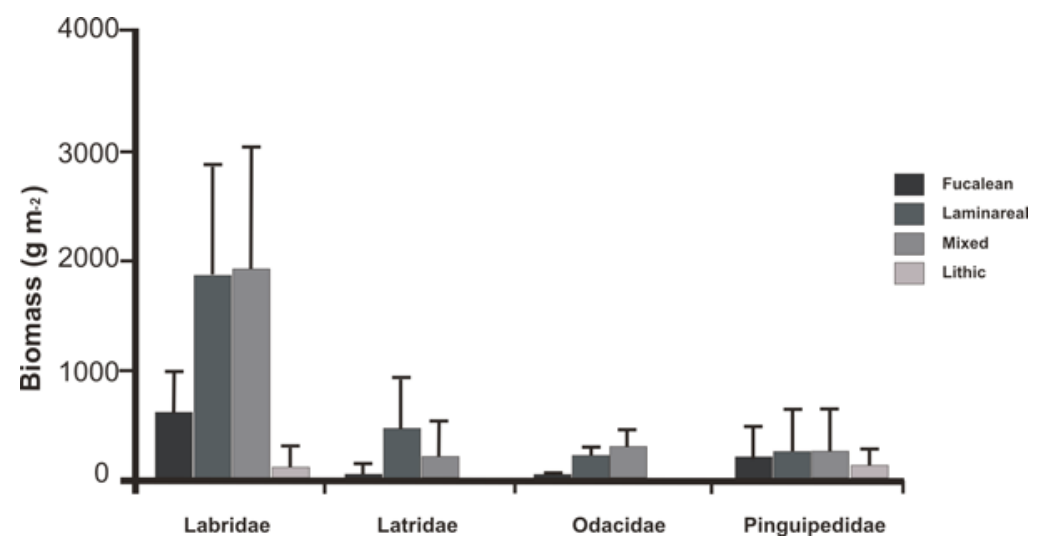

Figure 4.11 Mean biomass ( $\mathrm{g}$ wet weight per $\left.\mathrm{m}^{-2}\right) \pm(2 S E)$ of the four most important families among different habitat groups

\subsection{Discussion}

Resource partitioning among fishes and fish assemblages may be a common feature in temperate algal-dominated ecosystems. Results from this study suggest that (a) differences in macroalgal composition evidenced at different study sites explained patterns in reef fish diversity; (b) the associations between substratum species and with different levels of habitat heterogeneity were persistent throughout the different seasons surveyed; (c) fish biomass changed through seasons and sites, suggesting a pelagic transitory component of fish assemblages; and (d) different levels of heterogeneity (estimated by the composition of the substratum as no-macroalgae, single macroalgal stand and mixed canopies) drive patterns in fish abundance and biomass.

Macroalgal structures dominate the substratum at all sites. There was a substantial difference in the composition of the alga-dominated substratum among sites. Studies elsewhere have emphasized the large variability in algal assemblages in subtidal environments (Dayton 1985b). Organizational processes 
explaining these changes are dissimilar in the literature. Some studies attribute the variation in algal assemblages to the grazing impacts of urchins (Lawrence 1975) while others indicate no changes in algal-assemblage composition due to grazing (Foster and Schiel 1975). Regulatory processes mediated by top-down control offer another interesting explanation for the variation in the abundance of algal stand. These have been reported for mammals (Estes et al. 1978) and fishes (Cowen 1983) which stabilize the strong impacts of grazers (i.e., urchins) on seaweed communities. Variation can also depend on productivity which also varies at different geographic scales (Connell and Irving 2008). Algal composition may also arise from competition between macroalgal stand (Santelices and Ojeda 1984).

Variation in terms of habitat composition at Kapiti Island may predict the different fish species, an observation which is consistent in coral reef $(\mathrm{O}$ hman et al. 1997) and temperate communities (Holbrook et al. 1990a). Two possible explanations can be put forward here (1) associations between reef bottom are coupled with different feeding habits for fishes; and (2) small species such as triplefins tend to use different habitats than larger reef fishes, thus decreasing the co-occurrence of fishes with increasing size similarity. In terms of trophichabitat associations, fishes partition their habitat associations according to different feeding habits. The biomass of the piscivorous kahawai, Arripis trutta, was more associated with no-macroalgae habitats. The abundance of herbivores, grazers and microcarnivores have association with substratum species. The herbivore Odax pullus is associated with single laminarean and mixed canopies, species that are consumed by this species; while A. arctidens is preferentially found in boulders and with fucalean species, where it presumably feeds on red 
algae (Choat and Clements 1992). Carnivorouos fishes such as the wrasses Pseudolabrus miles and Notolabrus fucicola were associated with single laminarean (E. radiata) and mixed algae respectively. $N$. celidotus, in turn, showed a more generalist response as it was more associated with mixed algae and boulders with foliose algae. Clear differential habitat use was evident for the microcarnivorous clade such as triplefins. This partitioning may be due to their size suceptibility to predation (e.g., the blue cod abundance, a potential predator of young triplefins, were more associated with no-macroalgae treatments). In general, small-sized fishes (i.e., triplefins) are located in areas with high available refuge, heterogeneous habitats in shallow subtidal environments (Hixon and Beets 1993). This pattern contrary to intertidal habitats where small sized fishes often occur in open areas as opossed to more heteogeneous ones where their predator occur (Rojas and Ojeda 2010).

Biomass indicated changes in the fish assemblage composition throughout seasons and sites. Important contributions of pelagic and planktivorous species to the seasonal variability of total biomass was evidenced. Changes occurred over summer and spring when most of pelagic species frequented the near-shore habitats of Kapiti Island. Most of these species are transitory with little or no association with different habitat types. On the contrary, habitat composition has a more substantial influence than season for the other components (benthic-demersal) of the fish assemblages. This is congruent with other studies that incorporate few seasonal changes. Such studies emphasize the importance of the environmental differences among habitat types (Valesini et al. 2004). Valesini et al. (2004) suggest that spatial differences in the composition of marine fauna can be explained by heterogeneity of the 
physical environment such that a particular response between associated fish fauna and habitat can be evidenced.

The present study stresses the importance of large-brown macroalgae habitats as heterogeneous structures with site specific differences. Consistent patterns were identified between the different levels of heterogeneity and the abundance and distribution of fish species between sites and seasons. A clear partition of habitat use was present among different members of the fish assemblage at Kapiti Island. Further analysis of this data should be directed towards the application of niche-based models and to understand how habitat types affect the "fitness" of a species. For instance, strong partitioning by depth and habitat has been identified among the triplefin assemblages, which may have contributed to the diversification and speciation of triplefins (i.e., 17 species) on New Zealand's shores (Wellenreuther et al. 2007). 


\section{CHAPTER 5}

\section{Disentangling the effects of macroalgae on the abundance of temperate reef}

\section{fishes}

\subsection{Abstract}

Habitat heterogeneity may mediate the relationship between organisms and their environment. However, the demographic and behavioural responses of organisms to different sources of habitat heterogeneity (e.g., structural complexity, composition) may vary, and consequently, different sources of heterogeneity may interact to shape the abundance of individual species and composition of a species assemblage. I focused on habitat-forming macroalgae, and conducted a set of laboratory experiments to determine the macroalgal preferences of two species of temperate reef fish. In a subsequent field experiment, I manipulated macroalgal heterogeneity at two sites in Wellington, New Zealand, to determine the relative importance of different sources of habitat heterogeneity to the abundance of locally common reef fishes. Specifically, I manipulated three sources of habitat heterogeneity: (1) macroalgal species identities; (2) combinations of macroalgal species (i.e., mixed stands); and (3) macroalgal density. The laboratory experiments indicated that two common fishes readily distinguish and exhibit preferences for different forms of macroalgae. The field experiment indicated that the abundance of reef fishes varied as a function of experimentally induced habitat heterogeneity. I detected within-species variation in responses to macroalgal composition (suggesting ontogenetic habitat shifts), and larger-scale influences on the abundance of reef 
fishes (effects attributable to location). Macroalgal identities affected the abundance of 7 of 15 reef fish species. Composition of macroalgal stands shaped the abundance of 5 of 7 reef fish species, and the overall structure of the local fish assemblage. Generally, heterogeneity in vegatative structures appeared to increase breadth of habitat use for reef fishes. This work suggests strong behaviourally mediated linkages between the abundance of reef fishes and the composition of vegetative structures in a temperate, macroalgal-dominated ecosystem.

\subsection{Introduction}

Habitat heterogeneity is widely viewed as a precursor to biological diversity. Homogenization of ecological systems by human activities (e.g., intensive fishing or farming) is often correlated with a progressive decrease in biodiversity (Loreau et al. 2004). This has led some workers to suggest that the protection and enhancement of habitat heterogeneity should form the basis for conservation and management of ecological communities (Fuhlendorf et al. 2006). However, "habitat heterogeneity" is a term that potentially encapsulates a wide range of environmental variables (e.g., composition, patch or "grain" size, structural complexity), and these individual variables may act separately or in combination to shape the behavioural and/or demographic responses of individual species. Moreover, individual species (or age-classes within a species) may vary in their responses to habitat heterogeneity. Consequently, a more sophisticated understanding of relationships between habitat heterogeneity and species responses may be desirable. 
In temperate marine environments, brown macroalgal forests are known to influence the abundance and distribution of associated macrofaunal assemblages (Dayton 1985b; Schiel and Foster 1986; Graham 2004). The structure and composition of macroalgal stands (and the morphology of individuals for a given species of macroalgae) can vary considerably, often as a function of local environmental conditions (Schiel and Foster 1986). Understanding how algal-associated organisms such as reef fishes respond to local-scale variation in the structure of macroalgal communities requires recognition of how different components of macroalgal habitats (e.g., species identity, structural complexity, density) potentially interact to influence the abundance of a dependent species.

Vegetative structures of macroalgae may provide a range of "services" to fish, including food (or feeding sites) and refuge from potential predators. Fish and other organisms may use the same vegetative structures of an individual alga for different purposes, or they may partition their activities among different components of the alga (e.g., fronds may be used for refuge/shelter, holdfasts for feeding sites; (Steneck et al. 2002; Christie et al. 2007)). In addition, the role and importance of specific vegetative features to fishes may vary with their ontogeny, and/or depend upon local environmental conditions (e.g., degree of wave exposure, presence of predators, (Taylor and Cole 1994; Christie et al. 2007). Specific macroalgal traits may act separately or in synergy with others to shape patterns of distribution and abundance of fishes.

Experiments that attempt to partition and explore the effects of different components of habitat heterogeneity (e.g., the relative importance of habitatforming species' identities, densities, and multi-species composition) are rare 
(but see Benedetti-Cecchi 2004). Consequently, important complexities that may underlie relationships between temperate reef fishes and macroalgal habitats remain largely unexplored.

Given the strong effects of habitat attributes on fitness of dependent species (described above), we expect to find that reef fishes discriminate among different components of habitat heterogeneity (i.e., presence/absence of macroalgae, macroalgal species identity, and the composition of algal stands). Consequently, we hypothesize that (1) habitat heterogeneity will shape the distribution and abundance of individuals over small spatial scales; (2) reef fishes may differ in their responses to particular sources of habitat heterogeneity (and these responses may depend upon local environmental contexts); and consequently, (3) different macroalgal habitats will support different species assemblages.

\subsection{Methods}

5.3.1 Laboratory experiment - Capacity for behaviourally mediated habitat preference

To determine whether common fish in our study system exhibit preferences for different macroalgal habitats, I conducted a choice experiment in a large outdoor recirculating tank ( $9 \times 6 \times 1.2 \mathrm{~m}$ depth) at the National Institute of Water and Atmospheric Research (NIWA), Wellington, New Zealand. I estimated behavioural preferences of two species of locally common reef fish (Notolabrus celidotus and N. fucicola) for five different benthic substrata.

Notolabrus celidotus (commonly known as the "spotty") and N. fucicola (the "banded wrasse") are reef fishes of the family Labridae, and among the most 
common inhabitants of reefs in the Wellington region. Both species feed upon invertebrates, with N. fucicola also consuming other small fishes (Russell 1983; Denny and Schiel 2001; Francis 2001). Notolabrus celidotus and N. fucicola reach total lengths (TL) of up to 300 and $600 \mathrm{~mm}$ respectively (Francis 2001). I collected 10 small $N$. celidotus $(\mathrm{TL}<150 \mathrm{~mm}), 10$ large $N$. celidotus $(\mathrm{TL}>150$ $\mathrm{mm}$ ), and 10 large $N$. fucicola (TL $>150 \mathrm{~mm}$ ) using baited traps. All captured individuals were transferred to indoor concrete holding tanks and allowed to acclimatise for at least $48 \mathrm{~h}$ prior to their use in experimental trials.

Initial field observations led me to identify and select three locally common species of macroalgae as potentially important habitats for reef fishes in our area: Macrocystis pyrifera, Carpophyllum maschalocarpum, and Cystophora retroflexa. These three algal species are abundant on shallow subtidal reefs of Wellington harbour (e.g., Kau Bay) and the adjoining (and comparatively waveexposed) south coast (e.g., Island Bay, see Fig. 5.1a). In the study area, $M$. pyrifera (Fig. 5.1b) can reach up to $6 \mathrm{~m}$ in stipe length, and often forms large surface canopies aided by air-filled pneumatocysts; $M$. pyrifera provides shade and vertically-structured habitat through the water column. Carpophyllum maschalocarpum (Fig. 5.1c) has flattened blades with ellipsoid vesicles. Cystophora retroflexa (Fig. 5.1d) has a conical holdfast, a zig-zag stipe, rounded blades, and globose vesicles. Relative to M. pyrifera, C. maschalocarpum and $C$. retroflexa are smaller bushy-type macroalgae, reaching up to 0.5 to $1.5 \mathrm{~m}$ in stipe length (for further details see Adams 1997). In the Wellington region, $M$. pyrifera, C. maschalocarpum and C. retroflexa reach mean densities of $3.8( \pm 1.6$ $\mathrm{SD}), 4.1( \pm 2.4 \mathrm{SD}), 1.0( \pm 1.5 \mathrm{SD})$ stipes per $\mathrm{m}^{2}$ respectively. I collected intact seaweed specimens (and associated epifauna) of all three species that were 
attached to small boulders using an open mesh collecting bag $(0.5 \mathrm{~mm}$ mesh size). I attempted to minimize losses of associated epifauna by transferring seaweeds to tanks of seawater immediately after collection. I maintained specimens in outdoor tanks supplied with flow-through seawater, and these storage tanks were covered with black $0.5 \mathrm{~mm}$ mesh shade cloth to approximate light conditions from the sites of collection.

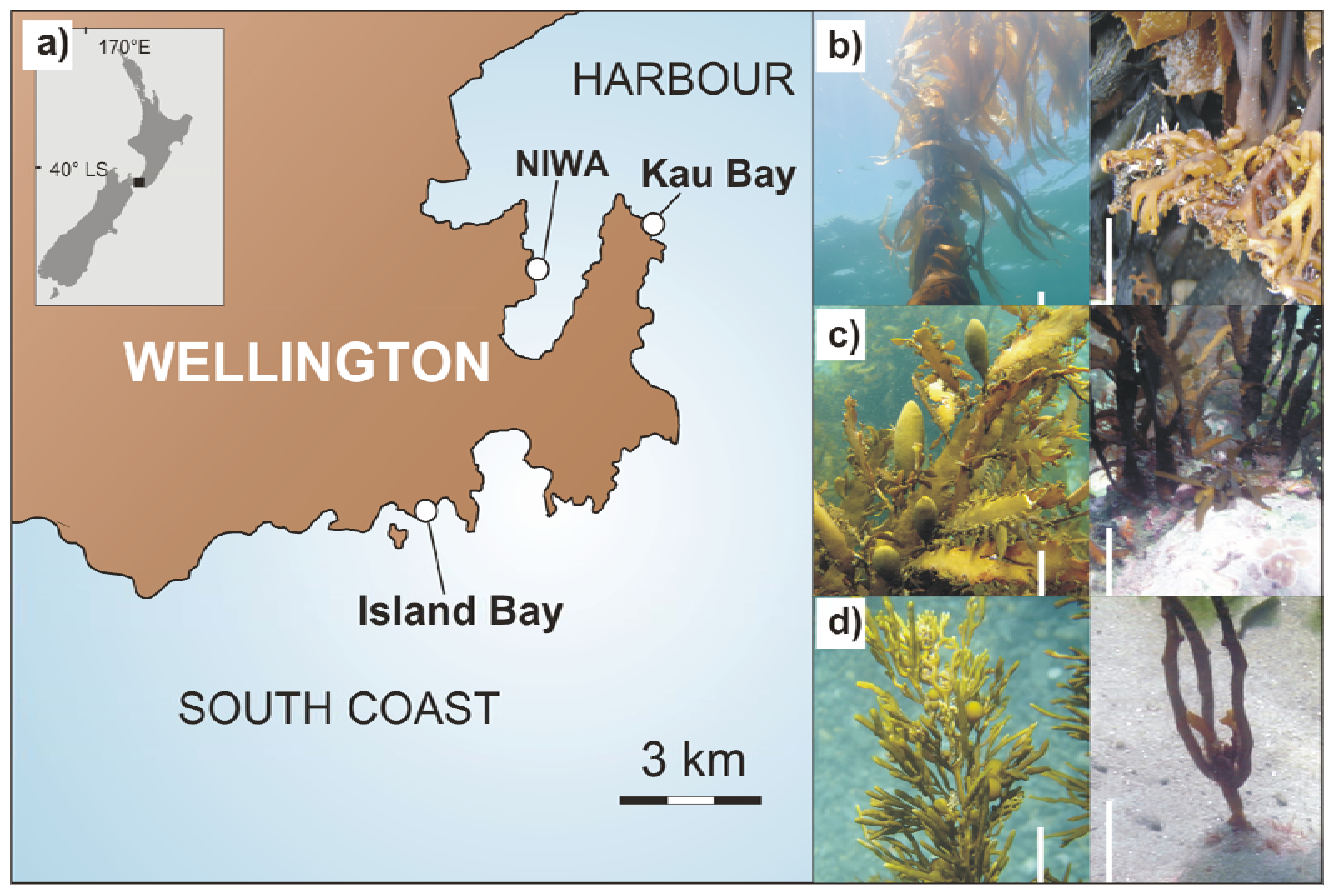

Figure 5.1 a) Map giving locations of the study sites in Wellington Region, New Zealand; photographs of blades and their holdfasts for: b) Macrocystis pyrifera (Laminareales), c) Carpophyllum maschalocarpum (Fucales), and d) Cystophora retroflexa (Fucales). Scale bar $=300 \mathrm{~mm}$.

The experimental design consisted of five treatments that I established within a single large tank: (1) four individuals of $M$. pyrifera, (2) six individuals of $C$. maschalocarpum, (3) six individuals of $C$. retroflexa, (4) 6-7 boulders (30 to $50 \mathrm{~cm}$ diameter) with no macroalgae, and (5) a control (an identified patch within the tank with no macroalgae or rocks). Different numbers of individuals per species were used to balance the biomass among treatments, and also reflected natural densities found in the field. Treatments were arrayed in a 
randomized order in a roughly circular pattern and separated from one another by $3 \mathrm{~m}$. Experimental trials consisted of the release of a single focal individual of either $N$. celidotus or $N$. fucicola in the middle of the tank (i.e., equidistant from the five treatments). The position of the focal individual was assessed (from a viewing platform above the tank) 60 minutes after release, and scored as a "choice" for one of the five available habitats, or else "no choice" (i.e., when the focal individual was not clearly associated with any of the five experimental patches within the tank). Following each trial, the focal individual was removed from the experimental tank, and the positions of habitat treatments within the tank were reshuffled in preparation for the next trial. Trials (i.e., focal individuals) were replicated in time from February through May 2007, and occurred between 10:00 am to 12:00 pm. Algal specimens were replaced periodically (as tissues degraded) over the course of the experiment. Focal individuals were used in trials only once. I assessed behavioural preferences for a total of $20 \mathrm{~N}$. celidotus (10 of them juveniles, i.e., $<150 \mathrm{~mm}$ in standard length, SL) and 10 N. fucicola.

I analyzed the preferences of $N$. celidotus (juveniles and adults separately) and $N$. fucicola (adults only) for the 5 choices (treatments) in our tank study using a randomization test. We used Bray-Curtis distances (BCDs) between observed and expected values of fish preference to each macroalgal treatment as our test statistic using the following formula:

$$
B C D=\frac{\sum_{n=5} \mid \text { observed }- \text { expected } \mid}{\sum \text { observed }+\sum \text { expected }}
$$


High values for $\mathrm{BCD}$ indicate preferences of any of the five different treatments $(n=5)$, and $p$-values were constructed by calculating the proportion of values in the null distribution (generated from 10000 permutations of the data) that were greater than observed by BCD (I evaluated significance for $\alpha=0.05$ ).

5.3.2 Field experiment - Effects of habitat heterogeneity on the abundance of reef fishes and the local fish assemblage

I manipulated macroalgae presence, density, and composition to evaluate the separate and synergistic effects of these sources of variation on the abundance and assemblage structure of reef fishes. From December 2006 to February 2007, I established and maintained an experimental grid of habitat patches (using the same set of algal species described for tank experiments above) at each of the two sites in the Wellington region (Kau Bay and Island Bay, Fig. 2.1). Sites differed in wave exposure, temperature, and the distribution and relative abundance of fishes and macroalgal species. Kau Bay, located within the comparatively sheltered Wellington Harbour, is exposed to northerly winds and protected from southerly swells, with recorded sea temperatures of $17.2{ }^{\circ} \mathrm{C}$ ( \pm 0.9 SD) during the study period. At Kau Bay, all of the macroalgal species used in the study were locally abundant, and experimental patches were created (described below) from locally obtainable macroalgae. At Kau Bay, shallow sea bottom $(0-6 \mathrm{~m})$ is composed of mixture of rock, cobbles, and small boulders at depth more than 6-7 $\mathrm{m}$ the seafloor is mainly composed of small cobbles and fine sand grain. The second study site, Island Bay, is partially protected from periodic large southerly swells by a small offshore island (Taputeranga Island), and during the study period had average sea temperatures of $15.2^{\circ} \mathrm{C}( \pm 1.5 \mathrm{SD})$. 
Both C. maschalocarpum and C. retroflexa are abundant at Island Bay, although M. pyrifera was present in only low abundance (consequently, construction of experimental habitat patches required supplemental algal material transplanted from nearby sites). The seafloor at Island Bay is characterized by having small boulders and cobbles at all depths.

At each site, I used nylon lines to demarcate a grid of 17 by $32 \mathrm{~m}$ between 4 and $8 \mathrm{~m}$ depth. Grids were used to position 36 habitat patches in a randomised block design. Each patch measured $4 \mathrm{~m}^{2}(2 \mathrm{~m} \times 2 \mathrm{~m})$, and was separated from adjacent patches within the grid (or ambient reef habitats for patches located along a grid edge) by $1.5 \mathrm{~m}$ of rock or sand substratum cleared of all macroalgae. Grids consisted of 4 transects parallel to shore (along relatively uniform depth strata, i.e., blocks). Along each transect I randomized placement of the following nine habitat treatments: (1) no macroalgae; (2) $1 \mathrm{X}$ ambient density M. pyrifera; (3) 1X ambient density C. maschalocarpum; (4) 1X ambient density $C$. retroflexa; (5) $2 \mathrm{X}$ ambient density $M$. pyrifera; (6) $2 \mathrm{X}$ ambient density C. retroflexa; (7) 1X M. pyrifera + 1X C. maschalocarpum; (8) 1X M. pyrifera +1 X C. retroflexa; (9) 1X C. maschalocarpum +1 X C. retroflexa. The number of individuals used to construct "ambient densities" varied among algal species, and these approximated global averages for the Wellington region. Specifically, I used as our 1X treatments: 4 individuals for M. pyrifera, and 6 individuals for both $C$. maschalocarpum and $C$. retroflexa, in order to standardize the biomass among species (see Table 5.1 for further details). Each patch was constructed by placing the seaweed (with holdfast attached to small boulders) and maintained by replacing missing seaweeds during the experiment. 
The habitat treatments were designed to simulate components of habitat heterogeneity that we hypothesized a priori to be potentially important determinants of fish abundance. This included: treatment identities (as above), species richness (SR: 3 levels, either: no, single, or mixed macroalgal species), biomass (0, 1 and 2), and site (2 levels, Kau Bay or Island Bay). The overall experimental design was unbalanced (due to logistic constraints) and partially hierarchical to facilitate important contrasts between single- and mixed stands of macroalgae of comparable canopy densities (see Table 5.1).

Table 5.1 Design of field experiment with nine habitat treatments and four replicates of each treatment. Factors include: a) Treatment identities: ( 9 levels) and numbers of macroalgae individuals manipulated (n) b) (SR): Species richness (3 levels), and c) Site (two levels). Treatments were applied to $4 \mathrm{~m}^{2}$ habitat patches. Treatment identities are abbreviated as: NA, no macroalgae; MP, (Macrocystis pyrifera); CM (Carpophyllum maschalocarpum); CR, (Cystophora retroflexa); $2 \mathrm{X}$ ambient MP, double density of $M$. pyrifera; $2 \mathrm{X}$ ambient $\mathrm{CR}$, double density of $C$. retroflexa; $\mathrm{MP}+\mathrm{CM},(M$. pyrifera and $C$. maschalocarpum $) ; \mathrm{MP}+\mathrm{CR},(M$. pyrifera and $C$. retroflexa $) ; \mathrm{CM}+\mathrm{CR},(C$. maschalocarpum and C. retroflexa).

\section{Treatments}

\begin{tabular}{lcccccc} 
Factors & $\mathbf{1}$ & $\mathbf{2}$ & $\mathbf{3}$ & $\mathbf{4}$ & $\mathbf{5}$ & $\mathbf{6}$ \\
\cline { 1 - 2 } $\begin{array}{c}\text { a) Treatments identities } \\
\text { Biomass }\end{array}$ & NA & MP & CM & CR & 2X MP & 2X CR \\
(n) & 0 & 1 & 1 & 1 & 2 & 2 \\
$\begin{array}{l}\text { b) Species richness (SR) } \\
\text { c) Sites }\end{array}$ & No algae & \multicolumn{5}{c}{ One algal species } \\
\end{tabular}




\section{Treatments}

\begin{tabular}{|c|c|c|c|}
\hline Factors & 7 & 8 & 9 \\
\hline a) Treatments identities & $\mathrm{MP}+\mathrm{CM}$ & $\mathrm{MP}+\mathrm{CR}$ & $\mathrm{CM}+\mathrm{CR}$ \\
\hline Biomass & 2 & 2 & 2 \\
\hline (n) & 10 & 10 & 12 \\
\hline b) Species richness (SR) & \multicolumn{3}{|c|}{ Two algal species } \\
\hline c) Sites & \multicolumn{3}{|c|}{ Island Bay and Kau Bay } \\
\hline
\end{tabular}

I sampled fish distribution and abundance across our experimental grids the day before (day zero) and the day after the construction of the experimental plots, and then at weekly intervals thereafter for seven weeks. Using SCUBA, I recorded the identity and size of all observed fishes within a given habitat patch for a period of two minutes. All surveys were conducted between 10:00 and 13:00 $\mathrm{h}$ to minimise potentially confounding effects of diel variation in fish behaviour. On each sample date, and following stormy conditions (which detached/moved seaweeds and boulders outside the treatment grid), I maintained experimental treatments as required (by repositioning and/or replacing lost or damaged seaweed individuals). I completed seven days of fish surveys at Island Bay and six days at Kau Bay over the course of this study period.

I used two separate analyses to explore sources of variation in fish distribution and abundance attributable to habitat heterogeneity. First, I evaluated variation in fish abundance across the 9 treatment identities (Table 5.1). In a secondary analysis, I pooled several treatments to explore the effect of species richness (SR, three levels: no algae present, 1 algal species, or 2 algal species) (see Table 5.1). Both sets of analyses also included study site (Kau Bay or Island Bay) as a fixed effect, and sampling day as a random effect (I excluded 
counts made prior to the manipulation for these analyses). I used linear mixed models to conduct statistical tests. Linear mixed models can be used to describe relationships between a response variable and covariates in data or factors in association with a random effect (Pinheiro and Bates 2000; Bolker et al. 2009). I used this test to estimate the differences in the variation in abundance of a particular reef fish (see below) in a particular treatment (treatment identity) or group of treatments (SR). Such patterns may indicate which components of habitat heterogeneity may be important for a fish species. In this context, a particular treatment (or component of habitat heterogeneity) was deemed to be important to a fish species (and in some instances, patterns were evaluated separately for juveniles and adults) if the fish species' abundance showed little or no variation in the mean abundance during the course of the study. The LMM framework allowed me to consider all factors (fixed and random) that potentially contributed to the structure of the sampling data along the different days (McMahon and Diez 2007). LMM works well for unbalanced data sets (Baayen et al. 2008). Methods for estimating linear mixed effect models have addressed the disadvantages of traditional ANOVA or least square regression equations when using random effects or repeated measures (i.e., reduced statistical power with repeated measures as the number of parameters increases linearly with random factors, reduced power with unbalanced or missing data, and requirements for disparate methods for treating continuous and categorical responses (Pinheiro and Bates 2000; Baayen et al. 2008)). In linear mixed models the random effect describes deviation from the population mean; the individual values of the adjustments made to intercepts and slopes are calculated once the random effects parameters have been estimated. 
Formally, the Linear Mixed model of the present experiment is summarized as:

$y_{i j}=X_{i j} \beta+b_{i}+\varepsilon_{i j}$

where $y_{i j}$ is the observed response of the abundance of particular fish species for observation $\mathrm{j}$ (treatments) on day $\mathrm{i}, X_{i j}$ is the manipulated treatment identities (or SR levels) and the interaction with the study site (Island Bay and Kau Bay) matrix, consisting of columns representing factor contrasts and covariates. $\beta$ represents the mean population coefficient of each treatment (9 levels of treatments identities (i.e., factors) for the first analysis and 3 for SR levels on the second analysis) on different sampling days, $b_{i}$ is a random variable representing the deviation from the population mean abundance for the ith Day, and $\varepsilon_{i j}$ is a random variable representing the deviation in abundance for observation of $j$ on day $i$ from the mean abundance for day $i$.

To complete the statistical model I specify the distribution of the random variables, $b_{i}, \mathrm{i}=1, \ldots, \mathrm{M}$ (random variables, sampling Days in this study, 5 at Kau Bay and 6 at Island Bay) and ${ }^{\varepsilon_{i j}}, \mathrm{i}=1, \ldots, \mathrm{M} ; \mathrm{j}=1, \ldots$, ni $(9$ or 3 levels, treatment identities or SR respectively). I modelled both (random variables from the observations of each treatments and sampling Days) as independent, constant variance, and with mean of zero. The variances are denoted by $\sigma_{b}^{2}$ for the $b_{i}$, or "between-sampling day" variability, and $\sigma^{2}$ for the ${ }^{\varepsilon_{i j}}$, or "within-sampling day" variability. This is summarized in (3)

$b_{i} \sim \mathrm{N}\left(0, \sigma_{b}^{2}\right), \varepsilon_{i j} \sim \mathrm{N}\left(0, \sigma^{2}\right)$ 
Using the linear mixed models, all parameters and interactions were estimated. To reduce the difficulty involved in approximating the degrees of freedom and interpretating the fixed effects parameters independently from the random effect (Baayen et al. 2008) we used Markov chain Monte Carlo (MCMC) simulation. Using MCMC, I estimated the posterior distribution of the parameters in order to estimate the highest posterior density (HPD) interval (see below). MCMC is an algorithm that approximates the posterior probability distribution of the parameters by generating samples from a Markov chain whose stationary distribution is precisely the posterior distribution of the parameters. This is achieved by proposing candidate values using repeating Monte Carlo simulations from a specified transition probability and accepting or rejecting these values with a given probability (the Metropolis-Hastings acceptance ratio), which is based on the conditional likelihood of the model given the candidate parameter values. After sufficient draws, this procedure will allow the Markov Chain to reach its stationary distribution, and any samples drawn from there on will be from this distribution (see Andrieu et al. 2003 for details). Specifically, MCMC sampled the conditional distributions of parameter subsets in a cycle (e.g., the variance), thus allowing the variation in all remaining parameters (e.g., fixed effects, random effects) to be reflected in the distribution of the parameter of interest (Andrieu et al. 2003; Baayen et al. 2008). I cycled through these steps (described above) for 10000 iterations and generated a sample from the posterior distribution of each parameter. Further, I obtained the highest posterior density (HPD) interval for each of the fixed and random effects, and used these to evaluate statistical significance. The Bayesian highest posterior density (HPD) intervals were calculated to include $95 \%$ of the probability density. I used HPDs 
because they are the shortest intervals with the given probability content, they do not depend on normality assumptions, and thus provide more powerful and robust statistical inference (Chen and Shao 1999). HPD intervals that do not include zero provide statistical evidence of significant effects of the specified parameters, with the range of intervals indicating the variability of the response (Pinheiro and Bates 2000; McMahon and Diez 2007). All univariate analyses were conducted using the Lme4, Coda, and language-R packages in R 2.10 (R Development Core Team 2008).

To evaluate effects of habitat heterogeneity on local fish assemblages (multivariate community), I used a constrained canonical analysis (CAP) (Anderson and Willis 2003). Specifically, I asked if the abundance of reef fishes varied between sites, treatment identities (TI, no-algae and algal treatments), and sampling dates. The p-values for site effects were obtained using 999 permutations of the experimental data. We used the "ljack-knife" procedure of CAP to determine the allocation success of each level of TI; values $>15 \%$ (the approximate expected value for random assignment) were considered to be evidence of a significant TI parameter (Anderson and Willis 2003). I used nonmetric multivariate ordination (n-MDS) plots based on Euclidean distances to visualise differences in community structure among patch identities (TI). For clarity, I'm presenting only the centroids from Bray-Curtis measures obtained for each TI from a principal coordinate (PCO) analysis (for details see, Terlizzi et al. 2005). 


\subsection{Results}

\section{Laboratory experiment}

Notolabrus fucicola preferentially associated with patches containing either M. pyrifera or C. maschalocarpum (BCD test, $\mathrm{p}<0.01$ ), and avoided patches without macroalgae (Fig. 5.2). In contrast, neither size class of $N$. celidotus showed any statistically detectable macroalgal preference (both BCD test, $\mathrm{p}>0.05)$. Despite the lack of strong statistical evidence for habitat preference, both large and small $N$. celidotus size classes showed a trend for selective habitat use, selecting either $C$. maschalocarpum or $C$. retroflexa patches in 30\% of all trials (Fig. 5.2).

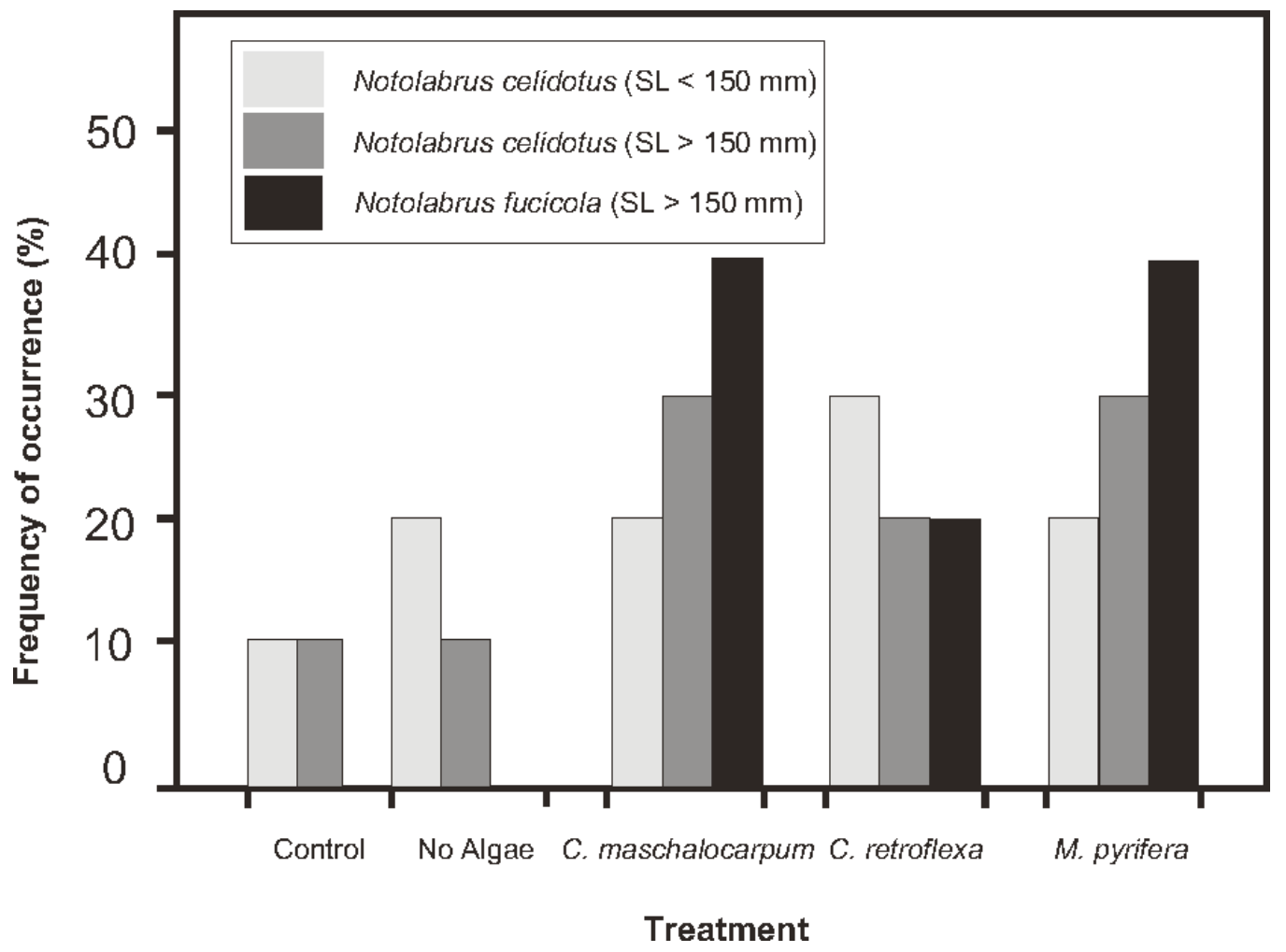

Figure 5.2 Frequency of occurrence (\%) of Notolabrus celidotus (SL $<150 \mathrm{~mm}), N$. celidotus (SL $>150 \mathrm{~mm}$ ), and $N$. fucicola (SL ranges $150-390 \mathrm{~mm}, n=10$ ) in the tank experiments in the five different treatments: 1) an identified empty section of the tank ("Control"); 2) cobbles without attached macroalgae ("No algae"); 3) Carpophyllum maschalocarpum; 4) Cystophora retroflexa, and 5) Macrocystis pyrifer 


\section{Field experiment}

I recorded a total of 16 species of reef fish over the course of our observations; 15 species were observed at Island Bay, while a subset of 6 of these species plus one additional species were sighted at Kau Bay. Though the species richness of reef fishes documented for Island Bay was greater, fish abundance was low relative to Kau Bay. Following the construction of habitat patches, both the abundance and the number of fish species increased by 8 -fold at Island Bay. Abundance peaked on the third and fourth sampling day; richness peaked on the fourth day with 11 species identified (Table 5.2). At Kau Bay, abundance and fish species richness reached a maximum on the last sampling day, abundance was three times higher than on the sampling day prior to the start of the experiment.

Abundances of species such as $N$. celidotus and Forsterygion lapillum were 3 times higher at Kau Bay than at Island Bay throughout the sampled days; together, these two species accounted for more than 55\% of fish censused at Island Bay and more than $94 \%$ of fish censused at Kau Bay (Table 5.2). Notolabrus celidotus was the most abundant species at both sites, with recently recruited juveniles accounting for most of the fish recorded in surveys (Table 5.2). The second most abundant species at Island Bay was Forsterygion maryannae; the second most abundant species at Kau Bay was F. lapillum. More than $50 \%$ of the F. lapillum individuals counted at Kau Bay were recent recruits (evidenced by their size, coloration, and behaviour patterns).

In total, six species (N. celidotus, F. varium, F. maryannae, F. lapillum, Latridopsis ciliaris, and Odax pullus) were common and routinely observed (i.e., on almost every sampling date) across all sampling days at Island Bay after the 
start of our experiment. Four species (N. celidotus, F. lapillum, Parapercis

colias, and N. fucicola) were observed across each sampling date at Kau Bay.

We therefore limited our more detailed statistical analyses to these most abundant species at both sites (i.e., Odax pullus, small and large $N$. celidotus, small and large $F$. lapillum, Parapercis colias, small and large $F$. varium, $N$. fucicola, and F. maryannae).

Table 5.2 Identities of the fifteen species of reef fish sighted in the field experiments. Numbers represent the cumulative counts of fish across all sampling days: Island Bay $(\mathrm{n}=7$ days) and Kau Bay ( $\mathrm{n}=7$ days). For both sites, day 0 represent sampling day before the habitat manipulation. Values in brackets () represent abundance of small (i.e., juvenile) individuals $(\mathrm{SL}<50 \mathrm{~mm}$ for Labridae and Odacidae and $\mathrm{SL}<30 \mathrm{~mm}$ for Tripterygiidae).

\begin{tabular}{|c|c|c|c|c|c|c|c|c|}
\hline \multirow{2}{*}{$\begin{array}{l}\text { Family } \\
\text { Species }\end{array}$} & \multicolumn{8}{|c|}{ Island Bay } \\
\hline & Day 0 & Day 1 & Day 2 & Day 3 & Day 4 & Day 5 & Day 6 & Total \\
\hline \multicolumn{9}{|l|}{ Syngnathidae } \\
\hline Stigmatopora sp. & 0 & 0 & 0 & 0 & 1 & 0 & 0 & 1 \\
\hline Hippocampus abdominalis & - & - & - & - & - & - & - & \\
\hline \multicolumn{9}{|l|}{ Carangidae } \\
\hline Pseudocaranx dentex & 0 & 0 & 0 & 0 & 25 & 0 & 0 & 25 \\
\hline \multicolumn{9}{|l|}{ Latridae } \\
\hline Latridopsis ciliaris & 0 & 2 & 1 & 4 & 7 & 5 & 1 & 20 \\
\hline Nemadactylus macropterus & 0 & - & - & 1 & - & - & - & 1 \\
\hline \multicolumn{9}{|l|}{ Mugilidae } \\
\hline Adrichetta forsteri & 0 & 2 & 0 & 0 & 0 & 0 & 0 & 2 \\
\hline \multicolumn{9}{|l|}{ Labridae } \\
\hline Notolabrus celidotus & $30(19)$ & $207(67)$ & $163(83)$ & $22(20)$ & $131(20)$ & $95(82)$ & $75(70)$ & 723 \\
\hline Notolabrus fucicola & 0 & 39 & 37 & 71 & 20 & $27(5)$ & 29 & 223 \\
\hline Pseudolabrus miles & 0 & 0 & 0 & 0 & 0 & 1 & 4 & 5 \\
\hline \multicolumn{9}{|l|}{ Odacidae } \\
\hline Odax pullus & 0 & $4(2)$ & 1 & $6(1)$ & $5(1)$ & 5 & 3 & 24 \\
\hline \multicolumn{9}{|l|}{ Pinguipedidae } \\
\hline Parapercis colias & 0 & 0 & 0 & 0 & 1 & 0 & 0 & 1 \\
\hline \multicolumn{9}{|l|}{ Tripterygiidae } \\
\hline Forsterygion lapillum & 0 & 0 & 11 & $82(36)$ & $76(20)$ & $73(13)$ & $68(34)$ & 310 \\
\hline Forsterygion varium & $4(1)$ & $8(1)$ & $21(10)$ & $70(21)$ & $48(11)$ & $40(1)$ & $43(11)$ & 234 \\
\hline Forsterygion maryannae & 0 & $6(6)$ & 1 & 82 & 59 & 116 & 74 & 338 \\
\hline Notoclinus fenestratus & 0 & 1 & 0 & 0 & 0 & 0 & 0 & 1 \\
\hline Ruanoho whero & 0 & 0 & 0 & 0 & 1 & 2 & 1 & 4 \\
\hline Total Individuals & 34 & 269 & 235 & 338 & 374 & 364 & 298 & 1912 \\
\hline Total Species & 2 & 8 & 7 & 8 & 11 & 9 & 9 & 15 \\
\hline
\end{tabular}

- Represents species absent at this site 
Cont, Table 5.2

\begin{tabular}{|c|c|c|c|c|c|c|c|}
\hline \multirow{2}{*}{$\begin{array}{l}\text { Family } \\
\text { Species }\end{array}$} & \multicolumn{7}{|c|}{ Kau Bay } \\
\hline & Day 0 & Day 1 & Day 2 & Day 3 & Day 4 & Day 5 & Total \\
\hline \multicolumn{8}{|l|}{ Syngnathidae } \\
\hline Stigmatopora sp. & - & - & - & - & - & - & \\
\hline Hippocampus abdominalis & 1 & 0 & 0 & 0 & 0 & 0 & 1 \\
\hline \multicolumn{8}{|l|}{ Carangidae } \\
\hline Pseudocaranx dentex & - & - & - & - & - & - & \\
\hline \multicolumn{8}{|l|}{ Latridae } \\
\hline \multicolumn{8}{|l|}{ Latridopsis ciliaris } \\
\hline Nemadactylus macropterus & - & - & - & - & - & - & \\
\hline \multicolumn{8}{|l|}{ Mugilidae } \\
\hline Adrichetta forsteri & - & - & - & - & - & - & \\
\hline \multicolumn{8}{|l|}{ Labridae } \\
\hline Notolabrus celidotus & $319(194)$ & $442(198)$ & $510(231)$ & $448(273)$ & $418(276)$ & $652(427)$ & 2789 \\
\hline Notolabrus fucicola & 3 & 7 & 10 & 7 & $25(3)$ & $15(5)$ & 67 \\
\hline Pseudolabrus miles & - & - & - & - & - & - & \\
\hline \multicolumn{8}{|l|}{ Odacidae } \\
\hline Odax pullus & - & - & - & - & - & - & \\
\hline \multicolumn{8}{|l|}{ Pinguipedidae } \\
\hline Parapercis colias & 3 & 18 & 8 & 9 & 25 & 17 & 80 \\
\hline \multicolumn{8}{|l|}{ Tripterygiidae } \\
\hline Forsterygion lapillum & 0 & 0 & $157(128)$ & $90(88)$ & $304(121)$ & $290(133)$ & 841 \\
\hline Forsterygion varium & 0 & 0 & $9(8)$ & 0 & $11(7)$ & 19 & 39 \\
\hline Forsterygion maryannae & - & - & - & - & - & - & \\
\hline Notoclinus fenestratus & - & - & - & - & - & - & \\
\hline Ruanoho whero & 0 & 0 & $4(4)$ & 0 & 0 & $20(8)$ & 24 \\
\hline Total Individuals & 326 & 467 & 698 & 554 & 783 & 1013 & 3841 \\
\hline Total Species & 4 & 3 & 6 & 4 & 5 & 6 & 7 \\
\hline
\end{tabular}

- represents species absent at this site

Linear mixed model analyses suggested that reef fishes varied in their responses to the treatment manipulations and habitat heterogeneity (nomacroalgae, single and mixed algae). Figure 5.3 gives estimates of fish abundance $( \pm 2 \mathrm{SE})$ across the 9 treatments (pooled by sampling dates), and significant effects were identified using HPD values given in table 5.3. 
a)

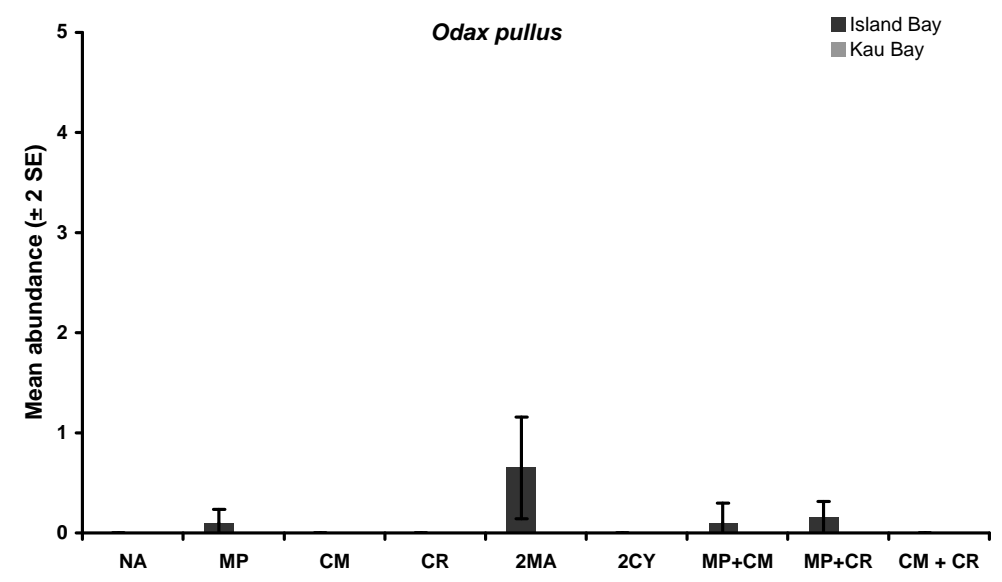

b)

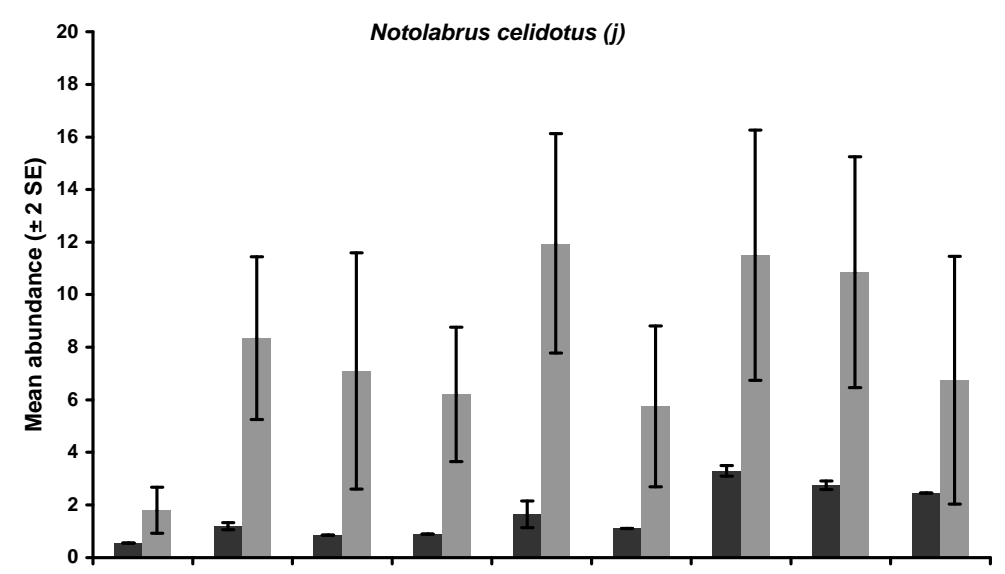

c)

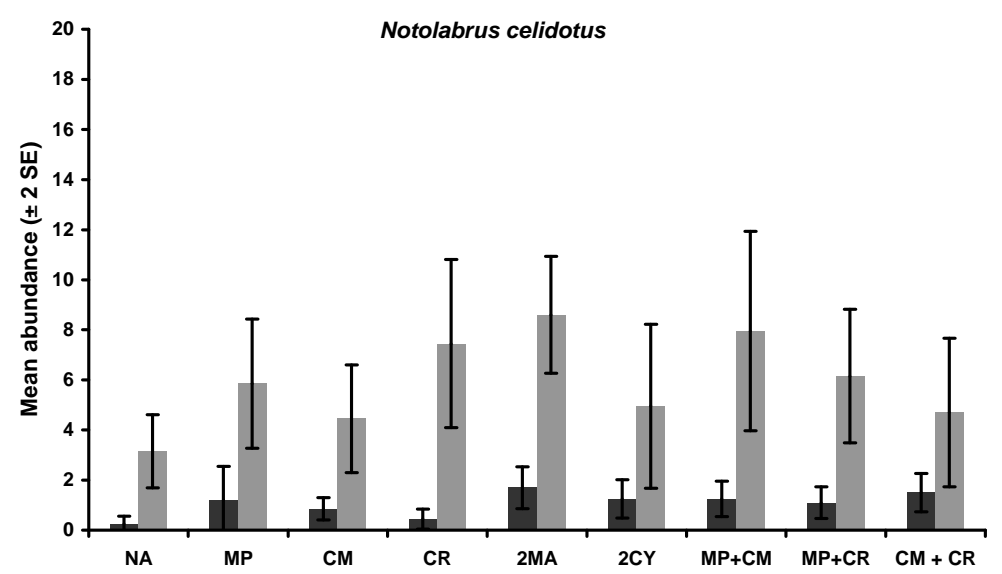


d)

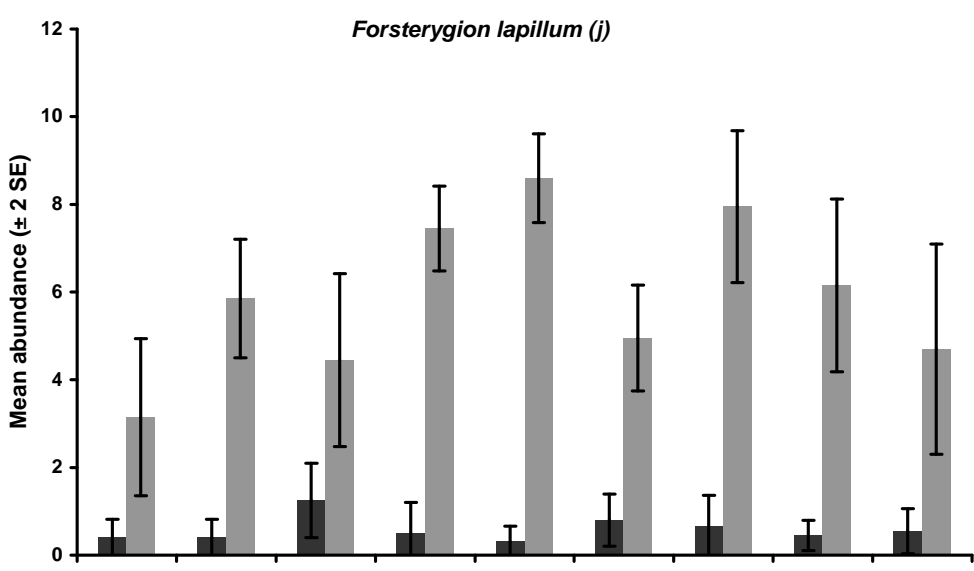

e)
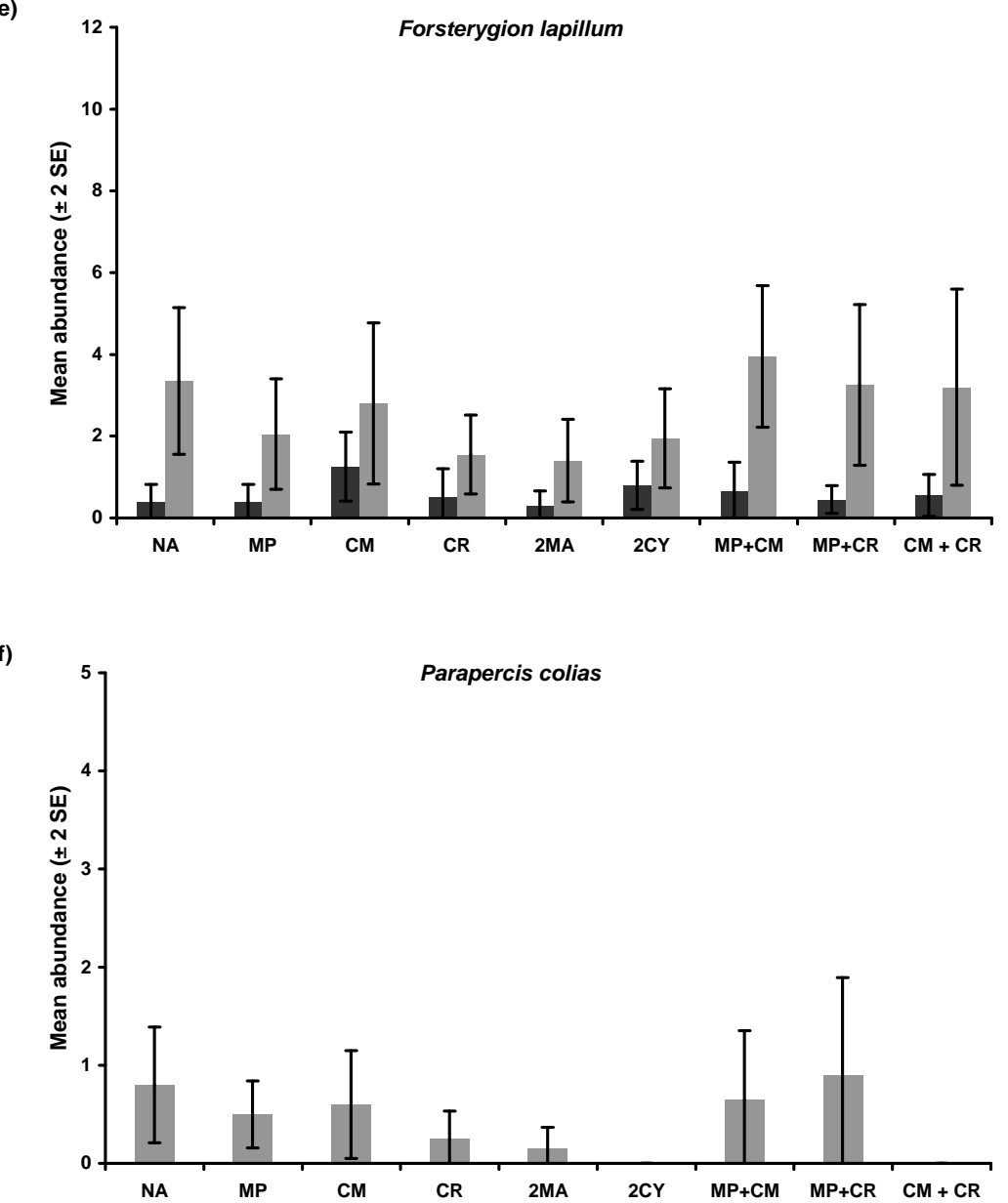
g)

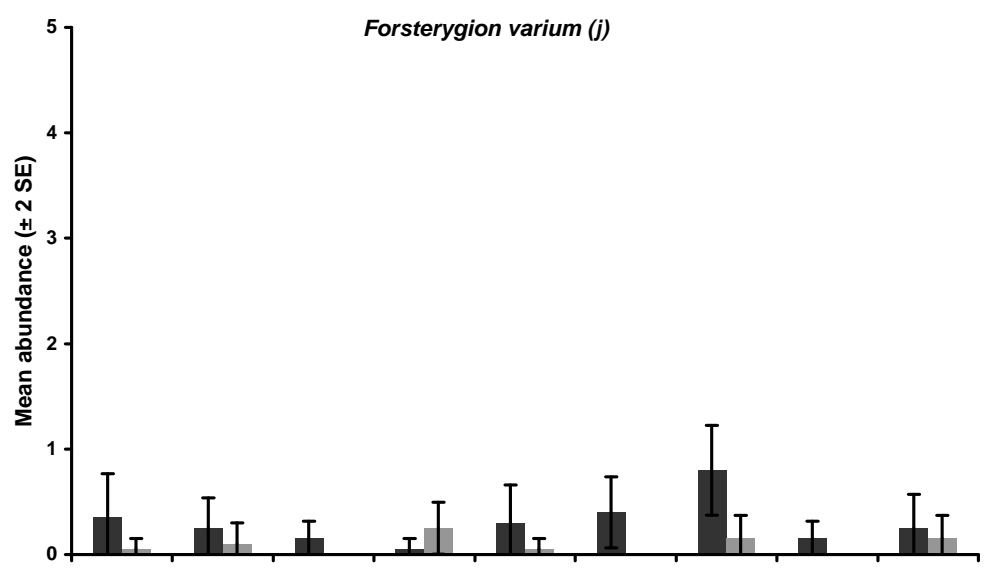

h)

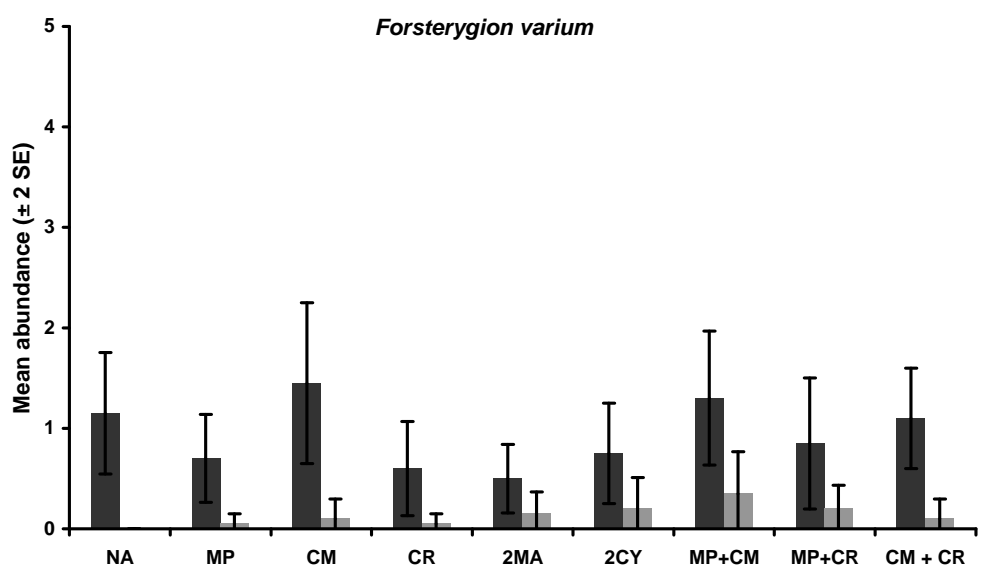

i)

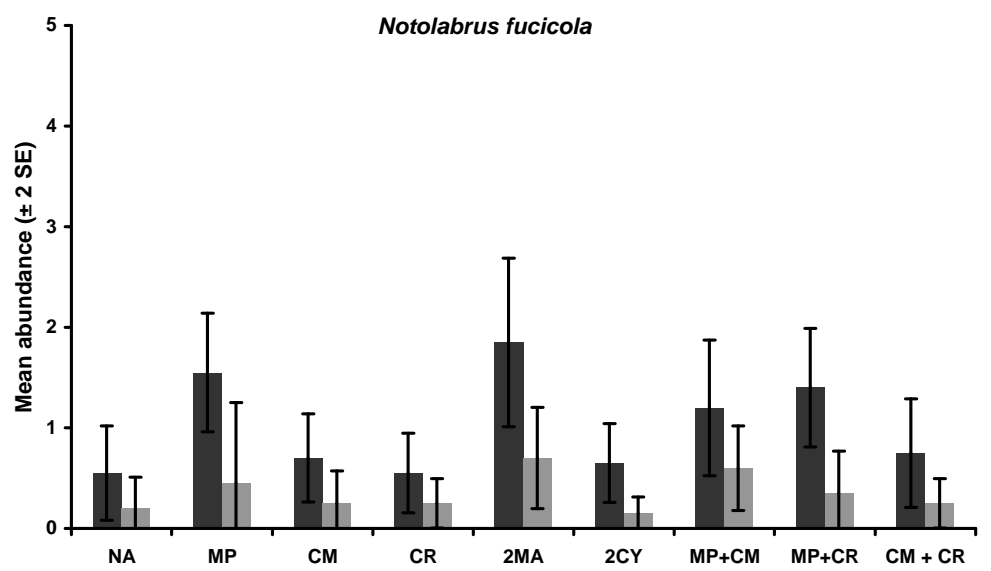




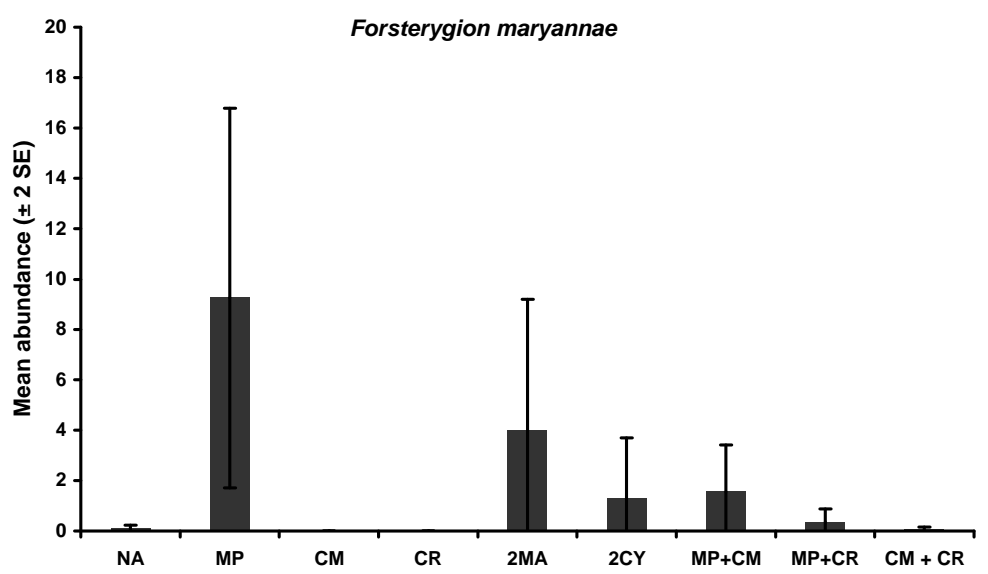

Figure 5.3 Mean abundance ( $\pm 2 \mathrm{SE}$ ) of small (juvenile) and large individuals species over the 9 treatment identities (TI) at two study sites. a) Odax pullus; b) Notolabrus celidotus ( $\mathrm{SL}<50 \mathrm{~mm})$ ); c) N. celidotus $(\mathrm{SL}>50 \mathrm{~mm})$; d) Forsterygion lapillum (SL $<30 \mathrm{~mm}$ ); e) F. lapillum (SL $>30 \mathrm{~mm}$ ); f) P. col, Parapercis colias; g) F. varium (SL $<30 \mathrm{~mm}$ ); h) F. varium (SL >30mm); i) N. fucicola; and i) F. maryannae. Refer to Table 2.1 for abbreviations on the treatment identities (TI). Data were pooled across the different sampling days.

Table 5.4 Summary of significance values of High Posterior Density (HPD) interval obtained after Markov Chain Monte Carlo (MCMC) simulations on the abundance of 7 species at the 9 manipulated treatments identities (TI) at two sites (Kau Bay and Island Bay). Treatment identities are abbreviated as: NA, no macroalgae; MP, (Macrocystis pyrifera); CM (Carpophyllum maschalocarpum); CR, (Cystophora retroflexa); 2X density MA, (double density of M. pyrifera); 2X density CR (double density of Cystophora retroflexa); MP + CM, (M. pyrifera and C. maschalocarpum); MP + CR, (M. pyrifera and C. retroflexa); $\mathrm{CM}+\mathrm{CR},(C$. maschalocarpum and C. retroflexa). Values in bold are significant at $p$-values $<0.05$

\begin{tabular}{|c|c|c|c|c|c|}
\hline \multirow[b]{2}{*}{ Site } & \multirow[b]{2}{*}{ TI } & \multicolumn{4}{|c|}{$\begin{array}{l}\text { a) Odax pullus } \\
\text { HPD interval }\end{array}$} \\
\hline & & Estimate & Lower & Upper & $p$-value \\
\hline Kau Bay & NA & & & & \\
\hline Island Bay & NA & 0.00 & -0.20 & 0.20 & 1.00 \\
\hline Kau Bay & MP & - & - & - & - \\
\hline Island Bay & MP & 0.10 & -0.10 & 0.30 & 0.31 \\
\hline Kau Bay & $\mathrm{CM}$ & - & - & - & - \\
\hline Island Bay & $\mathrm{CM}$ & 0.00 & -0.20 & 0.21 & 1.00 \\
\hline Kau Bay & CR & - & - & - & - \\
\hline Island Bay & CR & 0.00 & -0.20 & 0.21 & 1.00 \\
\hline Kau Bay & 2X MP & - & - & - & - \\
\hline Island Bay & 2X MP & 0.65 & 0.45 & 0.85 & 0.00 \\
\hline Kau Bay & $2 \mathrm{X} \mathrm{CR}$ & - & - & - & - \\
\hline Island Bay & 2X CR & 0.00 & -0.20 & 0.20 & 1.00 \\
\hline Kau Bay & $\mathrm{MP}+\mathrm{CM}$ & - & - & - & - \\
\hline Island Bay & $\mathrm{MP}+\mathrm{CM}$ & 0.10 & -0.11 & 0.29 & 0.31 \\
\hline Kau Bay & $\mathrm{MP}+\mathrm{CR}$ & - & - & - & - \\
\hline Island Bay & $\mathrm{MP}+\mathrm{CR}$ & 0.15 & -0.05 & 0.35 & 0.13 \\
\hline Kau Bay & $\mathrm{CM}+\mathrm{CR}$ & - & - & - & - \\
\hline Island Bay & $\mathrm{CM}+\mathrm{CR}$ & 0.00 & -0.20 & 0.20 & 1.00 \\
\hline
\end{tabular}


Cont, Table 5.3

\begin{tabular}{lccccc}
\hline & & \multicolumn{5}{c}{ b) Notolabrus celidotus ( SL<50mm) } \\
\multicolumn{1}{c}{ Site } & TI & Estimate & Lower & Upper & p-value \\
\hline Kau Bay & NA & 1.80 & -1.35 & 4.93 & 0.22 \\
Island Bay & NA & 0.55 & -2.73 & 3.61 & 0.71 \\
Kau Bay & MP & $\mathbf{8 . 3 5}$ & $\mathbf{5 . 1 9}$ & $\mathbf{1 1 . 5 0}$ & $\mathbf{0 . 0 0}$ \\
Island Bay & MP & 1.20 & -1.99 & 4.35 & 0.41 \\
Kau Bay & CM & $\mathbf{7 . 1 0}$ & $\mathbf{4 . 0 7}$ & $\mathbf{1 0 . 4 0}$ & $\mathbf{0 . 0 0}$ \\
Island Bay & CM & 0.85 & -2.31 & 3.98 & 0.56 \\
Kau Bay & CR & $\mathbf{6 . 2 0}$ & 3.05 & $\mathbf{9 . 4 1}$ & $\mathbf{0 . 0 0}$ \\
Island Bay & CR & 0.90 & -2.26 & 4.12 & 0.54 \\
Kau Bay & 2X MP & $\mathbf{1 1 . 9 5}$ & $\mathbf{8 . 8 3}$ & $\mathbf{1 5 . 0 9}$ & $\mathbf{0 . 0 0}$ \\
Island Bay & 2X MP & 1.65 & -1.67 & 4.76 & 0.26 \\
Kau Bay & 2X CR & $\mathbf{5 . 7 5}$ & $\mathbf{2 . 5 9}$ & $\mathbf{8 . 8 6}$ & $\mathbf{0 . 0 0}$ \\
Island Bay & 2X CR & 1.10 & -1.97 & 4.36 & 0.45 \\
Kau Bay & MP + CM & $\mathbf{1 1 . 5 0}$ & $\mathbf{8 . 1 6}$ & $\mathbf{1 4 . 5 5}$ & $\mathbf{0 . 0 0}$ \\
Island Bay & MP + CM & $\mathbf{3 . 3 0}$ & $\mathbf{- 0 . 0 2}$ & $\mathbf{6 . 2 7}$ & $\mathbf{0 . 0 2}$ \\
Kau Bay & MP + CR & $\mathbf{1 0 . 8 5}$ & $\mathbf{7 . 7 5}$ & $\mathbf{1 4 . 0 2}$ & $\mathbf{0 . 0 0}$ \\
Island Bay & MP + CR & 2.75 & -0.54 & 5.86 & 0.06 \\
Kau Bay & CM + CR & $\mathbf{6 . 7 5}$ & $\mathbf{3 . 6 4}$ & $\mathbf{9 . 9 0}$ & $\mathbf{0 . 0 0}$ \\
Island Bay & CM + CR & 2.45 & -0.83 & 5.56 & 0.09 \\
\hline
\end{tabular}

Cont, Table 5.3

c) Notolabrus celidotus (SL >50 mm)

HPD interval

\begin{tabular}{lccccc}
\multicolumn{1}{c}{ Site } & TI & Estimate & Lower & Upper & p-value \\
\hline Kau Bay & NA & $\mathbf{3 . 1 5}$ & $\mathbf{1 . 0 2}$ & $\mathbf{5 . 4 4}$ & $\mathbf{0 . 0 0}$ \\
Island Bay & NA & 0.25 & -1.93 & 2.43 & 0.81 \\
Kau Bay & MP & $\mathbf{5 . 8 5}$ & $\mathbf{3 . 6 3}$ & $\mathbf{8 . 0 7}$ & $\mathbf{0 . 0 0}$ \\
Island Bay & MP & 1.20 & -1.10 & 3.36 & 0.26 \\
Kau Bay & CM & $\mathbf{4 . 4 5}$ & $\mathbf{2 . 2 4}$ & $\mathbf{6 . 6 2}$ & $\mathbf{0 . 0 0}$ \\
Island Bay & CM & 0.85 & -1.35 & 3.16 & 0.42 \\
Kau Bay & CR & $\mathbf{7 . 4 5}$ & $\mathbf{5 . 1 7}$ & $\mathbf{9 . 5 9}$ & $\mathbf{0 . 0 0}$ \\
Island Bay & CR & 0.45 & -1.72 & 2.79 & 0.67 \\
Kau Bay & 2X MP & $\mathbf{8 . 6 0}$ & $\mathbf{6 . 4 5}$ & $\mathbf{1 0 . 8 3}$ & $\mathbf{0 . 0 0}$ \\
Island Bay & 2X MP & 1.70 & -0.54 & 3.87 & 0.11 \\
Kau Bay & 2X CR & $\mathbf{4 . 9 5}$ & $\mathbf{2 . 7 4}$ & $\mathbf{7 . 2 4}$ & $\mathbf{0 . 0 0}$ \\
Island Bay & 2X CR & 1.25 & -0.90 & 3.50 & 0.24 \\
Kau Bay & MP + CM & $\mathbf{7 . 9 5}$ & $\mathbf{5 . 8 2}$ & $\mathbf{1 0 . 2 6}$ & $\mathbf{0 . 0 0}$ \\
Island Bay & MP + CM & 1.25 & -0.85 & 3.51 & 0.24 \\
Kau Bay & MP + CR & $\mathbf{6 . 1 5}$ & $\mathbf{3 . 9 9}$ & $\mathbf{8 . 4 5}$ & $\mathbf{0 . 0 0}$ \\
Island Bay & MP + CR & 1.10 & -1.23 & 3.21 & 0.30 \\
Kau Bay & CM + CR & $\mathbf{4 . 7 0}$ & $\mathbf{2 . 4 5}$ & $\mathbf{6 . 8 8}$ & $\mathbf{0 . 0 0}$ \\
Island Bay & CM + CR & 1.50 & -0.70 & 3.76 & 0.16 \\
\hline
\end{tabular}


d) Forsterygion lapillum (SL < 30 mm)

HPD interval

\begin{tabular}{lcrrrr}
\multicolumn{1}{c}{ Site } & TI & Estimate & Lower & Upper & p-value \\
\hline Kau Bay & NA & $\mathbf{3 . 3 5}$ & $\mathbf{1 . 6 0}$ & $\mathbf{4 . 9 5}$ & $\mathbf{0 . 0 0}$ \\
Island Bay & NA & 0.40 & -1.25 & 2.08 & 0.57 \\
Kau Bay & MP & $\mathbf{2 . 0 5}$ & $\mathbf{0 . 4 0}$ & $\mathbf{3 . 7 9}$ & $\mathbf{0 . 0 0}$ \\
Island Bay & MP & 0.40 & -1.33 & 1.99 & 0.57 \\
Kau Bay & CM & $\mathbf{2 . 8 0}$ & $\mathbf{1 . 0 6}$ & $\mathbf{4 . 4 1}$ & $\mathbf{0 . 0 0}$ \\
Island Bay & CM & 1.25 & -0.43 & 2.92 & 0.08 \\
Kau Bay & CR & 1.55 & -0.16 & 3.18 & 0.03 \\
Island Bay & CR & 0.50 & -1.14 & 2.15 & 0.48 \\
Kau Bay & 2X MP & 1.40 & -0.23 & 3.10 & 0.05 \\
Island Bay & 2X MP & 0.30 & -1.29 & 2.07 & 0.67 \\
Kau Bay & 2X CR & $\mathbf{1 . 9 5}$ & $\mathbf{0 . 2 9}$ & $\mathbf{3 . 6 0}$ & $\mathbf{0 . 0 1}$ \\
Island Bay & 2X CR & 0.80 & -0.84 & 2.52 & 0.26 \\
Kau Bay & MP + CM & $\mathbf{3 . 9 5}$ & $\mathbf{2 . 2 1}$ & $\mathbf{5 . 5 9}$ & $\mathbf{0 . 0 0}$ \\
Island Bay & MP + CM & 0.65 & -1.02 & 2.29 & 0.36 \\
Kau Bay & MP + CR & $\mathbf{3 . 2 5}$ & $\mathbf{1 . 5 8}$ & $\mathbf{4 . 8 9}$ & $\mathbf{0 . 0 0}$ \\
Island Bay & MP + CR & 0.45 & -1.24 & 2.11 & 0.53 \\
Kau Bay & CM + CR & $\mathbf{3 . 2 0}$ & $\mathbf{1 . 5 2}$ & $\mathbf{4 . 8 6}$ & $\mathbf{0 . 0 0}$ \\
Island Bay & CM + CR & 0.55 & -1.24 & 2.15 & 0.44 \\
\hline
\end{tabular}

Cont, Table 5.3

e) Forsterygion Iapillum (SL < $30 \mathrm{~mm}$ )

HPD interval

\begin{tabular}{lcrrrr}
\multicolumn{1}{c}{ Site } & TI & Estimate & \multicolumn{1}{c}{ Lower } & Upper & p-value \\
\hline Kau Bay & NA & $\mathbf{3 . 3 5}$ & $\mathbf{1 . 7 6}$ & $\mathbf{4 . 8 9}$ & $\mathbf{0 . 0 0}$ \\
Island Bay & NA & 0.40 & -1.08 & 2.06 & 0.57 \\
Kau Bay & MP & $\mathbf{2 . 0 5}$ & $\mathbf{0 . 3 8}$ & $\mathbf{3 . 5 8}$ & $\mathbf{0 . 0 0}$ \\
Island Bay & MP & 0.40 & -1.21 & 1.96 & 0.57 \\
Kau Bay & CM & $\mathbf{2 . 8 0}$ & $\mathbf{1 . 2 0}$ & $\mathbf{4 . 3 8}$ & $\mathbf{0 . 0 0}$ \\
Island Bay & CM & 1.25 & -0.28 & 2.90 & 0.08 \\
Kau Bay & CR & 1.55 & -0.06 & 3.11 & 0.03 \\
Island Bay & CR & 0.50 & -1.10 & 2.05 & 0.48 \\
Kau Bay & 2X MP & 1.40 & -0.15 & 3.03 & 0.05 \\
Island Bay & 2X MP & 0.30 & -1.24 & 1.92 & 0.67 \\
Kau Bay & 2X CR & $\mathbf{1 . 9 5}$ & $\mathbf{0 . 3 3}$ & $\mathbf{3 . 5 2}$ & $\mathbf{0 . 0 1}$ \\
Island Bay & 2X CR & 0.80 & -0.73 & 2.41 & 0.26 \\
Kau Bay & MP + CM & $\mathbf{3 . 9 5}$ & $\mathbf{2 . 3 8}$ & $\mathbf{5 . 5 8}$ & $\mathbf{0 . 0 0}$ \\
Island Bay & MP + CM & 0.65 & -0.91 & 2.24 & 0.36 \\
Kau Bay & MP + CR & $\mathbf{3 . 2 5}$ & $\mathbf{1 . 6 5}$ & $\mathbf{4 . 8 1}$ & $\mathbf{0 . 0 0}$ \\
Island Bay & MP + CR & 0.45 & -1.13 & 2.03 & 0.53 \\
Kau Bay & CM + CR & $\mathbf{3 . 2 0}$ & $\mathbf{1 . 5 8}$ & $\mathbf{4 . 7 4}$ & $\mathbf{0 . 0 0}$ \\
Island Bay & CM + CR & 0.55 & -0.99 & 2.15 & 0.44 \\
\hline
\end{tabular}




\begin{tabular}{lccccc} 
& \multicolumn{5}{c}{ f) Parapercis colias } \\
\multicolumn{1}{c}{ Site } & TI & Estimate & Lower & Upper & p-value \\
\hline Kau Bay & NA & $\mathbf{0 . 8 0}$ & $\mathbf{0 . 2 4}$ & $\mathbf{1 . 3 2}$ & $\mathbf{0 . 0 0}$ \\
Island Bay & NA & - & - & - & - \\
Kau Bay & MP & 0.50 & -0.05 & 1.02 & 0.05 \\
Island Bay & MP & - & - & - & - \\
Kau Bay & CM & $\mathbf{0 . 6 0}$ & $\mathbf{0 . 0 5}$ & $\mathbf{1 . 1 3}$ & $\mathbf{0 . 0 2}$ \\
Island Bay & CM & - & - & - & - \\
Kau Bay & CR & 0.25 & -0.33 & 0.76 & 0.33 \\
Island Bay & CR & - & - & - & - \\
Kau Bay & 2X MP & 0.15 & -0.43 & 0.66 & 0.56 \\
Island Bay & 2X MP & - & - & - & - \\
Kau Bay & 2X CR & 0.00 & -0.56 & 0.54 & 1.00 \\
Island Bay & 2X CR & - & - & - & - \\
Kau Bay & MP + CM & $\mathbf{0 . 9 0}$ & $\mathbf{0 . 3 6}$ & $\mathbf{1 . 4 4}$ & $\mathbf{0 . 0 0}$ \\
Island Bay & MP + CM & - & - & - & - \\
Kau Bay & MP + CR & $\mathbf{0 . 6 5}$ & $\mathbf{0 . 1 0}$ & $\mathbf{1 . 1 7}$ & $\mathbf{0 . 0 1}$ \\
Island Bay & MP + CR & - & - & - & - \\
Kau Bay & CM + CR & 0.00 & -0.54 & 0.55 & 1.00 \\
Island Bay & CM + CR & - & - & - & - \\
\hline
\end{tabular}

Cont, Table 5.3

\begin{tabular}{lcllll}
\hline \multicolumn{5}{c}{ Site } & \multicolumn{5}{c}{ g) Forsterygion varium (SL $<30$ mm) } \\
\hline Kau Bay & NI & Estimate & Lower & Upper & p-value \\
Island Bay & NA & 0.05 & -0.23 & 0.34 & 0.70 \\
Kau Bay & MP & 0.10 & $\mathbf{0 . 0 6}$ & $\mathbf{0 . 6 2}$ & $\mathbf{0 . 0 1}$ \\
Island Bay & MP & 0.25 & -0.18 & 0.37 & 0.43 \\
Kau Bay & CM & 0.00 & -0.04 & 0.52 & 0.05 \\
Island Bay & CM & 0.15 & -0.28 & 0.29 & 1.00 \\
Kau Bay & CR & 0.25 & -0.02 & 0.42 & 0.24 \\
Island Bay & CR & 0.05 & -0.22 & 0.34 & 0.05 \\
Kau Bay & 2X MP & 0.05 & -0.23 & 0.33 & 0.70 \\
Island Bay & 2X MP & $\mathbf{0 . 3 0}$ & $\mathbf{0 . 0 2}$ & $\mathbf{0 . 5 8}$ & $\mathbf{0 . 0 2}$ \\
Kau Bay & 2X CR & 0.00 & -0.28 & 0.28 & 1.00 \\
Island Bay & 2X CR & $\mathbf{0 . 4 0}$ & $\mathbf{0 . 1 2}$ & $\mathbf{0 . 6 7}$ & $\mathbf{0 . 0 0}$ \\
Kau Bay & MP + CM & 0.15 & -0.13 & 0.43 & 0.24 \\
Island Bay & MP + CM & $\mathbf{0 . 8 0}$ & $\mathbf{0 . 5 2}$ & $\mathbf{1 . 0 8}$ & $\mathbf{0 . 0 0}$ \\
Kau Bay & MP + CR & 0.00 & -0.28 & 0.28 & 1.00 \\
Island Bay & MP + CR & 0.15 & -0.14 & 0.43 & 0.24 \\
Kau Bay & CM + CR & 0.15 & -0.13 & 0.43 & 0.24 \\
Island Bay & CM + CR & 0.25 & -0.04 & 0.52 & 0.05 \\
\hline
\end{tabular}




\begin{tabular}{lclllll}
\hline \multicolumn{5}{c}{ Site } & \multicolumn{5}{c}{ h) Forsterygion varium (SL > 30 mm) } \\
& TI & Estimate & Lower & Upper & p-value \\
\hline Kau Bay & NA & 0.00 & -0.52 & 0.51 & 1.00 \\
Island Bay & NA & $\mathbf{1 . 1 5}$ & $\mathbf{0 . 6 1}$ & $\mathbf{1 . 6 3}$ & $\mathbf{0 . 0 0}$ \\
Kau Bay & MP & 0.05 & -0.44 & 0.59 & 0.83 \\
Island Bay & MP & $\mathbf{0 . 7 0}$ & $\mathbf{0 . 2 2}$ & $\mathbf{1 . 2 5}$ & $\mathbf{0 . 0 0}$ \\
Kau Bay & CM & 0.10 & -0.40 & 0.65 & 0.66 \\
Island Bay & CM & $\mathbf{1 . 4 5}$ & $\mathbf{0 . 9 4}$ & $\mathbf{1 . 9 5}$ & $\mathbf{0 . 0 0}$ \\
Kau Bay & CR & 0.05 & -0.47 & 0.56 & 0.83 \\
Island Bay & CR & $\mathbf{0 . 6 0}$ & $\mathbf{0 . 1 0}$ & $\mathbf{1 . 1 3}$ & $\mathbf{0 . 0 1}$ \\
Kau Bay & 2X MP & 0.15 & -0.39 & 0.65 & 0.52 \\
Island Bay & 2X MP & 0.50 & -0.01 & 1.03 & 0.03 \\
Kau Bay & 2X CR & 0.20 & -0.33 & 0.70 & 0.39 \\
Island Bay & 2X CR & $\mathbf{0 . 7 5}$ & $\mathbf{0 . 2 5}$ & $\mathbf{1 . 2 7}$ & $\mathbf{0 . 0 0}$ \\
Kau Bay & MP + CM & 0.35 & -0.16 & 0.86 & 0.13 \\
Island Bay & MP + CM & $\mathbf{1 . 3 0}$ & $\mathbf{0 . 7 9}$ & $\mathbf{1 . 8 2}$ & $\mathbf{0 . 0 0}$ \\
Kau Bay & $\mathrm{MP}+\mathrm{CR}$ & 0.20 & -0.32 & 0.72 & 0.39 \\
Island Bay & $\mathrm{MP}+\mathrm{CR}$ & $\mathbf{0 . 8 5}$ & $\mathbf{0 . 2 9}$ & $\mathbf{1 . 3 2}$ & $\mathbf{0 . 0 0}$ \\
Kau Bay & $\mathrm{CM}+\mathrm{CR}$ & 0.10 & -0.45 & 0.59 & 0.66 \\
Island Bay & $\mathrm{CM}+\mathrm{CR}$ & $\mathbf{1 . 1 0}$ & $\mathbf{0 . 5 4}$ & $\mathbf{1 . 5 8}$ & $\mathbf{0 . 0 0}$ \\
\hline
\end{tabular}

Cont, Table 5.3

\begin{tabular}{lcllll}
\multicolumn{5}{c}{ Site } & \multicolumn{5}{c}{ i) Notolabrus fucicola } \\
HPD interval & \\
\hline Kau Bay & TI & Estimate & Lower & Upper & p-value \\
Island Bay & NA & 0.20 & -0.44 & 0.77 & 0.46 \\
Kau Bay & MP & 0.45 & -0.02 & 1.17 & 0.04 \\
Island Bay & MP & $\mathbf{1 . 5 5}$ & -0.14 & 1.05 & 0.09 \\
Kau Bay & CM & 0.25 & -0.35 & 0.85 & 0.35 \\
Island Bay & CM & $\mathbf{0 . 7 0}$ & $\mathbf{0 . 0 7}$ & $\mathbf{1 . 2 7}$ & $\mathbf{0 . 0 1}$ \\
Kau Bay & CR & 0.25 & -0.36 & 0.85 & 0.35 \\
Island Bay & CR & $\mathbf{0 . 5 5}$ & -0.04 & 1.15 & 0.04 \\
Kau Bay & 2X MP & $\mathbf{0 . 7 0}$ & $\mathbf{0 . 1 2}$ & $\mathbf{1 . 3 1}$ & $\mathbf{0 . 0 1}$ \\
Island Bay & 2X MP & $\mathbf{1 . 8 5}$ & $\mathbf{1 . 2 4}$ & $\mathbf{2 . 4 4}$ & $\mathbf{0 . 0 0}$ \\
Kau Bay & 2X CR & 0.15 & -0.45 & 0.74 & 0.58 \\
Island Bay & 2X CR & $\mathbf{0 . 6 5}$ & $\mathbf{0 . 0 6}$ & $\mathbf{1 . 2 5}$ & $\mathbf{0 . 0 2}$ \\
Kau Bay & MP + CM & $\mathbf{0 . 6 0}$ & $\mathbf{0 . 0 0}$ & $\mathbf{1 . 1 9}$ & $\mathbf{0 . 0 3}$ \\
Island Bay & MP + CM & $\mathbf{1 . 2 0}$ & $\mathbf{0 . 5 8}$ & $\mathbf{1 . 8 0}$ & $\mathbf{0 . 0 0}$ \\
Kau Bay & MP + CR & 0.35 & -0.27 & 0.93 & 0.19 \\
Island Bay & MP + CR & $\mathbf{1 . 4 0}$ & $\mathbf{0 . 8 0}$ & $\mathbf{2 . 0 1}$ & $\mathbf{0 . 0 0}$ \\
Kau Bay & CM + CR & 0.25 & -0.34 & 0.88 & 0.35 \\
Island Bay & CM + CR & $\mathbf{0 . 7 5}$ & $\mathbf{0 . 1 5}$ & $\mathbf{1 . 3 6}$ & $\mathbf{0 . 0 1}$ \\
\hline
\end{tabular}




\begin{tabular}{lccccc}
\hline & \multicolumn{5}{c}{ j) Forsterygion maryannae } \\
\multicolumn{1}{c}{ Site } & TI & Estimate & HPD interval & \\
Lower & Upper & p-value \\
\hline Kau Bay & NA & - & - & - & - \\
Island Bay & NA & 0.10 & -3.18 & 3.61 & 0.95 \\
Kau Bay & MP & - & - & - & - \\
Island Bay & MP & $\mathbf{9 . 2 5}$ & $\mathbf{6 . 0 6}$ & $\mathbf{1 2 . 7 6}$ & $\mathbf{0 . 0 0}$ \\
Kau Bay & CM & - & - & - & - \\
Island Bay & CM & 0.00 & -3.43 & 3.34 & 1.00 \\
Kau Bay & CR & - & - & - & - \\
Island Bay & CR & 0.00 & -3.26 & 3.47 & 1.00 \\
Kau Bay & 2X MP & - & - & - & - \\
Island Bay & 2X MP & $\mathbf{4 . 0 0}$ & $\mathbf{0 . 8 3}$ & 7.43 & $\mathbf{0 . 0 1}$ \\
Kau Bay & 2X CR & - & - & - & - \\
Island Bay & 2X CR & 1.30 & -2.25 & 4.55 & 0.42 \\
Kau Bay & MP + CM & - & - & - & - \\
Island Bay & MP + CM & 1.55 & -1.68 & 5.08 & 0.34 \\
Kau Bay & MP + CR & - & - & - & - \\
Island Bay & MP + CR & 0.35 & -3.05 & 3.69 & 0.83 \\
Kau Bay & CM + CR & - & - & - & - \\
Island Bay & CM + CR & 0.05 & -3.35 & 3.37 & 0.98 \\
\hline
\end{tabular}

The butterfish, O. pullus, occurred at only 1 site (Island Bay) and on three treatments only (Fig. 5.3). The HPD interval (Table 5.3) did not contain zero in only one treatment ( $2 \mathrm{X}$ density of $M$. pyrifera), indicating that this habitat type had a positive effect on the abundance of $O$. pullus. Ambient densities of $M$. pyrifera and mixed macroalgae containing $M$. pyrifera had no detectable effect on O.pullus abundance (Fig. 5.3 and Table 5.3).

Abundance of small (i.e., juvenile) spotties, N. celidotus, responded positively to mixed macroalgae of $M$. pyrifera (which also included $C$. maschalocarpum) at both study sites. Abundance of small $N$. celidotus on patches without macroalgae was highly variable (and comparably low) at both sites. Abundances of larger sized N. celidotus differed only between study sites (more abundant at Kau Bay than Island Bay), and I found no evidence for a behavioural response of these larger individuals to the imposed algal treatments (i.e., large N. celidotus appear to behave as habitat "generalists") (Fig. 5.3 and Table 5.3).

The abundances of both small and large size classes of the common 
triplefin, F. lapillum were greater at Kau Bay relative to Island Bay. For Kau Bay in particular, our analyses suggest that $F$. lapillum behaves as a habitat "generalist", as it did not exhibit any preferences for our imposed treatments (Fig. 5.3 and Table 5.3).

The blue cod, Parapercis colias, occurred only at Kau Bay. P. colias were present in significant numbers only in patches with no macroalgae, patches with C. maschalocarpum, and with mixed macroalgae of $M$. pyrifera with $C$. maschalocarpum and C. retroflexa (Fig. 5.3 and Table 5.3).

The variable triplefin, Forsterygion varium showed no response to imposed habitat patches at Kau Bay (Fig. 2.3). At Island Bay I detected significant responses from small individuals only. Small $F$. varium, were present in significant numbers on patches with no macroalgae, and patches with $2 \mathrm{X}$ density of M. pyrifera and C. retroflexa. Mixed macroalgae (M. pryifera with $C$. maschalocarpum) were preferred by small $F$. varium at Island Bay only. Forsterygion varium were less abundant and less clearly associated with particular habitat patches at Kau Bay; I did not detect significant effects on their abundance at this site. At Island Bay, large $F$. varium appear to behave as habitat "generalists", as they showed no clear preferences for the imposed treatments despite being commonly recorded on all patch types (Fig. 5.3 and Table 5.3).

The banded wrasse, Notolabrus fucicola, exhibited strong preferences for patches containing macroalgae, and their abundance was comparably low and unpredictable in patches with no macroalgae. Abundance of $N$. fucicola was higher at 2X density of M. pyrifera at both study sites. Notolabrus fucicola also appeared to prefer patches comprised a mixture of macroalgal species (which also included $M$. pyrifera) at both study sites. The abundance of $N$. fucicola was 
relatively high in other types of patches (e.g., ambient density of M. pyrifera, $C$. retroflexa, and combination of fucalean) at the Island Bay site only (Fig. 5.3 and Table 5.3).

The oblique-swimming triplefin, Forsterygion maryannae, occurred at 1 site only (Island Bay). Their abundance was high on ambient and $2 \mathrm{X}$ density of M. pyrifera patches only (Fig. 5.3 and Table 5.3).

The abundance of most fishes was generally low on patches without macroalgae (Fig. 5.3). The HPD intervals indicate that, although in low abundance, some species consistently occurred on patches without macroalgae along the different sampling days. This is reflected by the positive and significant estimates of this parameter for N. celidotus, F. lapillum, and P. colias at Kau Bay (Fig. 5.4 c-f). At Island Bay, the HPD interval indicates that the only abundant species in patches with no-macroalgae were larger individuals of $F$. varium (Fig. $5.4 \mathrm{~h})$.

Irrespective of the macroalgal identities, estimated HPD intervals indicate that the habitat patches comprised of a single species macroalgae had positive effects on the abundance of both large and small size classes of $N$. celidotus and F. lapillum at Kau Bay (Fig. 5.4 b-e), and positive effects on the abundance of $O$. pullus, F. varium, F. maryannae and N. fucicola at Island Bay (Fig. 5.4 a, g-j).

HPD intervals indicate that the treatments comprised of mixed macroalgal stands had positive effects on the abundance of $N$. fucicola and small individuals of $N$. celidotus at both study sites (Fig. 5.3 b, i). Mixed stands of macroalgae had detectable positive effects on the abundance of large individuals of N. celidotus, F. lapillum, and P. colias at Kau Bay only (Fig. 2.3 c-f), and on both large and small $F$. varium at Island Bay only (Fig. 5.3 h-i). 
The HPD intervals estimated for sampling days (included as a random effect to control for unmeasured environmental variation, e.g., day-to-day variation in water visibility) had a variable effect in most fishes. The range of HPD interval was lowest for O. pullus and N. fucicola (Fig. 2.3 a,i) and highest (e.g., most variable) for $N$. celidotus, F. lapillum and F. maryannae. These results suggest that the estimated abundances of these species varied over the course of the experiment (Table 5.2, Fig. 5.4 b-e). 

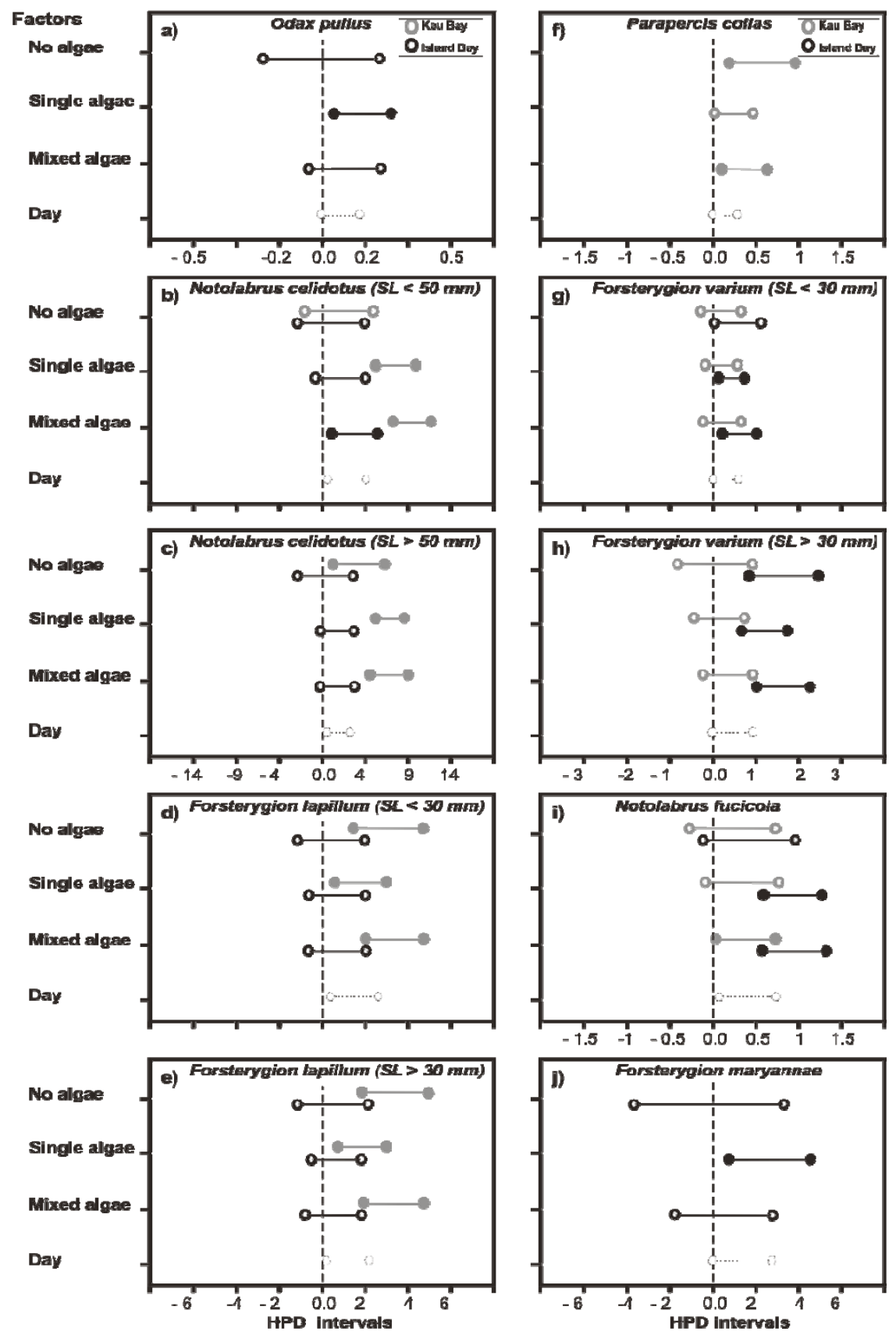

Figure 5.4 High Posterior Density (HPD) interval for a) the butterfish, Odax pullus (SL $<350 \mathrm{~mm})$; b) spotty juvenile, Notolabrus celidotus $(\mathrm{SL}<50 \mathrm{~mm}) \mathrm{c})$ N. celidotus $(\mathrm{SL}<$ $250 \mathrm{~mm}$ ); d) the common triplefin juvenile, Forsterygion lapillum (SL $<30 \mathrm{~mm}$ ); e) F.

lapillum (SL $<60 \mathrm{~mm}) ; \mathrm{f}$ ) the blue cod, Parapercis colias $(\mathrm{SL}<350 \mathrm{~mm})$; $\mathrm{g}$ ) the variable triplefin juvenile, Forsterygion varium $(\mathrm{SL}<30 \mathrm{~mm}) ; \mathrm{h})$ F. varium $(\mathrm{SL}<120$

$\mathrm{mm})$; i) the banded wrasse, Notolabrus fucicola $(\mathrm{SL}<400 \mathrm{~mm})$; and j) obliqueswimming triplefin, Forsterygion maryannae (SL $<60 \mathrm{~mm}$ ). Factors include: Site (Kau Bay and Island Bay) and species richness (SR, no macroalgae present, single species present, and mixed species stands). The interval represents the range of the HPD values. Symbols connected by a line reflect the $95 \%$ confidence interval for HPD. The width of the HPD confidence interval indicates the variability of the response (e.g., abundance of particular fish species). HPD values not overlapping 0 indicate statistical significance at $\alpha=0.05$ (also signalled by filled symbols). Note that the HPD interval of the random effects "Day" reflects the standard deviation estimated after MCMC (refer to methods for details). 
Variation in fish assemblages - CAP analysis indicated that most of the experimentally imposed patch types (treatment identities) developed into statistically distinct fish assemblages. Patches comprising two species of macroalgae and/or of no algae were particularly distinct, as evidenced by the relatively high percentage of allocation success, though the two sites differed in some respects ( $c f$. , allocation success for $M$. pyrifera $+C$. retroflexa between sites, Table 5.4).

Table 5.4 Canonical analysis of principal coordinates (CAP), results from Island Bay and Kau Bay. Total variation of the $\mathrm{m}$ axes (\% Var.) of the principal coordinate analysis (PCO), allocation success of a priori groups, assigned as percent of points allocated to each of the treatment identities (NA, no macroalgae; MP, Macrocystis pyrifera, CR, Cystophora retroflexa; CM, Carpophyllum maschalocarpum; $\mathrm{MP}+\mathrm{CR}$, M. pyrifera and $C$. retroflexa; $\mathrm{MP}+\mathrm{CM}, M$. pyrifera and $C$. maschalocarpum; $\mathrm{CM}+\mathrm{CR}, C$. maschalocarpum and C. retroflexa), Site (I.B. Island Bay and K.B. Kau Bay), square canonical correlation $\left(\delta^{2}\right)$, and $p$-value $(P)$ obtained after 999 randomisations.

\begin{tabular}{lcccccccccc}
\hline & & \multicolumn{8}{c}{ Allocation success (\%) } & \\
\cline { 3 - 10 } Site & \% Var & NA & MP & CR & CM & MP+CR & MP+CM & CM+CR & $\delta^{2}$ & $P$ \\
\hline I. B & 93.7 & 38 & 13 & 2 & 17 & 33 & 29 & 29 & 0.1 & 0.006 \\
K. B & 95.6 & 55 & 20 & 3 & 10 & 0 & 55 & 30 & 0.2 & 0.001 \\
\hline
\end{tabular}

MDS plots illustrate the nature of the between-site variation in fish assemblages, with experimental patch types clustering differently at the two sites in a pattern that is consistent with our univariate results throughout the different sampling days. At Island Bay, patches without macroalgae clustered with $M$. pyrifera + C. maschalocarpum while other treatments are spread across the ordination space (Fig. 5.5a). Assemblages of species that influenced this cluster at Island Bay were the most abundant species at this site (i.e., large N. celidotus, N. fucicola, F. varium and F. lapillum) as well as the blue moki Latridopsis ciliaris that was only sighted on these treatments. Species such as $F$. varium, $F$. lapillum, and large $N$. celidotus occurred in higher abundances in patches with 
no-algae and are responsible to the clustering in this site. At Kau Bay, patches without macroalgae were well separated from all the macroalgal treatments. Species that contributed to this cluster were the most abundant (i.e., F. lapillum, N. celidotus) as well as other species such as the blue cod Parapercis colias and the spectacled triplefin, Ruanoho whero, which were frequently observed on unvegetated patches. Those patches containing C. retroflexa clustered similarly with one another (all observed species of triplefins and $N$. celidotus comprised this assemblage), as did patches that contained M. pyrifera (Fig. 5.5b). Treatments with $M$. pyrifera with $C$. maschalocarpum formed another distinct assemblage (Fig. 5.5b), comprised of species such as small $N$. celidotus, $F$. lapillum, N. fucicola, and P. colias.
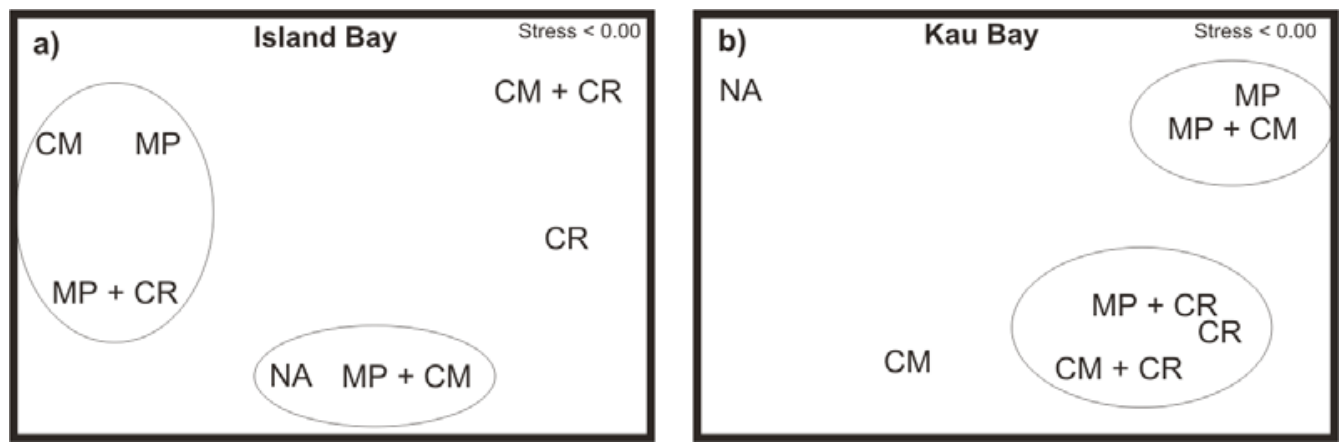

Figure 5.5 nMDS ordination plot of Euclidean distances among centroids of the interaction between different treatment identities (no-algae and macroalgae treatments, see Table 1 for description) constructed at two study sites a) Island Bay and b) Kau Bay. Centroids were separately computed for each site from Bray-Curtis dissimilarities of untransformed data using principal coordinates 


\subsection{Discussion}

Evidence that the diversity and abundance of reef fishes may be related to heterogeneity and physical complexity of benthic habitats at both small (i.e., manipulated patches) and large (i.e., site) scales were found. Following the construction of habitat-forming macroalgal patches, the abundance and overall diversity of reef fishes increased. Further, the experiments suggest that temperate reef fishes recognize and respond to different components of "habitat heterogeneity", including macroalgal presence, species identity, stand composition, and density. Results suggest that some macroalgae enhance the overall quality of a site by supporting more and different species of reef fishes.

In the tank study, two fishes (Notolabrus celidotus and N. fucicola) showed different behavioral responses in a habitat selectivity experiment. Notolabrus fucicola demonstrated a strong preference for both Macrocystis pyrifera and Carpophyllum maschalocarpum. Notolabrus celidotus, in contrast showed a more "generalist" response, and was observed to associate with all available habitats without any clear preference. In field experiments, these two species exhibited responses that were consistent with the tank study: N. fucicola demonstrated a statistically significant response to manipulated habitat features whereas $N$. celidotus did not.

Our analyses of the field experiment suggests 1) most reef fishes examined responded to some component of habitat heterogeneity, whether presence/absence of macroalgae, composition of macroalgal stands (i.e., single or mixed species), and/or macroalgal densities; 2) most of these responses varied depending of the study site; 3 ) two of the three reef fishes for which I had stage-structured data showed evidence of habitat shifts between juvenile and 
adult stages (e.g., N. celidotus and F. varium); and 4) mixed-species macroalgal stands and $M$. pyrifera (irrespective of density) yielded the highest abundances of reef fishes.

Local abundances of reef fishes differed markedly between sites, suggesting some larger-scale environmental context (e.g., wave exposure, presence of other species, or local densities of resident fish) may mediate the importance of some components of habitat heterogeneity. Studies conducted by others indicate that processes related to recruitment that may occur over larger spatial scales readily influence patterns of abundance at small spatial scales (Caselle and Warner 1996). White and Caselle (2008) found that processes acting on both small and large scales influence the abundance of a reef fish. In temperate waters off California, abundance of adult kelp bass (Paralabrax clathratus) was determined by habitat availability (kelp abundance) and conspecific density at small scales; spatial variation in larval supply explained the abundance of kelp bass at larger scales (White and Caselle 2008). Recruitment of many reef fishes is variable in space and time, and at locations and times when the supply of recruits is sufficiently high, local populations may be limited and regulated by density dependent interactions on the reef (Shima 1999; Shima et al. 2008; White and Caselle 2008); in some cases these two sources of variation can interact to mask the positive effects of habitat quality at small spatial scales (i.e., "cryptic density dependence" sensu (Shima and Osenberg 2003)).

Some reef fishes showed habitat shifts between juvenile and adult stages. Juveniles of $N$. celidotus, for example, were absent in patches without macroalgae and present in abundance over manipulated patches with $M$. pyrifera 
(regardless of density and whether present in single- or mixed species stands). This response of juveniles was consistent at both study sites and different from responses of larger stages of $N$. celidotus. Forsterygion varium showed a similar trend: juvenile and adult stages differed in their use of microhabitats but this apparent ontogenetic variation in habitat use was only observed at one site. Ontogenetic shifts in habitat use have been described previously for these species (Jones 1984b; Connell and Jones 1991; McDermott and Shima 2006). In our study I did not detect ontogenetic changes in habitat use for Forsterygion lapillum (McDermott and Shima 2006), and I suggest that our study may have lacked the statistical power to detect these patterns. Implications and mechanisms underlying ontogenetic changes in habitats or resources warrant further study.

On temperate reefs, both experimental (DeMartini and Roberts 1990; Holbrook et al. 1990a; Levin and Hay 1996) and descriptive studies (Anderson and Millar 2004; Pérez-Matus et al. 2007; Williams et al. 2008) suggest that local demographic and/or behavioural responses of fishes are commonly shaped by variation in underlying macroalgal habitat attributes. Moreover, the ability of some species to detect and respond to habitat heterogeniety can account for variation in individual resource payoffs (Parker and Sutherland 1986; Hugie and Grand 1998; Levin et al. 2000). Local densities often reflect responses of individuals to structural attributes of the habitat (Levin et al. 2000). Results are concordant with other studies conducted in temperate regions that have identified strong linkages between fish abundance and algal identities (Stephens et al. 1984; Holbrook et al. 1990b; Anderson and Millar 2004). Here, I documented two categories of temperate reef fishes in this study: 1) "specialist" fish species that 
responded to particular macroalgal identities, i.e., those fishes that increased their abundance or their frequency of occurrence under the presence of macroalgae (i.e., M. pyrifera for N. fucicola, O. pullus, juvenile F. varium, $F$. maryannae in this study); and 2) "generalist" fish species, i.e., fishes with local abundances that were not determined by particular macroalgal identities (i.e., large $N$. celidotus and F. varium, F. lapillum, $P$. colias in this study). Specialists may comprise species that are more likely to gain benefits of resource provisioning from macroalgae. For example, the herbivore O. pullus feeds directly on reproductive branches and on blades of large brown algae (Choat and Clements 1992) and N. fucicola spends time in kelp structures searching for food occurring in kelp's holdfast (Denny and Schiel 2001). Further evidence of the trophic connections between these fishes and brown macroalgae is also supported by Hickford and Schiel (2008), who found that both fish species were highly susceptible to capture with gill nets placed in macroalgal habitats (due to enhanced risk of capture correlated with foraging behaviour; (Hickford and Schiel 2008)). I found that $N$. celidotus (the most abundant species in the study) was affected by the presence of macroalgae only at early juvenile stages (Jones 1984a); adults are generally more abundant on barren habitats, and this is presumably influenced by the distribution of food (Jones 1984b; Anderson and Millar 2004). For F. varium, which responded to the presence/absence of macroalgae, the absence of a clear linkage with a particular macroalgal identity may be due to intense competitive interactions with $N$. celidotus (Jones 1984b), or a relatively uniform distribution of their preferred food items (i.e., gammarid amphipods; (Feary et al. 2009)) across different algal structures used in this study (Taylor and Cole 1994). Other species that were not commonly observed 
across sampling days (and therefore excluded from analyses) may avoid macroalgal structures, or may otherwise respond to macroalgae in ways that are not easily detectable by our mode of sampling. For example, some species in our local area periodically may form dense feeding or schooling aggregations; such species with schooling behaviour (Pseudocaranx dentex, Latridopsis ciliaris, and Nemdactylus macropterus) may also be affected by the three dimensional structure of kelps (Siddon et al. 2008), but these behaviours (and their relationship with macroalgal structures) may occur too rarely to be detected by our sampling.

Variation in behavioral patterns was apparent from both tank and field experiments. Although I failed to quantify behavioural patterns for all fish species sighted during the study, results from these experiments suggest that species-specific behavioural responses may have a measurable influence on fish assemblages in temperate reef settings. Conceptually, this can be explained by distributional models that attempt to predict patterns of movement and dispersal of a species across different habitats (Hugie and Grand 1998; Levin et al. 2000). Both the ideal free distribution (IFD) and the ideal despotic distribution (IDD) describe trade-offs that arise from behavioural decisions of individuals (Kramer et al. 1997). In their application, both distributional models are sometimes based on untested assumptions of the individuals' ability to perceive and discriminate among locally available habitats and/or other resources (Roshier et al. 2008). From the perspective of an individual of a given focal species, the decision to move from one patch to another may depend upon a range of (potentially conflicting) motives that, for example, may include maximisation of food resources and/or mating opportunities, minimisation of risk from predators 
and/or competitors, etc (Kramer et al. 1997; Connell and Kingsford 1998; Crowe and Underwood 1998).

Species with ecological preferences are likely to be present where those preferences are met (Legendre et al. 1997). It is well known that fauna associated with habitat forming macroalgae are an important source of food for many predatory fishes in temperate regions (Taylor 1998a). The distribution and abundance of associated fauna with habitat forming macroalgae is influenced by differences in macroalgal fronds, thallus shapes (Taylor and Cole 1994; Christie et al. 2007) and holdfast size (Thiel and Vásquez 2000). These structures, manipulated indirectly in the present study, may induce different foraging patterns by fishes within different macroalgae species, or within phenotypically different individuals of the same species of macroalgae. While macroalgae provide substratum for an array of associated fauna, their size and shape, physiological (and chemical defence) status, and whether they are present as single or mixed species stands will alter their ability to support faunal assemblages that comprise a forage base for many reef fishes. More structurally complex habitats (e.g., small vs tall, single vs mixed species stands of macroalgae) may increase prey survivorship (see review by Heck and Crowder 1991). Therefore, fishes may select habitats that offer different rewards (payoffs) (Levin and Hay 1996; Levin et al. 2000), and spatial variation in these rewards may determine the uneven distributions of fishes in our study.

Fish species varied in their responses to different forms of heterogeneity in macroalgal habitats. This variability in responses suggests the need for a more sophisticated understanding of the relationship between the habitats and species. Variation in responses among species may result from different niche 
requirements (e.g., food and shelter) and/or the trade-offs that different components of macroalgal architecture represent for individuals. Environmental heterogeneity underpins the basis for management and conservation of many ecological systems (Fuhlendorf et al. 2006). While the effect of heterogeneity on species distribution is well understood for many terrestrial ecosystems (e.g., Dornelas et al. 2009) similar applications tend to be greatly simplified in marine ecosystems, where spatial management strategies are often limited to "no-take" areas (often with relatively little consideration of linkages between habitat and target species). Results suggest that species may respond in different ways to habitat features, and therefore that fish assemblages may differ from one area to another depending upon these features. These diverse responses to experimental manipulations of macroalgal structure suggest complex species interactions that may operate synergistically to shape the relationships between temperate reef fishes and associated macroalgal habitats. 


\section{CHAPTER 6}

Density and trait-mediated effects of fish predators on amphipod grazers: potential indirect benefits for the giant kelp, Macrocystis pyrifera

\subsection{Abstract}

Indirect effects of predators on primary producers may arise when predators suppress herbivore abundance and/or alter the behaviour patterns of herbivores in ways that reduce grazing pressure. Most studies highlight the role of predators in reducing herbivore abundance (i.e., density-mediated interactions), while behavioural effects (i.e, trait-mediated interactions) induced by predators are less commonly considered, and are often assumed to be of secondary importance. I used a mesocosm experiment to evaluate the consumptive and behavioural effects of two species of predatory fishes on amphipod grazers that feed and nest on the giant kelp, Macrocystis pyrifera. Only one (Notolabrus celidotus) of the two predator species reduced grazer abundance. Although the second predator species (Notolabrus fucicola) did not affect grazer abundance directly, it significantly reduced the grazing efficiency of amphipods on blades of $M$. pyrifera. The present study illustrates how density and trait-mediated interactions reduce grazer efficiency and provide potential indirect benefits to primary producers. To my knowledge, this is the first experimental evidence of a potential trophic cascade in kelp beds generated by consumptive and non-consumptive effects. When considered alongside results of other studies that highlight positive effects of macroalgae on reef fish 
demographic rates, these results provide compelling evidence that mutualistic relationships may exist between kelp and associated predatory fishes.

\subsection{Introduction}

Predation is a pervasive process that can influence community organization (Paine 1966; Schmitz 1998; Duffy and Hay 2001) and ecosystem functioning (Schmitz 1998; Sih et al. 1998; Schmitz 2009). A fundamental component of predation is the direct removal of prey, leading to reductions in the numerical abundance of prey populations (Murdoch et al. 2003). Such reductions are considered density-mediated interactions (DMI) between predators and prey (Abrams 1995). Most food-web studies have focused on DMIs, placing keystone predation, exploitative competition, and cascade effects in the context of changes in densities of predators and/or prey populations (Sih et al. 1998; Duffy and Hay 2001). However, predators can also induce phenotypic effects (i.e., trait-mediated interactions, TMI, on prey populations (Abrams 1995))ñ on prey populations (Lima 1998). These effects may include morphological, physiological, or behavioural responses from prey (Preisser et al. 2005). For example, when confronted with predators, most prey seek refuge, which may result in a period of inactivity (Sih 1980; Lima and Dill 1990). This shift in behaviour patterns can alter the per capita effects of the prey species on other species (see Werner and Peacor 2003, references therein). Though both density and trait-mediated interactions can, in principle, affect the dynamics of other species in the local community (Abrams 1995), the relative importance of these two pathways is poorly known in most cases (but see Luttbeg et al. 2003). 
Many temperate subtidal areas are characterized by the presence of habitat forming kelps (Dayton 1985a), including Macrocystis pyrifera, which forms dense forests in the Northern and Southern hemisphere (Pérez-Matus et al. 2007). Many seaweed populations are influenced by herbivory (Dayton 1985a). Although several species of large invertebrates are known to be important grazers of $M$. pyrifera (for review see Steneck et al. 2002), small mobile invertebrates (mesograzers) such as amphipods are also potentially important in structuring seaweed populations (Duffy and Hay 2000; Graham 2002; Haggitt and Babcock 2003). Amphipods are one of the most abundant and diverse groups of small invertebrates inhabiting M. pyrifera (Coyer 1984) and other temperate brown macroalgae (Taylor and Cole 1994). The cumulative effects of grazing by amphipods may be similar to other herbivores on kelp beds (Sala and Graham 2002), in some cases these effects may be stronger (Haggitt and Babcock 2003). Furthermore, the high diversity of amphipod species suggests that feeding patterns may vary (Duffy 1990), implying a potential range of ecological consequences attributable to this group of mesograzers (Duffy and Hay 2000).

In kelp habitats, amphipods also provide a link between kelp and higher trophic levels, including fish, which are voracious predators of amphipods (Jones 1988a; Holbrook et al. 1990b; Taylor 1998a). Top-down control of amphipods by fishes constitute a positive indirect effect, in which fishes benefit the health and growth of kelp (Davenport and Anderson 2007; Newcombe and Taylor 2010). Some marine fishes are known to substantially reduce the local abundance of amphipods, but no studies (to my knowledge) have addressed possible trait-mediated effects of fishes on amphipod-kelp interactions. In 
freshwater systems, several studies have indicated that amphipods under threat of predation tend to reduce foraging time (Andersson et al. 1986), mate less frequently (Cothran 2004), and alter their mating decisions (Dunn et al. 2008). These behavioral responses to predators may deleteriously affect prey populations and alter community structure via trophic cascades. How fishes in temperate kelp systems might affect interactions between amphipods and $M$. pyrifera remains unknown.

Many ecological communities are comprised of multiple predators that may target a common prey item and contribute to density- and/or trait-mediated interactions (Schmitz 2007). In some cases, the presence of multiple predators may actually reduce the overall risk of predation, when for example, two or more predators interfere with each other, or when predators also prey on each other (i.e., intraguild predation). Alternatively, the presence of two or more predators may enhance their individual effects (e.g., when the anti-predator behaviour of prey to one predator increases its risk to other predators; see Hixon and Carr 1997; Van Son and Thiel 2006).

Here, I use a mesocosm study to evaluate the separate and joint effects of two common reef fishes (Notolabrus celidotus and N. fucicola: Family Labridae) on the interaction between amphipod grazers and the kelp M. pyrifera. Specifically, we evaluated the effects of fishes on the survival (DMI) and grazing efficiency (TMI) of amphipods. Both fish predators are common inhabitants of M. pyrifera kelp forests, and both feed upon invertebrates including amphipods. We hypothesised that similar feeding modes exhibited by these two fishes would not lead to risk enhancement for amphipod prey. Instead, we predicted that the two fish predators might interfere with one another, leading to enhanced prey 
survival in the presence of both predators (Schmitz 2007). Finally, I hypothesised that the effects of fishes on amphipods would be consumptive, such that fishes might alter amphipod-kelp interactions primarily via density-mediated interactions

\subsection{Materials and Methods}

6.3.1 Preliminary studies and field collections

The gammarid amphipods used in this study (Pseudopleonexes lessoniae and Bircenna macayai) live and feed upon blades of Macrocystis pyrifera as well as other brown macroalgae. My preliminary studies confirmed that both amphipods leave similar grazing marks when consuming $M$. pyrifera; however, they differ in their sheltering behaviors (M. Thiel personal communication) (see Fig. 6.1 and 6.2 for illustrations). 

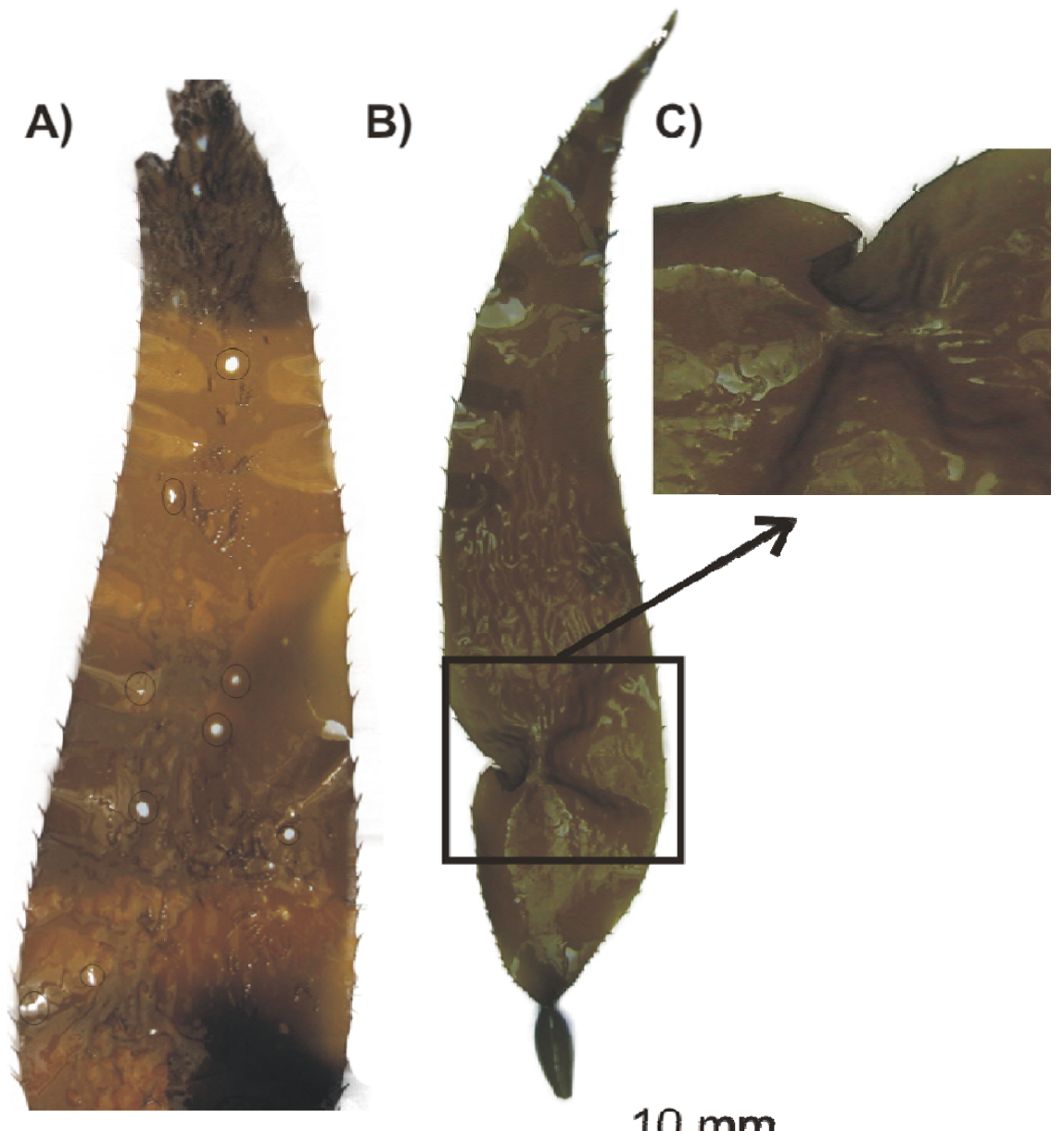

$10 \mathrm{~mm}$

Figure 6.1 depicting a) grazing marks on a blade of Macrocystis pyrifera after 3 days in experimental aquaria b) blade with single nest, and c) close-up of single nest constructed by one individual of Pseudopleonexes lessoniae. 


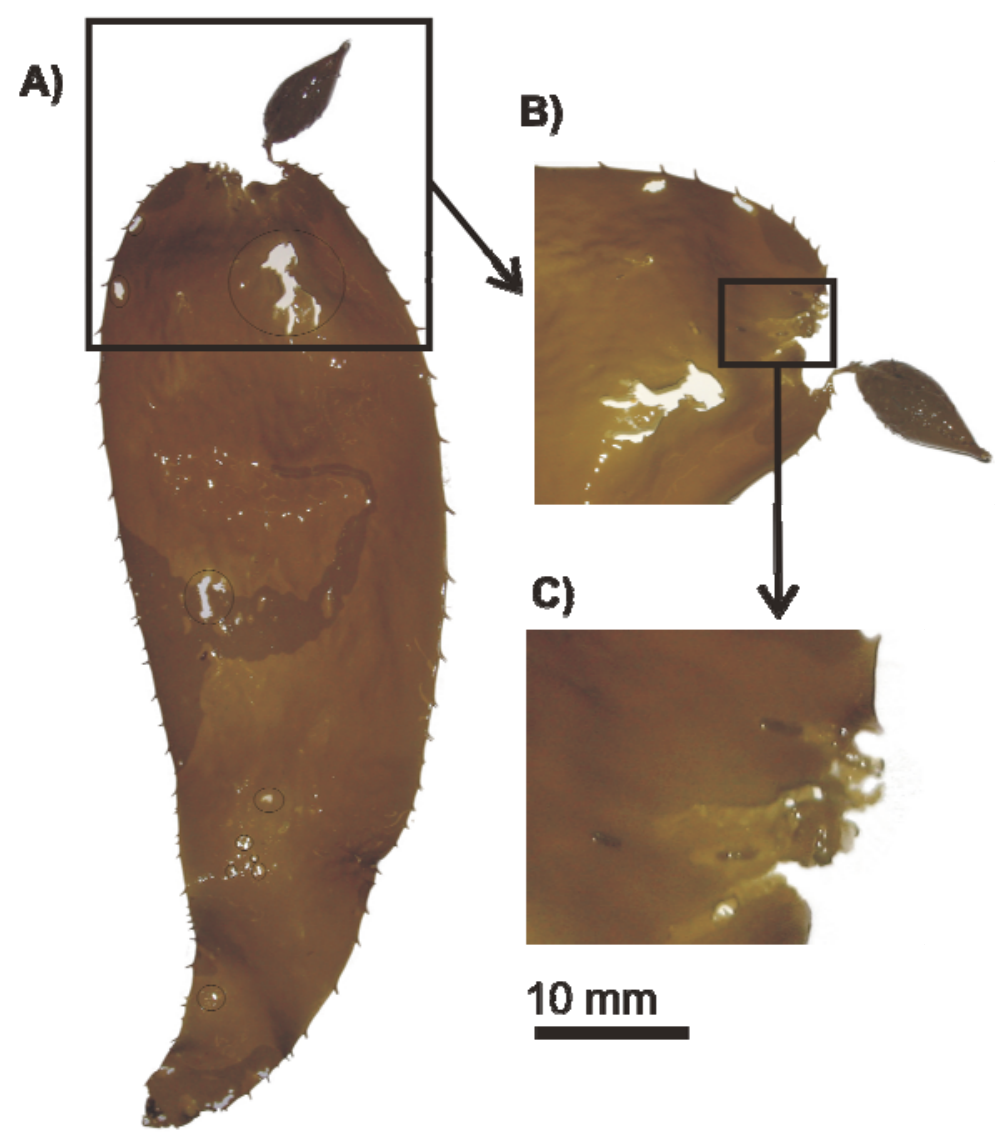

Figure 6.2 depicting a) grazing marks on a blade of Macrocystis pyrifera after 3 days in experimental aquaria b) a close-up of grazing marks and a blade that has become dislodged from pneumatocysts due to grazing, and c) close-up of feeding galleries with 3 individual Bircenna macayai

According to my surveys from a representative location within the study region (see below), mean amphipod densities can reach up to $11.52( \pm 4.82 S D)$ per frond of M. pyrifera (Fig. 6.3). Amphipods are common prey items for fish predators including the locally common labrids Notolabrus celidotus and $N$. fucicola (Russell 1983; Denny and Schiel 2001; Francis 2001). Juveniles and adult Notolabrus celidotus and $N$. fucicola are commonly found in association with M. pyrifera on rocky reefs of Wellington, New Zealand (see Chapters 4,5 and Pérez-Matus and Shima 2010). 


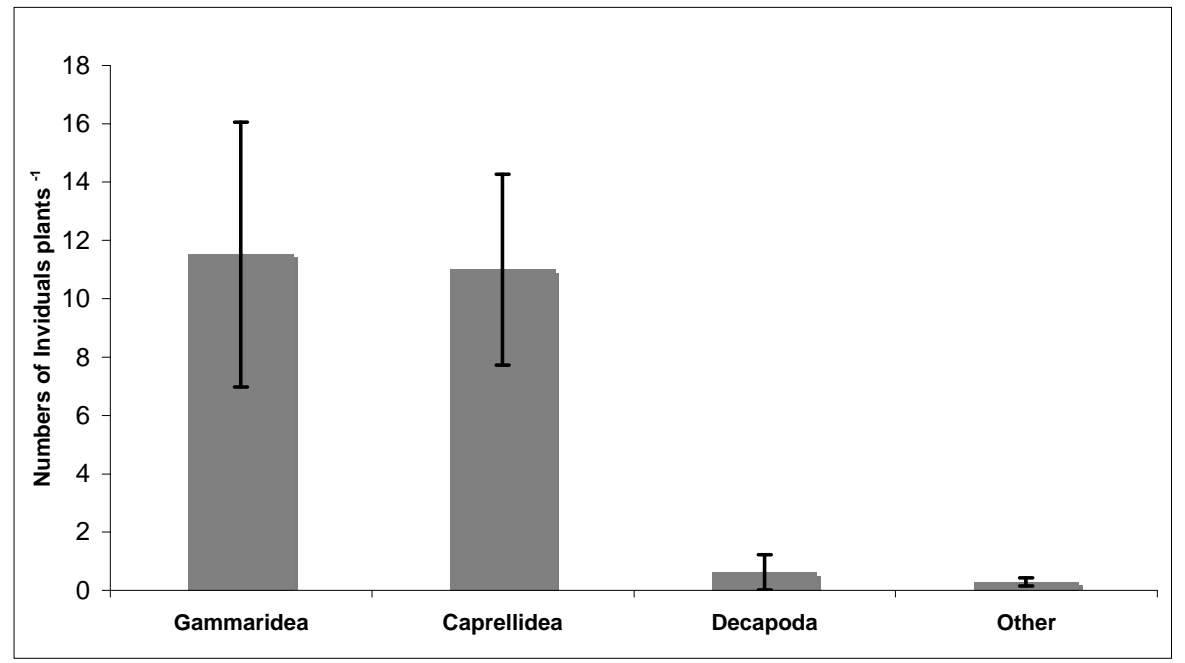

Figure 6.3 Mean $( \pm \mathrm{SD})$ of associated fauna on one-meter apical lengths of fronds of adults of $M$. pyrifera

I collected six one-meter apical lengths of fronds of adult $M$. pyrifera individuals, using mesh collecting bags $(0.5 \mathrm{~mm}$ mesh $)$ that were designed to retain the associated epifauna (including the mesograzers Pseudopleonexes lessoniae and B. macayai). I then used seawater to rinse the epifauna from each sampled M. pyrifera length into a sieve. I collected 12 juvenile $N$. celidotus (each $\sim 14 \mathrm{~cm}$ in total length, TL) and 12 juvenile $N$. fucicola $(\sim 20 \mathrm{~cm}$ TL) using baited traps (constructed with knotless $15 \mathrm{~mm}$ mesh, $75 \mathrm{~cm}$ in length, with a mesh opening of $8 \mathrm{~cm}$ diameter, baited with mussels, and deployed beneath kelp canopies for $\sim 10$ minutes). Prior to each experimental trial (see below), newly collected fish individuals were acclimatized (without food) between $24-32 \mathrm{~h}$ in indoor tanks with circulating seawater. Amphipods were acclimatized in separate tanks with aerated seawater only for the same period. All individuals (macroalgae, amphipods and fishes) were used only once (i.e., new organisms were collected for each trial). 


\subsubsection{Experimental design}

Experiments were conducted in outdoor tanks (mesocosms) at the National Institute of Water and Atmospheric Research (NIWA, Greta Point, Wellington), and all organisms used for these studies were collected from a common location

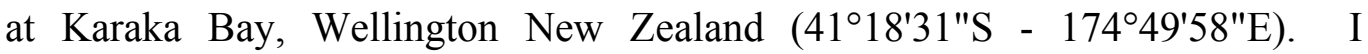
constructed 5 experimental mesocosms using black plastic tanks $(150 \mathrm{~cm}$ diameter, $45 \mathrm{~cm}$ height) supplied with recirculating water at a flow rate of $10 \mathrm{~L}$ $\min ^{-1}$ (Fig. 6.4 a). Tanks were covered with $0.5 \mathrm{~mm}$ mesh that provided shade to M. pyrifera (to more closely match the light environment experienced by seaweeds in the field) and prevented fishes from jumping out of the tanks. At the centre of each tank we constructed a cylindrical cage $(60 \mathrm{~cm}$ diameter and 2 $\mathrm{mm}$ mesh size, spanning the full height of the tank). This cage structure facilitated our manipulation of fish access to $M$. pyrifera and amphipods, as required for some experimental treatments (described below). To evaluate potential cage artefacts (Steele 1996), we used mock cages (with an open panel) for a set of our fish exclusion and control tanks (detailed below). Within each tank we added a single frond of $M$. pyrifera ( $\sim 50 \mathrm{~cm}$ length), which included an average of $20( \pm 3 S D)$ blades and the apical meristem (Fig. 6.4 b). In order to avoid the effects of grazing history on the experimental blades, I carefully selected fronds without grazing marks. 

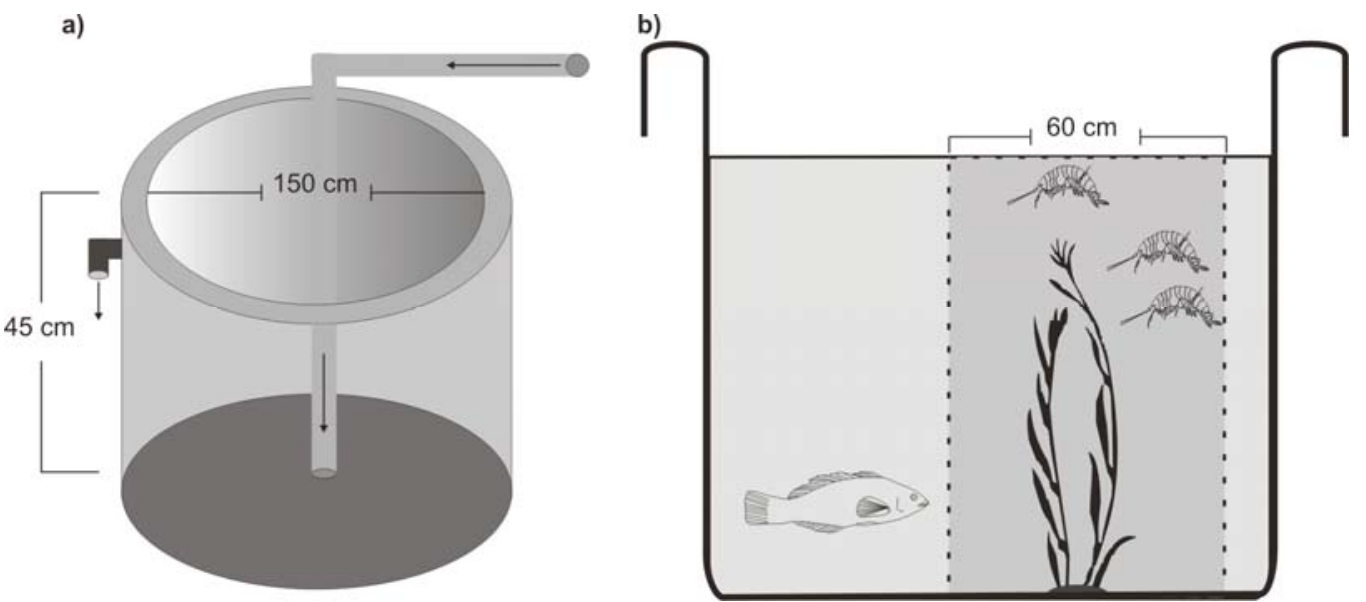

Figure 6.4 a) Mesocosm dimensions and arrows representing flow of seawater; and b) mesocosm shown in cross-section to illustrate placement of organisms relative to internal cage. Each mesocosm contained one cage. Each cage contained a single frond of M. pyrifera. For all treatments except the "autogenic" treatment, an initial population of amphipods was introduced to the kelp frond. Fish were then added to the cage as prescribed by the treatments (refer to methods). Organisms within tanks are not shown to scale.

Experimental fronds were established with standardized densities of mesograzers. To ensure that all epifauna were removed from experimental fronds, these were soaked in fresh water for 3 minutes immediately prior their addition to the experimental tanks (this effectively removed any remaining epifauna not captured by the initial sieving). This treatment did not seem to adversely affect M. pyrifera. I attached defaunated fronds to a rock at the bottom-centre of each tank with a plastic cable-tie. Finally, I supplied a standardized number and composition of amphipods to each mesocosm. The composition of amphipods added to each mesocosm was identical within trials. For all trials but one, I added 6 individuals of each species of amphipod. For the aberrant trial, I stocked mesocosms with 5 individuals of Pseudopleonexes lessoniae. and 2 of $B$. macayai (because I was limited by the total number of amphipods obtained from our prescribed collection regime). Amphipods were added to mesocosms one hour prior to the addition of predatory fishes. 
Using this basic conFig.uration, I established 5 unique treatments to evaluate the direct and indirect effects of $N$. celidotus and $N$. fucicola (separately and in combination) on the survivorship, nesting behaviour, and grazing efficiency of amphipods on M. pyrifera. Treatments were as follows: (1) " $N$. celidotus predator": 6 juvenile $N$. celidotus and amphipods were added to the central cage of the mesocosm (i.e., with M. pyrifera). (2) "N. fucicola predator": 6 juvenile $N$. fucicola and amphipods were added to the central cage of the mesocosm. (3) "Both predators": 3 juvenile N. celidotus and 3 juvenile $N$. fucicola and amphipods at ambient densities were added to the central cage of the mesocosm. (4) "Fish exclusion" in which three individuals of N. celidotus and three of $N$. fucicola were added to the tank but outside the cage (i.e., fishes had no direct access to kelp and amphipods, which were inside the cage), (5) "autogenic" in which kelp was included without either fish or amphipods; this treatment served as a control that enabled me to evaluate the overall performance of the kelp (e.g., background tissue accumulation or degradation) under experimental mesocosm conditions in the absence of grazing pressure. This treatment also helped me to develop protocols to distinguish between natural decay and grazing marks caused by amphipods.

I employed a "substitutive design" which held the overall predator density constant, because one of our primary goals was to evaluate interspecific interactions (Sih et al. 1998). Because I was constrained by the number of available tanks for mesocosms, I replicated treatments in time (i.e., "trials"; rotating the assignment of treatments across tanks for each trial). The duration of each experimental trial was six days. I completed a total of 8 trials $(n=8$ replicates) for each treatment, and all trials were completed between 10 February 
and 22 April 2009.

\subsubsection{Density-mediated effects of fishes on amphipods}

Lethal effects (i.e., predation) of fishes on amphipods were estimated as the proportion of amphipods surviving after each trial. Following each trial period, I removed fishes and sieved the contents of each tank, recording the number of remaining amphipods.

I used generalized linear models (GLM) (Crawley 2007) to analyse our data because our response variable (proportions based upon counts) had unequal variances and non-normally distributed errors. I contrasted all predator access treatments against the fish exclusion treatment (i.e., " $N$. celidotus predator", " $N$. fucicola predator", "Both Predators" vs. "Fish exclusion"), using the proportion of amphipods surviving as the response variable. For this GLM I specified a binomial error distribution and a logit link function. Data were overdispersed (residual deviance model $=43.7, \mathrm{df}=28$ ) and were corrected using a quasibinomial error distribution (Crawley 2007). I conducted a second set of contrasts to detect emergent impacts of multiple predators (Sih et al. 1998). I contrasted the proportion of amphipods surviving in the treatment with both fishes present against treatments with either $N$. celidotus or $N$. fucicola present (i.e., "Both Predators" vs. "N. celidotus predator" and "Both Predators" vs. " $N$. fucicola predator"). A significant difference between treatments was interpreted as evidence of emergent multiple predator effects (MPE). Data were overdispersed (residual deviance model $=72.16$, df $=28$ ) and were corrected using a quasibinomial error distribution (Crawley 2007). Moreover, I calculated the expected survival (E) of amphipods assuming independence in the presence of both fish predators (Vonesh and Osenberg 2003) as: 
$\mathrm{E}_{(\text {N.celidotus.N.fucicola })}=\left(\sigma_{\text {N.celidotus }} \times \sigma_{N . \text { fucicola }}\right) /\left(\sigma_{\text {fish-exclusion }}\right)$

where $\sigma$ is the mean proportion (\%) of amphipods that survived in each treatment. This was further compared with the mean number of survivors from the treatment when both fish predators where together, to detect risk reduction or enhancement on survivorship of amphipods (Vonesh and Osenberg 2003).

6.3.4 Trait-mediated effects of fishes on the grazing efficiency of amphipods

Grazing marks left by amphipods are indicative of their direct consumption of $M$. pyrifera tissue. I characterized grazing marks inflicted by the two amphipod species in the focal study. Undamaged portions $M$. pyrifera blades were individually immersed in indoor aquaria with seawater and with specimens of amphipods. These observations enabled me to identify grazing marks in the mesocosm experiment (and to differentiate these from algal decay). I assessed grazing activity on six randomly selected blades taken from each treatment/trial in our mesocosm experiment. I counted all apparent grazing marks, and to estimate grazing efficiency, I standardized these counts by the effective densities of amphipods (i.e., I multiplied the observed number of grazing marks by the ratio between the number of amphipods (initial number of individuals) and the number of blades within the mesocosm).

I conducted a preliminary analysis to validate our estimates of grazing mark by contrasting our "Fish exclusion" treatment (i.e, amphipods present) and our "Autogenic" control (i.e., amphipods absent). Following this initial assessment, I used GLM (with Poisson error distribution and log link function) to evaluate variation in amphipod grazing efficiency, contrasting each of the 
predator access treatments against the "Fish exclusion" treatment (i.e., " $N$. celidotus predator", "N. fucicola predator", "Both Predators", vs. "Fish exclusion”). Data were overdispersed (residual deviance model $=1183, \mathrm{df}=235$ ) and were corrected using a quasipoisson error distribution (Crawley 2007). All statistical tests were performed using R 2.10.

\subsection{Results}

\subsubsection{Density-mediated effects}

When fish were excluded from the inner cage of mesocosms, amphipods persisted at $\sim 50 \%$ of their initially stocked densities. I attributed these losses of amphipods to emigration from the kelp fronds (mesh size of $0.5 \mathrm{~mm}$ did not prevent movement of amphipods). Where $N$. celidotus was present alone, amphipods were reduced to $\sim 10 \%$ of their initial stocked densities (Fig. 6.5a), and relative to the "fish exclusion" treatment, this suggests an $80 \%$ decrease in amphipod survival $(t=3.12, \mathrm{df}=28, P<0.001)$. A similar reduction in survival (i.e., population were reduced to $\sim 12 \%$ of initial densities) was observed in the treatment where both fish species had access to amphipods $(t=2.63, \mathrm{df}=28, P<$ 0.01). When only $N$. fucicola had access, amphipod populations persisted at $\sim 40 \%$ of initial stocking densities, and relative to the "fish exclusion" treatment, this did not reflect a significant reduction in amphipod survival $(t=0.55, \mathrm{df}=28$, $P=0.55)($ Fig. 6.5a).

Results from this mesocosm experiment do not suggest emergent multipredator effects. The expected proportion of amphipod survivors (assuming the effects of predators were independent of one another), this was determined to be 
$8.6 \%$ and did not differ significantly from observed proportion $(12.3 \pm 10.1$ $[$ mean $\pm 95 \% \mathrm{CI}] \%$ ), indicating an absence of emergent multi-predator effects (or our inability to detect such effects given our level of replication) when both predatory fishes were together $(t=-0.57, \mathrm{df}=28, p>0.05)$. In this case, the absence of an emergent multi-predator effect is not surprising because only one predator (N. celidotus) appeared to be an effective consumer of amphipods in the mesocosm experiment (e.g., Fig. 6.5 a).

\subsubsection{Trait-mediated effects of fishes}

Both amphipod species (Pseudopleonexes lessoniae and Bircenna macayai) caused visible marks on $M$. pyrifera in our preliminary aquarium experiment, and marks concordant with these observations were readily identifiable in both the mesocosm experiment and our casual field observations. Both species damaged only the blade lamina of $M$. pyrifera, and left no grazing marks on pneumatocysts. Both species generated deep bites on the blades that can result in complete holes. However, only Pseudopleonexes lessoniae inflicted substantial lateral damage and bites along the blades, such that within 3 days blades routinely became detached from the pneumatocyst. In contrast, grazing by Bircenna macayai more commonly resulted in the formation of a "gallery" of $\sim 1 \mathrm{~cm}$ long, and within this structure grazing appeared to proceed primarily beneath the blade surface (e.g., from within a "burrow" structure). Pseudopleonexes lessoniae constructed nests within a period of hours, and they can also leave grazing marks inside the nests (see photographs of grazing marks, nests and galleries).

After 3 days with $M$. pyrifera blades in aquaria, both amphipod species consumed substantial amounts of algae, and their activity gave a very clear 
"search image" for grazing marks, and this informed my estimates of grazing efficiency in my mesocosm treatments (see Figures 6.1 and 6.2 for details).

Grazing efficiency of amphipods increased 15-fold in the absence of fish predators (i.e., relative to the Autogenic treatment, where amphipods were not added: $t=-6.27, \mathrm{df}=235, P<0.001)$. I believe this significant difference validates my identification of grazing marks left by amphipods.

Relative to the "fish exclusion" treatment, the presence of $N$. celidotus and $N$. fucicola alone resulted in a 5-fold decrease $(t=-5.72, \mathrm{df}=235, P<0.001$; Fig. 1b) and a 2-fold decrease $(t=-2.11, \mathrm{df}=235, P<0.01)$ in the number of grazing marks respectively. Relative to the "fish exclusion" treatment, the presence of both predators resulted in 2.5 -fold decrease in the number of grazing $\operatorname{marks}(t=-4.175, \mathrm{df}=235, P<0.001$; Fig. $6.5 \mathrm{~b})$. 

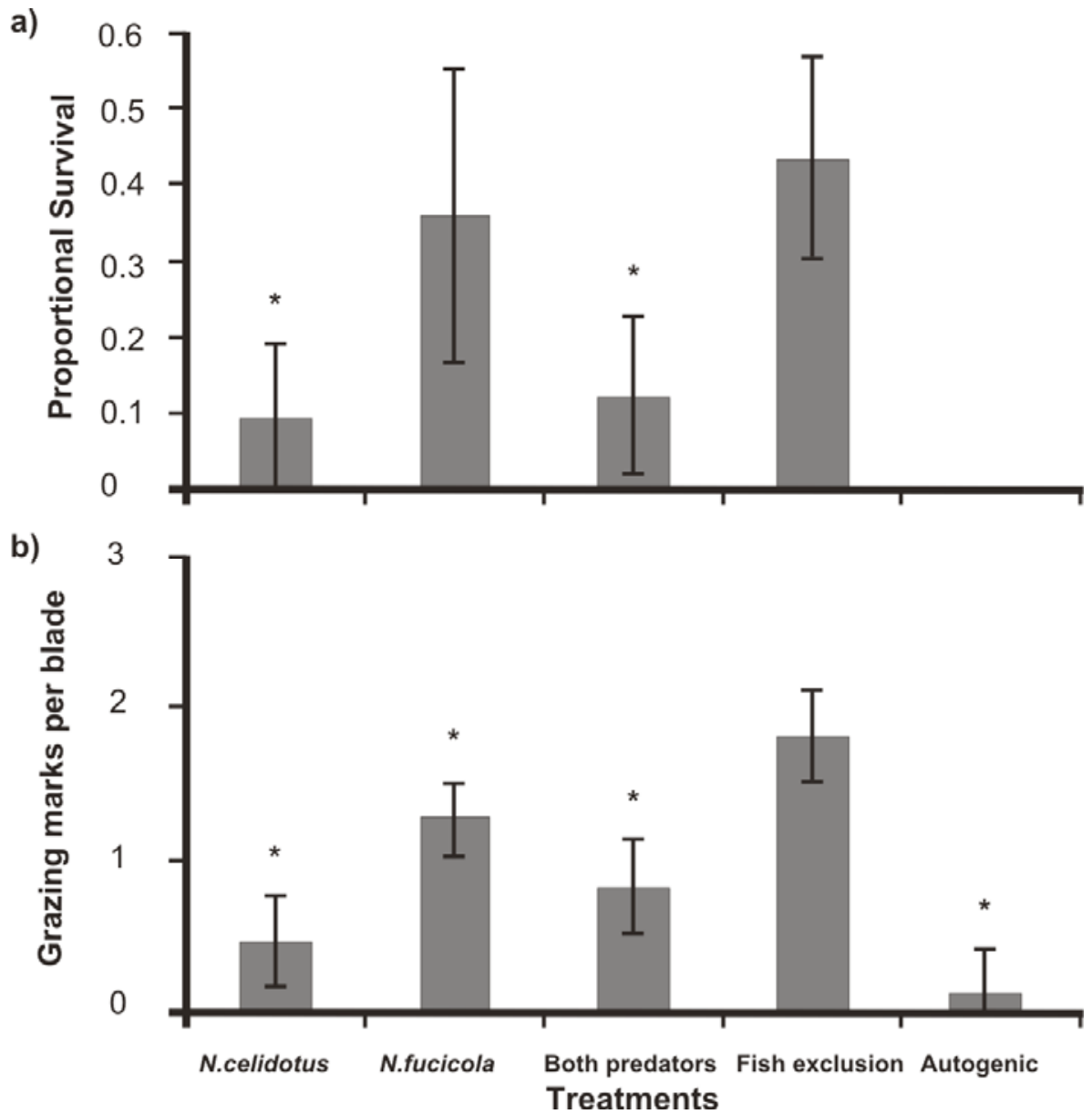

Figure 6.5 a) Proportional survival $( \pm 95 \% \mathrm{CI})$ of amphipods; b) mean $( \pm 95 \% \mathrm{CI})$ of per-capita number of grazing marks per blade. Treatments are as follows: "N. celidotus" present, "N. fucicola" present, "Both predators" predators, "Fish exclusion" and "Autogenic control". * denotes significant $(\mathrm{P}<0.05)$ differences relative to the treatment "Fish exclusion". 


\subsection{Discussion}

The present study suggests that two temperate reef fishes exert positive indirect effects on seaweeds (via consumption or behavioural modification of grazers), and that these two fish species do not interfere with one another or otherwise enhance the risk of their prey.

Specifically, I found that both fish species in our study independently reduced the grazing pressure of amphipods on $M$. pyrifera, and importantly, they appeared to produce this effect via different mechanisms. Notolabrus celidotus exerted a direct effect on the amphipod-algae interaction by reducing the numerical abundance of amphipods grazers via consumption. In contrast, $N$. fucicola did not appear to directly consume our focal amphipod species (at least in the context of our experimental mesocosms). Instead, $N$. fucicola exerted an indirect effect on amphipod-algae interactions, perhaps by altering the behaviour of amphipods.

In the presence of $N$. celidotus, amphipods survived poorly and this may explain their reduced grazing activities on blades of $M$. pyrifera. Thus, $N$. celidotus appears to affect amphipod-algae interactions via a density-mediated interaction (DMI). In contrast, the presence of $N$. fucicola appears to induce a behavioural change in amphipods that also results in reduced grazing activity, and this is consistent with $N$. fucicola provisioning benefits to M. pyrifera via a trait-mediated interaction (TMI). The strength of the DMI in this system appears to be twiace as strong as the TMI. Some authors have argued that DMIs are more important in magnitude than TMIs (but see Huang and Sih 1990). The strength of both DMIs and TMIs depend on the foraging behaviour of predators and risk effects posed to prey species (Schmitz and Suttle 2001). In short, prey 
species may trade-off risks of starvation with risk of being eaten (both are function of foraging time) (Schmitz et al. 1997). Both DMIs and TMIs must be considered when evaluated predatory impacts on communities.

The importance of trait-mediated effects is apparent across a range of environments. Turner $(1996,1997)$ demonstrated the effects of a TMI involving molluscivorous fish and a snail grazer on periphyton dynamics in a freshwater system. Similarly, Trussell et al. $(2002,2004)$ found that TMIs could be even more important than the direct consumption by predators in some marine tide pools. Most studies of TMIs, however, have been conducted with predators on target prey: non-consumptive effects become important in community dynamics interesting when predators induce behavioural changes in non-targeted prey whilst reducing the strength of herbivory on plants (Walser and Schausberger 2009).

This study confirms that the mere presence of a predator (e.g., N. fucicola) can reduce herbivore damage by a non-target prey. Reduced foraging activity and increased use of shelters to decrease detection by predators are common anti-predator behaviours. These have been described previously in several amphipod-fish predator interactions (Williams and Moore 1985; Andersson et al. 1986; Bollache et al. 2006). According to the trait compensation hypothesis, prey with poor morphological defence might show stronger anti-predator behaviors than morphologically well-defended prey (Dewitt et al. 1999). Amphipods may initiate a series of behavioural actions to avoid natural enemies (e.g., N. celidotus) or unusual predators (e.g., N. fucicola in our study). Both amphipod species and both sexes of amphipods examined here have the ability to construct "nests" by curling the blades of macroalgae (Appadoo and Myers 2003), or they may 
generate "galleries" that provide sites for reproduction and refuge from predators while feeding. Like many crustaceans, amphipods may use chemical cues to detect- and escape from predators (Hazlett 1999). I observed losses of amphipods of close to $50 \%$ when predators were present in the experimental mesocosm but unable to access their prey. One possible explanation for these losses is that the prey (i.e., amphipods) may detect chemical cues from fish predators, and subsequently, attempt to emigrate to a safer location. Unfortunately, this experimental design did not include a treatment with amphipods present and fish absent from the mesocosm so I'm unable to address this possibility directly.

I was unable to identify a significant emergent multiple predator effect (MPE) on amphipod survival when both fish predators where present. I did not find risk reduction or enhancement of prey consumption, suggesting that when they are together, these predators do not interfere with each other. Amphipod survival was low when $N$. celidotus was present alone. Amphipod survival was similarly low when $N$. celidotus was present with $N$. fucicola; this is considered to be a trivial MPE (Sih et al. 1998). This is concordant with the majority of MPE studies which have found that multiple predators are not substitutable in their consumption of prey (reviewed by Sih et al. 1998). Although amphipods frequently occur in the diet of both fishes (Russell 1983; Denny and Schiel 2001), the lack of substitutable predatory effects between $N$. fucicola and N. celidotus may be explained by a combination of a lack of competition for prey resources (suggesting resource partitioning) and a narrow habitat domain of amphipods (i.e, occurring only on fronds of $M$. pyrifera). For example, if in the field one predator forages more commonly on fronds while the other forages on the 
holdfast as have been suggested (Jones 1984b; Denny and Schiel 2001), MPEs would be expected to be trivial (or else dependent upon the degree to which amphipods move between these microsites within $M$. pyrifera). Hence, spatial partitioning of prey and predator activities could simplify to, effectively, two separate single predator-prey systems, where only one predator is able to reduce amphipods numerically in each microsite (Schmitz 2007 ).

Reported ontogenetic changes in the diet of the fish predators offer another explanation to the observed differences between fish species in their propensity to consume amphipod prey. Both $N$. celidotus and N. fucicola undergo dietary shifts in their preferences for small crustaceans such as amphipods (Jones 1984b; Denny and Schiel 2001). According to Denny and Schiel (2001), larger N. fucicola (such as those used for this study) consume more hard-shelled prey than smaller size classes ( $\sim 150 \mathrm{~mm}$ in TL), which more regularly consume amphipods. While larger $N$. fucicola may no longer target amphipods as prey, amphipods may be unable to distinguish between size classes of known fish predators.

Grazing activities of amphipods may have substantial effects on many marine communities (Haggitt and Babcock 2003). At least one study suggests that grazing pressure increases following El Niño events, when amphipod populations have been observed to increase (Tegner and Dayton 1987). Grazing by amphipods may be severe enough to limit recruitment (Tegner and Dayton 1987; Graham 2002) and lead to compensatory growth of $M$. pyrifera (Cerda et al. 2009). Fishes are known to mediate amphipod populations by consumptive effects that can reduce local densities of amphipods (Newcombe and Taylor 2010). Thus, fishes may also be expected to regulate grazing pressure and 
benefit $M$. pyrifera via DMIs. In the study area, fish densities are elevated in vegetative structures (Pérez-Matus and Shima 2010) and maybe sufficiently high to suppress amphipod populations. My results are partially consistent with other experiments conducted in mesocosms (Duffy and Hay 2000; Newcombe and Taylor 2010) and field caging experiments manipulating fish predators (Davenport and Anderson 2007; Korpinen et al. 2007), in that they revealed a significant effect of amphipods on benthic biota in the absence of fish predators. The present experiment also suggest that fishes may similarly benefit $M$. pyrifera via a non-consumptive (i.e., TMI) effect on prey behaviour. The data provided in this study motivate future research into the behaviour, ecology and evolution of possible mutualistic relationships between kelp and their associated fish fauna. 


\section{CHAPTER 7}

\section{Summary, final considerations and future research}

The relationships between environmental variables and the distribution and abundance of fishes provide essential insights into the processes that regulate the structure of subtidal reef communities (Luckhurst and Luckhurst 1978; Jennings et al. 1996). A range of interactions between fishes and their environment determine observed distributions and abundances of fishes. Mediated by potentially conflicting behavioural decisions, fishes may partition resources given by different macroalgal elements (e.g., algae with different morphologies, different combinations of macroalgae, etc.). Results of this study indicate variation in the use of particular habitat. This variation potentially reflects different adaptations such as feeding, and refuge from competition and predation. Since reef habitats are spatially and temporally heterogeneous, adaptations to particular habitat elements may lead to diversification (Wellenreuther et al. 2007; Wellenreuther and Clements 2008).

\subsection{Diversity of fishes on temperate reefs: the importance of spatial hierarchies}

Reef fish assemblages vary greatly at scales of 10 s to 1000 s of kilometres (Connolly et al. 2005). Interestingly the abundance, richness and diversity (including evenness) vary as a function of spatial scale (Chapter 2). At local 
scales, for example, fish species diversity is better explained at smaller scales, whereas patterns of abundance and species richness can be explained at intermediate and larger spatial scales respectively.

Canopy-forming kelp forests are important conduits for ecological processes and energy production on temperate coasts (North 1971; Steneck et al. 2002) but these changes depending of the scale of observation (see Connell and Irving 2008). It is necessary then to identify how processes are distributed at both local and biogeographical scales. Researchers seek to relate ecological phenomena across scales and to estimate the extent and limits of the spatial generalization (Whittaker and Levin 1977). This becomes highly important for conservation as it gives stakeholders a set of boundaries where management practices are successful.

Explaining global patterns in species diversity has occupied ecologists for more than 50 years (Fernández et al. 2007; Jaksic and Marone 2007a). Contributions to the understanding of diversity patterns are at the community level where species distributions are coupled with resource use. Spatial patterns in community structure are often coupled between habitat and the associated fish communities (Burgess et al. 2010). Patterns of habitat use by species are known to be consistent throughout species' distribution range (Wellenreuther et al. 2008). In Chapter 2, I explored the differences in the relative abundance of fishes in macroalgal habitats among three different regions. This chapter is descriptive and incorporates several concepts from macro-ecological theory. Importantly, this chapter indicates that different levels of spatial hierarchies (sites, locations, regions) act differently for species richness (i.e., colonization, speciation), abundance (perhaps related to the productivity of each particular 
location and region), and diversity (proportions of species differ among sites). Traditionally, diversity studies have identified the persistent relationship between species richness (S) and the environment and how species partition the resources available (MacArthur 1957). This allowed researchers to conclude that environmental influences shape populations, and permit them to co-exist at local scales.

The comparative study of reef fish faunas performed in Chapter 2 showed that two or three families with dissimilar species dominate most reef fish assemblages at the surveyed locations. The different identities may indicate that the observed relationship of diversity among macroalgal habitats is explained by the evolutionary diversification of lineages (see Ricklefs et al. 2004). This may represent historic (i.e., phylogenetic) influences on ecological communities undergone by each location (Ricklefs 2006). Speciation among heterogeneous habitat and the scale at which generalities of patterns of diversity and abundance on habitats warrant further research (Ricklefs 2006). This chapter is descriptive but it directed subsequent chapters to finer-scale patterns in species richness and abundance at different habitat heterogeneity levels.

Using time series observations at different sites and seasons (Chapters $2-$ 4) I was able to identify variation in abundance and the proportion of species in relation to different macroalgal structures and other aspects of habitat heterogeneity. These variations were attributable to different niche requirements in the use of macroalgal stands. Other studies have reported different distributions and concentrations of food (small mobile invertebrates associated with macroalgae) among algal elements (Taylor and Cole 1994; Taylor 1998b), and different types of refuge provided from predators (particularly for recently 
recruited fish) (Anderson 1994). The provision of different "services" to fishes determines which habitats are capable of sustaining more fish species. Not all macroalgal habitats have the same influence over fish occurrence, abundance and size distributions. For example, I found that macroalgal habitats composed of mixed canopies of laminarians and fucaleans harboured more fish and greater fish biomass.

\subsection{The effects of macroalgae on fish populations}

Both observational and experimental studies performed in this thesis enabled me to characterize fish species as: (i) "habitat specialists" whose abundance depended on specific algal structures, (ii) "habitat generalist" fishes that are not affected by macroalgal elements, and (iii) "macroalgal habitat avoiders" whose abundances were reduced by the three-dimensional structure of macroalgae. This classification is important as it categorized fishes into different levels, thus their effects over the community of temperate reefs (distribution, abundance, composition) cannot be overlooked. For example, the absence of top fish predators in kelp-dominated areas generate urchin barrens, consequently decreasing the habitat heterogeneity and productivity of kelp environments (Cowen 1983) I explored potential benefits to generalist and specialist fishes from kelp (see below) in Chapter 6 but further research could incorporate how different categories of fishes collectively affect community patterns.

Experimental studies that assess the importance of macroalgae over the distribution, behaviour and abundance of reef fishes are well-documented in the literature. Table 7.1 summarizes experimental manipulations conducted in other 
temperate regions. A total of 21 manipulative studies showed that macroalgae (in its varying forms) could have important effects on coastal fishes. Most of these experiments comprised removals of macroalgae. Responses of fishes to removal were species-specific and varied throughout ontogeny. Macrocystis pyrifera was the most-frequently manipulated large brown macroalgae, with removals, manipulations or additions performed in 7 of the studies. This was followed by Sargassum spp. and Ecklonia radiata with 6 and 4 manipulated studies, respectively. Spatial extents of manipulated patches also varied greatly. Lastly only 4 studies incorporated separated each year classes of fish with habitat associations.

Although variable responses were evident from these studies, most of the fish species increased in abundance in the presence of large brown macroalgae. Feeding preferences or refuge from predators were the dominant explanations for the presence of fishes in macroalgae (Table 7.1). Habitat manipulations in temperate regions are still scarce but useful for the understanding of the mechanisms that regulate composition of reef fishes in macroalgal-dominated environments. The scarcity of studies in temperate habitats, however, impedes us in classifying large-brown macroalgae as 'essential' habitat for the associated fish species. In the absence of macroalgal habitats, abundance and diversity of temperate reef fishes will reduce, and trophic structure will change. 
Table 7.1 Summary of published experimental studies of the response of fish species to macroalgal habitats. Factor represents species that were either removed or added as independent treatment. Design represents the number of treatments/replicates and the scale of the study. Duration of the experiments stated in months unless mentioned. Variable corresponds to observed dependent factor. Main conclusions represented from results of the experiment only refer to references to main conclusions of the study. (Columns 2-4 Adapted from Cole \& Alcock, unpublished data).

$\frac{\mathrm{N}}{1} \frac{\text { Factor }}{\text { Removal of fucaleans and }}$ laminarians

2 Addition and removal of

Sargassum filipendula

and Zonaria tournefortii

3 Removals of macroalgae

(Fucales and

Laminariales)

$4 \quad$ Addition and removals of

Sargassum filipendula

Density of S. filipendula

Combination of $S$.

filipendula, turf as

Dictyopteris and Zonaria

Algal height

8 Removal Total, leaving

understorey algae

Removal of Ecklonia radiata

Design

3/3 sites; 12 by $10 \mathrm{~m}$

Duration

12

$3 ; 20 \times 5 \mathrm{~m}$

2

Indep. $2 \times 2,5 \times 5,10 \times 10$

$\mathrm{m}$.

$2 / 8 ; 1.5 \mathrm{~m}^{2}$

$2 / 6 ; 1.5 \mathrm{~m}^{2}$

$3 / 6,6,9 ; 1.5 \mathrm{~m}^{2}$

$3 / 7 ; 1.5 \mathrm{~m}^{2}$

$3 / 2$ sites; $28 \mathrm{~m}^{2}$

$2 / 2 ; 2 \mathrm{~m}^{2}$

$2 / 2 ; 400 \mathrm{~m}^{2}$

Ecklonia radiata

1 Control, Macrocystis

pyrifera harvesting

12 Removal of blades of $M$. pyrifera
Main Conclusions

Only one species (Acanthaluteres vittiger) responded negatively to removal

Abundance was positively to associated to additions of $S$. filipendula only

Scale and age-dependent. Total triplefin abundance was higher after removal

5-, 3- fold increases in abundance and species richness

respectively after addition of algae

Species-specific variation

8-fold increased in abundance of fish indicate selection of

Sargassum rather than other algae

2 fold increased in taller and 7 fold increase in taller than medium or small algae

2 fold increased in understorey algae w/out kelp treatments

Bites increased of 15-20 fold after removal due to increase in

foliose algae

\section{Increased after removal}

Depth differences associated with Kelp fishes.

Adult kelp bass was lower when cover of algae was high. YOY increased the abundance after cover of fronds.
Reference

(Edgar et al. 2004b)

(Levin and Hay 2002)

(Syms and Jones 1999)

(Levin and Hay 1996)

(Levin and Hay 1996)

(Levin and Hay 1996)

(Levin and Hay 1996)

(Levin 1993)

(Jones 1992)

(Choat and Ayling 1987)

(Moreno and Jara 1984)

(Ebeling and Laur 1985) 
Cont, Table 7.1

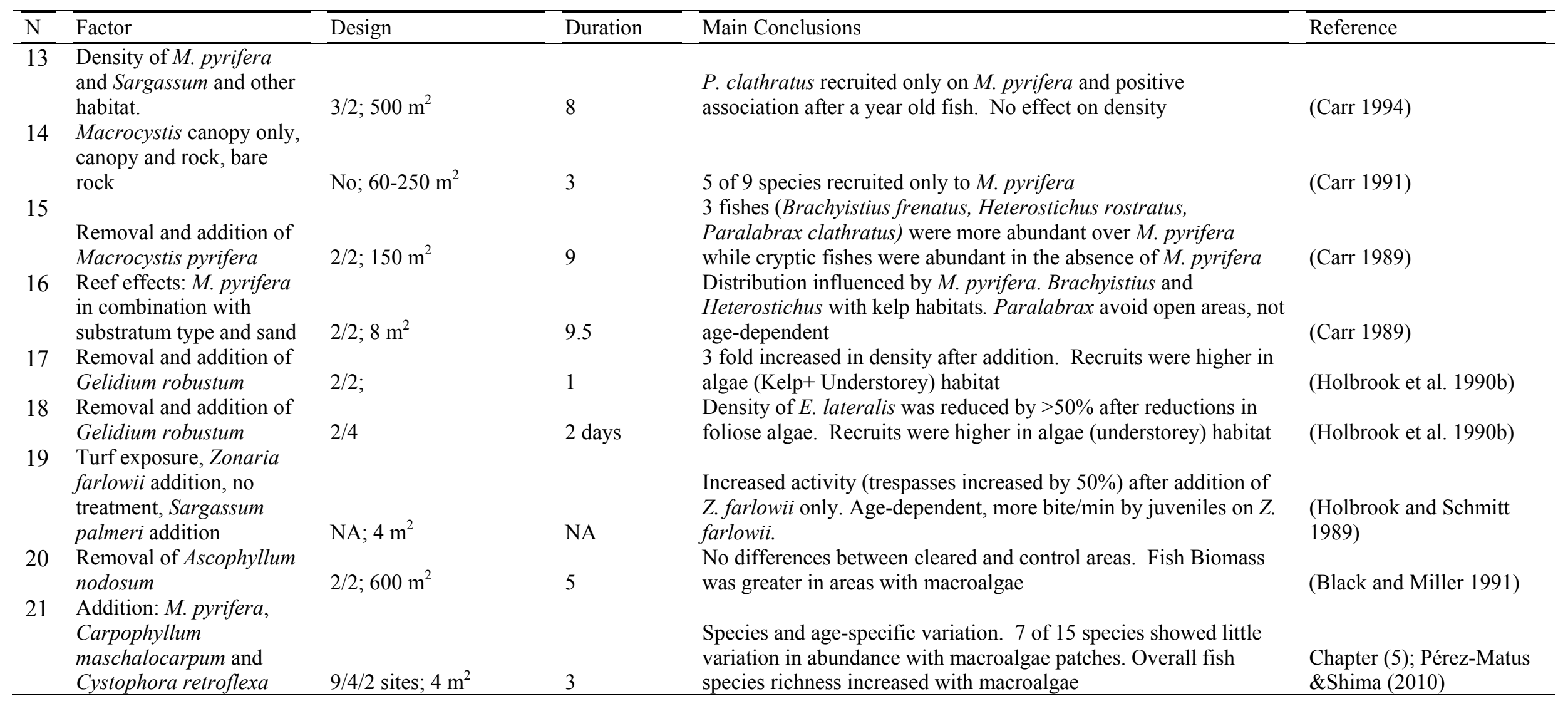




\subsection{Potential positive effects of fishes on macroalgal habitats: towards the concept of mutualism}

I have identified the importance of macroalgae to the abundances of some reef fishes. Fishes respond to different sources of variations in macroalgal attributes (Chapters 2-5). The presence of macroalgae in their varying forms and combinations may allow the partitioning of fishes into different niches. The population influence of a particular habitat element may set a series of feedbacks between interacting fish species. In the last chapter (Chapter 6), I used mesocosm studies to identify the influence of the most abundant fishes associated with different kelp structures on the density and behaviour of small grazers (while acknowledging the limitations that mesocosm studies have (Stachowicz et al. 2008)). Mesograzers are small mobile crustaceans such as amphipods, which mostly feed on macroalgae and can have deleterious effects on algae (Duffy 1980; Duffy and Hay 2000; Haggitt and Babcock 2003).

Experiments that scrutinize feedback loops among macroalgae, amphipods, and fishes are scarce in the literature. Most studies of trophic cascade dynamics in subtidal environments have focused on the relationship between algae and sea urchins (Sala et al. 1998) and the importance of amphipods in macroalgae communities has mainly received attention in recent years (Davenport and Anderson 2007; Newcombe and Taylor 2010). Positive indirect effects of fishes on grazers have been shown but most are represented as density-mediated effects: predatory fishes reduced the populations of grazers. In Chapter 6, I found that potential positive indirect effects on seaweeds are not only density-mediated. The mere presence of a predator can alter the behaviour of grazers leading to positive effects on macroalgae. This study represents the 
first evidence of potential positive indirect effects of fishes on kelp by both density and trait-mediated interactions. The magnitude of positive indirect effects mediated by the predatory influence or by behavioural changes on prey may vary between systems (Werner and Peacor 2003; for a review). Future work on the trait-mediated interactions should be incorporated in large-brown macroalgae systems.

The data provided in this thesis motivates future research into the behaviour, ecology and evolution of possible mutualistic relationships between kelp (or other habitats) and their associated fauna such as fishes. As opposed to competition and predation, mutualism is an interaction that benefits the fitness of two or more interacting organisms (Jaksic and Marone 2007b) and promotes coexistence (Schmitt and Holbrook 2003). There are different kinds of mutualism such as commensalism, obligate mutualism (when two species depend from one another, e.g., species-specific pollinization of plants by insects (Ehrlich and Raven 1964)), competitive mutualism (when a species benefits from the competition of two other species, (Vadermeer 1980; Schmitt and Holbrook 2003), and facultative mutualism which occurs when the benefits of one species do not depend on other species (e.g., dispersion of gametes and seeds by herbivores (Bustamante and Canals 1995)). Understanding the costs, benefits, and fitness outcomes from mutualistic relationships between fishes and macroalgae warrants further research. 


\section{Bibliography}

Abrams PA (1995) Implications of dynamically variable traits for identifying, classifying, and measuring direct and indirect effects in ecological communities. The American Naturalist 146: 112-134

Adams NM (1997) Common seaweeds of New Zealand. Canterbury University Press

Anderson MJ, Millar RB (2004) Spatial variation and effects of habitat on temperate reef fish assemblages in northeastern New Zealand. Journal of Experimental Marine Biology and Ecology 305: 191-221

Anderson MJ, Willis TJ (2003) Canonical analysis of principal coordinates: a useful method of constrained ordination for ecology. Ecology 84: 511524

Anderson TW (1994) Role of macroalgal structure in the distribution and abundance of a temperate reef fish. Marine Ecology Progress Series 13: 279-290

Andersson KG, Bronmark C, Herrmann J, Malmqvist B, Otto C, Sjorstrom P (1986) Presence of sculpins (Cottus gobio) reduces drift and activity of Gammarus pulex (Amphipoda). Hydrobiologia 133: 209-215

Andrieu C, De Freitas N, Doucet A, Jordan MI (2003) An Introduction to MCMC for Machine Learning. Machine Learning 50: 5-43

Angel A, Ojeda FP (2001) Structure and trophic organization of subtidal fish assemblages on the northern Chilean coast: the effect of habitat complexity. Marine Ecology Progress Series 217: 81-91

Appadoo C, Myers AA (2003) Observations of the tube-building behaviour of the marine amphipod Cymadusa filosa. Journal of Natural History 37: 2151-2164

Arana P, Ziller S (1985) Antecedentes generales sobre la actividad pesquera realizada en el archipielago de Juan Fernández. In: Arana P (ed) Investigaciones marinas en el Archipielago de Juan Fernández. Ediciones Universidad Católica de Valparaíso, Valparaiso, pp 125-153

Arias-González JE, Done TJ, Page CA, Cheal AJ, Kininmonth S, Garza-Pérez JR (2006) Towards a reefscape ecology: relating biomass and trophic structure of fish assemblages to habitat at Davies Reef, Australia. Marine Ecology Progress Series 320: 29-41

Ault RT, Johnson CR (1998) Spatially and temporally predictable fish communities on coral reefs. Ecological Monographs 68: 25-50

Baayen RH, Davidson DJ, Bates DM (2008) Mixed-effects modelling with crossed random effects for subjects and items. Journal of Memory and Language 59: 390-412

Beck M (2000) Separating the elements of habitat structure: independent effects of habitat complexity and structural components on rocky intertidal gastropods. Journal of Experimental Marine Biology and Ecology 249: 29-49

Bélisle M (2005) Measuring landscape connectivity: the challenge of behavioral landscape ecology. Ecology 86: 1988-1995

Bell SS, McCoy ED, Mushinsky HR (1991) Habitat structure: The physical arrangement of objects in space. Chapman and Hall, pp 483 
Bellwood D, Hughes T (2001) Regional-scale assembly rules and the biodiversity of coral reefs. Science 292: 1532-1534

Bellwood DR, Wainwright PC (2001) Swimming ability in labrid fishes: implications for habitat use and cross- shelf distribution on the Great Barrier Reef. Coral Reefs 20: 139-150

Benedetti-Cecchi L (2004) Increasing accuracy of causal inference in experimental analyses of biodiversity. Functional Ecology 18: 761-768

Black R, Miller RJ (1991) Use of the intertidal zone by fish in Nova Scotia. Environmental Biology of Fishes 31: 109-121

Bolker BM, Brooks ME, Clarck CJ, Geange SW, Poulsen JR, Stevens MHH, White JS (2009) Generalized linear mixed models: a practical guide for ecology and evolution. Trends in Ecology and Evolution 24: 127-135

Bollache L, Kaldonski N, Troussard J-P, Lagrue C, Rigaud T (2006) Spines and behaviour as defences against fish predators in an invasive freshwater amphipod. Animal Behavior 72: 627-633

Briggs JC (1961) The east Pacific barrier and the distribution of marine shore fishes. Evolution 15: 545-554

Briggs JC (1995) Global Biogeography. Developments in Paleontology and Stratigraphy. Elsevier, Amsterdam

Buckley LB, Roughgarden J (2005) Lizard habitat partitioning on islands: the interaction of local and landscape scales. Journal of Biogeography 312: 2113-2121

Burgess SC, Osborne K, Caley MJ (2010) Similar regional effects among local habitats on the structure of tropical reef fish and coral communities. Global Ecology and Biogeography 19: 363-375

Burnham KP, Anderson DR (1998) Model selection and multimodel inference: a practical information-Theoretic approach. Springer Science

Burridge C, Melendez R, Dyer B (2006) Multiple origins of the Juan Fernández kelpfish fauna and evidence for frequent and unidirectional dispersal of cirrhitoid fishes across the South Pacific. Systematic Biology 55 566-578

Bustamante RO, Canals M (1995) Dispersal quality in plants: how to measure efficiency and effectiveness of a seed disperser. Oikos 73: 133-136

Carr MH (1989) Effects of macroalgal assemblages on the recruitment of temperate zone reef fishes. Journal of Experimental Marine Biology and Ecology 126: 59-76

Carr MH (1991) Habitat selection and recruitment of an assemblage of temperate zone reef fishes. Journal of Experimental Marine Biology and Ecology 146: 113-137

Carr MH (1994) Effects of macroalgal dynamics on recruitment of a temperate reef fish. Ecology 75: 1320-1333

Caselle JE, Warner RR (1996) Variability in recruitment of coral reef fishes: the importance of habitat at two spatial scales. Ecology 77: 2488-2504

Cerda O, Karsten U, Rothäusler E, Tala F, Thiel M (2009) Compensatory growth of the kelp Macrocystis integrifolia (Phaeophyceae, Laminariales) against grazing of Peramphithoe femorata (Amphipoda, Ampithoidae) in northern-central Chile. Journal of Experimental Marine Biology and Ecology 377: 61-67

Chen MH, Shao QM (1999) Monte Carlo estimation of bayesian credible and HPD intervals. Journal of Computational and Graphical Statistics 8: 6992 
Choat JH, Ayling AM (1987) The relationship between habitat structure and fish faunas on New Zealand reefs. Journal of Experimental Marine Biology and Ecology 110: 257-284

Choat JH, Clements KD (1992) Diet in odacid and aplodactylid fishes in Australia and New Zealand. Australian Journal of Marine and Freshwater Research 43: 1451-1459

Christie H, Jørgensen NM, Norderhaug KM (2007) Bushy or smooth, high or low; importance of habitat architecture and vertical position for distribution of fauna on kelp Journal of Sea Research 58: 198-208

Clarke KR (1993) Non-parametric multivariate analyses of changes in community structure. . Australian Journal of Ecology 18: 117-143

Clarke KR, Chapman MG, Somerfield PJ, Needham HR (2006) Dispersionbased weighting of species counts in assemblage analyses. Marine Ecology Progress Series 320: 11-27

Clarke KR, Warwick RM (1994) Similarity-based testing for community pattern: the two-way layout with no replication. Marine Biology 118: 167-176

Clarke T (1995) Larvae of nearshore fishes in oceanic waters of the Central Equatorial Pacific. Pacific Science 49: 134-142

Connell SD, Irving AD (2008) Integrating ecology with biogeography using landscape characteristics: a case study of subtidal habitat across continental Australia. Journal of Biogeography 35: 1608-1621

Connell SD, Jones GP (1991) The influence of habitat complexity on post recruitment processes in temperate reef fish population Journal Experimental Marine Biology and Ecology 151: 271-294

Connell SD, Kingsford MJ (1998) Spatial, temporal and habitat-related variation in the abundance of large predatory fish at One Tree Reef, Australia. Coral Reefs 17: 49-57

Connolly SR, Hughes TP, Bellwood DR, Karlson RH (2005) Community Structure of Corals and Reef Fishes at Multiple Scales. Science 306: 1363-1365

Consoli P, Romeo T, Giongrandi T, Andaloro A (2008) Differences among fish assemblages associated with a nearshore vermetid reef and two other rocky habitats along the shores of Cape Milazzo (northern Sicily, central Mediterranean Sea). Journal of the Marine Biological Association of the United Kingdom 88: 401-410

Cothran RD (2004) Precopulatory mate guarding affects predation risk in two freshwater amphipod species. Animal Behaviour 68: 1133-1138

Cowen RK (1983) The effect of sheephead (Semicossyphus pulcher) predation on red sea urchin (Strongylocentrotus franciscanus) populations: an experimental analysis. Oecologia 58: 249-255

Cowen RK, Sponaugle S (1997) Relationship between early life history and recruitment among coral reef fishes. In: Chambers RC, Trippel EA (eds) Early life history and recruitment in fish populations Chapman \& Hall, London, pp 423-449

Coyer JA (1984) The invertebrate assemblage associated with giant kelp, Macrocystis pyrifera, at Santa Catalina Island, California: a general description with emphasis on amphipods, copepods, mysids, and shrimps. Fishery Bulletin 82: 55-66

Crawley MJ (2007) The R book. John Wiley \& Sons, Ltd, Chichester, West Sussex, England 
Crowe TS, Underwood AJ (1998) Testing behavioural "preference" for suitable microhabitat. Journal of Experimental Marine Biology and Ecology 225: $1-11$

Darwin C (1859) On the origin of species by means of natural selection. J. Murray, London

Davenport AC, Anderson TW (2007) Positive indirect effects of reef fishes on kelp performance: the importance of mesograzers. Ecology 88: 15481561

Dayton PK (1985a) Ecology of kelp communities. Annual Review of Ecology, Evolution, and Systematics 16: 215-245

Dayton PK (1985b) The structure and regulation of some South American kelp communities. Ecological Monographs 55: 447-468

De Clerck O, Leliaert F, Verbruggen H, Lane CE, De Paula JC, Payo DA, Coppejans E (2006) A revised classification of the Dictyoteae (Dictyotales, Phaeophyceae) based on rbcL and 26S ribosomal DNA sequence analyses. Journal of Phycology 42: 1271-1288

DeMartini EE, Friedlander A (2004) Spatial patterns of endemism in shallowwater reef fish populations of the Northwestern Hawaiian Islands. Marine Ecology Progress Series 271: 281-296

DeMartini EE, Roberts DA (1990) Effects of giant kelp (Macrocystis) on the density and abundance of fishes in a cobble-bottom kelp forest. Bulletin of Marine Science 41: 287-300

Denny CM, Schiel DR (2001) Feeding ecology of the banded wrasse Notolabrus fucicola (Labridae) in southern New Zealand: prey items, seasonal differences, and ontogenetic variation. New Zealand Journal of Marine and Freshwater Research 35: 925-933

Dewitt TJ, Sih A, Hucko JA (1999) Trait compensation and cospecialization in a freshwater snail: size, shape and antipredator behaviour. Animal Behaviour 58: 397-407

Dornelas M, Moonen AC, Magurran AE, Bàrberi P (2009) Species abundance distributions reveal environmental heterogeneity in modified landscapes. Journal of Applied Ecology 46: 666-672

Duffy JE (1990) Amphipods on seaweeds: partners or pests ? Oecologia 83: 267276

Duffy JE, Hay ME (2000) Strong impacts of grazing amphipods on the organization of a benthic community. Ecological Monographs 70: 237263

Duffy JE, Hay ME (2001) Ecology and evolution of marine consumer-prey interactions. . Sinauer Press, Sunderland, Massachusetts

Dunn AM, Dick JT, Hatcher MJ (2008) The less amorous Gammarus: predation risk affects mating decisions in Gammarus duebeni (Amphipoda). Animal Behavior 76: 1289-1295

Ebeling AW, Laur DR (1985) The influence of plant cover on surfperch abundance at an offshore temperate reef. Environmental Biology of Fishes. 12: 169-179

Edgar G, Banks S, Fariña J (2004a) Regional biogeography of shallow reef fish and macro-invertebrate communities in the Galapagos archipelago. Journal of Biogeography 31: 11107-11124

Edgar GJ, Barrett NS, Morton AJ, Samson CR (2004b) Effects of algal canopy clearance on plant, fish and macroinvertebrate communities on eastern 
Tasmanian reefs. Journal of Experimental Marine Biology and Ecology 312: $67-87$

Ehrlich PR, Raven PH (1964) Butterflies and plants: a study in coevolution Evolution 18: 586-608

Estes JA, Smith NS, Palmisano JS (1978) Sea otter predation and community organization in the western Aleutian Islands, Alaska. Ecology 59: 822833

Feary DA, Wellenreuther M, Clements KD (2009) Trophic ecology of New Zealand triplefin fishes (Family Tripterygiidae). Marine Biology 156: $1703-1714$

Fernández M, Holl J, Kimberlin S (2007) Global patterns of biodiversity In: Denny M, Gaines SD (eds) Encyclopedia of Rocky Shores. University of California Press, Califronia, pp 71-76

Ferry-Graham LA, Wainwright PC, Westneat MW, Bellwood DR (2002) Mechanisms of benthic prey capture in wrasses (Labridae). Marine Biology 141: 819-830

Floeter SR, Krohling W, Gasparin JL, Ferreira CEL, R. ZI (2007) Reef fish community structure on coastal islands of the southeastern Brazil: the influence of exposure and benthic cover. Environmental Biology of Fishes 78: 147-160

Foster MS, Schiel DR (1975) Regulation of algal community development in a Macrocystis pyrifera forest. Marine Biology 32: 331-342

Fowler-Walker MJ, Connell SD (2002) Opposing states of subidal habitat across temperate Australia: consistency and predictability in kelp canopy benthic association. Marine Ecology Progress Series 240: 49-56

Francis M (2001) Coastal fishes of New Zealand: an identification guide. Reed publishing Auckland

Francis MP (1996) Geographic distribution of marine reef fishes in the New Zealand region. New Zealand Journal of Marine and Freshwater Research 30: 35-55

Francis MP, Grace RV, Paulin CD (1987) Coastal fishes of the Kermadec Islands. New Zealand Journal of Marine and Freshwater Research 21: 113

Fraschetti S, Terlizzi A, Benedetti-Cecchi L (2005) Patterns of distribution of marine assemblages from rocky shores: evidence of relevant scales of variation. Marine Ecology Progress Series 296: 13-29

Froese R, Pauly D (2009) FishBase. World Wide Web electronic publication. www.fishbase.org

Fuhlendorf SD, Harrell WC, Engle DM, Hamilton RG, Davis CA (2006) Should heterogeneity be the basis for conservation? grassland bird response to fire and grazing. Ecological Applications 16: 1706-1716

Gárate A, Pacheco A (2004) Cambios en la distribución y abundancia de la ictiofauna de aguas someras en San Bartolo (Lima, Perú) después del ENSO 1997-98. Ecología Aplicada 3: 148-153

Gardner JP, Curwen MJ, Long J, Williamson R, Wood AR (2006) Benthic community structure and water column characteristics at two sites in the Kermadec Islands Marine Reserve, New Zealand. New Zealand Journal of Marine and Freshwater Research 40: 179-194

Gaston KJ (2000) Global patterns in biodiversity. Nature 405: 220-227 
Graham MH (2002) Prolonged reproductive consequences of short-term biomass loss in seaweeds. Marine Biology 140: 901-911

Graham MH (2004) Effects of local deforestation on the diversity and structure of southern California giant kelp forest food webs. . Ecosystems 7: 733743

Graham MH, Kinlan BP, Druehl LD, Garske LE, Banks S (2007a) Deep-water kelp refugia as potential hotspots of tropical marine diversity and productivity. Proceedings of the National Academy of Sciences 104: 16576-16580

Graham MH, Vásquez JA, Buschmann AH (2007b) Global ecology of the giant kelp Macrocystis from ecotypes to ecosystems. Oceanography and Marine Biology: An Annual Review 45: 39-88

Haase KM, Mertz DF, Sharp WS, Garbe-Schonberg CD (2000) Sr-Nd-Pb isotope ratios, geochemical compositions, and Ar-40/Ar- 39 data of lavas fromSan Felix Island (Southeast Pacific): Implications for magma genesis and sources. Terra nova 12: 1290-1296

Haggitt TR, Babcock RC (2003) The role of grazing by the lysianassid amphipod Orchomenella aahu in dieback of the kelp Ecklonia radiata in northeastern New Zealand. Marine Biology 143: 1201-1211

Hazlett BA (1999) Responses to multiple chemical cues by the crayfish Orconectes virilis Behaviour 136: 161-177

Heck KLJ, Crowder L (1991) Habitat structure and predator prey interactions in vegetative aquatic systems In: Bell SS, McCoy ED, Mushinsky HR (eds) Habitat structure: the physical arrangement of objects in space. Chapman and Hall, pp 281-299

Herrick JE, Sarukhán J (2007) A strategy for ecology in an era of globalization. Frontiers in Ecology and the Environment 5: 172-181

Hickford MJ, Schiel DR (1995) Catch vs Count: effects of gill-netting on reef fish populations in southern New Zealand. Journal of Experimental Marine Biology and Ecology 188: 215-232

Hickford MJ, Schiel DR (2008) Experimental gill-netting of reef fish: Speciesspecific responses modify capture probability across mesh sizes. Journal of Experimental Marine Biology and Ecology 358

Hixon M, Beets J (1993) Predation, prey refuges, and the structure of coral-reef fish assemblages. Ecological Monographs 63: 77-101

Hixon MA, Carr MH (1997) Synergistic predation, density dependence, and population regulation in marine fish. Science 277: 946-949

Holbrook SJ, Schmitt RJ (1989) Experimental analyses of patch selection by foraging black surfperch (Embiotoca jacksoni Agazzi). Journal of Experimental Marine Biology and Ecology 79: 39-64

Holbrook SJ, Carr MH, Schmitt RJ, Coyer JA (1990a) Effect of giant kelp on local abundance of reef fishes: the importance of ontogenetic resource requirements. Bulletin of Marine Science 47: 104-114

Holbrook SJ, Schmitt RJ, Ambrose RF (1990b) Biogenic habitat structure and characteristics of temperate reef fish assemblage. Australian Journal of Ecology 15: 489-503

Holbrook SJ, Forrester GH, Schmitt RJ (2000) Spatial patterns in abundance of a damselfish reflect availability of suitable habitat. Oecologia 122: 109-120

Holbrook SJ, Brooks AJ, Schmitt RJ (2002) Predictability of fish assemblages on coral patch reefs. Marine and Freshwater Research 53: 181-188 
Huang CF, Sih A (1990) Experimental studies on behaviorally mediated, indirect interactions through a shared predator. Ecology 71: 1515-1522

Hugie DM, Grand TC (1998) Movement between patches, unequal competitors and the ideal free distribution. Evolutionary Ecology 12: 1-19

Hurlbert SH (1971) The nonconcept of species diversity: a critique and alternative parameters Ecology 52: 577-586

Irving AD, Connell SD, Gillanders BM (2004) Local complexity in patterns of canopy-benthos associations produces regional patterns across temperate Australasia. Marine Biology 144: 361-368

Jaksic FM, Marone L (2007a) Diversidad. In: Jaksic FM, Marone L (eds) Ecología de Comunidades. Ediciones Universidad Católica de Chile, Santiago, pp 119-130

Jaksic FM, Marone L (2007b) Mutualismo. In: Jaksic FM, Marone L (eds) Ecología de Comunidades, 2da Edición Ediciones Universidad Católica de Chile, Santiago de Chile, pp 336

Jennings S, Boulle DP, Polunin NVC (1996) Habitat correlates of the distribution and biomass of Seychelles' reef fishes. Environmental Biology of Fishes 46: 12-25

Jennings S, Brierley AS, Walker JW (1994) The inshore fish assemblages of the Galápagos Archipelago. Biological Conservation 70: 49-57

Jones GP (1984a) Population Ecology of the temperate reef fish Pseudolabrus ceidotus Bloch \& Schneider (Pisces: Labridae). I. Factors Influencing Recruitment. Journal of Experimental Marine Biology and Ecology 75: 257-276

Jones GP (1984b) The influence of habitat and behavioural interactions on the local distribution of the wrasse, Pseudolabrus celidiotus. Environmental Biology of Fishes 10: 43-58

Jones GP (1988a) Ecology of rocky reef fish of north-eastern New Zealand: a review. New Zealand Journal of Marine and Freshwater Research 22: 445-462

Jones GP (1988b) Experimental evaluation of the effeets of habitat-structure and competitive interactions on the juveniles of two coral reef fishes. Journal of Experimental Marine Biology and Ecology 123: 115-126

Jones GP (1992) Interactions between herbivorous fishes and macro-algae on a temperate rocky reef. Journal of Experimental Marine Biology and Ecology 159: 217-235

Jones GP, Syms C (1998) Disturbance, habitat structure and the ecology of fishes on coral reefs. Australian Journal of Ecology 23: 287-297

Kaiser J, Regalado A (2010) Latin America. Chile's earthquake may set back research for years. Science 327: 1308-1309

Kingsford MJ (1995) Drift algae: A contribution to near-shore habitat complexity in the pelagic environment and an attractant for fish. Marine Ecology Progress Series 116: 297-301

Kingsford MJ, Battershill C (1998) Studying temperate marine environments: a handbook for ecologists. Canterbury university Press, Christchurch, New Zealand

Korpinen S, Jormalainen V, Honkanen T (2007) Bottom-up and cascading topdown control of macroalgae along a depth gradient. Journal of Experimental Marine Biology and Ecology 343: 52-63 
Kramer DL, Rangeley RW, Chapman LJ (1997) Habitat selection: patterns of spatial distribution from behavioural decisions In: Godin JGJ (ed) Behavioural ecology of teleost fishes. Oxford University Press, Oxford, pp 36-80

Kruskal W, Wallis W (1952) Use of ranks in a one-criterion variance analysis. Journal of the American Statistical Association 47: 583-621

Landaeta MF, Castro LR (2004) Concentration area of Ichthyoplankton around Juan Fernández Archipelago, Chile. Ciencia y Tecnología del Mar 27: 43-53

Lawrence JM (1975) On the relationships between marine plants and sea urchins. Oceanography and Marine Biology Annual Reviews 13: 213-286

Lawton J (1996) The Ecotron facility at Silwood Park: The value of "big bottle" experiments. Ecology 77: 665-669

Lecchini D, Shima JS, Banaigs B, Galzin R (2005) Larval sensory abilities and mechanisms of habitat selection of a coral reef fish during settlement. Oecologia 143: 326-334

Legendre P, Gallaher ED (2001) Ecologically meaningful transformations for ordination of species data. Oecologia 129: 271-280

Legendre P, Galzin R, Harmelin-Vivien ML (1997) Relating behavior to habitat: Solutions to the fourth-corner problem. Ecology 547-562

Legendre P, Legendre L (1998) Numerical Ecology Elsevier

Levin PS (1993) Habitat structure, conspecific presence and spatial variation in the recruitment of a temperate reef fish. Oecologia 92: 176-185

Levin PS, Hay ME (1996) Responses of temperate reef fishes to alterations in algal structure and species composition. Marine Ecology Progress Series 134: $37-47$

Levin PS, Hay ME (2002) Fish-seaweed association on temperate reefs: do small-scale experiments predict large-scale patterns? Marine Ecology Progress Series 232

Levin PS, Tolimieri N, Nicklin M, Sale P (2000) Integrating individual behavior and population ecology: the potential for habitat-dependent population regulation in a reef fish. Behavioral Ecology 11: 565-571

Levin SA (1992) The problem of pattern and scale in ecology. Ecology 73: 1943-1967

Lima SJ (1998) Nonlethal effects in the ecology of predator-prey interactions. BioScience 48: 25-34

Lima SL, Dill LM (1990) Behavioral decisions made under the risk of predation: a review and prospectus. Canadian Journal of Zoology 68: 619-640

Loreau M, Naeem S, Inchausti P, Bengtsson J, Grime JP, Hector A, Hooper DU, Huston MA, Raffaelli D, Schmid B, Tilman D, Wardle DA (2004) Biodiversity and Ecosystem Functioning: Current Knowledge and Future Challenges. Science 294: 804-808

Luckhurst BE, Luckhurst K (1978) Analysis of the influence of substrate variables on coral reef fish communities. Marine Biology 49: 317-323

Luttbeg B, Rowe L, Mangel M (2003) Prey state and experimental design affect relative size of trait-and density-mediated indirect effects. Ecology 84: $1140-1150$

MacArthur RH (1957) On the relative abundance of bird species. Proceedings of the Academy of Natural Sciences 43: 293-295 
MacArthur RH (1965) Patterns of species diversity. Biological Review 40: 510533

MacArthur RH, Wilson EO (1963) An equilibrium theory of insular zoogeography. Evolution 17: 373-387

MacArthur RH, Wilson EO (1967) The theory of island biogeography. Princeton University Press, Princeton, New Jersey

MacNeil MA, Graham NAJ, Polunin NVC, Kulbicki M, Galzin R, HarmelinVivien M, Rushton S (2009) Hierarchical drivers of reef-fish metacommunity structure. Ecology 90: 252-264

Macpherson E, Hastings PA, Robertson DR (2009) Macroecological patterns among marine fishes. In: Witman JD, Roy K (eds) Marine Macroecology. The University of Chicago Press, Chicago

Mann G (1954) La vida de los peces en aguas chilenas. Ministerio de Agricultura, Instituto de Investigaciones Veterinarias y Universidad de Chile, Santiago de Chile

McArdle BH, Anderson MJ (2001) Fitting multivariate models to community data: a comment on distance-based redundancy analysis. Ecology 82: 290-297

McCormick MI, Choat JH (1987) Estimating total abundance of a large temperate-reef fish using visual strip-transects. Marine Biology 96: 469478

McDermott CJ, Shima JS (2006) Ontogenetic shifts in microhabitat preference of the temperate reef fish Forsterygion lapillum: implications for population limitation. Marine Ecology Progress Series 320: 259-266

McGehee MA (1994) Correspondence between assem- blages of coral reef fishes and gradients of water motion, depth and substrate size off Puerto Rico. Marine Ecology Progress Series 105: 243-255

McMahon SM, Diez M (2007) Scales of association: hierarchical linear mixed models and the measurement of ecological data. Ecology Letters 10: 437452

Molina JI (1782) Saggio sulla storia naturale de Cile. Stamperia di S. Tommaso d'Aquino, Bologna

Mora C, Chittaro PM, Sale PF, Kritzer JP, Ludsin SA (2003) Patterns and processes in reef fish diversity. Nature 421: 933-936

Moreno CA, Jara HF (1984) Ecological studies on fish fauna associated with Macrocystis pyrifera belts in the south of Fueguian Islands, Chile. Marine Ecology Progress Series 15: 99-107

Moyle PB, Cech JJ (1982) Fishes: an introduction to Ichthyology. Prentice Hall

Munday PL (2002) Does habitat availability determine geographical-scale abundances of coral-dwelling fishes? Coral Reefs 21: 205-116

Murdoch W, Briggs C, Nisbet R (2003) Consumer-resource dynamics. Princeton University Press, Princeton, New Jersey, USA.

Nelson JS (1984) Fishes of the World. New York: John Wiley \& Sons

Newcombe EM, Taylor RB (2010) Trophic cascade in a seaweed-epifauna-fish food chain. Marine Ecology Progress Series 408: 161-167

North WJ (1971) The Biology of Giant Kelp Beds (Macrocystis) in California. Verlag Von J. Cramer, Lehre, Germany

O'Hara RB, Kotze DJ (2010) Do not log-transform count data. Methods in Ecology and Evolution 1: 118-122 
O hman MC, Rajasuriya A, Ólafsson E (1997) Reef fish assemblages in northwestern Sri Lanka: distribution patterns and influences of fishing practises. Environmental Biology of Fishes 49: 46-61

Paine RT (1966) Food web complexity and species diversity The American Naturalist 100: 65-75

Parker GA, Sutherland WJ (1986) Ideal free distributions when individuals differ in competitive ability: Phenotype-limited ideal free models. Animal Behavior 34: 1222-1242

Patten BC (1962) Species diversity in net phytoplankton of Raritan Bay. Journal of Marine Research 20: 57-75

Peet RK (1974) The measurement of species diversity. Annual Review of Ecology and Systematics 5: 285-307

Pequeño G, Lamilla J (2000) The littoral fish assemblage of the desventuradas Islands (Chile), has zoogeographical affinities with the western Pacific. Global Ecology and Biogeography 9: 431-437

Pequeño G, Sáez S (2000) Los peces litorales del archipiélago de Juan Fernández (Chile): endemismo y relaciones ictiogeográficas. Investigaciones Marinas 28: 27-37

Pérez-Matus A, Ferry-Graham LA, Cea A, Vásquez JA (2007) Community structure of temperate reef fishes in kelp dominated subtidal habitats of northern Chile. Marine and Freshwater Research 58: 1069-1085

Pérez-Matus A, Shima JS (2010) Disentangling the effects of macroalgae on the abundance of temperate reef fishes. Journal of Experimental Marine Biology and Ecology 388: 1-10

Pianka ER (1966) Latitudinal gradients in species diversity: a review of concepts. The American Naturalist 100: 33-46

Pinheiro JC, Bates DM (2000) Mixed-Effects models in S and S-plus. SpringerVerlag, New York

Preisser EL, Bolnick DI, Benard MF (2005) Scared to death? the effect of intimidation and consumption in predator-prey interactions Ecology 86: 501-509

R Development Core Team (2010) R: a language and environment for statistical computing. The $\mathrm{R}$ foundation ofr statistical Computing, Vienna. Available at www.R-project.org

Ricklefs RE (2004) A comprehensive framework for global patterns in biodiversity. Ecology Letters 7: 1-15

Ricklefs RE, Qian H, White PS (2004) The region effect on mesoscale plant species richness between eastern Asia and eastern North America Ecography 27: 129-136

Ricklefs RE (2006) Evolutionary diversification and the origin of the diversityenvironment relationship. Ecology 87: 3-13

Roberts CM, Ormond RFG (1987) Habitat complexity and coral reef fish diversity and abundance on Red Sea fringing reefs. Marine Ecology Progress Series 41: 1-8

Robertson DR (2001) Population maintenance among tropical reef fishes: inferences from small-island endemics. Proceedings of the National Academy of Sciences 98: 5667-5670

Rohde K (1992) Latitudinal gradients in species diversity: the search for the primary cause. Oikos 65: 514-527 
Rojas JM, Ojeda FP (2010) Spatial distribution of intertidal fishes: a pattern dependent on body size and predation risk? Environmental Biology of Fishes 87: 175-185

Rojas JR, Pequeño G (1998) Peces Serránidos de la Isla Alejandro Selkirk, Archipiélago Juan Fernández, Chile (Pisces: Serranidae): Análisis ictiogeográfico. Investigaciones Marinas 26: 41-58

Roshier DA, Doerr VA, Doerr ED (2008) Animal movement in dynamic landscape: interaction between behavioural strategies and resource distributions. Oecologia 156: 465-477

Rozbaczylo N, Castilla JC (1987) Invertebrados marinos del Archipiélago de Juan Fernández. In: Castilla JC (ed) Islas Oceánicas Chilenas: Conocimiento científico y necesidades de investigaciones. Ediciones Universidad Católica de Chile, Santiago, pp 167-189

Russell BC (1983) The food and feeding habits of rocky reef fish of northeastern New Zealand. New Zealand Journal of Marine and Freshwater Research 17: 121-145

Sala E, Boudouresque CF, Harmelin-Vivien M (1998) Fishing, trophic cascades, and the structure of algal assemblages: evaluation of an old but untested paradigm. Oikos 82: 425-439

Sala E, Graham MH (2002) Community-wide distribution of predator-prey interaction strength in kelp forests. Proceedings of the Academy of Natural Sciences 99: 3678-3683

Sale P (1980) Assemblages of fish on patch reefs-predictable or unpredictable? Environmental Biology of Fishes 5

Sale PF (1988) Perception, pattern, chance and the structure of reef fish communities. Environmental Biology of Fishes 21: 3-15

Sale PF, Guy JA, Steel WJ (1994) Ecological structure of assemblages of coral reef fishes on isolated patch reefs. Oecologia 98: 83-99

Santelices B (1992) Marine phytogeography of the Juan Fernández Archipelago: A new assessment. . Pacific Science 46: 438-452

Santelices B, Ojeda FP (1984) Population dynamics of coastal forests of Macrocystispyrifera in Puerto Toro, Isla Navarino, southern Chile. Marine Ecology Progress Series 14: 175-183

Schaffers AP, Raemakers IP, Sykora K, Ter Braak CJF (2008) Arthropod assemblages are best predicted by plant species composition Ecology 89: 782-794

Scheltema RS (1986) On dispersal and planktonic larvae of benthic invertebrates: An eclectic overview and summary of problems. Bulletin of Marine Science 39: 290-322

Schiel DR (1988) Algal interactions on shallow subtidal reefs in northern New Zealand: a review. New Zealand Journal of Marine and Freshwater Research 22: 481-489

Schiel DR (1990) Macroalgal assemblages in New Zealand: structure, interactions and demography. Hydrobiologia 192: 59-76

Schiel DR, Foster MS (1986) The structure of subtidal algal stands in temperate waters. Oceanography and Marine Biology Annual Reviews 24: 265-307

Schiel DR, Foster MS (2006) The population biology of large brown seaweeds: ecological consequences of multi-phase life histories in dynamic coastal environments. Annual Reviews of Ecology, Evolution and Systematics 37: $343-372$ 
Schiel DR, Kingsford MJ, Choat JH (1986) Depth distribution and abundance of benthic organisms and fishes at the subtropical Kermadec Islands. New Zealand Journal of Marine and Freshwater Research 20: 521-535

Schmitt RJ, Holbrook S, Brooks AJ, Lape JCP (2009) Intraguild predation in a structured habitat: distinguishing multiple-predator effects from competitor effects. Ecology 90: 2434-2443

Schmitt RJ, Holbrook SJ (2003) Mutualism can mediate competition and promote coexistence Ecology Letters 6: 898-902

Schmitz O (1998) Direct and indirect effects of predation and predation risk in old-field interaction webs. American Naturalist 151: 327-342

Schmitz OJ (2003) Top predator control of plant biodiversity and productivity in an old-field ecosystem. Ecology Letters 6: 156-163

Schmitz OJ (2007) Predator diversity and trophic interactions. Ecology 88: 24152426

Schmitz OJ (2009) Effects of predator functional diversity on grassland ecosystem function. Ecology 90: 2339-2345

Schmitz OJ, Beckerman AP, O'Brien KM (1997) Behaviorally mediated trophic cascades: effects of predation risk on food web interactions. Ecology 78 : 1388-1399

Schmitz OJ, Krivan V, Ovadia O (2004) Trophic cascades: the primacy of traitmediated indirect interactions. Ecology Letters 7: 153-163

Schmitz OJ, Suttle KB (2001) Effects of top predator species on direct and indirect interactions in a food web. Ecology 82: 2072-2081

Schoener T (1974) Resource partitioning in ecological communities. Science 185: 27-39

Sernapesca (2009) Anuario estadístico de pesca 2009. Ministerio de Economía, Fomento y Turismo. Servicio Nacional de Pesca Valparaíso

Shima JS (1999) Variability in relative importance of determinants of reef fish recruitment. Ecology Letters 2: 304-310

Shima JS, Osenberg CW (2003) Cryptic density dependence: effect of covariation between density and site quality in reef fish. Ecology: 46-52

Shima JS, Osenberg CW, Mary CMS (2008) Quantifying site quality in a heterogeneous landscape: recruitment of a reef fish. Ecology 89: 86-94

Siddon EC, Siddon CE, Stekoll MS (2008) Community level effects of Nereocystis luetkeana in southeastern Alaska. Journal of Experimental Marine Biology and Ecology 361: 8-15

Sih A (1980) Optimal Behavior: can foragers balance two conflicting demands? Science 210: 1041-1043

Sih A, Englund G, Wooster D (1998) Emergent impacts of multiple predator on prey. Trends in Ecology \& Evolution 13: 350-355

Simpson EH (1949) Measurement of Diversity. Nature 163: 688

Smith CL (1978) Coral reef fish communities: a compromise view. Environmental Biology of Fishes 3: 109-128

Stachowicz JJ, Best RJ, Bracken MES, Graham MH (2008) Complementarity in marine biodiversity manipulations: Reconciling divergent evidence from field and mesocosm experiments. Proceedings of the national Academy of Sciences 105: 18842-18847

Steele MA (1996) Effects of predators on reef fishes: separating cage artifacts from effects of predation Journal of Experimental Marine Biology and Ecology 198: 249-267 
Steneck RS, Graham MH, Bourque BJ, Corbett D, Erlandson JM, Estes JA, Tegner MJ (2002) Kelp forest ecosystems: biodiversity, stability, resilience and future. Environmental Conservation 29: 436-459

Stephens JS, Morris PA, Zerba K, Love M (1984) Factors affecting fish diversity on a temperate reef: the fish assemblage of Palos Verdes Point, 19741981. Environmental Biology of Fishes 11: 249-275

Stuessy TF, Foland KA, Sutter JF, Sanders RW, Silva M (1984) Botanical and geological significance of potassium-argon dates from the Juan Fernández Islands. Science 225: 49-51

Swearer S, Caselle JE, Lea DW, Warner RR (1999) Larval retention and recruitment in an island population of a coral-reef fish. Nature 402: 199802

Swearer S, Shima JS, Hellberg ME, Thorrold SE, Jones GP, Robertson DR, Morgan SG, Selkoe KA, Ruiz GM, Warner RR (2002) Evidence of selfrecruitment in demersal marine populations. Bulletin of Marine Science 70: $251-271$

Syms C, Jones GP (1999) Scale of disturbance and the structure of a temperate fish guild. Ecology 80: 921-940

Taylor DI, Schiel DR (2010) Algal populations controlled by fish herbivory across a wave exposure gradient on southern temperate shores. Ecology 91: 201-211

Taylor RB, Cole RG (1994) Mobile epifauna on subtidal brown seaweeds in northeastern New Zealand. Marine Ecology Progress Series 115: 271-282

Taylor RB (1998a) Density, biomass and productivity of animals in four subtidal rocky reef habitats: the importance of small mobile invertebrates. Marine Ecology Progress Series 172: 37-51

Taylor RB (1998b) Seasonal variation in assemblages of mobile epifauna inhabiting three subtidal brown seaweeds in northeastern New Zealand. Hydrobiologia 361: 25-35

Tegner MJ, Dayton PK (1987) El Niño effects on southern California kelp forest communities Advances in Ecological Research 17: 243-279

Terlizzi A, Benedetti-Cecchi L, Bevilacqua S, Fraschetti S, Guidetti P, Anderson MJ (2005) Multivariate and univariate asymmetrical analyses in environmental impact assessment: a case study of Mediterranean subtidal sessile assemblages. Marine Ecology Progress Series 289: 27-42

Thiel M, Vásquez JA (2000) Are kelp holdfast islands on the ocean floor? indication for temporarily closed aggregations of peracarid crustaceans. Hydrobiologia 440: 45-54

Thresher RE, Gunn JS (1986) Comparative analysis of visual census techniques for highly mobile, reef-associated piscivores (Carangidae). Environmental Biology of Fishes 17: 93-116

Tolimieri N (1995) Effects of microhabitat characteristics on the settlement and recruitment of a coral reef at two spatial scales. Oecologia 230: 52-63

Tolimieri N (1998) Contrasting effects of microhabitat use on large-scale adult abundance in two families of Caribbean reef fishes. Marine Ecology Progress Series 167: 227-239

Vadermeer JH (1980) Indirect mutualism: variations on a theme by Stephen Levine. American Naturalist 116: 441-448 
Valesini FJ, Potter IC, Clarke KR (2004) To what extent are the fish composition at nearshore sites along a heterogeneous coast related to habitat type? Estuarine Coastal and Shelf Science 60: 737-754

Van Son TC, Thiel M (2006) Multiple predator effects in an intertidal food web. Journal of Animal Ecology 75: 25-32

Vásquez JA, Buschmann A (1997) Herbivore-kelp interactions in Chilean subtidal communities: a review. Revista Chilena de Historia Natural 70: 41-52

Vásquez JA, Véliz D, Pardo LM (2001) Diversidad, estructura y funcionamiento de ecosistemas costeros rocosos del norte de Chile. In: Alveal K, Antezana T (eds) Sustentabilidad de la Biodiversidad. Universidad de Concepción, Concepción, pp 293-308

Vonesh JR, Osenberg CW (2003) Multi-predator effects across life-history stages: non-additivity of egg- and larval-stage predation in an African treefrog. Ecology Letters 6: 503-508

Walser A, Schausberger P (2009) Non-consumptive effects of predatory mites on thrips and its host plants. Oikos 118: 934-940

Watson RA, Quinn TJ (1997) Performance of transect and point count underwater visual census methods. Ecological Modelling 1997: 103-112

Wellenreuther M, Barret PT, Clements KD (2007) Ecological diversification in habitat use by subtidal triplefin fishes (Tripterygiidae). Marine Ecology Progress Series 330: 235-246

Wellenreuther M, Clements KD (2008) Determinants of habitat association in a sympatric clade of marine fishes. Marine Biology 154: 393-402

Wellenreuther M, Syms C, Clements KD (2008) Consistent spatial patterns across biogeographic gradients in temperate reef fishes. Ecography 31: 84-94

Werner EE, Peacor SD (2003) A review of trait-mediated indirect interactions in ecological communities. Ecology 84: 1083-1100

White JW, Caselle JE (2008) Scale-dependent changes in the importance of larval supply and habitat to abundance of a reef fish. Ecology 89: 13231333

Whittaker RH, Levin SA (1977) The role of mosaic phenomena in natural communities. Theoretical Population Biology 12: 117-139

Williams DD, Moore KA (1985) The role of semiochemicals in benthic community relationships of the lotic amphipod Gammarus pseudolimnaeus: a laboratory analysis. Oikos 44: 280-286

Williams GJ, Cameron MJ, Turner JR, Ford RB (2008a) Quantitative characterisation of reef fish diversity among nearshore habitats in a northeastern New Zealand marine reserve. New Zealand Journal of Marine and Freshwater Research 42: 33-46

Williams GJ, Cameron MJ, Turner JR, Ford RB (2008b) Quantitative characterisation of reef fish diversity among nearshore habitats in a northeastern New Zealand marine reserve. New Zealand Journal of Marine and Freshwater Research 42: 33-46

Willis TJ (2001) Visual census methods underestimating density and diversity of cryptic reef fishes. Journal of Fish Biology 59: 1408-1411

Wolanski E, Hamner W (1988) Topographically-controlled fronts in the ocean, and their influence on the distribution of organisms. Science 241: 177181 
Yáñez E, Silva C, Vega R, Espíndola F, Álvarez L, Silva N, Palma S, Salinas S, Menschel E, Ha ussermann V, Soto D, Ramírez N (2009) Seamounts in the southeastern Pacific Ocean and biodiversity on Juan Fernández Seamounts, Chile. Latin American Aquatic Research 37: 555-570 


\section{APPENDIX 1}

\section{Disentangling the effects of macroalgae on the abundance of}

\section{temperate reef fishes}

Jembe

Journal of Experimental Marine Biology and Ecology 388 (2010) 1-10

Contents lists available at ScienceDirect

Journal of Experimental Marine Biology and Ecology

journal homepage: www.elsevier.com/locate/jembe

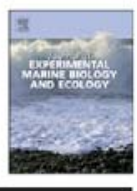

Disentangling the effects of macroalgae on the abundance of temperate reef fishes Alejandro Pérez-Matus*, Jeffrey S. Shima

\begin{tabular}{|c|c|}
\hline ARTICLE INFO & A B STRACT \\
\hline $\begin{array}{l}\text { Articicle history: } \\
\text { Received } 10 \text { August } 2009 \\
\text { Received in revised form } 24 \text { March } 2010 \\
\text { Accepted } 26 \text { March } 2010 \\
\text { Keywarts: } \\
\text { Habitat theterogencity } \\
\text { Habitat preference } \\
\text { Kelp beds } \\
\text { New Zealand } \\
\text { Temperate reefs }\end{array}$ & $\begin{array}{l}\text { Habitat heterogeneity may mediate the relationship between organisms and their environment. However, } \\
\text { the demographic and behavioural responses of organisms to different sources of habitat heterogeneity (e.g. } \\
\text { structural complexity and composition) may vary, and consequently, different sources of heterogeneity may } \\
\text { interact to shape the abundance of individual species and composition of a species assemblage. We focused } \\
\text { on habitat-forming macroalgac, and conducted a set of laboratory experiments to determine the macroalgal } \\
\text { preferences of two species of temperate reef fish. In a subsequent field experiment, we manipulated } \\
\text { macroalgal heterogeneity at two sites in Wellington, New Zealand, to determine the relative importance of } \\
\text { different sources of habitat heterogeneity to the abundance of locally common reef fishes. Specifically, we } \\
\text { manipulated three sources of habitat heterogeneity: (1) macroalgal species identities: (2) combinations of } \\
\text { macroalgal species (i.e.. mixed stands): and (3) mactoalgal density. Our laboratory experiments indicated } \\
\text { that two common fishes readily distinguish and exhibit preferences for different forms of macroalgac. Our } \\
\text { field experiment indicated that the abundance of reef fishes varied as a function of experimentally induced } \\
\text { habitat heterogeneity. We detected within-species variation in responses to macraalgal composition } \\
\text { (suggesting ontogenetic habitat shifts), and larger-scale influences on the abundance of reef fishes (effects } \\
\text { attributable to location). Macroalgal identities affected the abundance of } 7 \text { of } 15 \text { reef fish species. } \\
\text { Composition of macroalgal stands shaped the abundance of } 5 \text { of } 7 \text { reef fish species, and the overall structure } \\
\text { of the local fish assemblage. Generally, heterogeneity in vegetative structures appeared to increase breadth } \\
\text { of habitat use for reef fishes. This work suggests strong behaviourally mediated linkages between the } \\
\text { abundance of reef fishes and the composition of vegetative structures in a temperate, macroalgal-dominated } \\
\text { ecosystem. }\end{array}$ \\
\hline
\end{tabular}

1. Introduction

Habitat heterogeneity is widely viewed as a precursor to biological diversity. Homogenization of ecological systems by human activities ( $\mathrm{eg}$. intensive fishing or farming) is often correlated with a progressive decrease in biodiversity (Loreau et al., 2004). This has led some workers to suggest that the protection and enhancement of habitat heterogeneity should form the basis for conservation and management of ecological con variables (e.g. composition, patch or "grain" size, and structural vaniables (eg, compostion, pat or "grain size, and structura complexity), and these individual variables may act separately or in combination to shape the behavioural and/or demographic responses of individual species. Moreover, individual species (or age-classes within a species) may vary in their responses to habitat heterogeneity. Consequently, a more sophisticated understanding of relationships between habitat heterogeneity and species responses may be desirable.

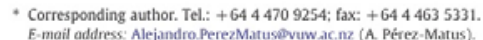
$0022-0981 / 5$ - see front matter O 2010 Elsevier B.V. All rights reserved. doi: 101016 fjembe 201003013
In temperate marine environments, brown macroalgal forests are known to influence the abundance and distribution of associated macrofaunal assemblages (Dayton, 1985: Schiel and Foster, 1986: Graham, 2004). The structure and composition of macroalgal stands (and the morphology of individuals for a given species of macroalgae) can vary considerably, often as a function of local environmental conditions (Schiel and Foster, 1986). Understanding how algal-associated organisms such as reef fishes respond to local-scale variation in the structure of macroalgal communities requires recognition of how different components of macroalgal habitats (e.g., species identity,
structural complexity, density) potentially interact to influence the structural complexity, density) potente
abundance of a dependent species.

Vegetative structures of macroalgae may provide a range of "services" to fish, including food (or feeding sites) and refuge from potential predators. Fish and other organisms may use the same vegetative structures of an individual alga for different purposes, or they may partition their activities among different components of the alga (e.g., fronds may be used for refuge/shelter and holdfasts for feeding sites: Steneck et al., 2002: Christie et al., 2007). In addition, the role and importance of specific vegetative features to fishes may vary with their ontogeny, and/or depend upon local environmental conditions (e.g. degree of wave exposure and presence of predators, Taylor and Cole, 
1994: Christie et aL., 2007). Specific macroalgal traits may act separately or in synergy with others to shape patterns of distribution and abundance of fishes,

Experiments that attempt to partition and explore the effects of different components of habitat heterogeneity (e.g. the relative importance of habitat-forming species' identities, densities, and multispecies composition) are rare (but see Benedetti-Cecchi, 2004). Consequently, important complexities that may underlic relationships between temperate reef fishes and macroalgal habitats remain largely unexplored.

Given the strong effects of habitat attributes on fitness of dependent species (described above) we expect to find that reef fishes dependent species (described above), we expect to find that reef fishes discrininate (i.e., presere/atse the composition af al statis). Conseguenty. we hypothesise that (1) habitat heterogeneity will shape the distribetion and abundance of individuats over seir responses to particular sources of habitat heterogeneity (and these responses may depend upon local environmental contexts); and consequently, (3) different macroalgal habitats will support different species assemblages

\section{Materials and methods}

2.1. Laboratory experiment - capacity for behaviourally mediated habitat preference

To determine whether common fish in our study system exhibit preferences for different macroalgal habitats, we conducted a choice experiment in a large outdoor recirculating tank $(9 \times 6 \times 1.2 \mathrm{~m}$ depth $)$ at the National Institute of Water and Atmospheric Research (NIWA). Wellington, New Zealand. We estimated behavioural preferences of two species of locally common reef fish (Notolabrus celidotus and Notolabrus fucicola) for five different benthic substratums.

$N$. celidorus (commonly known as the "spotty") and $N$ fucicole (the -banded wrasse") are reef fishes of the fanly babridae, and among the bandce wasse mostcom wis (Russell, 1983: Denny and Schiel, 2001: Find $N$. fucicola reach total lengths (TL) of up to 300 and $600 \mathrm{~mm}$ respectively
(Francis, 2001). We collected 10 small $N$. celidotus ( $\mathrm{TL}<150 \mathrm{~mm}$ ), 10 large N. celidotus $(\mathrm{TL}>150 \mathrm{~mm})$, and 10 arge $N$. fucicola $(\mathrm{TL}>150 \mathrm{~mm})$ using baited traps. All captured individuals were transferred to indoor concree holding tanks and allowed to acclimatise for at least $48 \mathrm{~h}$ prior their use in experimental trials

Initial field observations led us to identify and select three locally common species of macroalgae as potentially important habitats for reef fishes in our area: Macrocystis pyrifera, Carpophyllum maschalocarpum. and Cystophora retroflexa. These three algal species are abundant on shallow subtidal reefs of Wellington harbour (ę., Kau Bay) and the adjoining (and comparatively wave exposed) south coast (eg island adjoining (and comparatively wave-exposed) south coast (e.g. Island Bay, see fig. Ia). In the study area, M. pyrifera (Fig. 1b) can reach up to $6 \mathrm{~m}$ in stipe length, and often forms large surface canopies aided by airfilled pneumatocysts: M. pyrifera provides shade and verticallystructured habitat through the water column. C. maschalocarpum (rig. (Fig. and globose vesicles. Relative to $M$. pynjera, C. maschalocarpum and C. retroflexa are smaller bushy-type macroalgae, reaching up to 0.5 to $1.5 \mathrm{~m}$ in stipe length (for further details see Adams, 1997). In the Wellington region, $M$. pyrifera, $C$-maschalocarpum and $C$.retrexa reach mean densities of $3.8( \pm 1.6 \mathrm{SD}), 4.1( \pm 2.4 \mathrm{SD}), 1.0( \pm 1.5 \mathrm{SD})$ per $\mathrm{m}^{2}$ respectively (A.P.M. unpublished data). We collected intact seaweed specimens (and associated epifauna) of all three species that were attached to small boulders using an open mesh collecting bag $(0.5 \mathrm{~mm}$ mesh size). We attempted to minimise losses of associated epifauna by transferring seaweeds to tanks of seawater immediately after collection. We maintained specimens in outdoor tanks supplied with flow-through seawater, and these storage tanks were covered with black $0.5 \mathrm{~mm}$ mesh shade cloth to approximate light conditions from the sites of collection.

Our experimental design consisted of five treatments that we established within a single large tank: (1) four individuals of $M$. pyrifera. (2) six individuals of $\mathrm{C}$ maschalocarpum, (3) six individuals of $\mathrm{C}$ retroflexa, (4) 6-7 boulders ( 30 to $50 \mathrm{~cm}$ diameter) with no macroalgae, and (5) a control (an identified patch within the tank with no macroalgae or rocks). Different numbers of individuals per species were used to balance the Diferens biomass among treatments, and also reflected natural densities found in the field. Treatments were arrayed in a randomised order in a roughly circular pattern and separated from one another by $3 \mathrm{~m}$. Experimental

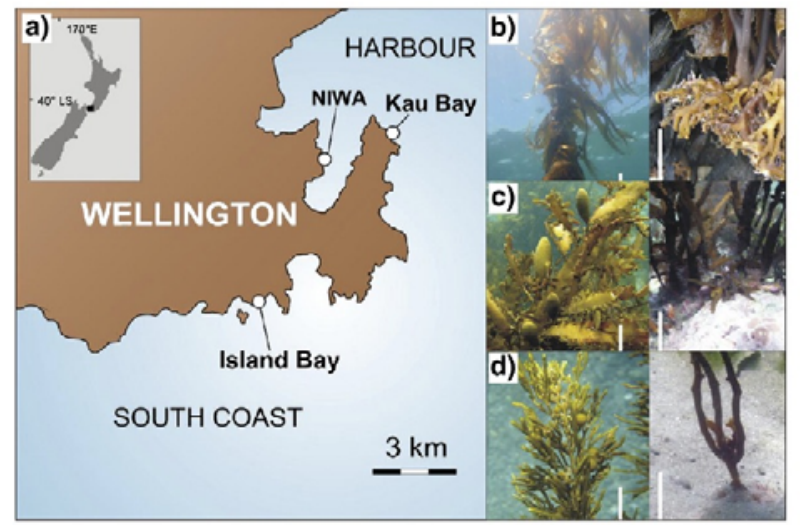
Fig. 1. a) Map giving locations of the study sites in Wellington Region, New Zealand; photographs of blades and their holdfists for: b) Macrocystis pynjera (Laminareales),
c) Carpophyylum maschalocarpum (Fucales), and d) Cystophora retroflexa (Fucales). (photo credits: E. Maccaya and A. Pérez-Matus). 
N. celidotus or $N$. fucicola in the middle of the tank (i.e... equidistant from the five treatments). The position of the focal individual was assessed (from a viewing platform above the tank) $60 \mathrm{~min}$ after release, and scored as a "choice" for one of the five available habitats, or else "no choice" (i.e., when the focal individual was not clearly associated with any of the five experimental patches within the tank). Following each trial, the focal individual was removed from the experimental tank, and the positions of habitat treatments within the tank were reshuffled in preparation for the next trial. Trials (i.e. focal individuals) were replicated in time from February through May 2007, and occurred between 10:00 am to 12:00 pm. Algal specimens were replaced periodically (as tissues $12: 00 \mathrm{pm}$. Algal specimens were replaced periodically (as tissues degraded) over the course of the experiment. Focal individuals were used in trials only once. We assessed behavioural preferences for a total of $20 \mathrm{~N}$. celidotus ( 10 of them juveniles, i.e., $<150 \mathrm{~mm}$ in standard length, SL) and $10 \mathrm{~N}$. fucicola.

We analysed the preferences of $N$. celidotus (juveniles and adults separately) and $N$. fucicola (adults only) for the 5 choices (treatments) in our tank study using a randomization test. We used Bray-Curtis distances ( $\mathrm{BCD}$ ) between observed and expected values as our test statistic using the following formula:

$B C D=\frac{\sum_{n} \mid \text { observed }- \text { expected } \mid}{\sum \text { observed }+\sum \text { expected }}$

High values for $\mathrm{BCD}$ indicate preferences of any of the five different treatments $(n=5)$, and $p$-values were constructed by calculating the proportion of values in the null distribution (generated from 10,000 permutations of the data) that were greater than the estimated by $\mathrm{BCD}$ (we evaluated significance for $\alpha=0.05$ )

2.2. Field experiment - effects of habitat heterogeneity on the abundance of reef fishes and the local fish assemblage

We manipulated macroalgae presence, density, and composition to evaluate the separate and synergistic effects of these sources of variation on the abundance and assemblage structure of reef fishes. From December 2006 to February 2007, we established and maintained an experimental grid of habitat patches (using the same set of algal species experimental grid of habitat patches (using the same set of algal species Wellington region (Kau Bay and Island Bay, Fig 1). Sites differed in wave Wellington region (Kau Bay and lsland Bay. Fig. 1). Sites differed in wave fishes and macroalgal species. Kau Bay, located within the comparafishes and macroalgal species. Kau Bay, located within the compara-
tively sheltered Wellington Harbour, is exposed to northerly winds and tively sheltered Wellington Harbour, is exposed to northerly winds and
protected from southerly swells, with recorded sea temperatures of protected from southerly swells, with recorded sea temperatures of
$17.2^{\circ} \mathrm{C}( \pm 0.9$ SD) during the study period. At Kau Bay, all of the macroalgal species used in the study were locally abundant, and experimental patches were created (described below) from locally obtainable macroalgae. The second study site, Island Bay, is partially protected from periodic large southerly swells by a small offshore island (Taputeranga Island), and during the study period had average sea temperatures of $15.2^{\circ} \mathrm{C}( \pm 1.5 \mathrm{SD})$. Both $C$. maschalocarpum and C. retroflexa are abundant at Island Bay, although M. pyrifera was present

Table 1

Design of field experiment with nine habitat treatments. Factors include: a) treatment identities: ( 9 levels) and numbers of macroalgae individuals manipulated $(n)$ ), b) (SR): species

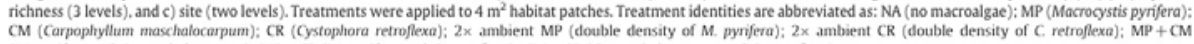
(M. pyrjera and $C$ maschalocarpum): $M P+C R(M$. pyrjera and $C$ retroflexa): $C M+C R(C$ maschalocarpum and $C$, retroflexa).

\begin{tabular}{|c|c|c|c|c|c|c|c|c|c|}
\hline \multirow[b]{2}{*}{ Fadtors } & \multicolumn{9}{|c|}{ Treatments } \\
\hline & 1 & 2 & 3 & 4 & 5 & 6 & 7 & 8 & 9 \\
\hline $\begin{array}{l}\text { a) Treatments identities } \\
(n)\end{array}$ & & $\begin{array}{l}\text { MP } \\
4\end{array}$ & $\begin{array}{l}\mathrm{CM} \\
6\end{array}$ & $\begin{array}{l}\text { CR } \\
6\end{array}$ & $\begin{array}{l}2 \times M P \\
8\end{array}$ & $\begin{array}{l}2 \times \mathrm{CR} \\
12\end{array}$ & ${ }_{10}^{\mathrm{MP}}+\mathrm{CM}$ & $\begin{array}{l}\mathrm{MP}+\mathrm{CR} \\
10\end{array}$ & ${ }_{12}^{\mathrm{CM}}+\mathrm{CR}$ \\
\hline $\begin{array}{l}\text { b) Species richness (SR) } \\
\text { c) Sites }\end{array}$ & \multicolumn{6}{|c|}{$\begin{array}{l}\text { No algae } \\
\text { Island Bay and Kau Bay algal species }\end{array}$} & Two algal & & \\
\hline
\end{tabular}

habitat patches required supplemental algal material transplanted from nearby sites)

At each site, we used nylon lines to demarcate a grid of 17 by $32 \mathrm{~m}$ A in a randomised block design. Each patch measured $4 \mathrm{~m}^{2}(2 \mathrm{~m} \times 2 \mathrm{~m})$, and was separated from adjacent patches within the grid (or ambient reef habitats for patches located along a grid edge) by $1.5 \mathrm{~m}$ of rock or sand each transect we randomised placement of the following nine habit each transect we randomised placement of the following nine habitat treatments: (1) no macroalgac; (2) $1 \times$ ambient density M. pyrifera; (3) 1 ambient density C. maschalocarpum; (4) $1 \times$ ambient density C. retroflexa; (5) $2 \times$ ambient density $M$. pyrifera; (6) $2 \times$ ambient density C. retroflexc (7) $1 \times$ M individuals used to construct "ambient densities" varied among algal species, and these approximated global averages for the Wellington region (A.P.M. unpublished data). Specifically, we used as our $1 \times$ treatments: 4 individuals for $M$. pyrifera, and 6 individuals for both among species (see Table 1 for further details). Each patch was constructed and maintained for the duration of the experiment.

Our habitat treatments were designed to simulate components of habitat heterogeneity that we hypothesised a priori to be potentially important determinants of fish abundance. This included: treatment identities (as above). species richness (SR: 3 levels, either: no. single, or mixed macroalgal species), and site ( 2 levels, Kau Bay or Island Bay). The straints) and partially hierarchical to facilitate important contrasts between single-and mixed stands of macroalgae of comparable canopy densities (see Table 1).

We sampled fish distribution and abundance across our experimen tal grids the day before (day zero) and the day after the construction of our experimental plots, and then at weekly intervals thereafter for seven weeks. Using SCUBA, an observer recorded the identity and size of all observed fishes within a given habitat patch for a period of two minutes. All surveys were conducted between 10:00 and 13:00 $\mathrm{h}$ to minimise potentially confounding effects of diel variation in fish behaviour. On each sample date, and following stormy conditions, we maintained experimental treatments as required (by repositioning and/or replacing lost or damaged seaweed individuals). We completed seven days of fish surveys at Island Bay and six days at Kau Bay over the course of this study period.

We used two separate analyses to explore sources of variation in fish distribution and abundance attributable to habitat heterogeneity. First, $w$ evaluated variation in fish abundance across the 9 treatment identities the effect of species richness (SR, three levels: no algae present, 1 alg species, or 2 algal species) (see Table 1). Both sets of analyses also includer random effect (we excluded counts made prior to the manipulation for these analyses). We used unear mixed models to conduct statistical test. parallel to chore (along relatively uniform depth strata ie. blocks) Aloct (Table 1). In a secondary analysis, we pooled several treatments to explore study site (Kau Bay or Island Bay) as a fixed effect, and sampling day as a

Island Bay and Kau Bay 
Linear mixed models can be used to describe relationships between a response variable and covariates in data or factors in association with a random effect (Pinheiro and Bates, 2000; Bolker et al., 2009). This framework allowed us to consider all factors (fixed and random) that potentially contributed to the structure of our data (McMahon and Diez. 2007) and it works well for unbalanced data sets (Bayen et al., 2008). Methods for estimating linear mixed effect models have addressed the disadvantages of traditional ANOVA or least square regression equations when using random effects or repeated measures (ie, reduced statistical power with repeated measures as number of parameters increases linearly with random factors reduced power with unbales linearly with raire data, and requirements for disparate methods for treating continuous and categorical responses (Pinheiro and Bates, 2000; Baayen et al., 2008)). In linear mixed models the random effect describes deviation from the population mean; the individual values of the adjustments made to intercepts and slopes are calculated once the random effects parameters have been estim mixed models).

Using our linear mixed models, all parameters and interactions were estimated. To reduce the difficulty involved in aproximating the degrees of freedom and interpreting the fixed effects parameters independently from the random effect (Baayen et al., 2008) we used Markov chain Monte Carlo (MCMC) simulation. Using MCMC, we estimated the posterior distribution of the parameters in order to estimate the highest posterior density (HPD) interval (see below).MCMC is an algorithm that approximates the posterior probability distribution of the parameters by generating samples from a Markov chain whose stationary distribution is precisely the posterior distribution of the parameters. This is achieved by proposing candidate values using repeating Monte Carlo simulations from a specified transition probability and accepting or rejecting these values with a given probability (the MetropolisHastings acceptance ratio), which is based on the conditional likelihood of the model given the candidate parameter values. After sufficient draws, this procedure will allow the Markov Chain to reach its stationary distribution, and any samples drawn from there on will be from this distribution (see Andrien et al 2003 for detais). Spccifcallo distribution sampled the conditional distributions of parameter subsets in a cycle (eg., the variance), thus allowing the variation in all remaining parameters (e.g.n fixed effects, random effects) to be reflected in the distribution of the paraner et al., 2008). We cycled through these steps (described above) for 10,000 interations and generated a sample from the posterior distribution of each parameter. We obtained the highest posterior density (HPD) interval for each of the fixed and random effects, and used these to evaluate statistical significance. The Bayesian highest posterior density (HPD) intervals were calculated to include $95 \%$ of the probability density. We used HPDs because they are the shortest intervals with the given probability content, they do not depend on normality assumptions, and thus provide more powerful and robust statistical inference (Chen and Shao, 1999). HPD intervals that do not include zero provide statistical evidence of significant effects of the specified parameters, with the range of intervals indicating the variability of the response (Pinheiro and Bates, 2000; McMahon and Diez, 2007). All univariate analyses were conducted using the $L m e 4$, Coda, and language- $R$ packages in R 2.10 (R Development Core Team, 2008).

To evaluate effects of habitat heterogeneity on local fish assemblages, we used a constrained canonical analysis (CAP) (Anderson and Willis, 2003). Specifically, our analyses asked if the abundance of reef fishes varied between sites, treatment identities (TI, no algae and algal treats a pe used the jack-knife proced per CAP each level of 11 ; values $>15 \%$ (the approximate expected value for random assignment) were considered to be evidence of a significant T based on Euclidean distances to visualise differences in community structure among patch identities (TI). For clarity, we present only the centroids from Bray-Curtis measures obtained for each TI from a principal coordinate (PCO) analysis (for details see, Terlizzi et al, 2005).

\section{Results}

3.1. Laboratory experiment - capacity for behaviourally mediated habitat preference

N. fucicola preferentially associated with patches containing either M. pyrifera or $C$. maschalocarpum (BCD test, $p<0.01$ ), and avoided patches without macroalgae (Fig. 2). In contrast, neither size class of $N$. celidotus showed any statistically detectable macroalgal preference (both $\mathrm{BCD}$ test, $p>0.05$ ). Despite the lack of strong statistical evidence for habitat preference, both large and small $N$. celidotus size classes showed a trend for selective habitat use, selecting either $C$. maschalocarpum or C. retroflexa patches in $30 \%$ respectively of all trials (Fig. 2).

3.2. Field experiment - effects of habitat heterogeneity on the abundance of reef fishes and the local fish assemblage

We recorded a total of 16 species of reef fish over the course of our observations; 15 species were observed at Island Bay, while a subset of 6 of these species plus one additional species were sighted at Kau Bay. Though the species richness of reef fishes documented for Island Bay was greater, fish abundance was low relative to Kau Bay. Following the construction of habitat patches, both the abundance and the number of fish species increased by 8 -fold at Island Bay. Abundance peaked on the third and fourth sampling day; richness peaked on the fourth day with 11 species identified (Table 2). At Kau Bay, abundance and fish species richness reached a maximum on the last sampling day, abundance was three times higher than on the sampling day prior to the start of the experiment.

Abundances of species such as N. celidotus and Forsterygion lapillum were 3 times higher at Kau Bay than at Island Bay throughout the sampled days; together, these two species accounted for more than 55\% of fish censused at Island Bay and more than $94 \%$ of fish censused at Kau Bay (Table 2). N. celidotus was the most abundant species at both sites, with recently recruited juveniles accounting for most of the fish recorded in surveys (Table 2). The second most abundant species at Island Bay was Forsterygion maryannee; the second most abundant species at Kau Bay was F. lapillum. More than $50 \%$ of the F. lapillum

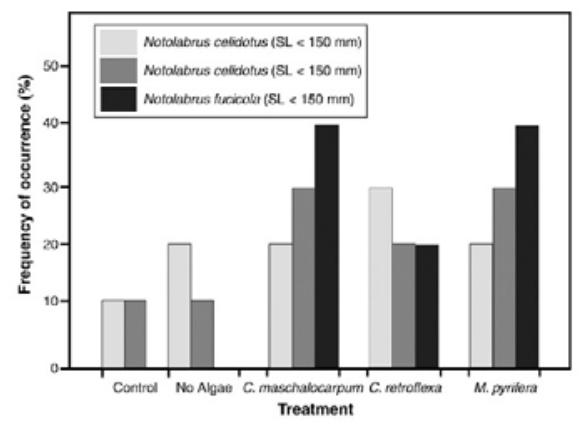

Fig. 2. Frequency of occurrence ( $(\%)$ of Notolabrus celidotus $(\mathrm{SL}<150 \mathrm{~mm})$, N. celidotus (SL $>150 \mathrm{~mm}$ ), and $N$ fucicola (SL. ranges $150-390 \mathrm{~mm}, n=10$ ) in the tank experiments in the five different treatments: 1) an identified empty section of the tank ("Control");
2) cobbles without attached macroas gase ("No algae"); 3) Carpophyyllum maschalocarpum: 4) Cystophora retroflexa, and 5) Macrocystis pyrifer 
Table 2

Identities of the fiften species of reef fish sighted in the field experiments. Numbers represent the cumulative counts of fish across all sampling days: Island Bay ( $n=7$ days) and Kau Bay $(n=7$ days $)$. For both sites, day 0 represents sampling day before the
( $\mathrm{LL}<50 \mathrm{~mm}$ for Labridae and Odacidae and $\mathrm{SL}<30 \mathrm{~mm}$ for Tripterygiidae).

\begin{tabular}{|c|c|c|c|c|c|c|c|c|c|c|c|c|c|c|c|}
\hline \multirow{2}{*}{$\frac{\text { Family }}{\text { Species }}$} & \multicolumn{8}{|c|}{ Island Bay } & \multicolumn{7}{|l|}{ Kau Bay } \\
\hline & Day 0 & Day 1 & Day 2 & Day 3 & Day 4 & Day 5 & Day 6 & Total & Day 0 & Day 1 & Day 2 & Day 3 & Day 4 & Day 5 & Total \\
\hline \multicolumn{16}{|l|}{ Syngnathidar } \\
\hline $\begin{array}{l}\text { Stigmatopora sp. } \\
\text { Hyppocampus. }\end{array}$ & 0 & 0 & 0 & 0 & 1 & 0 & 0 & 1 & $i$ & $\overline{0}$ & $\overline{0}$ & $\overline{0}$ & $\overline{0}$ & $\overline{0}$ & \\
\hline $\begin{array}{l}\text { Hyppocampus } \\
\text { abdominalis }\end{array}$ & - & & - & - & - & - & - & & 1 & 0 & 0 & 0 & & & 1 \\
\hline \\
\hline $\begin{array}{l}\text { Pseudocananx dentex } \\
\text { Latridare }\end{array}$ & 0 & 0 & 0 & 0 & 25 & 0 & 0 & 25 & - & - & - & - & - & - & \\
\hline Latridopsis aliaris & 0 & 2 & 1 & 4 & 7 & 5 & 1 & 20 & & & & & & & \\
\hline $\begin{array}{l}\text { Nemadactylus } \\
\text { macropterus }\end{array}$ & - & - & - & 1 & - & - & - & 1 & - & - & - & - & - & - & \\
\hline \multicolumn{16}{|l|}{$\begin{array}{l}\text { Mugilidac } \\
\text { Adridtuetto forsteri }\end{array}$} \\
\hline Adrichetta forsteri & 0 & 2 & 0 & 0 & 0 & 0 & 0 & 2 & $=$ & - & - & - & - & $=$ & \\
\hline \multicolumn{16}{|l|}{ Labridae } \\
\hline $\begin{array}{l}\text { Notolabrins cilvatus } \\
\text { Notolabrus fucicola }\end{array}$ & $\begin{array}{l}30(19) \\
0^{2}\end{array}$ & $\begin{array}{l}207(67) \\
39\end{array}$ & ${ }_{37}^{163(83)}$ & $\begin{array}{l}22(20) \\
71\end{array}$ & $\begin{array}{l}131(20) \\
20\end{array}$ & $\begin{array}{l}95(82) \\
27(5)\end{array}$ & $\begin{array}{l}75(70) \\
29\end{array}$ & $\begin{array}{l}723 \\
223\end{array}$ & 3 & $\begin{array}{l}424(198) \\
7\end{array}$ & 10 & $\begin{array}{l}498(213) \\
7\end{array}$ & $\begin{array}{l}25(25) \\
25(3)\end{array}$ & $\begin{array}{l}532(42) \\
15(5)\end{array}$ & 67 \\
\hline Pseudolabrus miles & 0 & 0 & 0 & 0 & 0 & 1 & 4 & 5 & - & - & - & - & - & - & \\
\hline Odax pullus & 0 & $4(2)$ & 1 & $G(1)$ & $5(1)$ & 5 & 3 & 24 & - & - & - & - & - & - & \\
\hline $\begin{array}{l}\text { Pinguipedidare } \\
\text { Parneneris colioss }\end{array}$ & & & & & & & & & & & & & & & \\
\hline \multicolumn{16}{|l|}{ Tripteryguidae } \\
\hline Forsterygion lapilhum & 0 & 0 & 11 & $82(36)$ & $76(20)$ & $73(13)$ & $68(34)$ & 310 & 0 & 0 & $157(128)$ & $90(88)$ & $304(121)$ & $290(133)$ & 841 \\
\hline Forsteryzion varium & $4(1)$ & $8(1)$ & $21(10)$ & $70(21)$ & $48(11)$ & $40(1)$ & 43(11) & 234 & 0 & 0 & $9(8)$ & 0 & $11(7)$ & & 39 \\
\hline $\begin{array}{l}\text { Forsteryzion } \\
\text { maryaunar }\end{array}$ & 0 & $6(6)$ & 1 & 82 & 59 & 116 & 74 & 338 & - & - & - & - & - & - & \\
\hline Notoclinus fenestratus & 0 & 1 & 0 & 0 & 0 & 0 & 0 & 1 & i & - & - & - & $=$ & -7 & \\
\hline Ruanoho whero & 0 & 0 & 0 & 0 & 1 & 2 & 1 & & 0 & 0 & 4(4) & 0 & 0 & $20(8)$ & 24 \\
\hline Total individuals & 34 & 269 & 235 & 338 & 374 & 364 & 298 & 1912 & 326 & 467 & 698 & 554 & 783 & 1013 & 3841 \\
\hline Total species & 2 & 8 & 7 & 8 & 11 & 9 & 9 & 15 & 4 & 3 & 6 & 4 & 5 & 6 & 7 \\
\hline
\end{tabular}

individuals counted at Kau Bay were recent recruits (evidenced by their size, colouration, and behaviour patterns).

In total, six species ( $N$. celidotus, Forsterygion varium, F. maryannae, E. lapillum, Latridopsis ciliaris, and Odax pullus) were common and F. lapillum, Latritop sampling days at Island Bay after the start of our experiment. Four species (N. celidotus, F. lapillum, Parapercis colias, and N. fucicola) were observed across each sampling date at Kau Bay. We therefore limited our more across each sampling date at Kau Bay. We therefore limited our more
detailed statistical analyses to these most abundant species at both sites

(i.e., O. pullus, small and large $N$. celidotus, small and large F. lapillum, $P$. colias, small and large $F$. varium, $N$. fucicola, and $F$, maryannae).

Linear mixed model analyses suggested that reef fishes varied in their responses to our treatment manipulations and habitat heteroge neity (no macroalgae, single and mixed algae). Table 3 gives estimates of neity (no macroalgae, single and mixed algae). Table 3 gives estimates of
fish abundance $(+$ SD) across the 9 treatments, and significant effects fish abundance $( \pm S D)$ across the 9 treatments, and
were identified using HPD values given Appendix 2 .

were identified using HPD values given Appendix 2 .
The butterfish, 0 . pullus, occurred at only 1 site (Island Bay) and on four treatments only (Table 3). The HPD interval (Appendix 2) did not

Table 3
Mean abundance ( \pm SD) of small (juvenile) and large individual species over the 9 treatment identities ( $T$ ) at two study sites. Numbers in bold represent significance at p-values $<0.05$

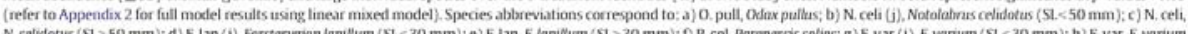
$(S L>30 \mathrm{~mm}$ ) : i) N fuci, N. fucicolc; and i) F, marya. F. maryannae. Refer to Table 1 for abbreviations on the treatment identities (TI). Data were pooled across the different sampling days

\begin{tabular}{|c|c|c|c|c|c|c|c|c|c|c|c|}
\hline Site & $\pi$ & 0. pull & N. celi (j) & N. celi & F. $\operatorname{lap}(j)$ & F. lap & P. col & F. $\operatorname{var}(\mathbf{j})$ & F. var & N. fuci & F. marya \\
\hline Kau Bay & NA & - & $2.57 \pm 1.51$ & $1.85 \pm 1.81$ & $3.3 \pm 1.81$ & $2.6+2.13$ & $1.33 \pm 0.89$ & $0.25 \pm 1.0$ & $0.50 \pm 1.0$ & $1.33 \pm 0.57$ & - \\
\hline Island Bay & $\mathrm{NA}$ & - & $83 \pm 2.04$ & $1.25 \pm 0.5$ & $20 \pm 1.0$ & $3.50 \pm 2.59$ & & $1.75 \pm 0.96$ & $1.64 \pm 0.84$ & $1.1 \pm 0.31$ & $1.0 \pm 1.0$ \\
\hline Kau Bay & MP & - & $4.91 \pm 2.89$ & $2.05 \pm 1.43$ & $3.15 \pm 1.82$ & $3.29 \pm 3.17$ & $1.11 \pm 0.33$ & $20 \pm 20$ & $0.25 \pm 1.0$ & $30 \pm 20$ & \\
\hline Island Bay & MP & $1.0 \pm 0.0$ & $2.18+1.17$ & $1.84 \pm 1.51$ & $2.0 \pm 1.55$ & $250 \pm 0.70$ & $0.25+1.0$ & $1.67+0.57$ & $1.17 \pm 0.39$ & $1.19 \pm 0.4$ & $18.50 \pm 14.29$ \\
\hline Kau Bay & $\mathrm{CM}$ & . & $4.90 \pm 3.75$ & $2.54 \pm 1.58$ & $3.73 \pm 2.49$ & $3.23 \pm 28$ & $1.2 \pm 0.42$ & $10 \pm 10$ & $0.50 \pm 10$ & $1.25 \pm 0.5$ & \\
\hline Island Buy & CM & - & $1.70 \pm 0.80$ & $1.06 \pm 0.25$ & $227 \pm 1.34$ & $1.80 \pm 1.15$ & & $1.0 \pm 1.0$ & $1.53 \pm 0.77$ & $1.08 \pm 0.28$ & $1.0 \pm 1.0$ \\
\hline Kau Bay & $\mathrm{CR}$ & - & $28 \pm 1.98$ & $2.44 \pm 1.37$ & $3.1 \pm 1.97$ & $3.78 \pm 2.44$ & $0.25 \pm 1.0$ & 1.25 & $0.25+1.0$ & $1.0 \pm 1.0$ & \\
\hline Istand Bay & $\mathrm{CR}$ & . & $50 \pm 0.67$ & $1.0 \pm 1.0$ & $3.33 \pm 2.51$ & $1.50 \pm 0.79$ & & & $1.20 \pm 0.42$ & $1.22 \pm 0.67$ & \\
\hline Kau Bay & $2 \times \mathrm{MP}$ & - & $6.46 \pm 4.79$ & $2.69 \pm 2.14$ & $3.50 \pm 1.69$ & $4.20 \pm$ & $1.50 \pm 0.71$ & 0.25 & $1.50 \pm 0.71$ & $1.56 \pm 1.01$ & \\
\hline 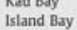 & $2 \times \mathrm{MP}$ & $1.80 \pm 0.28$ & $\begin{array}{l}6.46 \pm= \\
1.83 \pm\end{array}$ & $\begin{array}{l}2.06 \pm \\
1.70 \pm\end{array}$ & $\begin{array}{l}2.30 \pm 1.0 \\
2.0 \pm 1.0\end{array}$ & $2.211+$ & 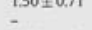 & & $\begin{array}{l}1.25 \pm 0.46 \\
\end{array}$ & $\begin{array}{l}1.36= \\
1.28\end{array}$ & 11,43 \\
\hline Kau Bay & $2 \times C R$ & - & $3.71 \pm$ & $2.15 \pm$ & $3.25 \pm$ & & $0.25+1.0$ & & 1.33 & & \\
\hline Istand B.yy & $2 \times C R$ & & $275=$ & $1.56 \pm$ & $266=$ & & & & & & \\
\hline Kau Bay & $\mathrm{MP}+\mathrm{CN}$ & - & & & & & $1.44 \pm 1.01$ & & 1.75 & & \\
\hline & & - & 3 & & & & & $1.33 \pm$ & & & \\
\hline & M & $=$ & 4. & & & & & - & & & \\
\hline Ist: & $\mathrm{MP}+\mathrm{CR}$ & & $15 \pm 2.02$ & & & & & $0.25 \pm$ & & $1.12 \pm 0.33$ & \\
\hline & $\mathrm{CM}+\mathrm{CR}$ & - & $16 \pm 2.15$ & $1.96 \pm 1.17$ & & $3.70 \pm$ & $0.25+1.0$ & & $0.50+1.0$ & $1.0 \pm 0.5$ & \\
\hline Island Bay & $\mathrm{CM}+\mathrm{CR}$ & - & $245 \pm 2.11$ & $1.36 \pm 0.65$ & $2.75 \pm 050$ & $20 \pm 156$ & & $1.66 \pm 155$ & $1.47 \pm 0.83$ & $1.0 \pm 0.1$ & \\
\hline
\end{tabular}

represents species atuent at sie ant 
contain zero in only one treatment $(2 \times$ density of $M$. pyrifera). indicating that this habitat type had a positive effect on the abundance of 0 . pullus. Ambient densities of $M$. pyrifera and mixed macroalgae containing $M$. pyrifera had no detectable effect on 0 . pullus abundance (Table 3 and Appendix 2).

Abundance of small (i.e., juvenile) spotties, N. celidotus, responded positively to mixed macroalgae of $M$. pyrifera (which also included C. maschalocarpum) at both study sites. Abundance of small $N$. celidotus on patches without macroalgae was highly variable (and comparably low) at both sites. Abundances of larger sized N. celidotus differed only between study sites (more abundant at Kau Bay than Island Bay), and we found study sites (more abundant at Kau Bay than Island Bay), and we found no evidence for a behavioural response of these larger individuals to our imposed algal treatments (i.e, large $\mathrm{N}$. celidotus appear to behave as habitat "generalists") (Table 3 and Appendix 2)

The abundances of both small and large size classes of the common triplefin, F. lapillum were greater at Kau Bay relative to Island Bay. For Kau Bay in particular, our analyses suggest that $F$. lapillum behaves as a habitat "generalist", as it did not exhibit any preferences for our imposed treatments (Table 3 and Appendix 2).

The blue cod, P. colias, occurred only at Kau Bay. P. colias were present in significant numbers only in patches with no macroalgae, patches with C. maschalocarpum, and with mixed macroalgae of $M$. pyrifera with C. maschalocarpum and C. retroflexa (Table 3 and Appendix 2).

The variable triplefin, $F$. varium showed no response to imposed habitat patches at Kau Bay (Table 3). At Island Bay we detected significant responses from small individuals only. Small $F$, varium, were present in significant numbers on patches with no macroalgae, and patches with $2 \times$ density of $M$. pyrifera and $C$. retroflexa. Mixed macroalgae ( $M$. pryifera with $C$. maschalocarpum) were preferred by small $F$, varium at Island Bay only. $F$. varium were less abundant and less clearly associated with particular habitat patches at Kau Bay; we did not detect significant effects on their abundance at this site. At Island Bay. large $F$, varium appear to behave as habitat "generalists", as they showed no clear preferences for the imposed treatments despite being commonly recorded on all patch types (Table 3 and Appendix 2).

The banded wrasse, N. fucicola, exhibited strong preferences for patches containing macroalgae, and their abundance was comparably low and unpredictable in patches with no macroalgae. Abundance of $N$. fucicola was higher at $2 \times$ density of $M$. pyrifera at both study sites. $N$. fucicola also appeared to prefer patches comprised of a mixture N. fucicola also appeared to prefer patches comprised of a mixture
macroalgal species (which also included $M$. pyrifera) at both study sites. macroalgal species (which also included M. pyrifera) at both study sites.
The abundance of $N$. fucicola was relatively high in other types of patches The abundance of $N$. fucicola was relatively high in other types of patches
(e.g. ambient density of $M$. pyrifera, C. retroflexa, and combination of Fucaleans) at the Island Bay site only (Table 3 and Appendix 2).

The oblique-swimming triplefin, F. maryannae, occurred at 1 site only (Island Bay). Their abundance was high on ambient and $2 \times$ density of M. pyrifera patches only (Table 3 and Appendix 2).

The abundance of most fishes was generally low on patches without macroalgae (Table 3). The HPD intervals indicate that, although in low abundance, some species consistently occurred on patches without macroalgae along the different sampling days. This is reflected by the positive and significant estimates of this parameter for $N$. celidotus F. lapillum, and P. colias at Kau Bay (Fig. 3c-f). At Island Bay, the HPD interval indicates that the only abundant species in patches with no macroalgae were larger individuals of $F$, varium (Fig. $3 \mathrm{~h}$ ).

Irrespective of the macroalgal identities, estimated HPD intervals indicate that the habitat patches comprised of a single species macroalgae had positive effects on the abundance of both large and small size classes of $N$. celidotus and $F$. lapillum at Kau Bay (Fig. 3b-e), and positive effects on the abundance of $O$, pullus, F, varium, F, maryannae and N. fucicola at Island Bay (Fig. $3 \mathrm{a}, \mathrm{g}-\mathrm{j}$ ).

HPD intervals indicate that the treatments comprised of mixed macroalgal stands had positive effects on the abundance of $N$. fucicola and macroalgal stands had positive effects on the abundance of $N$. fuccicola and
small individuals of $N$. celidotus at both study sites (Fig. 3b, i). Mixed small individuals of $\mathrm{N}$. celidotus at both study sites (Fig. 3b, i). Mixed
stands of macroalgae had detectible positive effects on the abundance of large individuals of $N$. celidotus, F. lapillum, and P. colias at Kau Bay only
(Fig. 3c-f), and on both large and small $F$. varium at Island Bay only (Fig. $3 \mathrm{~h}-\mathrm{i}$ ).

The HPD intervals estimated for sampling days (included as a random effect to control for unmeasured environmental variation, e.g. day-to-day variation in water visibility) had a variable effect in most fishes. The range of HPD interval was lowest for 0 . pullus and $N$. fucicola (Fig. 3a,i) and highest (e.g. most variable) for N. celidotus and F. lapillum. These results suggest that the estimated abundances of these species varied over the course of our experiment (Table 2 Fig. 3b-e).

3.3. Variation in fish assemblages

CAP analysis indicated that most of our experimentally imposed patch types (treatment identities) developed into statistically distinct fish assemblages. Patches comprising two species of macroalgae and/or of no algae were particularly distinct, as evidenced by the relatively high percentage of allocation success, though the two sites differed in some respects ( $\mathcal{f}$., allocation success for $M$. pyrifera $+C$. retroflexa between sites. Table 4). MDS plots illustrate the nature of the between-site variation in fish assemblages, with experimental patch types clustering differently at the two sites in a pattern that is consistent with our univariate results throughout the different sampling days. At Island Bay. patches without macroalgae clustered with M. pyrifera $+C$ maschalocarpum while other treatments are spread across the ordination space (Fig .4a). Assemblages of species that influenced this cluster at Island Bay were the most abundant species at this site (i.e., large $N$. celidotus, N. fucicola, F, varium and $F$. lapillum) as well as the blue moki $L$ caliaris that was only sighted on these treatments. Species such as F. varium, F. lapillum, and large $N$. celidotus occurred in higher abundances in patches with no algae and are responsible to the clustering in this site. At Kau Bay, patches without macroalgae were well separated from all the macroalgal treatments. Species that contributed to this cluster were the most abundant (i.e. $F$. lapillum, N. celidotus) as well as other species such as the blue cod $P$ colias and the spectacled triplefin Ruanoho whero, which were foctias and the spectacled triplefin, Ruanoho whero, which were frequently observed on unvegetated patches. Those patches containing C. retroflexa clustered similarly with one another (all observed species of triplefins and $N$. celidotus comprised this assemblage), as did patches that contained M. pyrifera (Fig. 4b). Treatments with M. pyrifera with C. maschalocarpum formed another distinct assemblage (Fig. 4b). comprised of species such as small N. celidotus, F. lapillum. N. fucicola.

\section{Discussion}

We found evidence that the diversity and abundance of reef fishes may be related to heterogeneity and physical complexity of benthic habitats at both small (i.e., manipulated patches) and large (i.e, site) scales. Following the construction of habitat-forming macroalgal patches, the abundance and overall diversity of reef fishes increased. Further, our experiments suggest that temperate reef fishes recognise and respond to different components of "habitat heterogeneity", including macroalgal presence, species identity, stand composition, and density. Our results suggest that some macroalgae enhance the overall quality of a site by supporting more and different species of reef fishes.

In our tank study, two fishes (N. celidotus and $N$. fucicola) showed different behavioural responses in a habitat selectivity experiment $N$. fucicola demonstrated a strong preference for both M. pyrifero and N. fucicola demonstrated a strong preference for both $M$. pyrijera and C. maschalocarpum. N. celidotus, in contrast showed a more "generalist" without any clear preference in fold experiments, hese two species withort any clear preference. In feld experiments, these two species exhibed reponses that we fucicola demonstrated a statistically signiffic features whereas $N$. celidotus did not. Our analyses of the field experiment suggest that 1) most reef fishes
that we examined responded to some component of habitat 
A. Pírez-Matus, J5, Shima / Journal of Experimental Marine Biology and Ecology 388 (2010) 1-10
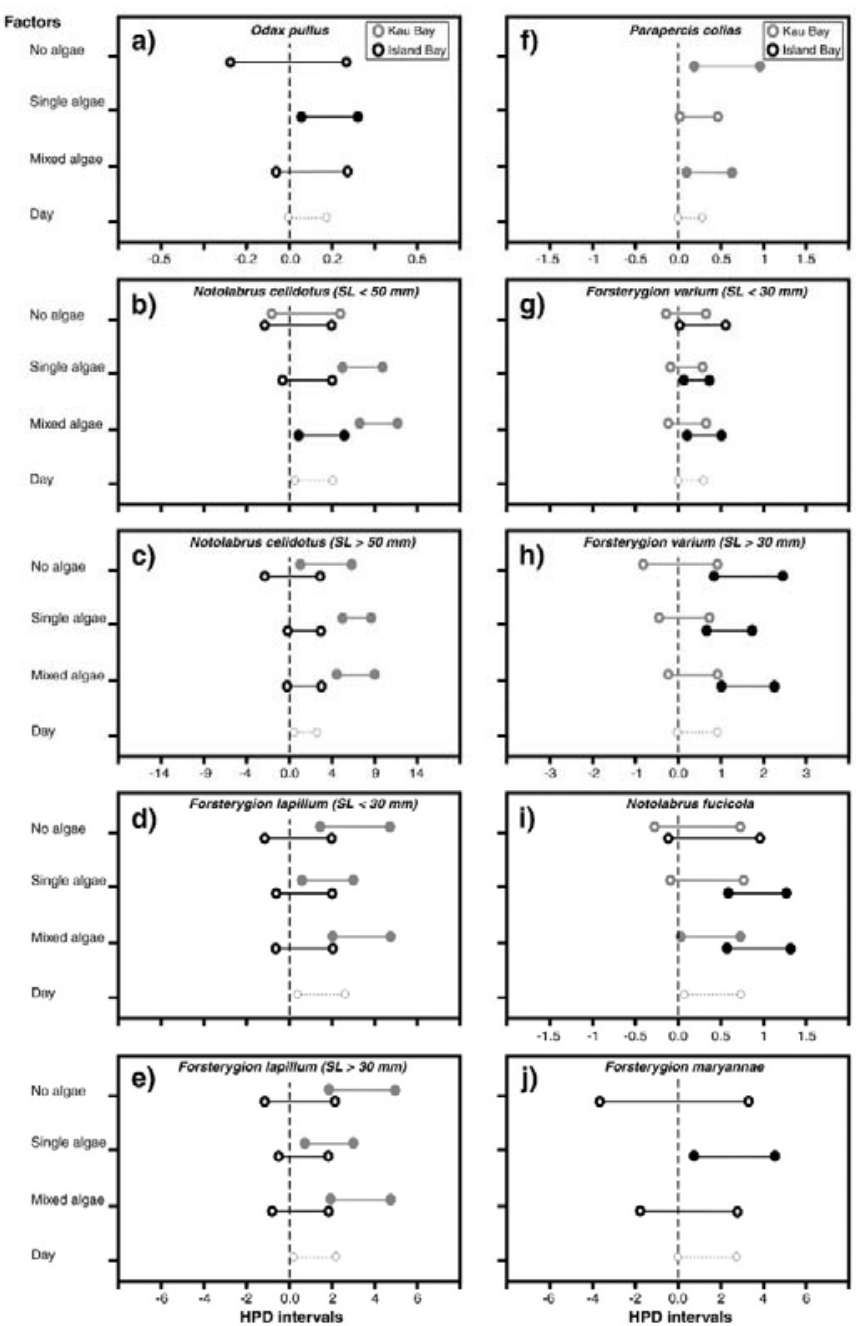

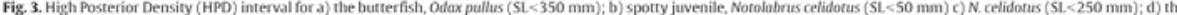

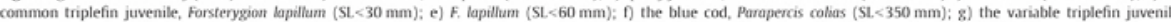

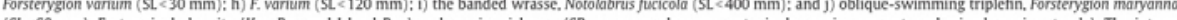

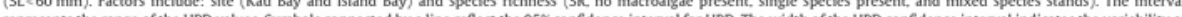
the response (es a wur interval of the random effects "Day" reflects the standard deviation estimated after MCMC (refer to Materials and methods for details).

heterogeneity, whether presence/absence of macroalgae, composition of macroalgal stands (ie., single or mixed species), and/or macroalgal sheltered study site; 3 ) two of the three reef fishes for which we had densities: 2) most of these responses varied between awave-exposed vs a and adult stages (eg. N. celidotus and $F$, varium): and 4) mixed species 
Table 4

Canonical analysis of principal coordinates (CAP), results from Island Bay and Kau Bay. Total variation of the $m$ axes ( $(\mathrm{Var}$ ). ) of the principal coordinate analysis (PCO). allocation Guccess or a mir groups. assigned as percent of points allocated to each of the treatment identities (NA no macroalgae, MP. Macrocystis pyrifera, CR. Castophoru retroflexa; CM,

\begin{tabular}{|c|c|c|c|c|c|c|c|c|c|c|}
\hline \multirow[t]{2}{*}{ Site } & \multirow[t]{2}{*}{$x$ Var. } & \multicolumn{7}{|c|}{ Allocation success $(x)$} & \multirow[t]{2}{*}{$\sigma^{2}$} & \multirow[t]{2}{*}{ p } \\
\hline & & $\overline{\mathrm{NA}}$ & MP & $\mathrm{CR}$ & $\mathrm{CM}$ & $\mathrm{MP}+\mathrm{CR}$ & $\mathrm{MP}+\mathrm{CM}$ & $\mathrm{CM}+\mathrm{CR}$ & & \\
\hline Island Bay & 93.75 & 38 & 13 & 2 & 17 & 33 & 29 & 29 & 0.13 & 0.006 \\
\hline Kau Bay & 95.56 & 55 & 20 & 3 & 10 & 0 & 55 & 30 & 0.22 & 0.001 \\
\hline
\end{tabular}

macroalgal stands and M. pyrifera (irrespective of density) yielded the highest abundances of reef fishes.

Local abundances of reef fishes differed markedly between sites, suggesting some larger-scale environmental context (e.g. wave exposure, presence of other species, or local densities of resident fish) may mediate the importance of some components of habitat heterogeneity. Studies conducted by others indicate that processes related to recruitment that may occur over larger spatial scales readily influence patterns of abundance at small spatial scales (Caselle and Warner, 1996). White and Caselle (2008) found that processes acting on both small and large scales influence the abundance of a reef fish. In temperate waters off California, abundance of adult kelp bass (Paralabrax clathratus) was determined by habitat availability (kelp abundance) and conspecific density at small scales; spatial variation in larval supply explained the abundance of kelp bass at larger scales (White and Caselle, 2008). Recruitment of many reef fishes is variable in space and time, and at locations and times when the supply of recruits is sufficiently high, local populations may be limited and regulated by density dependent interactions on the reef (Shima, 1999; Shima et al.. 2008: White and Caselle, 2008); in some cases these two sources of variation can interact to mask the positive effects of habitat quality at small spatial scales (ie. "cryptic density dependence" sensu (Shima and Osenberg, 2003)).

Some reef fishes showed habitat shifts between juvenile and adult stages. Juveniles of $N$, celidotus, for example, were absent in patches without macroalgae and present in abundance over manipules without macroalgae and present in abundance over manipulated patches with M. pyjer (regrdless of density and whether present in consistent at both study sites and different from responses of larger

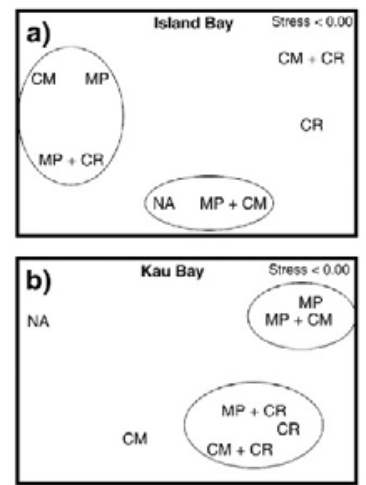

Fig. 4. n-MDS ordination plot of Euclidean distances among centroids of the interaction between different treatment identities (no algae and macroalgae treatments, see Table 1 for description) constructed at two study sites a) Island Bay and b) Kau Bay.
Centroids were separately computed for each site from Bray-Curtis dissimilarities of untransformed data using principal coordinates stages of N. celidotus. F. varium showed a similar trend: juvenile and adult stages differed in their use of microhabitats but this apparent ontogenetic variation in habitat use was only observed at one site. Ontogenetic shifts in habitat use have been described previously for Ontogenetic shifts in habitat use have been described previously for
these species (Jones, 1984b; Connell and Jones, 1991: McDermott and Shima, 2006). In our study we did not detect ontogenetic changes in habitat use for $F$. lapillum (McDermott and Shima, 2006), and we habitat use for F. lapillum (McDermott and Shima, 2006), and we suggest that our study may have lacked the statistical power to detect
these patterns. Implications and mechanisms underlying ontogentic these patterns. Implications and mechanisms underlying
changes in habitats or resources warrant further study.

Onanges in habitats or resources warrant further study.
On temperate reefs, both experimental (DeMartini and Roberts, 1990; On temperate reefs, both experimental (DeMartini and Roberts, 1990;
Holbrook et al., 1990a; Levin and Hay. 1996) and descriptive studies (Anderson and Millar, 2004; Pérez-Matus et al., 2007; Williams et al, 2008) suggest that local demographic and/or behavioural responses of fishes are commonly shaped by variation in underlying macroalgal habitat attributes. Moreover, the ability of some species to detect and respond to habitat heterogeneity can account for variation in individual resource pay-offs (Parker and Sutherland, 1986; Hugie and Grand, 1998; Levin et al., 2000). Local densities often reflect responses of individuals to structural attributes of the habitat (Levin et al., 2000). Our results are concordant with other studies conducted in temperate regions that have identified strong linkages between fish abundance and algal identities (Stephens et al., 1984; Holbrook et al., 1990b; Anderson and Millar, 2004). We documented two categories of temperate reef fishes in this study: 1) "specialist" fish species that responded to patienular macroalgat identities, is those fishes thet increased their a toundr macroalgal identices. ie., those fishes that increased their abundance or their frequency of occurrence under the presence of macroalgae (i.e, M. pyrifera for N. Jucicola, O. pullus, juvenile F. varium, F. maryannae in this study); and 2) "generalist fish species, i.e., fishes with local abundances that were not determined by a particular macroalgal identities (L.e..large N. celidotus and $F$, varium, $F$. lapilum, $P$. colias in this study). Specialists may comprise species that are more likely to gain benefits of resource provisioning from macroalgae. For example, the herbivore 0 . pullus feeds directly on reproductive branches and on blades of large brown algae (Choat and Clements, 1992) and $N$. fucicola spends time in kelp structures searching for food occurring in kelp's holdfast (Denny and Schiel, 2001). Further evidence of the trophic connections between these fishes and brown macroalgae is also supported by Hickford and Schiel (2008), who found that both fish species were highly susceptible capture with gill nets placed in macroalgal habitats (due to enhanced risk of capture correlated with foraging behaviour; Hickford and Schiel, 2008). We found that N. celidotus (the most abundant species in the study) was affected by the presence of macroalgae only at early juvenile stages (Jones, 1984a); adults are generally more abundant on barren habitats, and this is presumably influenced by the distribution of food (lones, 1984b; Anderson and Millar. 2004). For $F$. varium, which responded to the presence/absence of macroalgae, the absence of a clear linkage with a particular macroalgat identity maty be due to intense competitive interactions with $N$. celidotus celidotus their preferred food items (i.e., gammarid amphipods; Feary et al., 2009) actoss different algal structures used in this study (Taylor and Cole. 1994). Other species that were not commonly observed across sampling days (and therefore excluded from analyses) may avoid macroalgal structures, or may by our mode of sampling. For example, some species in our local area 
periodically may form dense feeding or schooling aggregations: such species with schooling behaviour (Pseudocaranx dentex, $L$ ciliaris, and Nemdactylus macropterus) may also be affected by the three dimensional structure of kelps (Siddon et al., 2008), but these behaviours (and their relationship with macroalgal structures) may occur too rarely to be detected by our sampling.

Variation in behavioural parterns was apparent from both tank and field experiments. Although we failed to quantify behavioural parterns for all fish species sighted during the study, results from these experiments suggest that species-specific behavioural responses may have a measusuggest that species-specific behavioural Tesponses may have a measurable influence on fish assemblages in temperate reef settings. Conceptually, this can be explained by distributional models that attempt to predict parterns of movement and dispersal of a species across different habitats (Hugie and Grand, 1998; Levin et al., 2000). Both the ideal free distribution (IFD) and the ideal despotic distribution (IDD) describe trade-offs that arise from behavioural decisions of individuals (Kramer et al., 1997). In their application, boch distributional models are sometimes based on untested assumptions of the individuals' ability to perceive and discriminate among locally available habitats and/or other resources (Roshier et al., 2008). From the perspective of an individual of a given focal species, the decision to move from one patch to another may depend upon a range of (potentially conflicting) motives that, for example, may include maximisation of food resources and/or mating opportunities, minimisation of risk from predators and/or competitors, etc (Kramer et al. 1997: Connell and Kingsford, 1998: Crowe and Underwood, 1998

Species with ecological preferences are likely to be present where those preferences are met (Legendre et al., 1997). It is well known that fauna associated with habitat-forming macroalgae are an important source of food for many predatory fishes in temperate regions (Taylor, 1998). The distribution and abundance of associated fauna with habitatforming macroalgae are influenced by differences in macroalgal fronds, forming mactoalgae are influenced by differences in macroalgal fronds, size (Thiel and Vassquez, 2000). These structures, manipulated indirectly in the present study, may induce different for, manipulated indirectly in the present study, may induce different foraging patterns by fishes within different macroalgae species, or within phenotypically different individuals of the same species of macroalgae. While macroalgae provide substratum for an array of associated fauna, their size and shape, physiological (and chemical defence) status, and whether they are present as single or mixed species stands will alter their ability to support faunal assemblages that comprise a forage base for many reef fishes. More structurally complex habitats (eg., small vs tall, single vs mixed species stands of macroalgae) may increase prey survivorship (see review by Heck and Crowder, 1991). Therefore, fishes may select habitats that offer different rewards (pay-offs) (Levin and Hay, 1996; Levin et al., 2000), and spatial variation in these rewards may determine the uneven distributions of fishes in our study.

Fish species varied in their responses to different forms of heterogeneity in macroalgal habitats. This variability in respons suggests the need for a more sophisticated understanding of the relationship between the habitats and species. Variation in responses among species may result from different niche requirements $(e g$, food and shelter) and/or the trade-offs that different components of macroalgal architecture represent for individuals. Environmental heterogeneity underpins the basis for management and conservation of many ecological systems (Fuhlendorf et al 2006). While the effect of heterogeneity on species distribution is well understood for many heterogencily on species distribution is 2009 ) simila terrestrial ecossticitions tend to be greatly simplified in marine ecosystems, where spatial management strategies are often limited to "no-take areas (often with relatively ittle consideration of hinkages between habitat and target species). Our results suggest that species may respond in different ways to habitat features, and therefore that fish assemblages may differ from one area to another depending upon these features. These diverse responses to experimental manipulations of macroalgal structure
suggest complex species interactions that may operate synergistically to shape the relationships between temperate reef fishes and associated macroalgal habitats.

\section{Acknowledgements}

Funding for this research has been provided by CONICYT-VUW PhD scholarship to APM and a FRST contract C01X0501. R. Stewart and N. Alcock (NIWA) provided support and assistance in both laboratory and field experiments. A. Smith. S.W Geange. E. Macaya, T. Eddy. C Cortés, and J. Allen (VUCEL) for field assistance. R. Cole and M. Francis provided advice and co-supervisory support during the study. N Valdivia, S. Pledger, and N. Shibanda provided statistical advice. Shima-Phillips lab, R. Cole, A. Perea-Blazquez, P. Neubauer, S.W. Geange, and three anonymous reviewers provided useful comments to earlier versions of the manuscript. [ST]

\section{Appendixes. Supplementary data}

Supplementary data associated with this article can be found, in the online version, at doi:10.1016/.j.jembe.2010.03.013.

\section{References}

Adams, N.M, 1997. Common Seaweeds of New Zealand. Canterbury University Press $48 \mathrm{pp}$. reef fish .assembl.geses in northe.stern New Ze.land. Journal of Experimental Marine Biology . and Ecology 305, 191-221.

Anderson, MJ. Willis. TJ., 2003. Canonical analysis of principal coordinates: a useful method of constrained ordination for ecology. Ecology 84 , $511-524$.
Andrieu, C, De Freitas, N. Doucet, A, Jordan, M. 2003, An introduction to MCMC for machine learning. Machine Learning 50,5-43.

Baayen. R.H. Davidson. D.J. Bates D.M. 2008. Mixed-efferts modelling with crossed

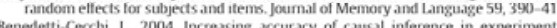
analyses of biodiversity. Functional Ecology 18, 761-768

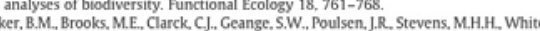
J.S. 2009. Ceneralized linear mixed models: a practical guide for ecology an

Caselle, JE. Warner, RR.. 1996. Variability in recruitment of coral reef fishes: the Caselle, J.E. Warner, RR., 1996. Variability in recruitment of coral
importance of habitat at two spatial scales. Ecology 77, 2488-2504 Chen, M.H. Shao, QM. 1999. Monte Carlo estimation of Bayesian credible and HP

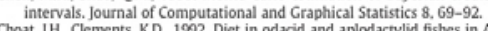
. H... Clements, K.D. 1992. Diet in odacid and aplodactylid fishes in Australia and Christic. H., Jorgensen, N.M., Norderhaug. K.M., 2007. Bushy or smooth, high or low: importance of habitat architecture and vertical position for distribution of fauna on kelp. Journal of Sea Research 58. 198-208.

processes in temperate reef fish population. Joumal of Experimental Marine Biolog and Ecology 151. 271-294.

Connell. S.D. Kingsford. MJ.. 1998. Spatial, temporal and habitat-related variation in the ab7.
t9-57.
Crowe. TS.

Crowe, TS. Underwood Af 1998. Testing behavioural "preference" for suitabe microhabitat, Journal of Experimental Marine Biology and Ecology 225, 1-11. Dayton, P.K., 1985. The structure and regulation of some South American kel communities. Ecological Monographs 55, 447-46.

and a $41,287-300$.

Denny. C.M. Schiel, D.R. 2001. Feeding ecology of the banded wrasses Notolabre fucicola (Labridac) in southern New Zealand: prey items, seasonal differences, and 925-933.

Dornelas. M. Moonen, A.C. Magurran, A.E., Bàrberi, P. 2009. Species abundance
distributions reveal environmental heterogeneity in modified handscapes. Journat distributions reveal environmental heterogeneity in modified handscapes. Journ. of Applied Ecology 46. 666-672.
keary. D. . Wellenreuther, M. Clements, K.D. 2009. Trophic ecology of New Zealand triplefin fishes (Family Tripterygidale). Marine Biology 156, 1703-1714.

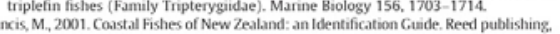

Auckland. 103 pp.
Fullendorf, S.D., Harrell, w.C. Engle, D.M. Hamilton, R.G. Davis. CA., 2006. Should
heterogeneity be the basis for conservation? grassland bird response to fire and heterogeneity be the basis for conservation? 8 .

Graham, M.H., 2004. Effects of local deforestation on the diversity and structure of 
Heck, KLJ, Cowder, L, 1991, H.thitat structure and prediator prey interaxtions in vegetative Phydical Arrangement of Objects in Space. Chapman and Hall, pp. 281-299. Hickford, MJ., Schicl, D.R. 2008. Experimental gill-netting of reef fish: species-specific responses modify capture probability actios
Marine Biology and Ecology $358,163-169$

Molthe Bilogy and tecology 358, $163-169$. abundance of reef fishes: the inportance of ontogenetic resource requirements. Bulletin of Marine Science 47, 104-114

Holbrook S.J.schmilt. R.J. Ambrose, RF. 1990b. Biogenenic habitat structure and characteristic (5)

hugie. DM. Crond TC. 1998. Movement between patches, unequal competitors und the ideal Iree distribution. Evolutionary Ecology $12,1-19$

nes. G.P. 1984a. Population ecology of the temperate reef fish Pseudolabrus ceidonus Bloch \& Schneider (Pisces: Labridae). L. Factors influencing recruitment. Journal of

Jones, C.P. 1984b. The influence of habitat and behavioural interactions on the local distributio

Kramer, D.L, Rangeley, RW. Chapman LL., 1997. Habitat selection: patterns of spattial

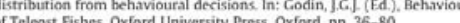

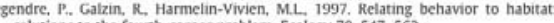
Solutions to the fourthi-corner problem. Ecology $78,547-562$
Levin, PS., Hay. M.E., 1996. Responses of temperate feef fishes to alterations in algal structure and species composition. Marine Ecology Progress Series $134,37-47$.
Levin, PS, Tolimieri, N, Nicklin, M. Sulle, P. 2000. Integrating individual behtuvior. population ecology: the potential for habitat-dependent population regulation in a reef fish. Behavioral Ecology 11, 565-571.

Loreau, M., Nacem, S. linchausta, P., Bengtsson, J., Grime. J.P., Hector, A. Hooper, D.U.

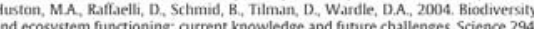

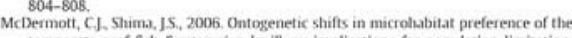
emperate reef fish ford Marine Ecology Progress Serics 320. 259-266. and the measurement of ecological data. Fcology Lefters 10,437-452. compectitive ability: phenotype-limited ideal free models. Animal Behavior 34, $1222-124$

erez-Matus, A. Ferry-Graham, LA. Cea, A. Vasquez, J.A., 2007. Community structure of temperate reef fishes in kelp dominated subtidal habitats of northern Chile.
Pinteiro, JC, Bates, D.M, 2000. Mixed-Effects Models in S and S-plus. Springer-Vertag. New York, $528 \mathrm{pp}$.

interaction between behavioural strategies and resource distributions. Oecologia

$156,465-477$. The food and feeding habits of rocky reef fish of northeastern New
Russell, B.C., 1983. Schicl, D.R. Foster, M.S. 1986. The structure of subtidal algal stands in temperate Shima, J.5. 1999, Variability in rine Biology Antual Reviews 24, 265-307. .

Shima I S. Osenters. C.W.. 2003. Cryptic density dependence, effect of covariation Shima, J.S., Osentyerg. C.W. Mary, C.M.S., 2008. Quantifying site quality in a beterogeneous landscape: recruitment of a reef fish. Ecology 89, 86-94

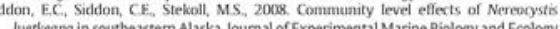
361, 8-15.

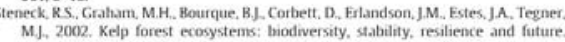
Environmental Conservation 29, $436-459.484$ Factors affecting fish diversity on a temperate reef: the fish assemblage of Palos Verdes Point, 1974-1981. Environmental Biology of Fishes 11, 249-275.

Taylor. R.B. 1998. Density, biomass and productivity of animals in four subtidal rocky reef 17237.51 .

Taylor, RB, Cole, R.G, 1994. Mobile epifauna on subtidal brown seaweeds in
northeastern New Zealand Marine Ecology Progress Series 115, 271-282 R Devclopment Core Team, 2008. R; a language and environment for statistic

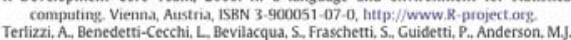
2005. Multivariate and univariate asymmetrical analyses in environmental impact
assessment: a cise study of Mediterrane.in subtidal sessie assemblayges, Marine

Ecology Progress Series 289, 27-42
Thiel, M. Visquezz.JA. 2000. Are kelp holdfast islands on the occan floor? - indication for White, JW, Gaselle, JE, 2008. Scale dependent changes in the importance of harval supply and habitat to abundance of a reef fish. Ecology 89, 1323-1333. Wiliams, G.. Cameron, M.... Tumer.,.R., Ford. R.B., 2008. Quantitative characterisation of reef fish diversity among nearshore habitats in a northeastemn New Zealand mariin 


\title{
APPENDIX 2
}

\section{Density- and trait-mediated effects of fish predators on}

\section{amphipod grazers: potential indirect benefits for the giant kelp}

\author{
Macrocystis pyrifera
}

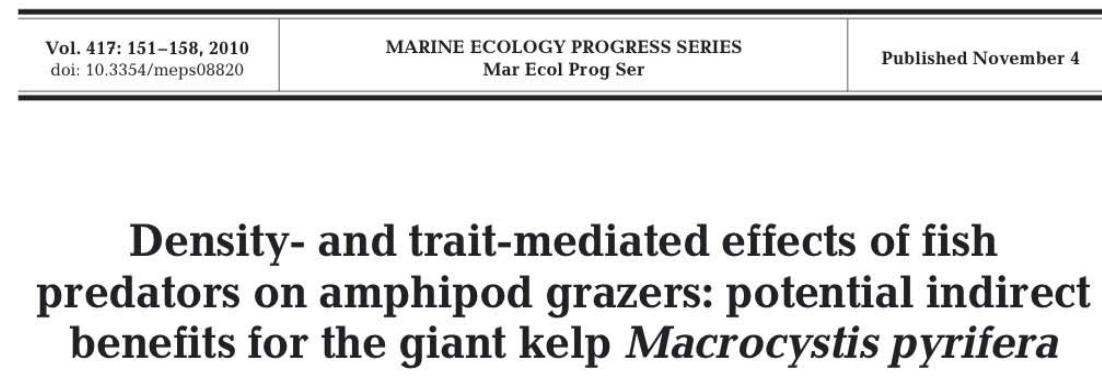

Alejandro Pérez-Matus*, Jeffrey S. Shima

School of Biological Sciences, Victoria University Coastal Ecology Lab, Victoria University of Wellington, PO Box 600 , Wellington, New Zealand

\begin{abstract}
Indirect effects of predators on primary producers may arise when predators suppress herbivore abundance and/or alter the behaviour patterns of herbivores in ways that reduce grazing pressure. Most studies highlight the role of predators in reducing herbivore abundance (i.e. densitymediated interactions), while behavioural effects (i.e. trait-mediated interactions) induced by predators are less commonly considered and are often assumed to be of secondary importance. We used a mesocosm experiment to evaluate the consumptive and behavioural effects of 2 species of predatory fishes on a fishes an ato labrus cellidotus, of the 2 predar specles redued grazer abundance. Although the second predator species, $N$. fucicola, did not affect grazer abundance directly, it significantly reduced the grazing efficiency of amphipods on blades of $M$. pyrifera. Our study illustrates how density- and trait-mediated interactions reduce grazer efficiency and provide potential indirect benefits to primary producers. To our knowledge, this is the first experimental evidence of a potential trophic cascade in kelp beds generated by consumptive and nonconsumptive effects. When considered alongside results of other studies that highlight positive effects of macroalgae on reef fish demographic rates, our results provide compelling evidence that mutualistic relationships may exist between kelp and associated predatory fishes.
\end{abstract}

KEY WORDS: Predation · Amphipods · Trait-mediated effects · Multiple predator effects · Reef fishes Kelp beds $\cdot$ New Zealand

\section{INTRODUCTION}

Predation is a pervasive process that can influence community organization (Paine 1966, Schmitz 1998, Duffy \& Hay 2001) and ecosystem functioning (Schmitz 1998, Sih et al. 1998, Schmitz 2009). A fundamental component of predation is the direct removal of prey, leading to reductions in the numerical abundance of prey populations (Murdoch et al. 2003). Such reductions are considered density-mediated interactions (DMI) between predators and prey (Abrams 1995). Most food web studies have focused on DMIs, placing keystone predation, exploitative competition and cascade effects in the context of changes in densities of predators and/or prey populations (Sih et al. 1998, Duffy \& Hay 2001). However, predators can also induce phenotypic effects (i.e. trait-mediated interactions [TMI] on prey populations, Abrams 1995) (Main 1987, Lima 1998). These effects may induce morphological, physiological or behavioural responses from prey (Preisser et al. 2005). For example, when confronted with predators most prey seek refuge, which may result in a period of inactivity (Sih 1980, Lima \& Dill 1990). This shift in behaviour patterns can alter the per capita effects of the prey species on other species (see Werner \& Peacor 2003 and references therein). Though both density- and trait-mediated interactions can, in principle, affect the dynamics of other species in the local community (Abrams 1995), the relative importance of these 2 pathways is poorly known in most cases (but see Luttbeg et al. 2003). 
Many temperate subtidal areas are characterised by the presence of habitat-forming kelps (Dayton 1985) including Macrocystis pyrifera, which forms dense forests in the Northern and Southern hemispheres (Graham et al. 2007). Many seaweed populations are influenced by herbivory (Dayton 1985). Although several species of large invertebrates are known to be important grazers of $M$. pyrifera (for review see Steneck et al. 2002), small mobile invertebrates (mesograzers), such as amphipods, are also potentially important in structuring seaweed populations (Duffy \& Hay 2000, Graham 2002, Haggitt \& Babcock 2003). Amphipods are one of the most abundant and diverse groups of small invertebrates inhabiting $M$. pyrifera (Coyer 1984) and other temperate brown macroalgae (Taylor \& Cole 1994). The cumulative effects of grazing by amphipods may be similar to other herbivores on kelp beds (Sala \& Graham 2002), and in some cases these effects may be stronger (see Haggitt \& Babcock 2003). Furthermore, the high diversity of amphipod species suggests that feeding patterns may vary (Duffy 1990), implying a potential range of ecological consequences attributable to this group of mesograzers (Duffy \& Hay 2000)

In kelp habitats, amphipods also provide a link between kelp and higher trophic levels, including fish, which are voracious predators of amphipods (Jones 1988, Holbrook et al. 1990, Taylor 1998). Top-down control of amphipods by fishes constitute a positive indirect effect in which fishes benefit the health and growth of kelp (Davenport \& Anderson 2007, Newcombe \& Taylor 2010). Some marine fishes are known to substantially reduce the local abundance of amphipods, but no studies (to our knowledge) have addressed possible trait-mediated effects of fishes on amphipod-kelp interactions. In freshwater systems, amphipod-ketr threat of predation tend to reduce foraging time (Andersson et al. 1986), mate less frequently (Cothran 2004) and alter their mating decisions (Dunn et al. 2008), These phenotypic responses to predators may munity structure via trophic cascades. How fishes in temperate kelp systems might affect interactions between amphipods and Macrocystis pyrifera remains unknown

Many ecological communities are composed of multiple predators that may target a common prey item and contribute to density- and/or trait-mediated interactions (Schmitz 2007). In some cases, the presence of multiple predators may actually reduce the overall risk of predation when, for example, 2 or more predators interfere with each other, or when predators also prey the presence of 2 or mo individual effects (e.g. when the antipredator behaviour of prey to one predator increases its risk to other predators; see Hixon \& Carr 1997, Van Son \& Thie 2006)

Here, we use a mesocosm study to evaluate the separate and joint effects of 2 common reef fishes, Notolabrus celidotus and $N$. fucicola (Family Labridac), on the interaction between amphipod grazers and the giant kelp Macrocystis pyrifera. Specifically, we evaluated the effects of fishes on the survival (DMI) and grazing efficiency (TMI) of amphipods. Both fish predators are common inhabitants of $M$. pyrifera kelp forests, and both feed upon invertebrates including amphipods. We hypothesised that similar feeding modes exhibited by these 2 fishes would not lead to risk enhancement for amphipod prey. Instead, we predicted that the 2 fish predators might interfere with each other, leading to enhanced prey survival in the presence of both predators (Schmitz 2007). Finally, we hypothesised that the effects of fishes on amphipods would be consumptive, such that fishes might alter amphipod-kelp interactions primarily via density. mediated interactions.

\section{MATERIALS AND METHODS}

Study species. The gammarid amphipods used in this study, Pseudopleonexes lessoniae and Bircenna macayai, live and feed upon blades of Macrocystis pyrifera as well as other brown macroalgae (Poore et al. 2008, Löerz et al. 2010). Our preliminary studies confirmed that both amphipods leave similar grazing marks when consuming M. pyrifera (A. Pérez-Matus unpubl. data); however, they differ in their sheltering behaviours (M. Thie pers. comm.) (see Figs. S1 \& S2 in the supplement at www.int-res.com/articles/suppl/m417p151_supp.pdf).

According to our preliminary surveys from a representative location within the study region, mean $( \pm \mathrm{SD}$ amphipod densities can reach up to $11.52 \pm 4.82$ individuals frond ${ }^{-1}$ of Macrocystis pyrifera. Amphipods are common prey items for tish predators including the colly common labrids Notolabrus celidotus and N. fucicola (Russell 1983, Jones 1984, Denny \& Schiel 2001, Francis 2001). Juvenile and adult $N$. celidotus and $N$. fucicola are commonly found in association with M. pyrifera on rocky reefs around Wellington, New Zealand (Pérez-Matus \& Shima 2010).

Field collections. We collected six $1 \mathrm{~m}$ apical lengths of fronds of adult Macrocystis pyrifera individuals using mesh collecting bags ( $0.5 \mathrm{~mm}$ mesh) designed to retain the associated epifauna (including the mesograzers Pseudopleonexes lessoniae and Bircenna macayai). We then used seawater to rinse the epif com 
sieve. We collected 12 juvenile Notolabrus celidotus (each $-14 \mathrm{~cm}$ in total length, TL) and 12 juvenile $N$ fucicola $(-20 \mathrm{~cm} \mathrm{TL})$ using baited traps. The traps were $75 \mathrm{~cm}$ in length, constructed with knotless $15 \mathrm{~mm}$ mesh with a mesh opening of $8 \mathrm{~cm}$ diameter, baited with mussels and deployed beneath kelp canopies for $\sim 10 \mathrm{~min}$. Before each experimental trial, newly collected individual fish were acclimatised (without food) for 24 to $32 \mathrm{~h}$ in indoor tanks with circulating seawater. Amphipods were acclimatised in separate tanks with aerated seawater only. All individuals (macroalgae, amphipods and fishes) were used only once (i.e. new organisms were collected for each trial).

Experimental design. Experiments were conducted in outdoor tanks (mesocosms) at the National Institute of Water and Atmospheric Research (NIWA, Greta Point, Wellington), and all organisms used for these studies were collected from a common location at Karaka Bay, Wellington New Zealand $\left(41^{\circ} 18^{\prime} 31^{\prime \prime} \mathrm{S}\right.$, $174^{\circ} 49^{\prime} 58^{\prime \prime} \mathrm{E}$ ). We constructed 5 experimental mesocosms using black plastic tanks $(150 \mathrm{~cm}$ diameter, $45 \mathrm{~cm}$ height) supplied with recirculating water at a flow rate of $101 \mathrm{~min}^{-1}$ (Fig. 1a). Tanks were covered with $0.5 \mathrm{~mm}$ mesh that provided shade to Macrocystis pyrifera (to more closely match the light environment experienced by seaweeds in the ocean) and prevented fish from jumping out of the tanks. At the centre of each tank we constructed a cylindrical cage $(60 \mathrm{~cm}$ diameter and $2 \mathrm{~mm}$ mesh size, spanning the full height of the tank). This cage structure facilitated our manipulation of fish access to $M$. pyrifera and amphipods. which was required for some experimental treatments. To evaluate potential cage artefacts (Steele 1996), we used mock cages (with an open panel) for a set of our

a

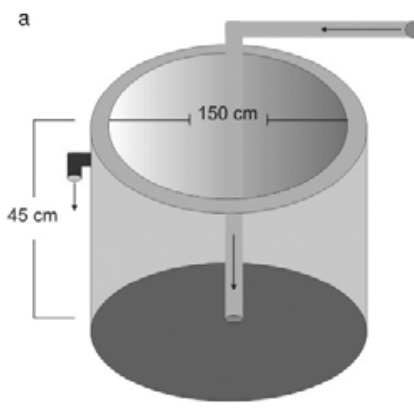

fish exclusion and control tanks (detailed below). Within each tank we added a single frond of $M$. pyrifera $(-50 \mathrm{~cm}$ length), which included an average $( \pm \mathrm{SD})$ of $20 \pm 3$ blades and the apical meristem (Fig. 1b). To avoid the effects of grazing history on the experimen tal blades, we carefully selected fronds without grazing marks.

Experimental fronds were established with standardised densities of mesograzers. To ensure that all epifauna were removed from experimental fronds, the fronds were soaked in fresh water for 3 min immediately before their addition to the experimental tanks. which effectively removed any remaining epifauna not captured by the initial sieving. This treatment did not seem to adversely affect Macrocystis pyrifera. We then attached defaunated fronds to a rock at the bottom in the centre of each tank with a plastic cable tie. Finally, we supplied a standardised number and composition of amphipods to each mesocosm. The composition of amphipods added to each mesocosm was identical within trials. For all trials but one, we added 6 individuals of each species of amphipod. For the aberrant trial, we stocked mesocosms with 5 individuals of Pseudopleonexes lessoniae and 2 of Bircenna macayai (because we were limited by the total number of amphipods obtained from our prescribed collection regime). Amphipods were added to mesocosms $1 \mathrm{~h}$ before the addition of predatory fishes.

Using this basic configuration, we established 5 unique treatments to evaluate the direct and indirect effects of Notolabrus celidotus and N. fucicola (separately and in combination) on the survivorship, nesting behaviour and grazing efficiency of amphipods on Macrocystis pyrifera. Treatments were as follows: (1)

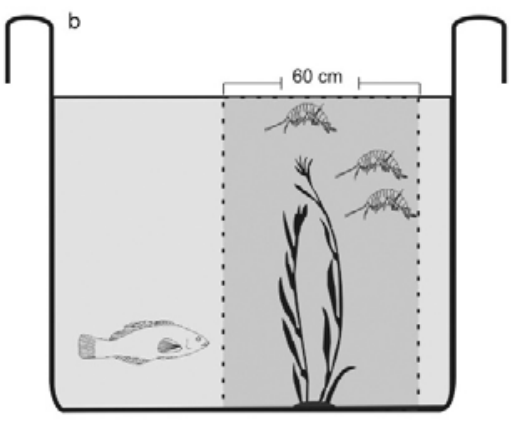

Fig. 1. Diagrammatic representation of mesocosm design. (a) Mesocosm dimensions and arrows representing flow of seawater. (b) Mesocosm shown in cross-section to illustrate placement of organisms relative to internal cage. Each mesocosm contained one cage. Each cage contained a single frond of Macrocystis pyrifera. For all treatments except the 'Autogenic' treatment, an initial population of amphipods was introduced to the kelp frond. Fish were then added to the cage as prescribed in the treatments
(refer to 'Materials and methods'). Organisms within tanks are not shown to scale 
'N celidotus predator': 6 juvenile $N$. celidotus and amphipods were added to the central cage of the mesocosm (i.e. with $M$. pyrifera); (2) 'N . fucicola predator' 6 juvenile $N$. fucicola and amphipods were added to the central cage of the mesocosm; (3) 'Both predators' 3 juvenile $N$. celidotus and 3 juvenile $N$. fucicola and amphipods at ambient densities were added to the central cage of the mesocosm; (4) 'Fish exclusion' 3 individuals of $N$. celidotus and 3 of $N$. fucicola were added to the tank but outside the cage (i.e. fish had no direct access to kelp and amphipods, which were inside the cage): (5) 'Autogenic': kelp was included without either fish or amphipods. This last treatment served as a control that enabled us to evaluate the overall performance of the kelp (e.g. background tis. sue accumulation or degradation) under experimenta mesocosm conditions in the absence of grazing pres. sure; this treatment also helped us to develop protocols to distinguish between natural decay and grazing marks caused by amphipods.

We employed a 'substitutive design' that held the overall predator density constant, because one of our primary goals was to evaluate interspecific interactions (Sib et al 1998). Because we were constrained b The ef avallable tanks for mesocosms, we replicated treatments in time (i.e. 'trials'; rotating the assignment of treatments across tanks for each trial) The duration of each experimental trial was $6 \mathrm{~d}$. We carried out a total of 8 trials ( $\mathrm{n}=8$ replicates) for each treatment, and all trials were completed between 10 February and 22 April 2009.

Density-mediated effects of fishes on amphipods. Lethal effects (i.e. predation) of the fishes on amphipods were estimated as the proportion of amphipods surviving after each trial. After each trial period, we removed the fish and sieved the contents of each tank, and recorded the number of remaining amphipods.

We used generalized linear models (GLM) (Crawley 2007) to analyse our data because our response variable (proportions based upon counts) had unequal variances and non-normally distributed errors. We contrasted all predator access treatments against the fish exclusion treatment (i.e. 'N. celidotus predator', 'N. fucicola predator', 'Both predators' versus 'Fish exclusion'), using the proportion of amphipods surviv ing as the response variable. For this GLM we specified a binomial error distribution and a logit link funclion- Data were overdispersed (resitol molel $=43.7$, dt $=28$ ) and were correcte quasibinomial error distribution (Crawley 2007). We conducted a second set of contrasts to detect emergent effects of multiple predators (Sih et al. 1998). We contrasted the proportion of amphipods surviving in the treatment with both fishes present against treat ments with either Notolabrus celidotus or $N$. fucicola present (i.e. 'Both Predators' versus ' $N$. celidotns predator' and 'Both Predators' versus ' $N$. fucicola predator'). A significant difference between treatments was interpreted as evidence of emergent multiple predator effects (MPE). Data were overdispersed (resid ual deviance model $=7216$, $\mathrm{df}=28$ ) and were corrected using a quasibinomial error distribution (Crawley 2007). Moreover, we calculated the expected survival $(E)$ of amphipods assuming independence in the presence of both fish predators (Vonesh \& Osenberg 2003) as:

$$
E_{N, \text { celidotus, N. fucicola }}=\frac{\sigma_{N \text {. celidotus }} \times \sigma_{N \text { fucicola }}}{\sigma_{\text {Pish-exclusion }}}
$$

where $\sigma$ is the mean proportion (\%) of amphipods that survived in each treatment. This was further compared with the mean number of survivors from the treatment when both fish predators where together to detect risk reduction or enhancement on survivorship of amphipods (Vonesh \& Osenberg 2003).

Trait-mediated effects of fishes on the grazing eificiency of amphipods. Grazing marks left by amphipods are indicative of their direct consumption of Macrocystis pyrifera tissue. We characterised grazing focal study. Undamaged portions of M. pyrifera blades were individually immersed in indoor aquaria with seawater and with specimens of amphipods. These observations enabled us to identify grazing marks in our mesocosm experiment (and to differentiate these from algal decay).

We assessed grazing activity on 6 randomly selected blades taken from each treatment/trial in our mesocosm experiment. We counted all apparent grazing marks, and to estimate grazing efficiency, we standardised these counts by the effective densities of amphipods, ie we multiplied the observed number of grazing marks by the ratio between the number of amphipods (initial number of individuals) and the number of blades within the mesocosm.

We conducted a preliminary analysis to validate our estimates of grazing marks, by contrasting our 'Fish exclusion' treatment (i.e. amphipods present) and our 'Autogenic' control (i.e. amphipods absent). Following this initial assessment, we used GLM (with Poisson error distribution and log link function) to evaluate variation in amphipod grazing efficiency, contrasting each of the predator access treatments against the 'Fish exclusion' treatment (i.e. 'N. celidotus predator', 'N. fucicola predator', 'Both predators', versus 'Fish exclusion'). Data were overdispersed (residual deviance model $=1183, \mathrm{df}=235$ ) and were corrected using a quasipoisson error distribution (Crawley 2007). All statistical tests were performed using $\mathrm{R}$ v. 2.11.1 (R Development Core Team 2010). 
RESULTS

\section{Density-mediated efiects of fishes on amphipods}

When fish were excluded from the inner cage of mesocosms, amphipods persisted at $-50 \%$ of their initially stocked densities. We attributed these losses of amphipods to emigration from the kelp fronds (mesh size of $0.5 \mathrm{~mm}$ did not prevent movement of amphipods). Where Notolabrus celidotus was present alone, amphipods were reduced to $\sim 10 \%$ of their initial stocked densities (Fig. 2a), and relative to the 'Fish exclusion' treatment, this suggests an $80 \%$ decrease in amphipod survival $(t=3.12, \mathrm{df}=28, \mathrm{p}<0.001)$. A similar reduction in survival (i.e. populations were reduced to $-12 \%$ of initial densities) was observed in the treatment where both fish species had access to amphipods ( $t=$ $2.63, \mathrm{df}=28, \mathrm{p}<0.01$ ). When only $N$. fucicola had access, amphipod populations persisted at $~ 40 \%$ of initial stocking densities, and relative to the 'Fish exclusion' treatment, this does not reflect a significant reduction in amphipod survival $(t=0.55, \mathrm{df}=28, \mathrm{p}=0.55)$ (Fig. $2 \mathrm{a}$ )
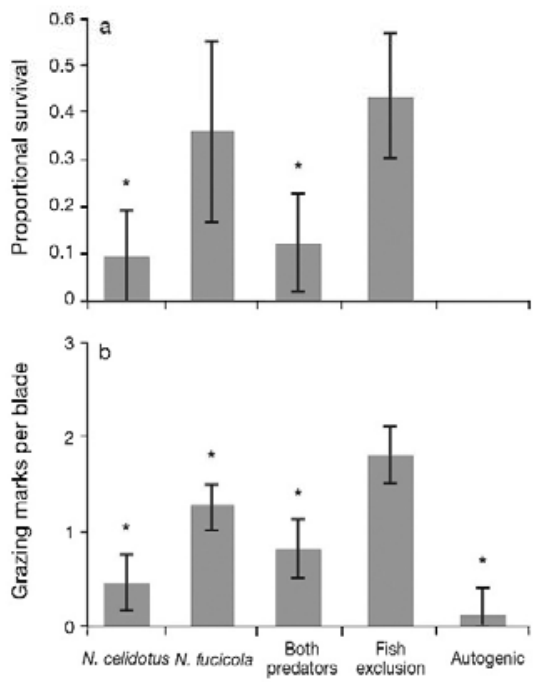

Treatments

Fig. 2. (a) Proportional survival (mean $\pm 95 \% \mathrm{Cl}$ ) of amphipods. (b) Per capita number of grazing marks per blade (mean $\neq 95 \%$ CI). Treatments are as follows: 'N. celidotus' present, 'N. fucicola present, 'Both predators' present, 'Fish exclusion' and differences relative to the treatment 'Fish exclusion'
Our results do not suggest emergent multipredator effects. The expected proportion of amphipod survivors (determined to be $8.6 \%$, assuming the effects of predators were independent of one another) did not differ significantly from the observed proportion of $12.3 \pm 10.1 \%$ (mean $\pm 95 \% \mathrm{Cl}$ ), indicating an absence of emergent multipredator effects (or our inability to detect such effects given our level of replication) when both predatory fishes were together $(t=-0.57, \mathrm{df}=28$. $p>0.05$ ). In this case, the absence of an emergent multipredator effect is not surprising because only one predator (Notolabrus celidotus) appeared to to be an effective consumer of amphipods experiment (e.g. Fig. 2a).

\section{Trait-mediated effects of fishes on the grazing}

\section{efficiency of amphipods}

Both Pseudopleonexes lessoniae and Bircenna macayai caused visible marks on Macrocystis pyrifera in our preliminary aquarium experiment, and marks concordant with these observations were readily identifiable in both the mesocosm experiment and our casual field observations. Both amphipod species damaged only the blade lamina of $M$. pyrifera and left no grazing marks on pneumatocysts. Both species generated deep bites on the blades that can result in complete holes. However, only $P$. lessoniae inflicted substantial lateral damage and bites along the blades, such that within $3 \mathrm{~d}$ blades routinely became detached from the pneumatocyst. In contrast, grazing by Bircenna macayai more commonly resulted in the formation of a 'gallery' of $\sim 1 \mathrm{~cm}$ long, and within this structure grazing appeared to proceed primarily beneath the blade surface (e.g. from within a 'burrow' structure). $P$. lessoniae constructed nests within a period of hours, and they can also leave grazing marks inside the nests (see supplement for photographs of grazing marks, nests and galleries).

After $3 \mathrm{~d}$ with Macrocystis pyrifera blades in aquaria, both amphipod species consumed substantial amounts of algae, and their activity gave us a very clear 'search image' for grazing marks (see supplement for details). These observations improved our estimates of grazing efficiency in our mesocosm treatments.

Grazing efficiency of amphipods increased 15 -fold in the absence of fish predators (i.e. relative to the 'Autogenic' treatment in which amphipods were not added, $t=-6.27, \mathrm{df}=235, \mathrm{p}<0.001)$. We believe this significant difference validates our identification of grazing marks left by amphipods.

Relative to the 'Fish exclusion' treatment, the pres-

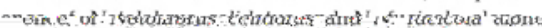
resulted in a 5 -fold decrease $(t=-5.72, \mathrm{df}=235, \mathrm{p}<$ 
0.001, Fig. $1 \mathrm{~b})$ and a 2-fold decrease $(t=-2.11, \mathrm{df}=235$ $p<0.01)$, respectively, in the number of grazing marks. Relative to the 'Fish exclusion' treatment, the presence of both predators together resulted in 2.5-fold decrease in the number of qrazing marks $(t=-4.175, \mathrm{df}=235$, $\mathrm{p}<0.001$; Fig. 1b).

\section{DISCUSSION}

Our study suggests that 2 temperate reef fishes exert positive indirect effects on seaweeds via consumption or behavioural modification of grazers, and that these 2 fish species do not interfere with one another or otherwise enhance the risk of their prey.

Specifically, we found that both fish species in our study independently reduced the grazing pressure of amphipods on Macrocystis pyrifera, and importantly, they appeared to produce this effect via different mechanisms. Notolabrus celidotus exerted a direct effect on chanisms. Notolabrus celidotus exerted a direct effect on ical abundance of amphipods grazers via consumption. In contrast, $N$. fucicola did not appear to directly consume our focal amphipod species (at least in the context of our experimental mesocosms). Instead, N fucicola ex. erted an indirect effect on amphipod-algae interactions, perhaps by altering the behaviour of amphipods.

In the presence of Notolabrus celidotus, amphipods survived poorly and this may explain their reduced grazing activities on blades of Macrocystis pyrifera. Thu celidotus appears to affect amphipod-algae interactions via a density-mediated interaction (DMI). In contrast, the presence of $N$. fucicola appears to induce a behavioural change in amphipods that also results in reduced grazing activity, and this is consistent with $N$. fucicola provisioning benefits to $M$ pyrifera via a trait-mediated interaction (TMI). The strength of the IDMI it appears to be twice as strong as the TMI. Some authors have argued that DMIs are more important in magnitude than TMIs (but see Huang \& Sih 1990). The strength of both DMIs and TMIs depends on the foraging behaviour of predators and risk effects posed to prey species (Schmitz \& Suttle 2001). In short, prey species may trade (Schmitz \& Suttle 2001). In short, prey species may trade off risks of starvation with risk of being eaten (both are
functions of foraging time) (Schmitz et al. 1997). Both DMIs and TMIs must be considered when evaluating predatory effects on communities.

The importance of trait-mediated effects is apparen across a range of environments. Turner $(1996,1997)$ demonstrated the effects of a TMI involving molluscivorous fish and snail grazer on periphyton dynamics in a freshwater system. Similarly. Trussell et al. (2002, 2004) found that TMIs could be even more importan than the direct constion by been conducted with predators on target prey. Nonconsumptive effects are important in community dynamics and few have documented the induced behavioural changes of predators in nontargeted prey whilst reducing the strength of herbivory on plants (see Walzer \& Schausberger 2009).

Our study confirms that the mere presence of a predator (e.g. Notolabrus fucicola) can reduce herbivore damage by a nontarget prey. Reduced foraging activity and increased use of shelters to decrease detec tion by predators are common antipredator behaviours. These have been described previously in several amThipod-fish predator interactions (Williams \& Moore 1985, Andersson et al. 1986, Bollache et al. 2006). According to the trait compensation hypothesis, prey with poor morphological defence might show stronger antipredator behaviours than morphologically well-de lended prey (Dewilt et a 1999). Amphipods may miticens to avoid naturat enemies (e.g. N. celidotus) or unusual predators (e.g. $N$. fucicola in our study). First, both amphipod species and both sexes of amphipods examined here have the abil ity to construct 'nests' (in the case of Pseudopleonexes lessoniac) by curling the blades of macroalgae (see Appadoo \& Myers 2003, Cerda et al 2010 for details on ampithoid nesting behavior), or they may generate 'galleries' (Bircenna macayai) that provide sites for re production and refuge from predators while feeding Nest occupancy is short, usually less than $4 \mathrm{~d}$ within a single nest, and amphipods exhibit high mobility within many crustaceans, amphipods may use chemical cues to detect and escape from predators (Hazlett 1999). We observed losses of amphipods of close to $50 \%$ when predators were present in our experimental mesocosm but unable to access their prey. One possible explanation for these losses is that the prey (i.e amphipods) may detect chemical cues from fish predators and, subsequently, attempt to emigrate to a safer location. Unfortunately, our design did not include a treatment with amphipods present and fish absent, so we are unable to address this possibility directly.

We were unable to identify a significant emergent multiple predator effect (MPE) on amphipod survival when both fish predators where present. We found nei ther risk reduction nor enhancement of prey consumption, suggesting that when they are together, these predators do not interfere with each other. Amphipod sent alone. Amphipod survival was similarly low when sent alone. Amphipod survival was similarly low when
$N$. celidotus was present with $N$. fucicola; this is considN. celidotus was present with N. fucicola; this is consid-
ered to be a trivial MPE (Sih et al. 1998). This agrees with the majority of MPE studies, which have found 
though amphipods frequently occur in the diet of both fishes (Russell 1983, Denny \& Schiel 2001), the lack of substitutable predatory effects between $N$. fucicola and $N$. celidotus may be explained by a combination of a lack of competition for prey resources (suggesting resource partitioning) and a narrow habitat domain of amphipods (i.e. occurring only on fronds of Macrocystis pyrifera). For example, if in the field one predator forages more commonly on fronds while the other forages on the holdfast, as have been suggested (Jones 1984 Denny \& Schiel 2001), MPEs would be expected to be trivial (or else dependent upon the degree to which amphipods move between these microsites within $M$. pyrifera). Hence, spatial partitioning of prey and predator activities could simplify, effectively, to 2 separate single predator-prey systems, where only one predator is able to reduce amphipods numerically in each microsite (Schmitz 2007).

Reported ontogenetic changes in the diet of the fish predators offer another explanation for the observed differences between fish species in their propensity to consume amphipod prey. Both Notolabrus celidotus and N. fucicola undergo dietary shifts in their preferences for small crustaceans such as amphipods (Jones 1984 Denny \& Schiel 2001). According to Denny \& Schiel (2001), large N. fucicola (such as those used for this study) consume more hard-shelled prey than do smaller size classes $(-150 \mathrm{~mm} \mathrm{TL})$, which more regularly consume amphipods. While large $N$. fucicola may no longer target amphipods as prey, amphipods may be unable to distinguish between size classes of known fish predators.

Grazing activities of amphipods may have substantial effects on many marine communities. At least one study suggests that grazing pressure increases following El Niño events, when amphipod populations have been observed to increase (Tegner \& Dayton 1987). Grazing by amphipods may be severe enough to limit recruitment (Tegner \& Dayton 1987, Graham 2002) and lead to compensatory growth of kelp (Cerda et al. 2009). Fish are known to mediate amphipod populations by consumptive effects that can reduce local densities of amphipods. Thus, fish may also be expected to regulate grazing pressure and benefit Macrocystis pyrifera via DMIs. In our study area, fish densities are elevated in vegetative structures (Pérez-Matus \& Shima 2010) and may be sufficiently high to suppress amphipod populations. Our results are partially consistent with other experiments conducted in mesocosms (Duffy \& Hay 2000 Newcombe \& Taylor 2010) and caging experiments in the field manipulating fish predators (Davenport \& An derson 2007, Korpinen et al. 2007), in that they revealed a significant effect of amphipods on benthic biota in the absence of fish predators. Our experiments also suggest that fish may similarly benefit $M$. pyrifera via a non. consumptive (i.e. TMI) effect on prey behaviour.
The data provided in this study may motivate future research into the behaviour, ecology and evolution of possible mutualistic relationships between kelp and their associated fish fauna. Acknowledgements. Funding for this research has been pro-
vided by a CONICYT-VUW PhD scholarship to A.P.-M. and FRST contract C01X0501. R. Stewart and P. Fisher (NIWA) provided support and assistance in laboratory experiment. We thank A. N. Lōerz, A. Poore and N. Killgallen for identification of amphipods. U. Rojas-Nazar, K. Klopfer, S. Hernández, B Magaña, P. Neubauer, S. Carrasco, E. Macaya, C. Saez and F. Warren provided assistance during intensive field collections for preliminary and mesocosm experimental set-ups. S. Pledger and S. W. Geange provided assistance in statistical analysis. R. Cole, S. W. Geange, E. Macaya, M. Thiel, N. Tolimier (responsible editor) $\mathrm{R}$. Taylor and 3 anonymous reviewers pro-

LITERATURE CITED

Abrams PA (1995) Implications of dynamically variable traits for identifying, classifying, and measuring direct and indirect effects in ecological communities. Am Nat 146. $112-134$

Andersson KG, Bronmark C, Herrmann J, Malmqvist B, Otto C, Sjorstrom P (1986) Presence of sculpins (Cottus gobio) fus pulex (Amphipoda). Hydrobiologia 133:209-21

Appadoo C, Myers AA (2003) Observations of the tubebuilding behaviour of the marine amphipod Cymadus filosa. J Nat Hist 37:2151-2164

L, Kaldonski N, Troussard JP, Lagrue C, Rigaud T 2006) Spines and behaviour as defences against fish predators in an

Cerda O, Karsten U, Rothäusler E, Tala F, Thiel M $(2009)$ Compensatory growth of the kelp Macrocystis integrifolia (Phaeophyceae, Laminariales) against grazing of Peramphithoe femorata (Amphipoda, Ampithoidae) in northerncentral Chile. J Exp Mar Biol Ecol 377:61-67

Cerda O.Hinojosa 1, Thiel M (2010) Nest-building behavior by the amphipod Peramphithoe femorata (Kroyer) on the kelp Macrocystis pynfera (Linnaeus) C. Agardh from nothe central Chile. Biol Bull (Woods Hole) 218: 248-258

Cothran RD (2004) Precopulatory mate guarding affects predation risk in two freshwater amphipod species. Anim

Coyer JA (1984) The invertebrate assemblage associated with giant kelp, Macrocystis pyrifera, at Santa Catalina Island. pods, copepods, mysids, and shrimps. Fish Bull 82.55-66 Crawley MJ (2007) The R book. John Wiley \& Sons, Chichester

(2007) Positive indirect effects of reef fishes on kelp performance: the importance of mesograzers. Ecology 88:1548-1561

ayton PK (1985) Ecology of kelp communities. Annu Rev Ecol Syst 16:215-24.5

Denny CM, Schiel DR (2001) Feeding ecology of the banded wrasse Notolabrus fucicola (Labridae) in southern New Zealand: prey items, seasonal differences, and ontogenetic variation. N Z J Mar Freshw Res 35:925-933

Dewitt TJ, Sih A, Hucko JA (1999) Trait compensation and cospecialization in a freshwater snail. size, shape and 
> Duffy JE (1990) Amphipods on seaweeds: partners or pests? Oecologia 83:267-276

- Duffy JE, Hay ME (2000) Strong impacts of grazing amphipods on the organizat
Monogr $70: 237-263$

Duffy JE, Hay ME (2001) Ecology and evolution of marine consumer-prey interactions. Sinauer Press, Sunderland, MA

Dunn AM, Dick JT. Hatcher MJ (2008) The less amorous Gammarus: predation risk affects mating decisions in marus duebeni (Amphipoda). Anim Behav 76:1289-1295

Francis M (2001) Coastal fishes of New Zealand: an identification guide. Reed Publishing. Auckland

Graham MH (2002) Prolonged reproductive consequences of short-term biomass loss in seaweeds. Mar Biol 140:901-911 Graham MH, Vasquez JA, Buschmann AH (2007) Global ecology of the giant kelp Macrocystis from ecotypes

Haggitt TR, Babcock RC (2003) The role of grazing by the lysianassid amphipod Orchomenella aahu in dieback of the kelp Ecklonia radiata in north-eastern New Zealand. Mar Biol 143:1201-1211

Hazlett BA (1999) Responses to multiple chemical cues by the crayfish Orconectes virilis. Behaviour 136:161-177

> Hixon MA, Carr MH (1997) Synergistic predation, density dependence, and population regulation in marine fish. Science 277:946-949

> Holbrook SJ, Schmitt RJ, Ambrose RF (1990) Biogenic habitat structure and characteristics of temperate reef fish assemblage. Aust J Ecol 15:489-503

- Huang CF, Sih A (1990) Experimental studies on behaviorally mediated, indirect interactions through a shared predator. Ecology 71:1515-1522

> Jones GP (1984) The influence of habitat and behavioural interactions on the local distribution of the wrasse. Pses CP (1988) Ecology of rocky reef fish of north-east

$>$ Jones GP (1988) Ecology of rocky reel fish of north-eastern New Zealand: a review. N Z J Mar Freshw Res 22:445-462 and $\mathrm{S}$, Jormalainen $\mathrm{V}$, Honkanen $\mathrm{T}(2007)$ Bottom-up depth gradient. J Exp Mar Biol Ecol 343:52-63

Lima SJ (1998) Nonlethal effects in the ecology of predator-prey interactions. Bioscience 48:25-34

$>$ Lima SL, Dill LM (1990) Behavioral decisions made under the risk of predation: a review and prospectus. CanJ Zool 68:619-640 Löerz AN, Killgallen NM, Thiel M (2010) Algal-dwelling Eophliantidae (Amphipoda): description of a new species and key to the world species, with notes on their biogeography. J Mar Biol Assoc UK 90:1055-1063

> Luttbeg B, Rowe L, Mangel M (2003) Prey state and experimental design affect relative size of trait- and densitymediated indirect effects. Ecology 84:1140-1150

Main KL (1987) Predator avoidance in seagrass meadows prey behavior, microhabi

Murdoch W. Briggs C. Nisbet R (2003) Consumer-resource dynamics. Princeton University Press, Princeton, N.I

> Newcombe EM, Taylor RB (2010) Trophic cascade in a seaweed-epifauna-fish food chain. Mar Ecol Prog Ser 408: 161-167

Paine RT (1966) Food web complexity and species diversity. Am Nat 100:65-7

$>$ Pérez-Matus A, Shima JS (2010) Disentangling the effects of macroalgae on the abundance of temperate reef fishes. J Exp Mar Biol Ecol 388:1-

Poore AGB, Hill NA, Sotka EE (2008) Phylogenetic and geographic variation in host breadth and composition by her62:21-38

Preisser EL, Bolnick DI, Benard MF (2005) Scared to death?

Editorial responsibility: Nicholas Tolimier

Seattle, Washington, USA
The effect of intimidation and consumption in predatorprey interactions. Ecology 86:501-509

R Development Core Team (2010) R: a language and environment for statistical computing The R Foundation for Statistical Computing, Vienna, Available at: www R-project or Russell BC (1983) The food and feeding habits of rocky ree fish of northeastern New Zealand. N Z J Mar Freshw Res 17: $121-145$

Sala E, Graham MH (2002) Community-wide distribution of predator-prey interaction strength in kelp forests. Proc Natl Acad Sci USA 99:3678-3683

Schmitz O (1998) Direct and indirect effects of predation and predation risk in old-field interaction wehs. Am Nat 151 $327-342$

Schmitz OJ (2007) Predator diversity and trophic interactions. Ecology 88:2415-2426

Schmitz OJ (2009) Effects of predator functional diversity on grassland ecosystem function. Ecology 90:2339-2345

Effects of top predator species on direct and indirect interactions in a food web. Ecology

mediated trophic cascades: effects of predation risk olly food web interactions. Ecology 78:1388-1399

Sih A (1980) Optimal behavior: Can foragers balance two conflicting demands? Science 210:1041-1043

A, Englund G, Wooster D (1998) Energent impacts of multiple predators on prey. Trends Ecol Evol 13:350-355 Steele MA (1996) Elfects of predators on reef fishes: separat-
ing cage artifacts from effects of predation. J Exp Mar Biol ing cage artifacts frol
Ecol 198:249-267

Steneck RS, Graham MH, Bourque BJ, Corbett D, Erlandson JM. Estes JA, Tegner MJ (2002) Kelp forest ecosystems: biodiversity, stability, resilience and future. Environ Conserv 29:436-459

Taylor RB (1998) Density, biomass and productivity of animals in four subtidal rocky reef habitats: the importance of

Taylor RB, Cole RG (1994) Mobile epifauna on subtidal brown seaweeds in northeastern New Zealand. Mar Ecol Prog Ser 115:271-282

- Tegner MJ, Dayton PK (1987) El Nino effects on southern California kelp forest communities. Adv Ecol Res 17:243-279 Trussell GC, Ewanchuk PJ, Bertness MD (2002) Field evidence of trait-mediated indirect interactions in a rock intertidal food web. Ecol Lett 5:241-24s

Trussell GC, Ewanchuk P., Bertness M, Silliman BR (2004) Trophic cascades in rocky shore tide pools: distinguishing

- Turner AM (1996) Freshwater snails alter habitat use in response to predation. Anim Behav 51:747-756

(ong-term effects of predation risk on Behav Ecol 8:120-125

n Son TC. Thiel M (2006) Multiple predator effects in an intertidal food web. J Anim Ecol 75:25-32

Vonesh JR, Osenberg CW (2003) Multi-predator effects across life-history stages: non-additivity of egg- and larval-stage predation in an African treefrog. Ecol Lett 6: 503-508

Walzer A, Schausberger P (2009) Non-consumptive effects of predatory mites on thrips and its host plant. Oikos 118 934-940

Werner EE, Peacor SD (2003) A review of trait-mediated indirect interactions in ecological communities. Ecology 84 $1083-1100$

Williams DD, Moore KA (1985) The role of semiochemicals in benthic community relationships of the lotic amphipoc 44:280-286

Submitted: May 28, 2010; Accepted: September 8, 2010 Proofs received from author(s): October 28, 2010 


\section{APPENDIX 3}

\section{Additional research}

During the course of this $\mathrm{PhD}$ research, I have also made significant contributions to a number of additional studies. I was actively involved in design, analysis and/or writing of different articles:

1. Eddy, T.D., Gardner, J.P., \& Pérez-Matus, A. (2010) Applying fishers' ecological knowledge to construct past and future lobster stocks in the Juan Fernández Archipelago, Chile. PloS One In press

2. Roesijadi, G., Rezvankhah, S., Pérez-Matus, A, Mitelberg, A., Torruellas, K., \& VanVeld, P.A. (2008) Dietary cadmium and benzo(a)pyrene increased intestinal metallothionein expression in the fish Fundulus heteroclitus. Marine Environmental Research 67: 25-30

3. Eddy, T., Ramirez, F., \& Pérez-Matus, A (2008) Oceanic Island Oceanic Islands: The Chilean Juan Fernández Archipelago: from Natural Observations to Management Challenges. JMBA GME 4: 14-16.

4. Pledger, S., Geange, S., Hoare, J., \& Pérez-Matus, A. (2007) Resource Selection: Tests and Estimation using Null Models. VUW Reports. 4: 22pp.

5. Macaya E., Morelissen B., Pérez-Matus A. \& Thiel M. Differential palatability of blades and pneumatocysts from floating algae: implications for long-distance dispersal. To be submitted 